THE CONSERVATION OF

NATURAL RESOURCES

IN THE UNITED STATES

GHARLES R. VAN HISE 



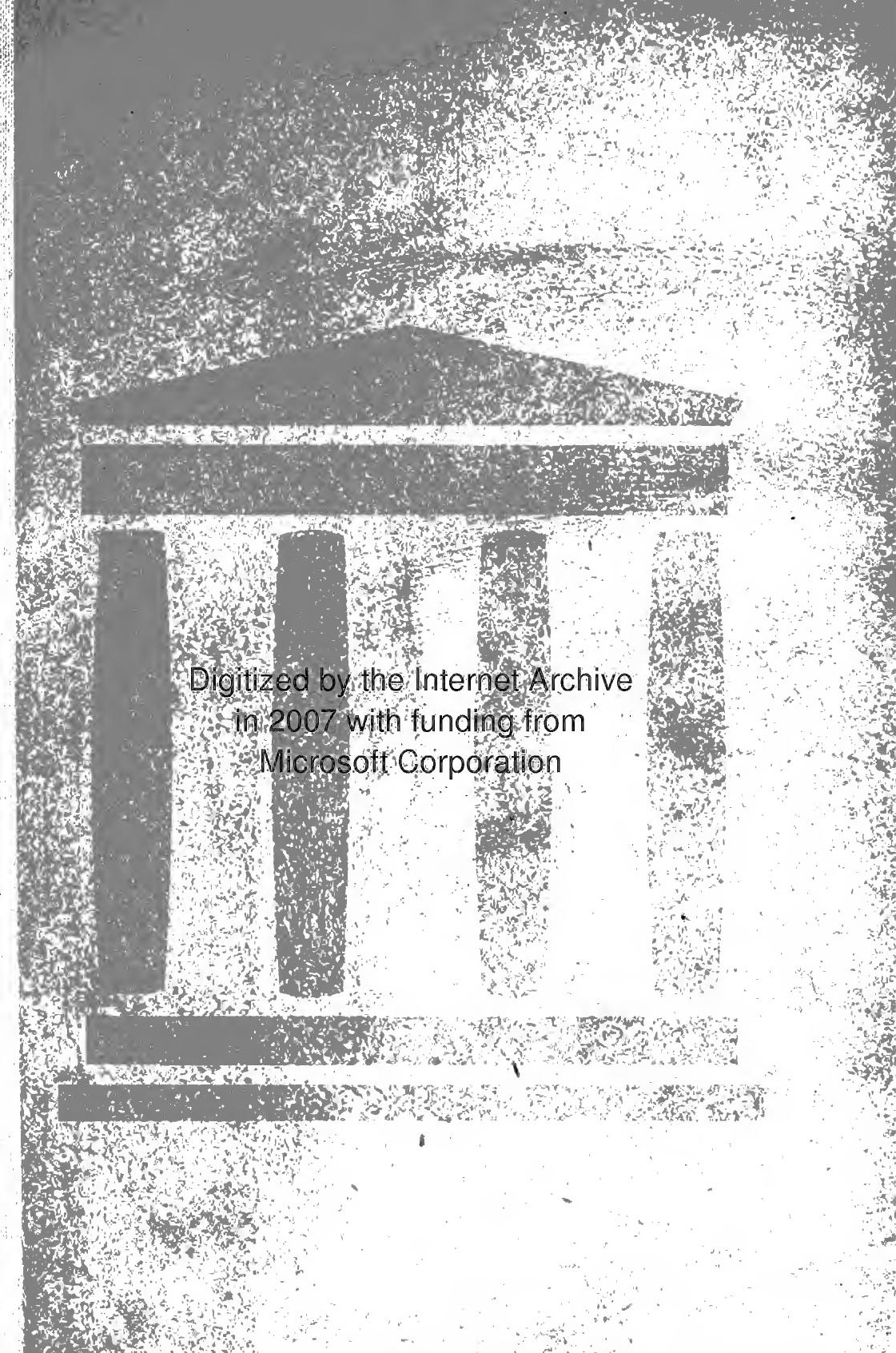

http: WwWwarchive org/details/conservatiónofna00vanhuoft 1400102

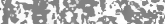
(x) $x^{2}$ 

THE CONSERVATION OF NATURAL RESOURCES

\author{
IN THE UNITED STATES
}




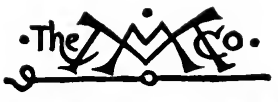

THE MACMILLAN COMPANY
NEW YORK - BOSTON CHICAGO

ATLANTA - SAN FRANCISCO

MACMILLAN \& CO., LIMITED

LONDON - BOMBAY - CALCUTTA

MELBOURNE

THE MACMILLAN CO. OF CANADA, LtD.

TORONTO 
V2555co

THE CONSERVATION

\title{
OF NATURAL RESOURCES
}

\section{IN THE UNITED STATES}

\author{
BY \\ CHARLES RICHARD VAN HISE \\ MADISON, WISCONSIN
}

ILLUSTRATED

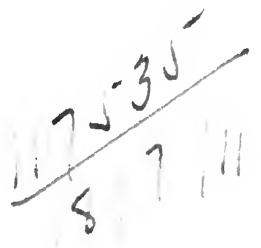

Nowo Wark

THE MACMILLAN COMPANY

1910

All rights reserved 
Copreient, 1910,

BY THE MACMILLAN COMPANY.

Set up and electrotyped. Published September, rgxa. Reprinted December, rgro. 


\section{PREFACE}

Tris book contains the substance of twenty lectures given at the University of Wisconsin. The lectures have been revised, but the general form in which they were given is retained. Many papers have been published in the government reports and in the various magazines upon special phases of the conservation of the natural resources of the United States; but no correlated statement covering the minerals, waters, forests, soils, their relations, and the relations of the subject as a whole to humanity, is available. It therefore seemed advisable to put into a handbook of moderate size the essential information which an intelligent citizen might desire in reference to conservation.

It is somewhat presumptuous for any one man to speak concerning fields which are so widely different from one another as are the minerals, waters, forests, and soils, and especially to speak of the relations of these subjects to political economy, and to law, existing and desirable; yet it is necessary, in order that there shall be unity of treatment, that the attempt be made by some one. Since no man can possibly be familiar with the facts of all these branches of knowledge, it is almost certain that occasional errors will have crept in; but there has been very earnest effort to verify so far as possible every statement of fact, and thus reduce such errors to a minimum.

It is certain that the specialist in any of the fields covered will be dissatisfied with the treatment of that field; but in order to cover the entire subject of conservation in a book of moderate size it is necessary to abbreviate; not only so, but to omit many ramifications of the subject which it would be interesting and profitable to follow. Doubtless, in the near future, there will be separate books on conservation for each of the divisions of the subject; and in such books there will 
be room for amplification which is not possible in a general handbook.

In the preparation of this book I have drawn on all available sources, and therefore am indebted to many. So far as material has been taken directly I have attempted to give references to the sources, but I cannot be sure that proper reference is made in every case. I claim no originality as to facts; they are all taken from various authorities. However, the great mine from which information has been exploited is the Report of the National Conservation Commission, with the accompanying papers, in three volumes, containing together 1840 pages. Had this report not been issued, it would not have been possible to write this book.

To many of my scientific friends I am indebted for direct information by letter; and especially I have called upon the officers of the United States Geological Survey and the Forest service, and the professors of the University of Wisconsin. Not only so, but I have had the advantage of criticism on parts of the manuscript by a number of men, among whom are the following: M. R. Campbell, Fred Dennett, C. W. Hayes, M. O. Leighton, W J McGee, D. W. Mead, R. A. Moore, F. H. Newell, A. L. Stone, Thomas R. Shipp, A. C. Veatch, I. C. White, A. R. Whitson. For their helpful criticism I am very grateful.

It is my hope that this book may serve a useful purpose in forwarding the great movement for conservation which, as it seems to me from the point of view of the not distant future of the human race, is more important than all other movements now before the people.

The University of Wisconsan, July, 1910. 


\section{TABLE OF CONTENTS}

INTRODUCTION

History of the Conservation Movement • • . . 2

PART I. - THE MINERAL RESOURCES

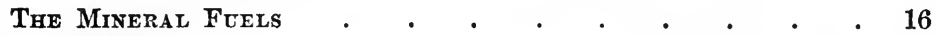

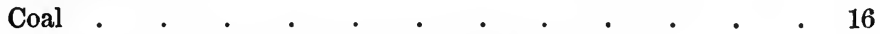

Classification and Occurrence of Coal . $\quad . \quad$. $\quad . \quad$. 19

Amount of Available Coal . $\quad . \quad$. $\quad . \quad$. $\quad . \quad$. 22

Consumption and Future Life of Coal . $\quad$. $\quad$. $\quad$. $\quad 23$

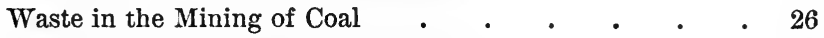

Waste of Coal in Beehive Coking Orens . . . . $\quad$. 28

Waste of Coal by Imperfect Combustion . . . . $\quad$. 29

Substitution of Gas for Steam Engine . . . . $\quad$. 31

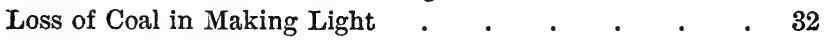

Increase of Carbon Dioxide in the Air ․ . . 33

General Statements . . . . . . . . 33

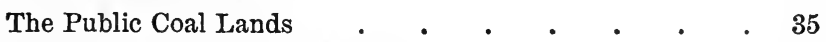

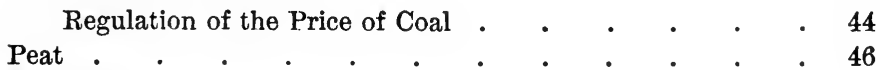

Petroleum . . . . . . . . . . . . . 47

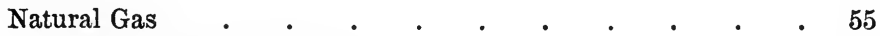

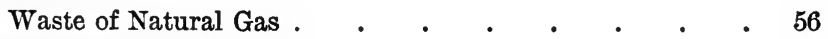

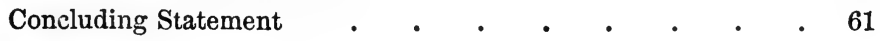

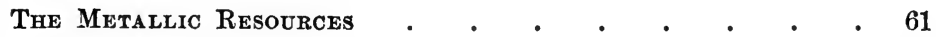

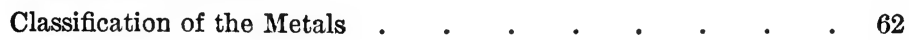

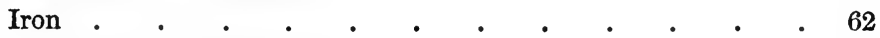

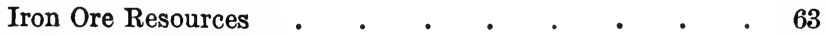

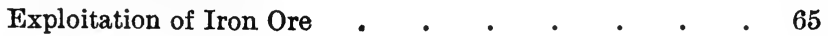

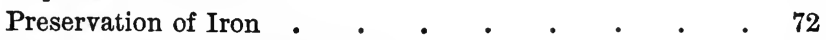

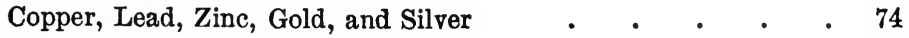

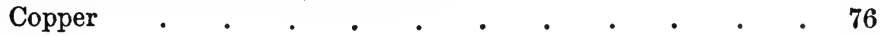

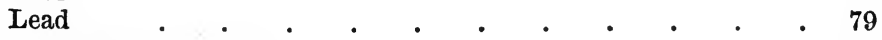

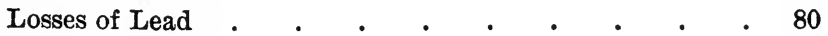

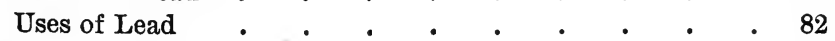
Zinc

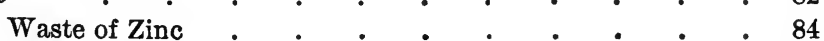

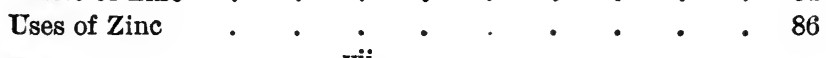


Gold $\quad . \quad 86$

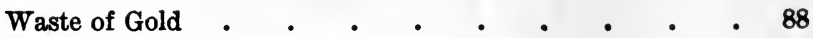

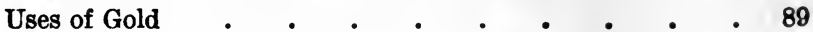

Silver .

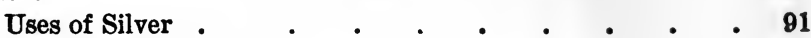

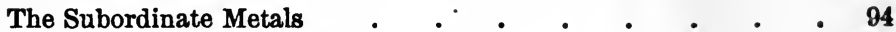

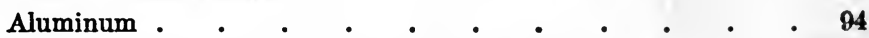

Concluding Statement in Reference to the Metals . $\quad$ _ $\quad$. 95

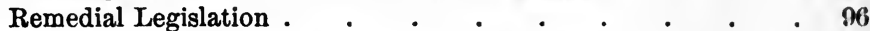

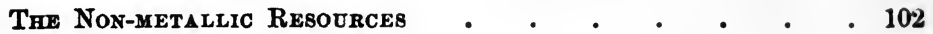

\section{PART II - WATER}

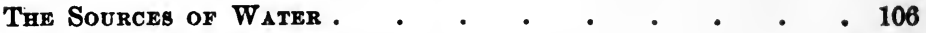

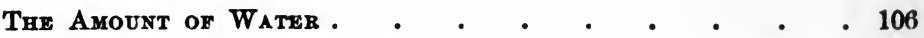

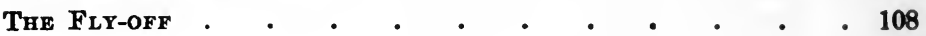

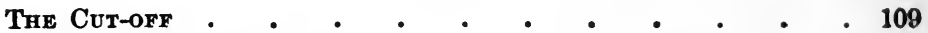

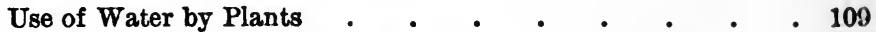

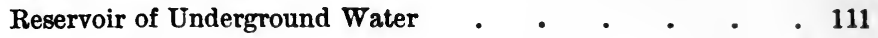

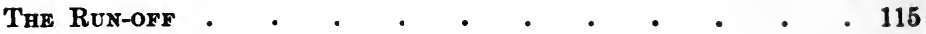

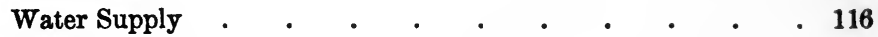

Water Powers . . .

The Water Power Available $\quad . \quad$. $\quad . \quad$. $\quad . \quad$. 118

Advantages of Water Power Development . . 122

Conditions for Satisfactory Development . . . . 125

Value of Water Powers . . . . . . . . . . 129

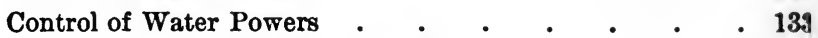

Control in Foreign Countries $\quad . \quad$. $\quad$. $\quad$. $\quad$. 141

Control in the United States _. . . . . 144

Control by the United States Government . . 145

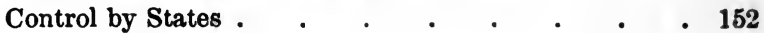

Navigation $\cdot \quad \cdot \quad \cdot \quad \cdot \quad \cdot \quad \cdot \quad \cdot \quad \cdot \quad \cdot \quad \cdot \quad \cdot 162$

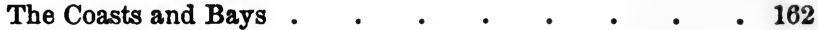

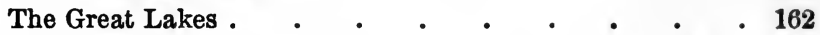

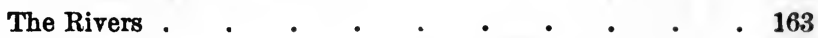

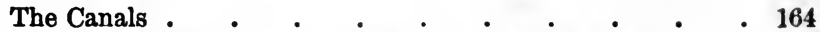

Comparison of Railway and Water Transportation . . 164

Improvement of Rivers . . . • • • • • 165

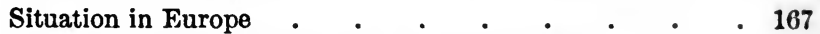

Why Water Transportation has not Developed . . . 168

Channels Shallow, Crooked, Shifting . . . . $\quad$. 169

Illegitimate Competition of Railroads . $\quad$ - $\quad$ . $\quad 169$

Coöperation of Railways and Waterways . . . . 171 
PAGR

Contrast between Great Lakes and Rivers . $\quad$ • . $\quad$ - 171

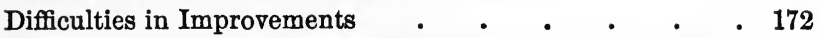

Improvements proposed by Inland Waterways Commission 175

Influence of Water Transportation on Freight Rates . $\quad 179$

Summary of Advantages of Waterways Development $\quad 181$

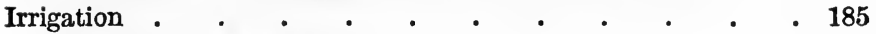

Importance of Irrigation $\quad . \quad$. $\quad . \quad$. $\quad .187$

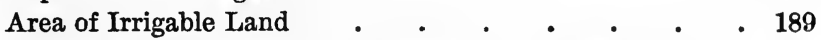

The Relation of Irrigation to Forests and to Reservoirs . 191

The Sources of Water . $\quad . \quad$. $\quad . \quad$. $\quad . \quad 191$

The Irrigated Lands . $\quad$ • . . . . . 192

(1) Coöperation . . . . . . . . . 193

(2) Irrigation Districts . . • . . 193

(3) The Cary Act . . . . . . 193

(4) The Reclamation Act . . . . . 194

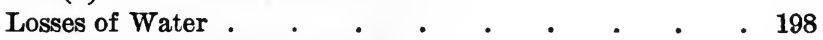

Irrigation in Subhumid Region $\quad \cdot \quad \cdot \quad$ • $\quad . \quad$. 199

Irrigation in Humid Region . . . . . 200

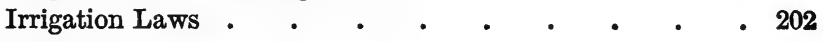

\section{PART III - FORESTS}

The Original Forests . . • . . . . . . . . 208

The Existing Forests . . . . . . . . . 210

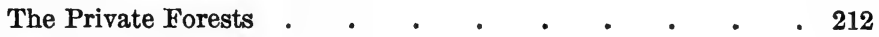

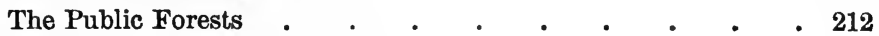

The Consumption of the Forest . • . . . . . 218

(1) Reduction of Waste in Cutting . . . . . . . 223

(2) Reduction of Waste in Milling and Manufacture . . 227

(3) Reduction of Loss in Turpentining . . . . . $\quad$. 229

(4) Extension of Life of Timber by Preservative Treatment . 231

(5) Utilization of By-products . . . . . . . . 232

(6) Reduction of Fire Losses . . . . . . . . . 235

The Control of Fires . . . . . . . . . 240

(7) Reforestation . . . . . . . . . . . . 244

(8) Maintenance of Forests on Essential Areas . . . 245

(9) Increase Forest Growth by Stocking . . . . . 254

(10) Battle with Insect Pests . . . . . . . 255

(11) Substitution of Other Products for Wood . . . . 256

(12) Reformation of the Tax Laws . . . . . . 257

Total Regults of Measures Advocated . . . • . . 259

Concluding Statements. . . . . . . . . . 260 


\section{PART IV - THE LAND}

The Soll . . . . . . . . . . . . . . 264

The Classification of the land . . . . . . . . 266

The Atlantic and Gulf Plains . . . . . . . 268

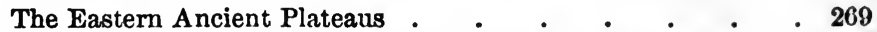

The Appalachian Ranges, Alleghany Plateaus, and Ozarks 270

The Lake Plains $\quad . \quad$. $\quad$. c . . . . 271

The Prairie Plains . . . . . . . . . . 271

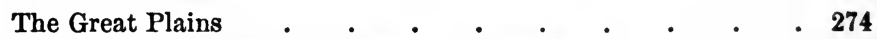

The Rocky Mountains and Western Plateaus . . . . 275

The Pacific Region . . . . . . . . . 275

General Statements . . . . . . . . 276

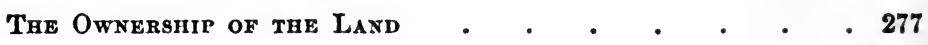

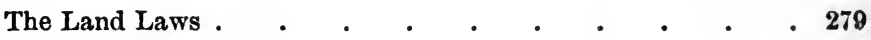

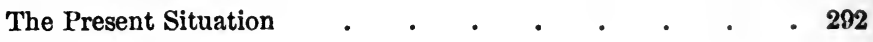

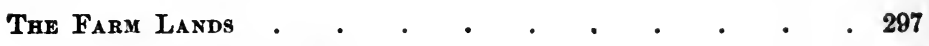

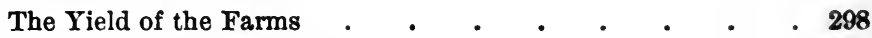

The Condition of the Land . $\quad$. $\quad$. $\quad$. $\quad$. $\quad$. 303

Mechanical Erosion . . . . . . . . . 307

Factors which control Frosion . . . . . . . 308

Remedies for Erosion . $\quad$. $\quad . \quad$. $\quad . \quad$. $\quad$. $\quad 310$

Loss of Essential Elements _ . . . . . . . . 314

Nitrogen . $\quad . \quad . \quad . \quad . \quad . \quad . \quad . \quad . \quad . \quad 316$

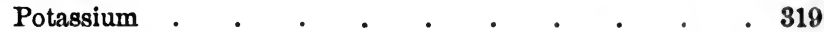

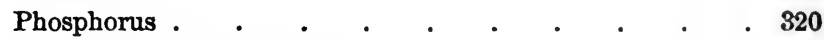

Losses of Phosphorus . $\quad . \quad$. $\quad . \quad$. $\quad . \quad$. 321

Sources of Phosphorus . $\quad . \quad$. $\quad . \quad$. $\quad . \quad$. 327

Remedies for Phosphorus Depletion . . . . 334

General Statements $\quad . \quad$. $\quad . \quad$. . . . . 338

Damage to Farm Crops $\quad$. $\quad$. $\quad$. $\quad$. $\quad$. $\quad$. $\quad$. $\quad$. 339

Noxious Insects and Mammals $\quad . \quad$. $\quad . \quad$. $\quad$. 339

Losses due to Mammals . . . . . . . 340

Plant Diseases . . . . . . . . . . . 340

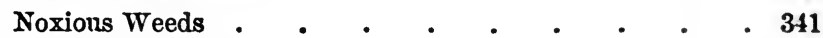

Diseases of Live Stock $\quad . \quad$. $\quad . \quad$. $\quad . \quad$. $\quad$. 342

Reclamation of Wet Lands $\quad . \quad$. $\quad . \quad$. $\quad . \quad$. $\quad$. 344

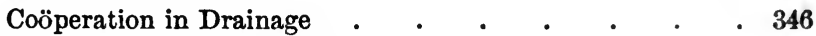

The Gains from Drainage . . . . . . . 347

Additional Improvements in Agriculture . . . . . 348

Total Increase in Value of Farm Products . . . . . $\quad$. 352

Needed a Great Campaign of Education . . . . . 353 


\section{PART V-CONSERVATION AND MANKIND}

The Principles of Conservation . . . . . . . . . . . 359

The Purpose of Conservation . . . . . . . . 363

The Conserfation of Man Himself . . . . . . 364

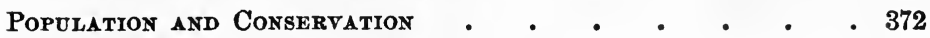

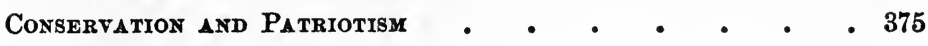

\section{APPENDICES}

Appendix I. Declaration of Governors for Congertation of Natural Resotrces . . . . . . . . 381

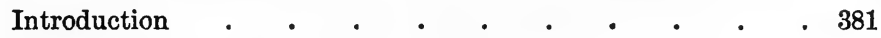

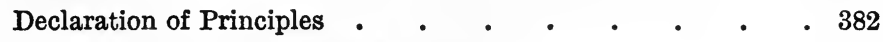

Appendix II. North Americhn Conservation Conference - 385

Declaration of Principles . . . . . . . . . . . 385

Public Health . . . . . . . . . . 386

Forests . . . . . . . . . . . . . 386

Waters . $\quad . \quad . \quad . \quad . \quad . \quad . \quad . \quad . \quad . \quad 388$

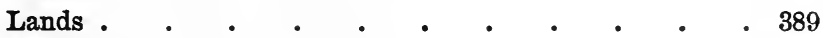

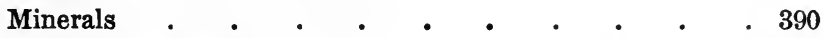

Protection of Game $\quad . \quad$. $\quad . \quad$. $\quad$. $\quad$. $\quad$. $\quad$. 391

Conservation Commissions . $\quad . \quad$. $\quad . \quad$. $\quad . \quad$. 391

World's Conservation Conference $\quad$ • $\quad$ • $\quad$ • $\quad$. 392

Appendix III. National Consertation Association . . . 394

Statement of Principles . . . . . . . . . . 394

Forests . . . . . . . . . . . . 394

Waters . $\quad . \quad . \quad . \quad . \quad . \quad . \quad . \quad . \quad .395$

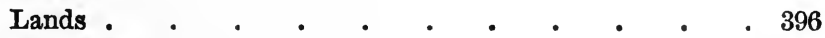

Minerals . . . . . . . . . . 396 



\section{LIST OF ILLUSTRATIONS}

PLATE

I. Pine boxed for three years, near Ocilla, Ga. Photo by

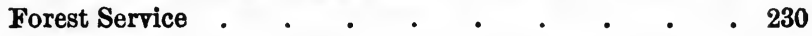

II. Fallen tree as result of too much boxing, near Ocilla, Ga. Photo by Forest Service . . . . . . 231

III. Path of forest fire, northwest of Chisholm, Minn. Photo by Forest Service . • • . . . . . . . 236

IV. Grove of hardy catalpa, Kansas. Photo by Forest Service . 244

V. White pine, fifty years old, Bridgewater, Mass. Photo by Forest Service . . . . . . . . .

VI. Reforested sand dunes, Manistee, Mich. Photo by Forest Service

VII. Nantahala Gorge, Western North Carolina, showing work of forest in holding soil on steep slopes. Photo by Forest Service

VIII. View of the Apennines, near Florence, Italy. Photo by Willis .

IX. Deforested area in the Basse-Alpes, France. Photo by Forest Service

X. Forest destruction in southern Appalachians by clearing of land for farming, Watauga County; N.C. Photo by Forest Service . $\quad$ • . . . . . . .

XI. Newly cleared steep hillside planted to corn in valley of Scott's Creek, Jackson County, N.C. Photo by Forest Service . 308

XII. Formation of system of gullies on abandoned field ; beginning of natural reforestation. Photo by Spillman . .

XIII. Gullied field showing destruction of level lands by erosion, near Craig, N.C. Photo by Forest Service . . $\quad 310$

XIV. Complete destruction of old fields by erosion, converting them into bad lands, Raymond, Miss. Photo by Whitney .

XV. Contour plowing on relatively gentle slopes, such as exist extensively in the prairie and lake plains. Photo by Spillman

XVI. Terracing on steep slopes in Louisiana. Photo by Whitney 
FiG.

1. Map showing distribution of coal fields of the United States, after Campbell and Parker . . . . . . .

2. Chart showing production of coal in the United States from 1846 to 1907 , after Campbell and Parker

3. Distribution of petroleum and natural gas fields in the United States, after Day . . • • • • • • 49

4. Annual production of petroleum, after Day . . . $\quad 61$

5. Decline in production of the New York and Pennsylvania oll fields, and its probable rate in the future, after Day . . . 63

6. Curve showing the production in long tons of iron ore, pig iron, and steel in the United States from 1870 to 1807, after Hayes

7. Production of copper in the United States from 1882 to 1907 , after Lindgren . . . . . . . .

8. Production of lead and consumption of lead as paint in the United States from 1880 to 1907, after Lindgren . . .

9. Production of zinc in the United States from 1880 to 1907 , after Lindgren

10. Production of gold in the United States and in the principal states and territories from 1885 to 1907 , after Lindgren.

11. Production of silver in the world and in the United States from 1880 to 1907, after Lindgren . . . . . . 92

12. Forest regions of the United States, after Kellogg . . . 211

13. The public forest lands, after Kellogg . . . . 213

14. Forest products of the United States in 1907, after Kellogg 219

15. Lumber cut by species in 1907, after Kellogg - • • . 219

16. Lumber cut by states in 1907, after Kellogg . . . . 221

17. Relative lumber production in ten states in 1880 and 1907 , after Kellogg . • . . . • . • • • • 222

18. Land regions of the United States . . . . . . 287

19. Percentage of improved land to total area, after Woodruff $\quad 273$

20. Acreage of improved land in 1900, after Woodruff . - . 801 


\section{THE CONSERVATION OF NATURAL RESOURCES}

IN THE UNITED STATES 


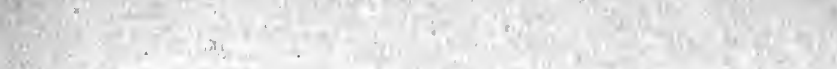

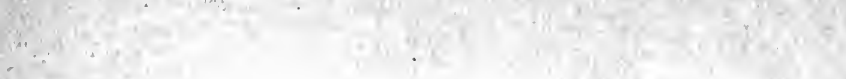




\section{THE CONSERVATION OF NATURAL RESOURCES}

\section{IN THE UNITED STATES}

\section{INTRODUCTION}

$\mathrm{B}$ $\mathrm{Y}$ natural resources are meant those resources provided by nature which may be used for the benefit of man. The natural resources from the point of view of conservation may be divided into two classes: those so abundant as to be practically unlimited in quantity, and those less abundant which are so limited in amount as to be unequal to the present or future needs of man. The first class requires no special consideration. These lectures will therefore be confined to the second class, and to the natural resources of the United States.

The natural resources limited in quantity should be conserved. By their conservation is meant that they should remain as nearly undiminished as possible in order that this heritage of natural wealth may pass in full measure to succeeding generations.

The full accomplishment of conservation of our limited natural resources is not possible. With reference to waters it may be. Ever the sun draws the water from the ocean; the currents of air carry it over the land; it falls upon the earth; and so the streams flow down to the sea perpetually. It may be that our forests can be so handled that in the future the annual growth shall equal the annual consumption. In that case forests may be perpetuated. The situation is not so clear with reference to soils and minerals. As yet it seems extremely difficult, if not impossible, so to handle the soils by agricultural processes as not to deplete them in their richness, in such a manner as not to result in 


\section{CONSERVATION OF NATURAL RESOURCES}

loss by erosion. With reference to the metals, their use necessarily dissipates some part of them; and therefore the total supply of the world's available metals is being diminished in quantity.

The mineral fuels, when taken from the ground and used, are gone. Thus it is impracticable, indeed impossible, to transmit to our descendants all the fuel which nature has granted us, except upon the basis of nonuse, and this no one would advocate.

Therefore the problem of the conservation of our natural resources has different aspects with reference to the different groups of these resources.

\section{HISTORY OF THE CONSERVATION MOVEMENT}

Until late in the nineteenth century the resources of this country were commonly regarded as inexhaustible. Some of them were considered an obstruction to the country's development. Over very large areas of the country the forests were regarded as an enemy to be destroyed and burned. Indeed at the present time this is locally true. Our lands were supposed to be illimitable. Any man might have a farm for the asking. It was held, and indeed is held by many at this time, that our mineral resources will last through the indefinite future, and therefore that they may be drawn upon advantageously as rapidly as possible.

It is under the prevalence of these ideas that our laws and customs have grown up. The laws and customs have been adapted to the ideas of the people. If the ideas are incorrect, it may be that our laws in reference to the natural resources are defective.

Resources not illimitable.

That these ideas in reference to the illimitable supply of our natural resources are incorrect has been appreciated by the scientist for many years. The foresters, the physiographers, the geologists, have shown the severe limitations of many of them. These views have been emphasized by the situation in other countries. The mountains of France, of Spain, of China, have been denuded of their forests in large 
measure, so that the supply of wood is inadequate to meet the needs of the people. In consequence of the removal of the forests from the mountains, the soil and disintegrated rock have been carried away by the running water and the bare rocks left protruding where once was thick vegetation resting upon abundant soil. The débris carried down from the mountains to the lowlands has destroyed extensive areas of once rich land.

It has long been known that in Spain and Italy, warm countries, because of insufficient fuel, the people suffer more from the cold than here in America. In the absence of forests and coal, fuel is so expensive as practically to be unavailable to the average citizens of those countries; and hence they shiver through the winter.

Many intelligent men have appreciated that in India People and China a large proportion of the people are insufficiently nourished. It is probably true that more than go to bed hungry.

half of the people of the world to-night will go to bed hungry; at least they will not have received sufficient nourishment during the day to be the most efficient to-morrow. You, who have read history, know how, during the years of abundant rains, the people of India and China multiply, and how in dry years famine and scourge come and reduce them again to the number that can be supplied by the fruits of the land. In scripture we read that the seven fat years were eaten up by the seven lean years; and this has been the history of eastern countries for thousands of years.

The modern conservation movement is the direct result of the work of scientific men. The great question of conservation has been more forwarded by the rapid reduction of our forests than by any other cause. The forests are the one Conservation movement due to scientific natural resource which has been so rapidly destroyed that in the early seventies it began to be appreciated that, if existing practice were continued, the end was not in the far distant future.

As the result of a memorial presented by the American Association for the Advancement of Science in 1873, reënforced by another memorial of the association in 1890, the 
movement was inaugurated which resulted in a forestry bureau in the department of agriculture, and in laws which led to the first national reserve in 1891. The national forest movement was further advanced later as the result of an elaborate consideration of the question by the National Academy of Sciences in 1897. The principle of the national forest once established, these forests were enlarged from time to time, but the great withdrawals of the forests from private entry have been during the past ten years.

Another line of forces which resulted in the modern conservation movement came directly from the work of Major J. W. Powell, and especially the publication of his "Lands of the Arid Region." Mainly as a result of this volume and the influence of Major Powell, in 1888 an irrigation division of the United States Geological Survey was established; and authority was given to the Secretary of the Interior to withdraw from private entry reservoir sites and other areas which in the future would be necessary for irrigation purposes.

For the past quarter of a century many of the scientific men of the country have been raising a warning voice in reference to the other natural resources of the country. The limitations of our supplies of gas, oil, and coal have been pointed out. Many have described the denudation of the land and the widespread destruction of the soil; but notwithstanding the above facts, it cannot be said that there was any national movement for conservation. Indeed, it is probable that such a novement could not have been inaugurated until the situation had become grave, until the menace to the future had become serious.

Among the men who have promoted the modern conservation movement, Mr. Gifford Pinchot has first place. While his work was primarily directed to the conservation of the forest, his vision, with enlarging horizon, saw the connection of the forests to the other resources of the country; and he therefore extended his campaign of education to include with the conservation of the forest the conservation of all natural resources which are limited in amount.

It was seen by Mr. Pinchot and other scientists, notably 
McGee, that there is a close connection between the forests and waters. There was a strong public demand that our rivers maintain a uniform flow for water powers and for navigation. Therefore those primarily interested in forests and those interested in waters became associated in the conservation movement. In consequence of the public sentiment in reference to waterways and forests, President Roosevelt, on March 14, 1907, appointed the Inland Waterways Commission. This commission included a number of representative congressmen, an engineer, a statistician, a forester, an irrigation chief, and a geologist. ${ }^{1}$ This Inland Waterways Commission in its first report to the President emphasized the interlocking character of the problem of natural resources, and pointed out how the control and use of water would conserve coal and iron and the soil, and at the same time also make necessary the preservation of the forests.

The White House Conference grew out of the Inland Waterways Commission. On a trip of that commission in May, 1907, it was suggested that there be a conference at Washington the ensuing year to consider the conservation of the natural resources.

Chairman Theodore E. Burton and Commissioner Gifford Pinchot were authorized to convey to the President the ideas of the commission in reference to this matter. Later it was suggested that since the question of conservation concerned not only the nation, but every state, such conference should include the governors. On October 3, 1907, the Inland Waterways Commission, through its chairman and secretary, Mr. Burton, and Mr. W J McGee, sent to President Roosevelt a letter, requesting that he call a conference which should primarily be a congress of governors.

The President approved the plan and in November of that year called a conference of the governors, each governor being invited to be accompanied by three assistants or ad-

The White House Conference.

1 The Inland Waterways Commission consisted of the following: Theodore E. Burton, Chairman; Francis G. Newlands, Vice Chairman; W J McGee, Secretary; William Warner, John H. Bankhead, Alexander MacKenzie, F. H. Newell, Gifford Pinchot, Herbert Knox Smith.

Conference called by President Roosevelt. 


\section{6 \\ CONSERVATION OF NATURAL RESOURCES}

visers. But as the time approached for the meeting, the idea grew and there were finally included in the invitation of the President, the Vice President, members of the Cabinet, both branches of Congress, heads of the scientific bureaus of Washington, representatives of the great national societies, both scientific and industrial, representatives of journals, and notable citizens.

Thus there assembled May 13, 1908, at the East Room of the White House, the President, Vice President, seven members of the Cabinet, nine justices of the Supreme Court, many members of Congress, the governors of thirty-four states, and representatives of the other twelve, the governors of all the territories, including Alaska, Hawaii, and Porto Rico, the President of the Board of Commissioners of the District of Columbia, representatives of sixty-eight national societies, four special guests, forty-eight general guests, and the members of the Inland Waterways Commission.

Character of White

House Conference.

Never before in the history of the nation had so representative an audience gathered together. For the first time in the history of the country the governors were assembled to consider a great national question. Even during the extreme stress of the Civil War the governors had not been asked to consult with the President and with one another upon the state of the nation. Apparently President Roosevelt must have thought that the question of conservation was one of fundamental importance before he took so far-reaching a step. Never before in the history of the nation had the scientific men of the country met upon equal footing with those engaged in politics. This in itself was sufficient to mark the White House Conference as a meeting of the first importance in reference to the future of the nation.

The audience of the 13th of May was indeed an impressive one. Upon the right of the President sat the Vice President and the members of his Cabinet. Upon his left were the justices of the Supreme Court. Before him were assembled the governors, the members of Congress, many of the leading scientific men of the country, and numerous other delegates. 
The conference was opened by a notable address by President Roosevelt. And he, I think, above any other public man of the country has shown a wonderful capacity to quickly and broadly comprehend the salient points of a great new movement.

Hence he was able, although not a man of science, to present most effectively and in wonderful proportion the views which the scientific men had been developing through the past twenty-five years with reference to conservation.

Following President Roosevelt's address there were a series of addresses by scientific men, by governors, by eminent citizens. The scope of these papers extended to the minerals, the forests, the soils, and the waters of the country. ${ }^{1}$ The facts presented in reference to our important resources were so startling that the governors drew up strong series of resolutions ${ }^{2}$ covering the entire subject of conservation, pointing out the extravagance and reckless waste of the past, and making it clear that upon the conservation of our natural resources depends the foundation of our prosperity. The governors unanimously requested the President from time to time as occasion demanded to again call them together to consider with him and with Congress the great question of conservation. Also they recommended the states to establish conservation commissions to coöperate with one another and with a similar national commission. Several of the governors announced that their very first acts upon reaching their respective states would be to appoint such commissions.

Shortly after the White House Conference the President appointed the National Conservation Commission, consisting of forty-nine well-known men, about one-third of whom are engaged in politics, one-third in the industries, and one-third in scientific work. This commission was divided into four Appointment of National Conservation Commission. sections, assigned respectively to the minerals, the waters,

1 Proceedings of a Conference of Governors in the White House, Washington, D. C., May 13-15, 1908. Washington, Government Printing Office, 1909.

${ }^{2}$ This declaration of principles is so comprehensive and so important that it is republished as Appendix I of this volume. See pp. 381-384. 
Inventory of natural resources.
Report of National Conservation Commission.

the forests, and the soils. Gifford Pinchot, generally recognized as the most potent force underlying the conservation movement, was appropriately named chairman of the Conservation Commission. ${ }^{1}$ Since the White House Conference to December, 1909, forty-one state conservation commissions and fifty-one conservation commissions, representing national organizations, have been created.

At the first meeting of the executive committee of the National Conservation Commission, held in Chicago, June 19, 1908 , it was agreed that the initial step was to have made an inventory of our natural resources. It was there pointed out that to the present time, we, as a nation, are in the position of a man, who, bequeathed a fortune, has gone on spending it recklessly, never taking the trouble to ask the amount of his inheritance, or how long it is likely to last.

This executive committee therefore determined so far as practicable to have made an estimate of the existing available resources, what proportion of these resources have already been utilized or exhausted, the rate of increase in their consumption, and if this rate continues how long these resources will last. The commission had no funds at its disposal, and therefore was obliged to depend upon existing organizations for this work. Fortunately the President gave an order directing that the heads of the scientific bureaus at Washington utilize their forces in making investigations requested by the commission, so far as such investigations lay in their respective fields. As a result of requests by the National Conservation Commission, the heads of several bureaus placed a considerable number of experts upon conservation work during the summer and autumn of 1908 .

The full national commission assembled December 1 of that year to hear the reports of the experts and the secretaries of the four sections. Based upon these reports the commission drew up a report which they presented to the governors again assembled December 8,1908 , and by the governors this report was, with their indorsement, transmitted

1 The full personnel and organization of the National Conservation Commission are found in the Report of the National Conservation Commission, Vol. I, pp. 115-117. 
to the President, January, 11, 1909. The report of this commission, the statements of the secretaries, and the reports of the experts have since been published in three volumes. ${ }^{1}$ These volumes give the first available inventory of the natural resources of the nation. This inventory is of course but an approximation to the truth, but it is an immense advance over guesses as to the natural wealth of the nation. It does furnish a basis for quantitative and therefore scientific discussion of the future of our resources. In advance of the appearance of the report it would not have been possible to give this set of lectures. Indeed, they are based upon the material contained in these volumes to a greater extent than upon all other sources of information.

The next step of President Roosevelt, after appointing North the national commission, was to invite the governors of Canada and Newfoundland, and the President of Mexico, to appoint commissioners to consider with the commissioners of the United States the question of conservation. In consequence of these invitations the first North American Conservation Conference was held in Washington, February 18, 1909. As at the White House Conference, a broad statement was adopted embodying the principles of conservation applicable to the North American continent, which the commissioners were expected to urge upon their respective countries. $^{2}$

To crown the brilliant series of administrative acts to bring the question of conservation to the foreground of human consciousness, President Roosevelt on February 16, 1909, requested the powers of the world to meet at The Hague for the purpose of considering the conservation of the natural resources of the entire globe.

During President Roosevelt's administration, the Secretary of the Interior, James R. Garfield, withdrew from private entry a large area of the public domain, either permanently

American Conservation

Conference.

Withdrawal of lands.

${ }^{1}$ Report of the National Conservation Commission, Senate Document No. 676, 60th Congress, 2d Session. Washington, Government Printing Office, 1909.

2 See Appendix II. 


\section{0 CONSERVATION OF NATURAL RESOURCES}

or for a time, until the lands withdrawn could be studied with reference to their wisest utilization. The larger portion of the great forests which still remained the property of the nation when Roosevelt became President - more than $148,000,000$ acres - was made a part of the national forests during his administration. Also the coal lands of the West, both in the United States and Alaska, were withdrawn from private entry until they could be studied by the geological survey and a report made upon them as to their value and as to methods of disposal. More than $80,000,000$ acres altogether were withdrawn by him for this purpose. About 1,500,000 acres in several states along 29 streams were withdrawn with reference to withholding from private entry the water power sites. Finally, 4,700,000 acres of phosphate lands in Idaho, Wyoming, and Montana were withdrawn from private entry until they could be studied by the geological survey and appropriate laws made in reference to their exploitation.

Thus, during President Roosevelt's administration, more than $234,000,000$ acres of land were withdrawn from private entry, the greater portion of which is to be permanently retained as the property of the nation.

President Roosevelt also recommended that the fee of all of the coal, oil, and gas lands still remaining in the possession of the government be retained permanently, and that the same be leased under proper regulations.

Service to Conservation of President Roosevelt.

Attitude of Congress.
Concerning President Roosevelt, there has been much difference of opinion in political matters. He has been severely criticized by many, warmly commended by others, but his aggressive action for the conservation of our resources has been commended by all parties alike. In the future I believe that what he did to forward this movement and to bring it into the foreground of the consciousness of the people will place him not only as one of the greatest statesmen of this nation but one of the greatest statesmen of any nation of any time.

In marked contrast to the position of President Roosevelt in reference to conservation was the attitude of the Six- 
tieth Congress. President Roosevelt asked an appropriation for the National Conservation Commission; and Senator Knute Nelson, of Minnesota, introduced an amendment to the sundry civil bill asking for an appropriation of $\$ 25,000$ for the necessary rent, assistance, and traveling expenses of the commission. This amendment went to the Senate committee on appropriations, of which Senator Eugene Hale was and is chairman, but the amendment was lost, having failed of favorable action in the committee. Thus an appropriation for the Conservation Commission asked by President Roosevelt failed in the Senate, and the commission was left without any funds. This was unfortunate enough, but it would not have been fatal had the commission still retained the authority to ask the heads of the scientific bureaus to have their forces do work desired by the commission, which was appropriate and proper for their respective bureaus to undertake; but in the House of Representatives there was attached a clause to the sundry civil bill, which after the passage of that act prevented all bureaus from doing any work for any commission, council, board, or similar body, appointed by the President, without reference to whether or not such work was appropriate for such bureaus to undertake. Thus, so far as lay in its power, Congress made without avail the appointment by the President of the National Conservation Commission.

This clause of the sundry civil bill was introduced by James A. Tawney, of Minnesota, and its adoption was advocated by him. This congressman should be held responsible to the people of the nation for so far as lay in his power rendering without avail the appointment of the National Conservation Commission.

As has already been pointed out, the first report of the Report National Conservation Commission contains the only authentic statement as to the amounts of our natural resources, the amounts which have been exhausted, and their probable future life. The report was published as a Senate document in a small edition. The popular edition of this volume, recommended by the commission, was refused approval by the

contains inventory of resources. 
Organization of National Conservation Association.

then committee on printing of the house, consisting of Charles P. Landis, of Indiana, James Breck Perkins, of New York, and D. E. Finley, of South Carolina. For thus preventing the people from gaining the advantage of the results of the great work of the Conservation Commission they should be held primarily responsible.

As yet the attitude of the Sixty-first Congress is undetermined. To the present time (June 1, 1910) none of the Conservation measures recommended by President Taft have been passed.

After the adoption of the Tawney clause and before the organization of the Association next to be mentioned, the organization of the Conservation movement was carried forward by the Joint Committee on Conservation, an unofficial body established at the second conference of the governors.

In the autumn of 1909 there was organized the National Conservation Association. ${ }^{1}$ This association is to be the center of a great propaganda for conservation. It is hoped that all organizations interested in special phases of the Conservation movement will become affiliated with it. The association is to have a board of managers, consisting of one representative of each state and territory; and each state is to have a committee. It is the duty of any state committee and its member of the board to develop the Conser-

\footnotetext{
a The National Conservation Association, organized in 1909, has the following officers: -
}

Honorary President, Charles W. Eliot, Cambridge, Masa.

President, Gifford Pinchot, Washington, D. C.

Vice President, Walter L. Fisher, Chicago, Ill.

Treasurer, Overton Price, Washington, D. C.

Secretary, Thomas R. Shipp.

\section{Executrve Committe:}

Gifford Pinchot, Chairman.

James R. Garfield, Cleveland, Ohio.

John F. Bass, Chicago, III.

Henry L. Stimson, New York.

Walter L. Fisher, Chicago, Ill.

Bernard N. Baker, Baltimore, Md.

Charles L. Pack, Lakewood, N. J.

John N. Teal, Portland, Oregon. 
vation movement in the state which they represent, and to be the channel of communication between the local and national organizations.

The foregoing sketch of the rise of the Conservation movement shows that it grew out of the work of scientific men. Until recently the movement was not organized, and it was partial, that is, mainly confined to the forests and arid land; it only became national when President Roosevelt called the White House Conference in 1908.

With the foundation of the National Conservation Association, the great movement for the conservation of the natural resources of the United States may be said to have been fairly launched. Already a large number of the more intelligent people of the country are beginning to grasp its importance, beginning to understand that upon conservation rests the possibility of a numerous and well-nourished population in this country. But as yet the great majority of the people have almost no knowledge of the movement. It is comparatively easy to get a subject into the consciousness of the cultivated group. It is enormously difficult to accomplish this work with the millions. And the conservation of our resources can only be accomplished by the coöperation of the nation, the states, and the individuals. Therefore there is before us a profound and wide campaign of education which must begin at the universities, in national and Coöperation required for Conservation. state organizations, and must extend from them through the secondary and primary schools to the whole people. There is no other question before the nation of such fundamental importance to the distant future of the country. Since it seems to me that the universities should take part in the leadership in this movement for the advancement of the nation as they have in others, this course of lectures is given at Wisconsin.

Bringing an appreciation of the importance of conservation to the foreground of human consciousness is a work which cannot be done by one man or one organization in one year, or by many men and many organizations in many years. It is a campaign of education which will extend 


\section{CONSERVATION OF NATURAL RESOURCES}

through generations. But losses have already been so great that the movement should be carried forward as rapidly as possible, especially in preventing further wanton waste. This must be done if our descendants are to have transmitted to them their heritage not too greatly depleted.

The natural resources may be divided into four divisions, Minerals, Waters, Forests, and Soils. Each of these will be considered in order. 


\section{PART I}

\section{THE MINERAL RESOURCES}

THE mineral resources of the United States are, fortunately for us, far greater than those of any other nation. Also the value of the minerals produced far exceeds that of any other country. At the present time the estimated annual value of the mineral products of the United States is in the neighborhood of $\$ 2,000,000,000$. This amount is second only to that of agriculture.

The mineral resources took the building of the world for Building of their manufacture. Somehow in some way out of the universe stuff the solar system formed. At a certain stage of its development the earth had reached, if not its present size, at least an approximation to it. During the various stages world required for making of mineral resources. of its development vast masses of volcanic rocks came up from the depths of the earth and spread over its surface. Other masses, varying from those of enormous size to those called dikes or stringers, intruded themselves into the crust of the earth, pushing aside the solid rocks, spread themselves between the layers, and occupied and widened the cracks. Thus the igneous rocks became an important part of the crust of the earth. From the volcanic masses waters and vapors issued, bearing metals in solution. These were deposited, and thus were produced with the assistance of other agents stores of metals. The atmospheric water falling upon the surface of the earth percolated into the crust and assisted in this gathering of the rare materials. Somehow in some way life formed upon the globe, and organic material took its share in the segregation of the mineral resources in various ways, by processes too complex for me to enter into in this set of lectures. 


\section{CONSERVATION OF NATURAL RESOURCES}

As a result of the work of all these and other agents the elements of value to man originally very widely dispersed and in exceedingly small quantity in the original rocks have been segregated into these mineral deposits of such supreme importance to us. The process of their formations took many millions of years. Probably some of the deposits which are at present being mined are the results of the work of agents of the kind described a hundred million years ago.

Mineral resources, if dissipated, gone forever.

Man took no part in the production of the mineral deposits; he has added to them in no way. If the earth is the heritage of humanity, the mineral deposits are a part of that heritage. Under our present laws we have largely intrusted that heritage to the care of individuals and corporations. They should so administer this trust that the supply of mineral wealth may remain as nearly intact as possible consistent with severely economical use, so that succeeding generations through unending years to come may have their share in these benefactions of nature. The mineral resources once dissipated are gone forever.

For the purposes of these lectures I shall classify the mineral resources into three divisions, fuel, metallic, and nonmetallic.

\section{THE MINERAL FUELS}

Until the middle of the nineteenth century the chief source of fuel, not only in this country, but in all countries, with the possible exception of England and some of the other European countries, were the forests; and even in these countries the use of mineral as a fuel goes back only a comparatively short time. Therefore the great draft upon our mineral fuels has been a comparatively recent development.

The mineral fuels may be divided into four classes: coal, peat, petroleum, and natural gas. This morning I shall speak of coal. 


\section{COAL $^{1}$}

In a general way I have spoken of the processes which have manufactured all of our mineral resources. I may perhaps amplify briefly with reference to coal.

In middle geological time, especially in the carboniferous period, the conditions were such that there was a very abunThe making of coal. dant vegetation. Especially was this true in extensive marshes and swamps. The trees grew to maturity; in the course of years they fell and were largely covered by water; upon their fallen bodies other trees grew up. Tree fiber, as you know, is mainly built of the constituents derived from the water and air, not mainly from the constituents of the soil. In carboniferous time these great luxuriant forests continued to grow in the same areas for many thousands of years. Where the conditions were favorable, perhaps by subsidence, the accumulated organic material was covered by the water, and therefore was protected from decay. Later a geological change came, and these deposits of woody fiber were buried deeply under débris. These buried forests are the source of carboniferous coal. One or two other great epochs later came in which the conditions were similar to those of carboniferous time, and very large deposits of organic material were piled up. These later periods are the cretaceous and tertiary. - After these organic deposits were built up and buried below the earth, as wood may be placed in a kiln and transformed to charcoal, so by the processes of nature, similar but not identical, the buried woody fiber of ancient times was transformed into coal. The change is most advanced in anthracite, less in bituminous coal, and least in lignite.

The change of wood to coal was accomplished by nature when the material was deeply buried and consequently under heavy pressure. Hence the material is compact instead of being porous. Thus we have anthracite or stone coal and charcoal, substantially the same chemically, one produced through

1 The facts concerning coal are mainly from "Coal Fields of the United States," Marius R. Campbell and Edward W. Parker, and "Public Coal I,ands Containing Deposits of Coal," T. J. Butler, N. C. C., Vol. III, pp. 426-443 and pp. 416-420. " "Estimates of Future Coal Production," Henry Gannett, pp. 443-445. 
Our responsibility as to coal.

Cannot add to coal.

Coal most important mineral resource. the slow working of geological processes deep within the earth, the other transformed rapidly by man in a charcoal kiln.

It is thus plain that the manufacture of the coal deposits of the earth is the result of millions of years of labor of sun and earth; for the sun is the source of energy, as you have learned who have studied biology, which, stored in wood, enables us to use that material as a source of heat.

I dwell upon the process of manufacture of coal because only by the appreciation of its salient features can you fully understand our responsibility in this matter, - can you fully understand what is involved in the mining and combustion of coal. When a ton of coal is mined and burned it is gone forever. The supply which we have is definite. It is true that for some small areas the processes of nature may be manufacturing coal at the present time, but that process is so slow as to be negligible; and, therefore, so far as we human beings are concerned, we must regard the supply of coal as absolutely limited, a supply of invaluable importance to us, which we may use once but once only.

Nor is there any way by which in the future we may hope to add to the coal supply. Upon this point there are frequently great misconceptions. The progress of science has been so rapid during the latter half of the ninetcenth century and the early part of this twentieth century, that many people have said that some way will be found to replace exhausted products; but we should discriminate between the wonderful discoveries which are in the realm of reason and those which are wholly impracticable, wholly visionary.

It is true that we may find some way to substitute other things for coal; indeed, in this course of lectures that part of the field will be covered, but coal itself when used is gone and cannot be manufactured by man. The nearest approach to this is to grow wood and transform that wood into charcoal; and even now the relatively small amount of charcoal made is a very heavy drain upon our forests.

Coal is by far the most important of all of the mineral products. Next to coal in importance is iron. These two are of much greater consequence than all of the other mineral 
products put together. The existence of extensive coal and iron fields has profoundly influenced modern civilization. The greatest commercial nations are Germany, England, and America, and each has extensive coal and iron deposits. Little Belgium, because of its important coal and iron deposits, is a hive of industry, occupying a position as a manufacturing nation far beyond what one would expect from its limited area and population.

It has been said that the nations that have the coal and iron will rule the world.

Fortunately for us in the United States the coal deposits both as to quality and quantity exceed those of any other nation of the world; indeed they probably exceed those of all other nations combined; ${ }^{1}$ Brooks places them at 60 to 70 per cent of the known coal deposits of the world. Probably second to the United States is China, but as yet this country has not largely begun to develop its supply of this material.

\section{CLASSIFICATION AND OCCURRENCE OF COAL}

The coal supplies of the United States may be divided into three classes; anthracite, bituminous, and lignite, including sub-bituminous.

You all know what anthracite or stone coal is. It is the coal which is essentially composed of carbon, with some impurities, mainly ash. Bituminous is the ordinary black coal, such as is used for manufacturing purposes. It contains a large amount of so-called hydrocarbons; or, in addition to carbon, it contains carbon and hydrogen united, both of which are combustible, with also some free water. Lignite is synonymous with brown coal. In this coal the process of transformation from wood has not gone so far as with the others. Frequently it shows the structure of the woody fiber. It usually contains a large percentage of water, is comparatively light and porous, and therefore is the least valuable of the three kinds of coal.

In efficiency for the production of heat, these three classes

${ }^{1}$ Hearing before the Congressional Committee to Investigate the Interior Department and the Forest Service, pp. 2847, 2877. 
Important anthracite deposits.
Loss of anthracite in mining. of coal are in the order from anthracite through bituminous to lignite. As yet in this country lignite has been comparatively little used. Especially is this true of the eastern half of the United States.

The anthracite deposits ${ }^{1}$ of the United States are by far the most important of any in the world. Indeed, no European country has anthracite comparable in quality or quantity to that of the United States. Some of the Welsh coals are called anthracite, but they would be called in this country semianthracite. In China also are some anthracite deposits; and possibly in some other countries relatively small quantities of this material are found.

While the anthracite coal deposits of the United States are the largest in the world, the chief deposits are confined to about four hundred and eighty square miles in the state of Pennsylvania. But in this small area in three different fields, separated from one another by short distances, there are a wonderful number of thick and important seams, so that the output has been very great indeed. It is estimated that originally in this state were $19,500,000,000$ tons of anthracite. Of this about $1,900,000,000$ tons had been taken out by the end of 1909 .

According to the Anthracite Coal Commission, to 1883, for every ton that was mined $1 \frac{1}{2}$ tons were lost. If it be supposed that since that time only one ton has been lost to one ton mined, the total loss of coal in mining to the end of 1909 is 2,340,000,000 tons. At the end of the year 1909, it is estimated that there remained in the ground about $15,354,000,000$ tons. Pennsylvania anthracite is used as a fuel all over the eastern part of the United States, from Maine to the Mississippi River; and even farther west, during the winter, it is the chief dependence of many millions of people for warmth.

There are a few subordinate areas of anthracite in Colorado which are of consequence to that state and to the West, but as compared with the Pennsylvania deposits they are very small.

1 The statements as to areas and quantities of coal are taken from Campbell and Parker, N. C. C., Vol. III, pp. 426 et seq. 


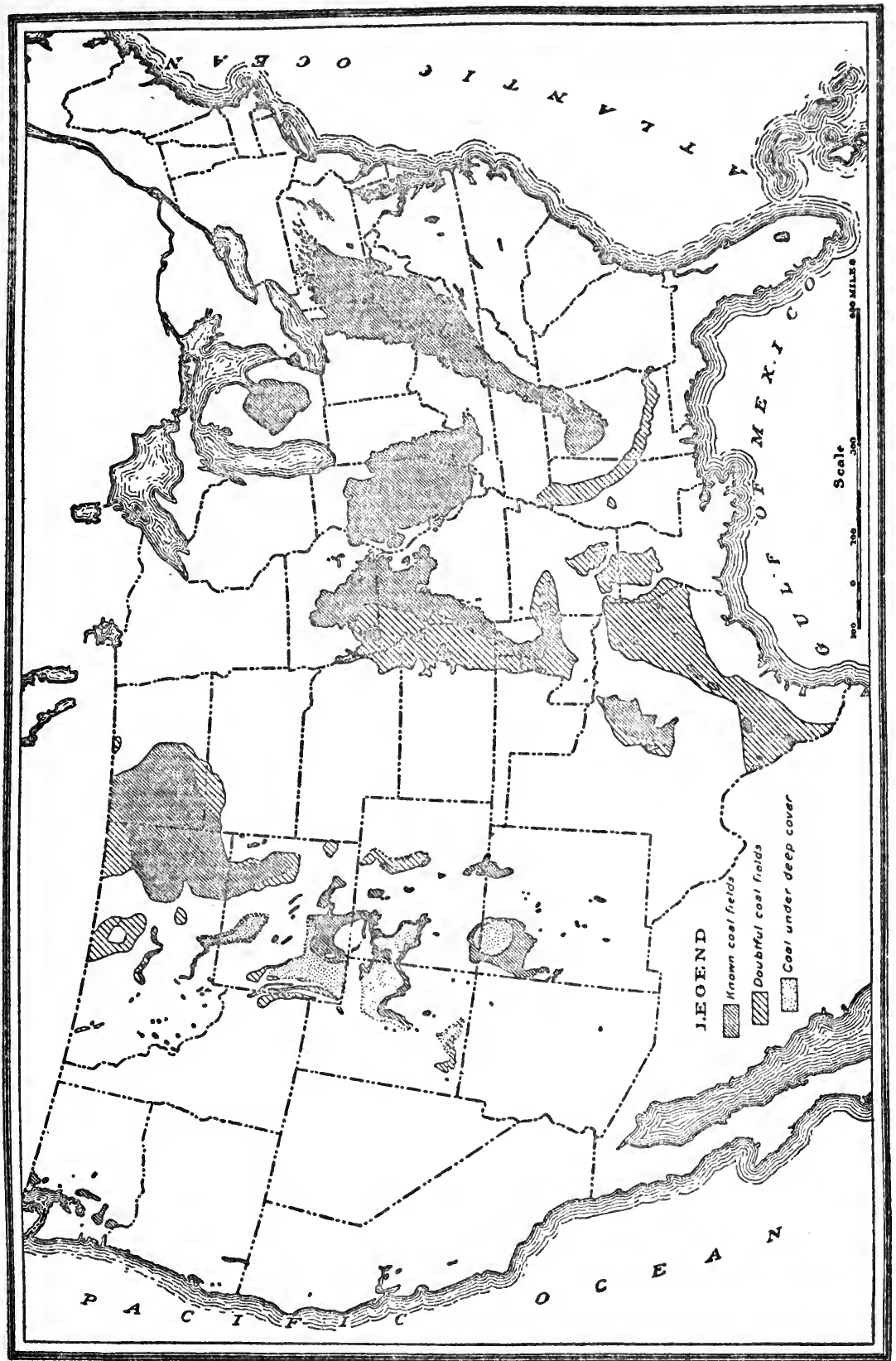

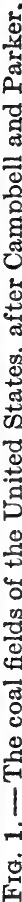




\section{CONSERVATION OF NATURAL RESOURCES}

Extent of bituminous coal.

The bituminous coal fields of the United States comprise about 250,000 square miles, mainly located in two great provinces. Of these the Appalachian is the most important, extending from Alabama to Pennsylvania. The second is the interior province, comprising the coal regions of Michigan, Illinois, Indiana, Kentucky, Iowa, Kansas, Missouri, Oklahoma, Arkansas, and Texas. Also some bituminous coals are found in the Rocky Mountain and Pacific coast provinces.

The lignites and sub-bituminous coals occupy nearly 250,000 square miles. They are mainly in three provinces: the gulf, including parts of the states of Alabama, Mississippi, Louisiana, Arkansas, Texas; the northern great plains, including parts of North Dakota and South Dakota, eastern Montana, and eastern Wyoming; and the Rocky Mountain province, including parts of Montana, Wyoming, Colorado, Utah, and New Mexico.

\section{THE AMOUNT OF AVAILABLE COAL}

Campbell and Parker estimate the aggregate coal area of the United States to be approximately 500,000 square miles, or about 13 per cent of the area of the country. They estimate at the end of 1907 that in this region there were available $3,076,204,000,000$ tons of coal, of which one third will be accessible only with difficulty. They estimate under present conditions the available and accessible coal at $1,922,979,000,000$ tons or somewhat less than two thirds of the total. These estimates are on the basis of limit in depth of 3000 feet for bituminous coal and 1000 feet for lignite; 20 inches were considered the minimum thickness of workable bituminous coal, and 3 feet for lignite. Some of the coal basins of the west extend to a greater depth than 3000 feet; and, where the seams are thick and good, these will doubtless be worked in the future. The same is true of seams less than 20 inches in thickness, especially those at moderate depth. Therefore the above estimates are conservative.

Not only is the coal of the United States great in 
amount, but from what has been said concerning its geographic occurrence, it is plain that it is well distributed, Coal well distributed. so that there are few parts of the United States which are not within 500 miles of a coal deposit. This matter is one of much consequence because the cost of coal depends so largely upon transportation. That the coals of the United States are not only extensive, but well distributed, is very important to the industrial and commercial development of the country.

\section{THE CONSUMPTION AND FUTURE LIFE OF COAL}

A few moments ago it was said that the use of mineral fuels was a comparatively new thing in this country; that before the middle of the nineteenth century the amount extracted was small. The total amount extracted up to and including 1845 was $27,700,000$ tons. In 1846 there were mined 5,000,000 tons; in 1850 this had risen to $7,000,000$; in 1875 to $52,000,000$; in 1900 , twenty-five years later, to 270,000,000 tons; and in 1907 to more than 480,000,000 tons.

This was the maximum to the present time, for in 1908 the total production fell to $415,842,698$ tons; and for 1909 the production is estimated by Parker to be between $440,000,000$ and $450,000,000$ short tons.

Not only has the increase in the use of coal been enormous, but the increase per capita has been surprising. According to a recent bulletin published by the geological survey, the amount of coal used per capita in 1850 was .278 ton; in 1870 it had reached .96 ton; and in 1900, 3.33 tons per capita. In 1907 it is estimated that the amount per capita was 5.6 tons. Thus the increase in the use of coal per capita from 1850 to 1907 was twentyfold.

The average increase in production in coal from 1846 to 1907 was at the rate of 7.36 per cent per annum; and this is practically equivalent to doubling the product every Coal mined doubled each decade. ten years. This means that the amount of coal mined during the first decade of the twentieth century will exceed the amount mined in all the previous decades. It means that

Increase in amount of coal used. 


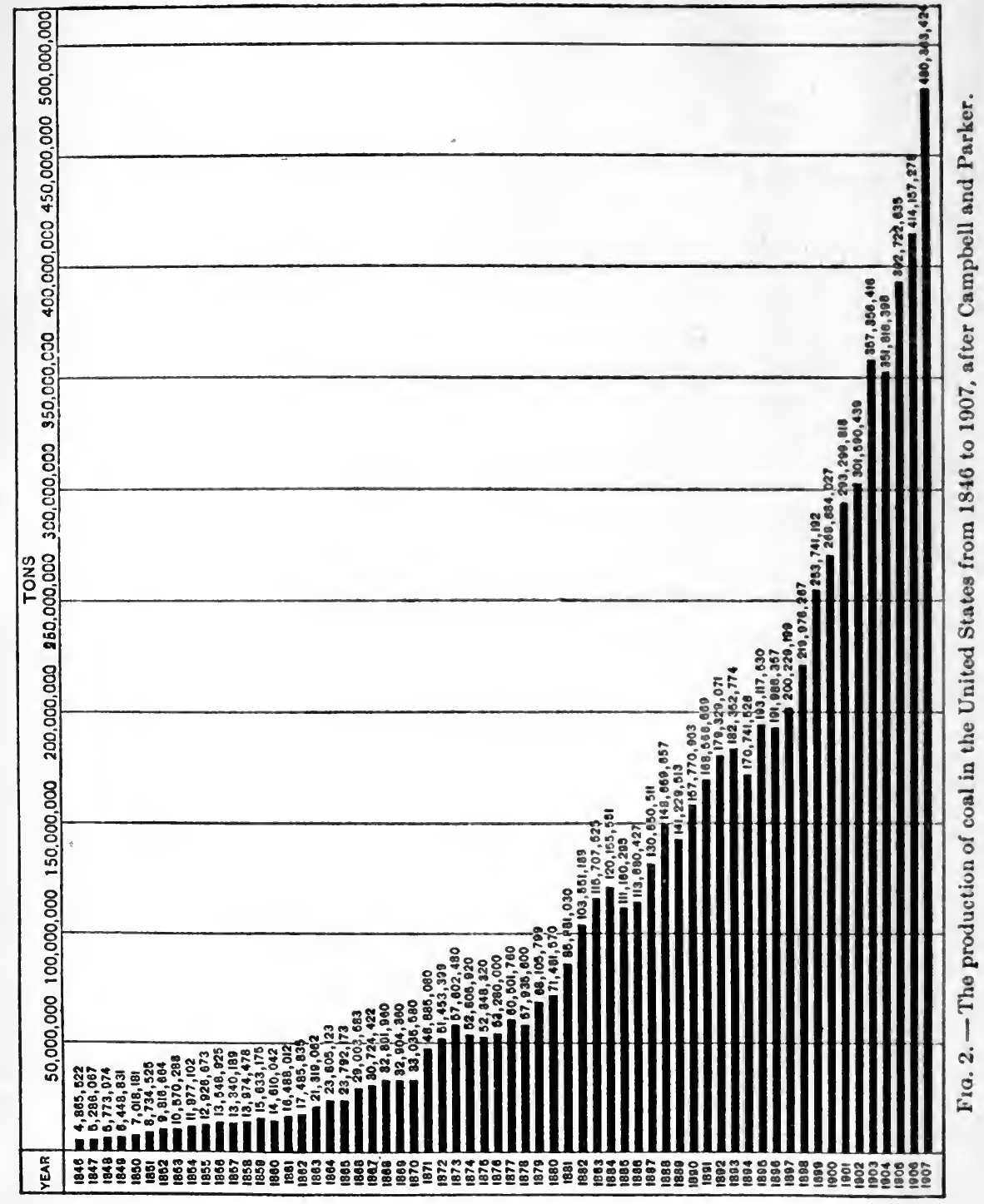


the amount mined in the last decade of the nineteenth century exceeded the amount which was mined in all previous decades of that century. Thus the rapid increase of the draft upon coal is nothing short of amazing. The question at once arises, if this rate of increase continues, How long will coal be available for the use of succeeding generations?

Up to 1908 the amount of coal mined was $7,240,000,000$ tons; but for every ton of anthracite taken out of the mines from one to one and one half tons have been wasted in mining, and for every ton of bituminous coal taken out at least one half of a ton has been thus wasted, so that the total quantity which has been mined or has been destroyed amounts to fully $10,935,000,000$ tons. If we suppose the rate of increase of exploitation to be the same in the future as to 1908, Mr. Gannett estimates that the available and accessible coal would be exhausted by the year 2027, and that the entire coal supply would be exhausted about the year 2050; that is, less than 150 years hence. However, for reasons given below it is believed that the coal will last much longer than this.

But in this matter of the life of the coal should we not consider a much longer period? The written history of the world extends back some thousands of years, at most 10,000. Necessity for prolonging In that time we have risen from the savage condition to the present civilized state. We hope for a future for our race not to be reckoned by thousands of years, but by tens of thousands, or hundreds of thousands, or even millions of years. And therefore, so far as our responsibility is concerned, it is immaterial whether the coal will be exhausted in 150 years, or 1500 years, or 15,000 years. Our responsibility to succeeding generations demands that we reduce its use to our absolute necessities, and therefore prolong its life to the utmost.

Hence we must reduce the waste of coal; we must so far as possible substitute other agents for coal; we must require that the coal mined be used with the highest state of efficiency.

I have already said the total amount of coal mined and 
Ratio

between coal mined and that available.

wasted is about $11,000,000,000$ tons. If this be compared with the total amount which is estimated to exist in this country, it is found that it is less than one half of one per cent. Thus the proportion of coal which is yet available is more than 99 per cent of the original amount. Happily the question of conservation has arisen in time so far as coal is concerned. We have yet mainly intact the great store which nature has given us. Since it is a resource which cannot be added to, the problem before us is to make it last as long as possible.

\section{WASTE IN THE MINING OF COAL}

To the end of prolonging the life of coal all waste should cease. The first of the wastes which must be reduced is that in mining. The waste in mining, which in the past has amounted to from 150 to 100 per cent for anthracite and to 50 per cent for bituminous coal of the amount taken out, is due to several causes.

In the first place numerous large pillars have been left to hold up the walls. Under a proper system of mining, pillars may be removed wholly or in part. There is no question that the amount of coal left in the pillars by modern mining methods can be greatly reduced.

Another waste in mining has been due to the fact that the beds are not always solid coal. Often in a bed is a layer of shale. In this case, very frequently the thinner bed of coal is disregarded, since to take it out would require the handling of the shale. In this manner sometimes from a fourth to a third of the available coal may be left in the ground.

Mining where more than one coal seam.
Another of the causes of waste in coal mining is the working of lower beds before the upper. It will be readily appreciated that where in a given area there are several beds at different levels, if the lower bed is worked first, the sinking of the ground will break the upper ones, mash the coal, and so leave it in a condition in which it is very difficult if not impossible to extract. Therefore where there are several coal beds, one above the other, and not far apart, the upper 
bed should be first mined, next the bed below, and last the deepest. 'Fortunately, economy in working has helped in this particular, for the material which is nearest the surface is most cheaply extracted; but very often it is the case that beds are so near one another that this factor has not controlled. The situation becomes complicated where the several beds differ not only in thickness but in quality. The desire upon the part of the operators to obtain the largest profit for the year, or for the decade, has led them to disregard their responsibility to coming generations in reference to mining first the higher beds and considering also the future availability of the thinner and poorer beds.

Another serious waste in coal in connection with mining is the production of very fine material called slack or culm, which is not always marketable. This waste has been Waste of coal slack. especially important with reference to anthracite and with the so-called dry or non-caking varieties of bituminous coal. At numerous mines many thousands of tons of this slack are thrown on the ground every year, and in order to free it from obstruction, are set on fire and burned. In the first place the amount of this slack may be greatly reduced by careful methods of mining, especially by the proper use of powder. Second, the slack which is left may be briquetted with coal tar and thus put into a form in which it can be utilized. As will be seen by the next section more than sufficient coal tar for this purpose may be produced by the substitution of the retort coke oven for the beehive oven.

These defective methods of coal mining under which from 50 to 150 per cent as much coal has been wasted as has been extracted must be modified. Modern mining methods must be introduced; lower seams must be worked first; they must be worked so as to reduce waste to a minimum; coal slack must be reduced in amount, and that necessarily formed utilized. The waste may thus be reduced to 25 per cent of the amount taken out, and possibly to 15 or 10 per cent. In conclusion it is but fair to say that in some districts there have been great improvements in economy of mining in recent years. For instance, 
Brooks ${ }^{1}$ states that in the Anthracite district of Pennsylvania, the waste in mining is already reduced to the lower of these figures.

WASTE OF COAL IN BEEHIVE COKE OVENS

Much of the waste of coal is in its use. Adjacent to Pittsburg are about 35,000 beehive coke ovens, and in the United States altogether are some 95,000. I do not know how many of you have traveled through the Connellsville coal region. If you have done so and have happened to look out of the window of the train, you have seen long rows of these beehive ovens from which flame is bursting and dense clouds of smoke issuing, making the sky dark. By night the scene is rendered indescribably vivid by these numerous burning pits. The beehive ovens make the entire region of coke manufacture one of dulled sky, cheerless and unhealthful.

Saving of by-products necessary.
The use of beehive ovens is an unnecessary and most reckless waste of our fuel resources. The retort oven not only yields a greater amount of coke per ton and of better quality than the beehive, but it yields a large quantity of valuable by-products. These are gas, tar, and ammonia. The first may be used for heat; the second is useful for many purposes, among these the briquetting of coal, the making of dyestuffs; and the last is a valuable fertilizer. Other countries are much more advanced than the United States in the manufacture of coke. In Germany nearly all of the coke is made in retort ovens. In the United States there were in 1907 only 3892 such ovens. The value of the byproducts of those ovens in that year was $\$ 7,548,000$, whereas the value of the coke was $\$ 21,665,000$. Thus the by-products reached more than one third of the value of the coke. It is calculated that if for the 95,000 beehive ovens retort ovens were substituted, there would be an economy of approximately $\$ 50,000,000$ per annum.

In no other country but the United States would such vast quantities of valuable products be recklessly wasted.

${ }^{1}$ Hearing before the Committee to investigate the Interior Department and Forestry Service, p. 2845. 
There is no possible excuse for the continuance of the use of the beehive oven. Because capital is invested in beehive ovens is no adequate reason for disregarding responsibility to the future, even if there were a financial loss. But as a matter of fact, the savings resulting from the substitution of retort ovens for beehive ovens will more than justify the necessary expenditure, even from the point of view of an investment. To make the change will require some years at best and doubtless during the transition the markets would expand so as to utilize the increasing amounts of byproducts.

Whenever I have gone through that Connellsville coal region, $I$ have felt that it is a shame that the unnecessary waste of the beehive coke oven is permitted to continue year after year. Professor I. C. White says that the waste in West Virginia alone in six months would be sufficient to endow a university with $\$ 10,000,000$. This is the waste in one state by one process, - the manufacture of coke by the obsolete beehive oven process.

\section{WASTE OF COAL BY IMPERFECT COMBUSTION}

We also waste coal in immense quantity in the production of power. In all the cities of the country black smoke is now belching forth from innumerable chimneys. This you may see in any manufacturing district. Smoke is unconsumed coal. When dense, it represents a loss of from a fifth to a third.

Methods are known by which coal may be nearly perfectly consumed and by so doing its efficiency greatly increased. This is accomplished by mechanical stokers. To illustrate, in the central heating plant which has just been completed at the university of Wisconsin the economy in the consumption of coal as compared with hand firing is about 35 per cent. The increased cost of the installation will be more than paid for by increased economy within two or three years. It is both economical and right that all large consumers of coal for heat or power shall be re- 


\section{0}

CONSERVATION OF NATURAL RESOURCES

Enormous waste of smoking chimney.

Smoking chimney injury to health.

quired to use some form of stoker which will get the highest efficiency. Smaller users of coal, so far as practicable, should unite and form central heating plants to distribute heat and power. At the present time there is no question of the economy of this in the case of power; and the practice in reference to heat has been sufficiently developed to show that this is advantageous. In reference to the latter, Randall ${ }^{1}$ reports that investigation of fifty-seven such plants indicates "that they are economical for the householder, and that their more general establishment and use will greatly reduce the amount of smoke generated in cities."

According to H. M. Wilson, 8 per cent of the coal used in the production of power, light, and heat, or $20,000,000$ tons of coal, are going up the chimneys each year in smoke. This represents a value of at least $\$ 40,000,000$. But according to Wilson this is a small part of the loss, the damage done to the cities being several times this amount. He places the aggregate at the enormous amount of $\$ 500,000,000$ per annum, one tenth of which is in the city of Chicago alone. This may be an overestimate, but even if the damage is not more than a half of the above amount it shows how serious is the smoke nuisance.

But waste in coal and damage to buildings are only a part of the evils of the smoking chimney. Did you ever think of the condition of the lungs of a person living in a city, the air of which is continually gray or black with smoke? The tissues are impregnated with the organic material inhaled day by day. That this condition is favorable to the development of tuberculosis is certain; also it weakens the body generally. We can calculate in percentages how much of the efficiency of the coal is lost by the smoking chimney; no man can calculate what this chimney costs in human suffering, in death; no man can calculate what it costs in the pleasantness of living. These things are not to be determined on a cash basis. While the perfect combustion of coal is most important economically, it is certain that the conservation of humanity by eliminating the smoking chimney is even more important than the conservation of coal.

1 Bull. 366, U. S. Geol. Survey, Washington, D. C. 


\section{SUBSTITUTION OF GAS FOR STEAM ENGINE}

Another method by which the efficiency of the coal can be increased is by the substitution of the gas engine for the steam engine.

I have just said that by the use of mechanical stokers the power developed by steam boilers could be increased about one third. But even with the best of firing the steam boiler is very inefficient. Under the most favorable conditions it does not produce in power more than about 15 per cent of the heat units of the coal; and it is probably true that in average practice the steam engine does not develop in power more than 5 to 10 per cent of the heat energy.

Every effort should be made to improve the efficiency of the steam engine; but at best it is likely permanently to continue a very extravagant method of converting heat into power. This fact has directed attention to the discovery of some other engine of greater efficiency as a substitute for the steam engine. Thus during recent years the gas engine has developed, and it is rapidly being introduced. The gas engine works upon a different principle from the steam engine. Instead of burning the coal under a boiler and making steam, the coal is transformed into gas and the gas is mixed with the air, making an explosive compound, the explosions taking place in the pistons of the engine and thus driving it.

The United States Geological Survey, as a result of extended experiments, has determined the efficiency of coal for the gas engine as follows: "The average consumption Economy of gas engine. of fuel for a brake horse power hour was 1.36 pounds of bituminous coal, or 1.99 pounds of lignite coal, the minimum consumption being 0.84 pound and 1.48 pounds, respectively. Comparative tests of 75 bituminous coals under a watertube boiler and in the gas producer showed that the average fuel consumption per brake horse power in the steam plant was 2.7 times that in the producer plant. Several low grade coals and lignites that were of little value, or even worthless, under the steam boiler gave excellent results in 
the producer. Other low grade fuels - such as roof slabs, culm, and washery refuse, and even a bone coal that contained 44 per cent of ash - have been used to advantage in the producer under proper commercial conditions." It is safe to say from these results that the draft upon coal in the production of power by the gas producer and gas engine is not half as great as with the steam boiler, since not only is the better coal far more efficient, but refuse material is available.

The Geological Survey reports that there are in the United States more than 500 producer gas plants ranging in size from 15 to 6000 horse power. Already gas engines are in operation from 2000 to 3500 horse power each.

Here then is a great field in which economy in the use of coal may be promoted. The results achieved show clearly the superior economy of the gas engine as compared with the steam engine; it is to be hoped that the substitution will take place as rapidly as practicable, and thus reduce the amount of coal required for power to about one half that used for the steam engine.

\section{LOSS OF COAL IN MAKING LIGHT}

The waste of energy in making light from coal is even more striking than with reference to power. When coal is used for making light, by consuming the coal, making steam, transforming the power of the steam into electric energy, and then transforming that into light, not one per cent of the available energy of the coal is transformed into light; a common estimate is one fifth of one per cent. The remainder is lost in the various stages of transformation. Here is another field for increased economy. Already some of the higher efficiency lamps have done better than this; but it is certainly true that under present practice, on an average, not one per cent of the energy of the coal is transformed into light. 


\section{INCREASE OF CARBON DIOXIDE IN THE AIR}

It is probable that the consumption of coal itself will lead to conditions which will require less coal for fuel. It has been shown by the physicist Arrhenius that the carbon dioxide of the atmosphere serves as does the glass of a hothouse to save the heat of the sun. Says he, "if the carbon dioxide is increased 2.5 to 3 times its present value, the temperature in the arctic regions must rise 8 to $9^{\circ} \mathrm{C}$. and produce a climate as mild as that of the Eocene period." 1

It is to be remembered that in the Eocene the climate was sufficiently warm so that abundant vegetation existed in Greenland.

The combustion of coal produces enormous quantities of carbon dioxide which passes into the atmosphere. If for the coming centuries the rate of coal combustion for the entire world were assumed to be at the rate of one billion tons per annum (probably two or three billion tons would be nearer the truth), there would be sent into the atmosphere over $2,900,000,000$ tons of carbon dioxide each year. In consequence of this the amount of carbon dioxide in the atmosphere would be doubled in about eight hundred years. ${ }^{2}$ To increase the carbon dioxide in the atmosphere to three times its present amount through coal combustion would require less than 1600 years; and the coal consumption may become so rapid as to accomplish this in 1000 years or less.

As the climate becomes milder, it is plain that for the temperate regions, in which is located the United States, less coal will be used for fuel.

\section{GENERAL STATEMENTS}

Other improvements have been made in the use of coal during the past few years; for instance, in 1875 it took

Investigation and economy.

${ }^{1}$ Arrhenius, Svante, On the influence of carbonic acid in the air upon the temperature of the ground; Philos. Mag., 5th ser., vol. 41, 1896, pp. 237276. Summary in Jour. Geol., vol. 7, pp. 623-625.

2 "A Treatise on Metamorphism," by Charles R. Van Hise, Monograph XLVII, U. S. Geol. Survey, pp. 463-465. 
from 3500- to 3700-weight of coke to make one ton of iron. Under present practice it only takes about 2200-weight, less than two thirds of the amount required thirty years ago.

The above illustrations of lack of efficiency in the use of coal and of improvements made are given to explain a principle. This is, we should never cease to strive to improve the efficiency and, therefore, the economy in the consumption of coal. Here is a great opportunity for advance, and hence investigations by the nation, by the state, by engineering societies, by universities, upon the subject are demanded. Expenditures of money for the purpose of producing a higher efficiency in the use of coal will undoubtedly be returned many fold.

In the future, water will be used to a much greater extent than in the past to develop power to make light, and this will greatly reduce the consumption of coal. This substitution is now rapidly taking place, or at least the increased demand for power is largely met by the use of water. At the present time under favorable conditions water power can be advantageously transmitted 200 or even 300 miles. This phase of the subject will not be further considered here, but will be developed under Waters, see p. 124.

Coal should be adapted to best use.

Not only should coal be conserved in every way possible, but the best uses should be made of the different varieties. At the present time, according to Dean Goss of Illinois, about one fifth of the 75,000,000 tons of anthracite coal mined in this country goes into the locomotive. For this purpose, bituminous coal will serve equally well; and since our supplies of bituminous coal are vastly larger than those of anthracite, the latter variety of coal should be kept for higher purposes.

Finally, it is extremely probable that the industrial expansion of the past will not continue indefinitely; and therefore there will not be the same necessity even under existing conditions for doubling the amount of coal mined every ten years. Indeed it is probable that in the near future the time required for doubling the output will be considerably extended. 
The considerations above given make it certain that coal will last longer than 150 years, the estimate of Mr. Gannett upon the hypothesis that the same rate of increase will continue in the future as in the past. It is believed that the rate of increase will not be so rapid as in the past, because of the facts which have been given. Improvements in mining will reduce the waste to 25 per cent, or perhaps 10 per cent; the coal slack will be utilized; the beehive oven will be abolished; the smoking chimney of the large manufacturing enterprises and of all large users of coal will be discontinued; discoveries will be made which will still further increase the efficiency of the coal used; water will be substituted for coal in the development of power.

But in order that these results shall be accomplished, and so prolong by ten or more times 150 years our coal supply, a great campaign of education will be required. Our laws should be so amended as to prohibit the uneconomic use of coal. This means that the unnecessary waste of coal in mining should be unlawful; it means that the manufacture of coke in beehive ovens should not be allowed; it means that manufacturing plants should be obliged to use mechanical stokers and obtain complete combustion.

But it may be said that such far-reaching proposals trench upon the rights of private owners. But has any one the right unnecessarily to destroy a natural product which it took the building of the world to make, because we chance to have intrusted to him the charge of that product? There is no question as to good morals in this matter. It is good morals to insist that such a product shall not be wasted; not only is it good morals, but it is good law (see p. 363).

\section{THE PUBLIC COAL LANDS}

I now wish to call your attention for a few minutes to the public coal lands, because in connection with them are special problems which are directly before the people at this Coal lands disposed of as agritime. It has been the policy of the government to dispose cultural. of its public domain, but in recent years the principle under- 
lying all the laws for such disposal has been that only a limited tract shall pass to one individual or one group of individuals. The first general coal land law was passed in 1873. Before that time the great and enormously valuable areas of coal land of the Middle West from Ohio to Missouri and Kansas, from Kentucky to Michigan, passed from the government to private hands, without respect to whether or not they were coal-bearing. The man who obtained possession of lands as agricultural or for any other purpose, also obtained possession of the coal which underlaid them. But in 1873 an act was passed under which known coal lands were separated from other lands and were to be disposed of as such. Even after this law was passed large tracts of coal lands passed to private owners as agricultural. Indeed, of the many million acres of government coal lands disposed of since 1873 , only about 500,000 acres, according to Butler, have been patented under the coal land laws. According to Woodruff $100,000,000$ acres of coal land were disposed of as agricultural lands.

Classification of coal lands.

Coal land law.

In order to meet this situation and other difficulties, the National Conservation Commission, in its first report (1908), recommended that the public lands be classified, and the timber, minerals, and surface disposed of separately. This recommendation was acted on in part by Congress in the so-called Mondell bill, approved March 3, 1909. Under this act a person who has entered lands as agricultural, which are subsequently classified as valuable for coal, may receive a patent for such lands; but the coal may be disposed of in accordance with the provision of the coal land laws.

The coal statute of 1873 provided for the sale of known coal lands at prices "not less than ten dollars per acre" for those that are more than fifteen miles from a completed railroad, and "not less than twenty dollars per acre" for lands within fifteen miles of a completed railroad. Under this act only 160 acres could be taken by an individual; but an association of individuals up to four might take up as many times 160 acres as there were persons in the association, limiting however the total amount for any one asso- 
ciation to 640 acres. The act still further provided that no individual or member of an association might enter or hold more than the above amount.

Notwithstanding the perfect clearness of the law of Congress, the act of 1873 until 1906 was interpreted by the land office of the interior department, so that the words "not less than" meant "not more than." In other words, the land office disposed of all coal lands which were taken up during these years at prices either $\$ 10$ or $\$ 20$ an acre, depending upon contiguity to a railroad, without reference to whether they were worth many times this amount.

President Roosevelt, appreciating the situation in reference to coal lands, during his administration, and mainly toward its close, while James R. Garfield was Secretary of the Interior, withdrew from private entry in the United States for classification by the Geological Survey more than $75,000,000$ acres of coal lands. These withdrawals have been increased during President Taft's administration, while R. A. Ballinger was Secretary of the Interior, so that the total area withdrawn to November 1, 1909, was 79,650,002 acres. In February, 1910, the Secretary of the Interior, in addition to the above, withdrew 588,000 acres of coal land in Wyoming. The total coal land withdrawal the first year of the Taft-Ballinger administration, i.e. to March 4, 1910, amounted to 7,675,000 acres; and the form of withdrawal of $9,000,000$ acres more was changed to cover all kinds of entry instead of coal alone.

In July, 1906, under the administration of President Roosevelt, when James R. Garfield was Secretary of the Price of coal lands. Interior, it was decided that the words "not less than" are not synonymous with the words "not more than," and, without any change in the law, a new scale was put into force under which the coal lands were disposed of at prices varying from $\$ 75$ to $\$ 100$ an acre, the first amount for good bituminous coal, and the second for anthracite. Still another scale was put in force in April, 1909, under which the prices range in most cases from $\$ 100$ to $\$ 300$ an acre for the best coal lands: that is, at the present time anthracite and 


\section{NATURAL RESOURCES OF UNITED STATES}

Prices of coal lands inadequate.

coking bituminous coal are disposed of at the rate of from two to three cents per ton, high grade non-coking bituminous at one to two cents per ton, low grade bituminous and high grade sub-bituminous at from one to one and one half cents per ton, and low grade sub-bituminous and lignite coal at the minimum price of $\$ 10$ to $\$ 20$ an acre.

But even this new scale of prices, according to the director of the Geological Survey, is rarely equal to one tenth of the royalties paid in the same districts to private interests. He says the prices "range from 5 to 30 per cent of the usual royalty paid in the West."' According to Ashley, the above prices placed on the government coal lands represent "one fifth of the computed royalty value, an ultra-conservative estimate which in turn is based on a conservative estimate that only 1000 tons per acre-foot of the coal computed to be in the ground can be recovered." Not only so, but in the calculations, all seams less than fourteen inches thick are ignored; as also all coal at greater depth than 3000 feet. Ashley further says: "In general the government price for lands containing several beds will average not far from one tenth of the estimated royalty value." These statements are from the official publication of the United States Geological Survey. ${ }^{2}$

Settlement for unlawfully taken lands.
That Ashley is correct in his conclusions is reënforced by what happened in the case of some of the coal lands which have been taken possession of unlawfully. For instance, in Horse Thief Cañon, Wyoming, large tracts of coal lands were fraudulently entered and coal mined. For such coal the company has settled with the government on the basis of eight cents per ton royalty, which means that the government has received for such coal lands $\$ 850$ per acre. Some of the coal lands in Colorado contain in a number of seams as much as fifty-six feet of commercial coal. These lands upon a basis of a royalty of eight cents a ton would yield $\$ 5000$ an acre. Yet a large portion of the Colorado coal lands have been disposed of at from $\$ 10$ to $\$ 20$ per acre.

${ }^{1}$ Thirtieth Annual Report, p. 10.

2 "The Value of Public Coal Land," George H. Ashley, Bulletin 424, U. S. Gcol. Survey, p. 14. 
Of the coal lands withdrawn in the United States, amounting to some $80,000,000$ acres, to November 1, 1909, 35,915,255 acres have been classified by the Geological Survey, and their Adequate price shoul 1 be placed o? sale is now going on rapidly. According to Ashley, "it may be of interest to note that the higher prices placed on government lands do not seem to have decreased their sale, but rather the contrary." This, notwithstanding "the predictions so freely made that the new prices would absolutely tie up their sales." A possible explanation of this phenomenon is that those who are seeking coal lands at prices far below the value appreciate that their opportunities will not last much longer.

The Secretary of the Interior, I understand, holds that after the coal lands are classified they must be sold under existing laws; but there is no law which prevents him from placing a value on them such as would be asked for such lands were they owned by private parties. Indeed, this is the only reasonable interpretation to be placed upon the law of 1873; otherwise a maximum price as well as a minimum would have been fixed by Congress. The people have the right to ask that not another acre of the public coal lands shall be disposed of at a price lower than would be demanded for them if these lands were in the hands of private parties. Further, in making estimates as the basis of sale all the assumptions should not be made in favor of the purchaser; that is, a valuation should be placed suffciently high upon all of the coal lands so that the public is protected beyond peradventure.

On November 16, 1906, under President Roosevelt's administration coal lands in Alaska were absolutely withdrawn as follows; those containing known workable coal, 792,320 The Alaskan coal lands. acres, and coal-bearing rocks which may contain coal, $8,092,160$ acres. The coal lands of Alaska include areas of high grade anthracite and bituminous coal, low grade bituminous coal, and lignites. According to G. C. Martin the grand total for this region of workable coal is more than $15,100,000,000$ tons, of which $1,611,700,000$ is anthracite, and 517,100,000 semi-anthracite. The semi-bituminous coal, 
Claims

filed on

Alaskan coal. that is, coal near semi-anthracite, amounts to $1,492,600,000$ tons, making a known total of high grade coal in Alaska of $3,621,400,000$ tons.

The absolute withdrawal of the Alaskan coal lands was necessary, since under the present law, if coal lands are disposed of in that territory, this must be done at the absurdly low rate of $\$ 10$ per acre.

At the present time claims have been filed upon probably two thirds of the best coal lands of Alaska. These claims are now owned or controlled by a few large corporations, although according to the law under which entries were made they must be bona fide ones of 160 acres by individuals, or at most 640 acres by four individuals, and in the interest of the entrymen. By an act of 1908 entries made in good faith under the previous law were allowed to be consolidated into single holdings not exceeding 2560 of contiguous land. As yet these claims have not been recognized by the government; and it is believed by the special agents of the land department who have examined and reported upon them that many and probably the majority of them are fraudulent.

Probably upon the average royalties could be obtained for the high grade coal in Alaska of fifteen to twenty-five cents a ton, although doubtless the royalties would need to be placed lower for the first ten years, Brooks ${ }^{1}$ thinks not over eight cents. Some of the large interests having claims pending before the land department estimate their profits in case their claims are validated at fifty cents a ton; and it is safe to assume that these estimates are not too high. It is therefore clear that the government on a leasing basis would finally receive from these lands a very large amount. It is to be hoped that this enormously valuable resource may remain the property of the United States; and certainly no part of these lands should be allowed to pass to private hands save upon the clearest proof of the legality of the claim. The rate of $\$ 10$ per acre for which the lands must be disposed of, if at all, for the Bering River

1 Hearing before the Congressional Committee to investigate the Interior Department and the Forestry Service, pp. 2844, 2905. 
field probably does not exceed one fifth to one fiftieth ${ }^{1}$ their real value.

Congress as soon as possible should pass a law which shall prohibit absolutely the further sale of the public coal lands, in order that they may be operated under the lease system. If it is advantageous for private parties to gain possession of the government coal lands and to operate or sublet them to others under the lease system, it is advantageous for the government to retain such lands and to grant leases for their mining to private parties. This would give the following advantages.

1. Leases could be made of various sizes adapted to the situation. At localities where the coal seams are numerous and thick, a lease to one company should cover only a moderate area. In other localities where there is perhaps only a single workable seam of coal, a lease should be for a larger area.

2. Conditions may be imposed which carefully guard the methods of exploitation so as to avoid waste. In this manner the ruinous competition which has been characteristic of the East and which has led to the mining of the thicker and richer seams, and leaving much of the poorer material behind, can be avoided. Leases will only be taken upon those seams which can be commercially handled on the basis of clean and complete mining. Other areas in which the seams are poorer or less advantageously located so that such mining cannot be done will not be opened up but will remain as a reserve for future generations.

3. A lease should be on the basis of a royalty per ton Further upon the amount of coal mined, with, however, the requirement of mining a reasonable minimum per annum, to prevent terms of lease. acquisition of coal lands, and holding them without operation. The amount of royalty per ton should be adjusted to the character of the coal, its ease of mining, and the relation to transportation and markets. A lease should be for a definite term of years, for instance ten or twenty years, as may seem best, at the end of which term the government should have the right to fix the royalty at a rate reasonable 
at that time. The lessee should have the first right for renewal upon such terms, but if renewal be not desired, some equitable arrangement should be made for compensation to the lessee for his plant.

If the government retains the coal lands and permits their operations on a lease system, it will obtain a fair return from them; and only by this system is this likely to be the case.

4. The retention by the government of the remaining coal lands of the public domain is very important in maintaining a reasonable price for coal, since if this be done, there will be competition of the coal from the land owned by the government with that which comes from private lands.

By lease prices may be controlled.

5. Also under the leasing system the maximum prices at which the product is sold may be fixed, and thus make it certain that the people may obtain coal at reasonable prices. The conditions of a lease may be such as the government desires to impose. If the price is fixed at which the product is sold, this would have to be taken into account in determining royalties; for the operator should have a fair return from his investment.

6. The exportation of coal from the leased lands may be prohibited at any time it becomes clear to the authorities that this is to the permanent interest of the nation. For my own part I have no doubt as to the advisability of such legislation in the near future.

It is indeed a question whether it would not have been wiser for the government to have retained all of the coal lands which were a part of her public domain, but that is a question which it is useless now to discuss. Certainly the remnant still owned should be retained through the indefinite future as the property of the people in order that they may gain the full advantage of ownership of a natural resource of such fundamental importance as coal.

Bill Secretary of the Interior Ballinger, with the approval of to lease coal lands. President Taft, in 1910 presented a bill to Congress, embodying the principles advocated for the disposal of the public 
coal lands. Among the provisions of the bill are the following: the lands in the United States and Alaska which contain coal are to be reserved from sale or entry; they are to be open for prospecting in parcels not to exceed 5120 acres, and subject to lease in tracts of not more than 2560 acres; the leases shall not be for more than thirty years, but they may be extended in periods of ten years under equitable terms; the original lease is to pay a royalty not to exceed fifteen cents per ton of run of mine coal, with a minimum rental of the land, the same however to be allowed as part payment of royalties. The bill further provides that a maximum price may be fixed beyond which the owner of the license shall not charge the public for coal and the prices may be graduated during the term of the lease. The surface rights of the land may be obtained under the non-mineral land laws. The provisions of this bill are in general excellent; but there is no adequate reason for limiting the amount of the royalty; this should be determined on an equitable basis in each case. It is to be hoped that the administration bill will be perfected and enacted into law.

Two states of the Union, Colorado and Wyoming, each owning coal lands, have adopted the lease system advocated. According to Ashley, in November, 1908, in Colorado there were 18,275 acres of coal land under lease, which yielded $\$ 104,000.42$ in royalties during the biennial period ending November 30 of that year. The Colorado leases illustrate all the principles advocated. The lessee must begin mining coal within six months after he has obtained the same; he must carry on mining continuously and mine a reasonable amount of coal; good mining methods must be used which will prevent waste and protect against various emergencies; he must pay a royalty of ten cents a short ton, or from three to more than ten times as much as the government is now parting with its coal lands for. This statement should be modified by the fact that the payment is made in the case of the lessee only as the coal is mined; whereas the government gets its money at once. It is clear, however, that the

Lease of coal lands by states. 
government is the organization that can best afford to wait until the coal is mined before it receives payment; but when the exploitation takes place it should receive adequate compensation.

\section{REgULATION OF THE PRICE OF COAL}

But even if the government retains possession of its remaining coal lands this is inadequate so far as anthracite is concerned, for this coal in Pennsylvania is already altogether in private hands. It has been definitely decided within the past few years that the rates which public utilities may charge may be fixed by the states, and so far as these are interstate, by the United States. This position was severely attacked a few years ago; but it is now firmly settled that the prices which public utilities charge may be fixed by regulation through commission, subject to the limitation that the prices determined may not confiscate private property.

Monopoly and prices.
The question arises as to what shall be done in the case of a product which is substantially a monopoly, or if not a monopoly, a product in which the conditions are such that the regulation of prices by competition as a matter of fact does not exist. Can the price of products be fixed under such circumstances? It has been held by many lawyers that the same principle applies in such cases as applies in the case of a public utility, such as the railroads. At various times in the history of civilization the prices of products have been fixed. The principle upon which such laws are based is that no one has the right to charge extortionate prices for any article. The fixing of prices was common under Roman law. In England prices have been fixed upon the following commodities: books, beer barrels, coal, wheat, rye, bread, labor, etc. In Massachusetts, the revised laws of 1649 regulated the prices of wages, bread, ferriage, mill tolls, and wharfage.' Not only so, but in New York and Massachusetts the scale of wages was fixed for farm laborers, mechanics, and teamsters. ${ }^{2}$ It is true that the fixing of prices

1 Freund, "The Police Power, Chicago," pp. 382-397. Gilmore, "The Green Bag," Vol. VII, 1905, pp. 627-632.

${ }^{2}$ A. A. Bruce, Mich. Law Review, Vol. VII, p. 634. 
of commodities has not been practiced for a long time; we have trusted to competition to control them. It has been believed that competition was the most effective force in the accomplishment of this result. Undoubtedly competition gave fairly satisfactory results as long as there were numerous competitors for each of the various products. But now a new situation confronts us. At the present time production of each of various commodities is controlled by a single corporation, or, if not so, by a few corporations which have a common interest in preventing competition. This modern tendency of concentration of ownership of a great product among a few individuals or corporations, and especially the concentration of great stores of natural wealth, raises the question, whether the conditions have returned which demand laws controlling the prices of commodities as in England and in Massachusetts two or three centuries ago. Unquestionably the right in law exists.

The only question, therefore, for consideration is that of expediency. The greater part of the anthracite of Pennsylvania is controlled by a few corporations and between Expediency of regulating price of them there is a close community of interest. If these corporations so administer their trust that it is unnecessary to pass laws to protect the public against extortion, this should not be done; but if on the other hand they administer their trust with reference to this great resource which it took the building of the world to make, and which is needed by many millions of people in this country, so as to impose extortion upon them, then laws should be passed regulating the business of these corporations.

It is not for me to say what form such regulations should take; but it is clear that the power rests in the states and the United States to control them, even to the extent of regulating the prices of the anthracite either directly or through commission, if this is the most expedient method of accomplishing the result.

It is understood that the efforts in the past to regulate prices by legislation in England and America were not very successful. If it were thought expedient to regulate the 
prices of other commodities as are the prices of articles furnished by public utilities, probably this could best be accomplished by putting upon the corporations concerned the duty of fixing the prices and giving a commission the power to readjust them upon complaint and investigation, or by fixing a maximum price. Certainly it is very doubtful whether a legislature can wisely fix the price of any article; the conditions change from time to time; prices need to be frequently adjusted. Not only so, but the fixing of a price, even of a maximum one, at any time requires an investigation by competent experts. Therefore if in the future public control develops in the direction of regulating prices of anthracite or any other commodity, the experience with the prices of services furnished by public utilities indicates that this should be done through an expert commission under general legislative enactments.

The above was written before the Taft-Ballinger bill in reference to the leasing of public coal lands and fixing a maximum price on the product was presented to Congress. A conservative administration now indorses the principle that private interests should not be free to levy such tribute upon the people as they may determine in reference to so fundamental a necessity as coal.

Amount of peat.

\section{PEAT:}

The next of the fuel resources of which I shall speak is peat. Peat is a swamp deposit commonly regarded as resulting from the partial decomposition of moss, and especially of that kind called sphagnum. In Europe there are mined something like $10,000,000$ tons of peat per annum. In the United States as yet peat has been very little used, but Charles A. Davis, of the United States Geological Survey, has made a reconnaissance of our peat reserves. He states that there are 11,000 square miles in the glacial regions of the northern and eastern United States, and in Virginia,

1 The facts concerning peat are mainly from "Peat Resources of the United States, Exclusive of Alaska," Charles A. Davis, N. C. C.,Vol. III, pp. 476-482. 
the Carolinas, and Florida, in which there are peat deposits of sufficient thickness to be of commercial value, or if not at present of commercial value, likely to have a commercial value in the future. He estimates that these areas are capable of yielding of air-dried peat some 12,888,500,000 tons, or more than the total amount of coal yet mined. Thus peat is an important fuel resource, but still as compared with coal it is very subordinate, since this amount is less than one half of one per cent of the estimated coal of the United States; and it must be remembered also that peat is less efficient as a heat producer than coal. Nevertheless, in the future, peat is likely to be used as a fuel in the home, as a source of producer gas, a source of illuminating gas, for the manufacture of charcoal, as a filler for fertilizers, and in the manufacture of papers, packing materials, and possibly as a source of the fertilizer, ammonium sulphate.

\section{PETROLEUM 1}

The known fields of petroleum in the United States aggregate some 8450 square miles. These are localized in six great regions: the Appalachian, Lima-Indiana, Illinois, Kansas-Oklahoma, Texas-Louisiana, and California. The yields in the past have averaged from 1000 to as much as 10,000 barrels per acre. The estimated quantity of petroleum already extracted and available in the future is believed to be somewhere between $10,000,000,000$ and $25,000,000,000$ barrels, with possibly $15,000,000,000$ barrels of 42 gallons as the best approximate estimate which can be given at the present time. In 1908 there were 179,572,479 barrels of this product produced; and the product of 1909 is estimated by Day at somewhere between $173,000,000$ and $178,000,000$ barrels. The total product to the end of 1909 has been about $2,155,000,000$ barrels.

It thus appears that there remains to be taken from the ground somewhere from eight to ten times as much petroleum

1 The facts given in reference to petroleum are mainly from Day, "The Petroleum Resources of the United States," N. C. C., Vol. III, pp. 446-464.

The amount of petroleum.
Rapid increase of output of petroleum. 
Decreased production of oil wells.
Life of petroleum.

as has yet been extracted. But the rate of increase of extraction has been going up very rapidly, so that since 1860 the product of any nine years has been equal to the entire previous output. Putting it another way, at the end of this year, 1909, the output of petroleum for the nine years of this twentieth century was between $1,155,000,000$ and $1,160,000,000$ barrels, or more than 50 per cent of the entire output of the country since oil began to be taken-from the ground. Thus, the acceleration in the production of petroleum is continuing at an astonishing rate. This has occurred notwithstanding the fact that the production of old petroleum fields is rapidly declining.

The increased production has been possible because as old fields have declined in their output new fields have been discovered, but this situation cannot be expected to continue long. Illustrating the decline of old fields, are Pennsylvania and New York, in which during the past seventeen years the product has been reduced one third from the greatest output. The production of West Virginia has declined 56 per cent from its maximum output. But these numbers give no idea of the real situation. The daily production per well in the Appalachian field has fallen from 207 barrels in 1861 to 1.73 barrels in 1907 . The output of Pennsylvania has been kept up to from one half to two thirds of the maximum only by an enormous increase in the number of wells.

If we suppose that we know the present fields of the United States and the present rate of increased exploitation should continue, the petroleum would be exhausted by about 1935; and if the present production goes on with no increase, the product would be exhausted in about ninety years.

The question thus arises as to what should be done in order to diminish the output of this product and thus make petroleum last as long as possible, since under the most favorable circumstances the time it will be available will be very short as compared with the future of the nation.

At the present time petroleum is used for lubricating purposes, for light, for power; and also there are derived from it many valuable by-products. It is clear that petro- 


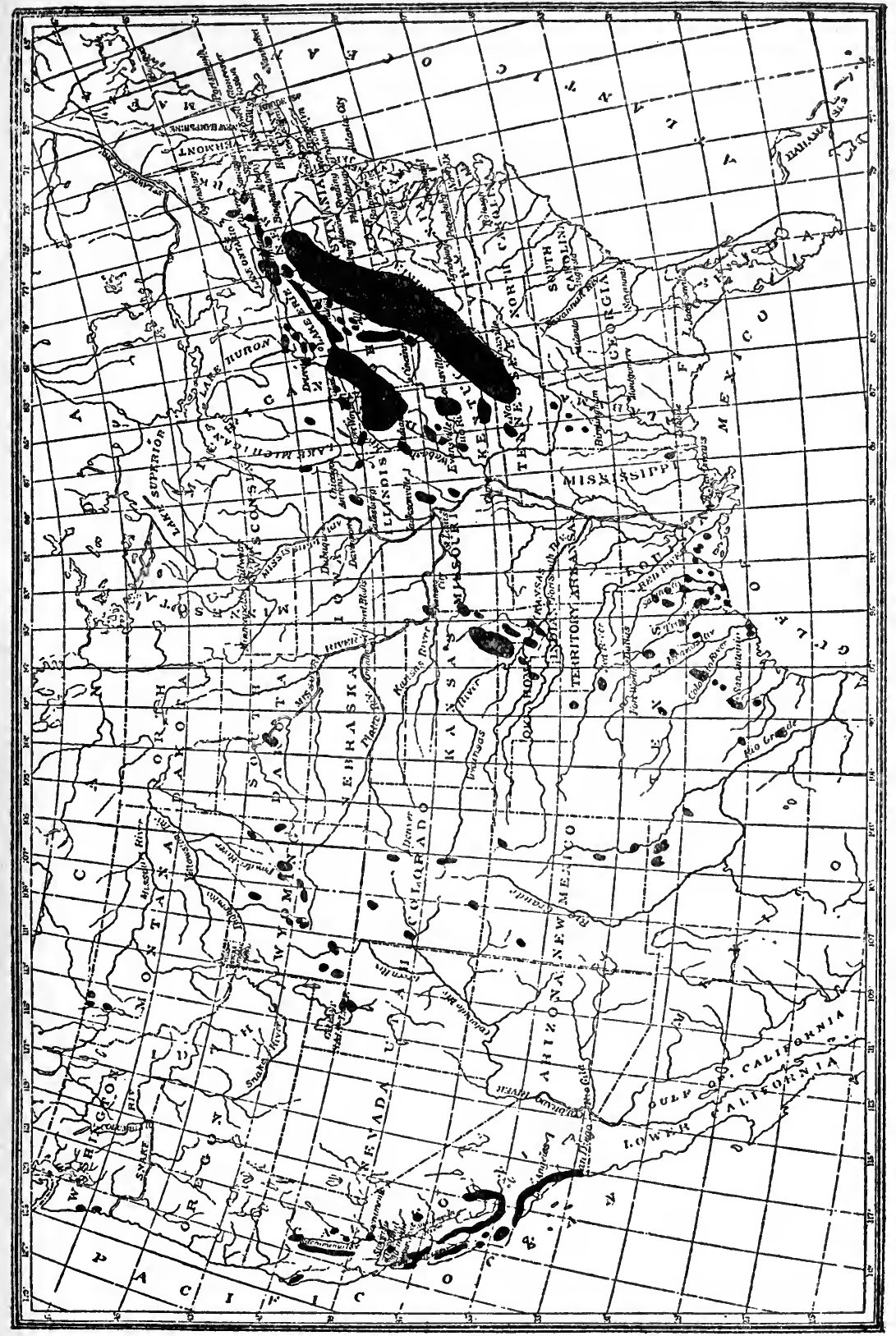

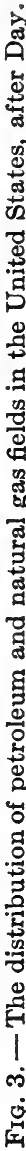


Petroleum for

lubricant.

Petroleum for

light.

Use of petroleum for power should be reduced.

leum should be used only for those purposes for which it is best adapted, and so far as other things can be substituted for it, this should be done.

First, petroleum should be used for lubricating purposes. So far as we can see there is no adequate substitute for petroleum as a lubricant. With the stupendous recent development of the manufacturing industries, the amount of lubricant required is very large. It is to be remembered in this connection that the great modern industrial expansion has been synchronous with the discovery and exploitation of petroleum. Lubricants, from the finest quality, such as that used in watches, to the coarser varieties, such as that used in heavy machinery and railroad trains, are absolutely necessary; and as yet we know of no other adequate source for this material. This product should be conserved as long as possible in order that lubricating material may be available. The use of petroleum to produce light should doubtless be continued. It is especially adapted to this purpose in villages, on farms, etc. But the necessity for petroleum for light is not so great as for lubricating purposes. Even in isolated houses light of a highly desirable quality may be cheaply produced by the use of acetylene, derived from carbide of calcium, a product manufactured from coal and limestone through the use of water power.

In $1907,35,000,000$ barrels of petroleum, or between one fourth to one fifth of the amount taken out of the ground, was used for power. For the production of power in a large way it is clear that coal and water should be substituted for petroleum, so far as a kind is used adapted to a higher purpose. One should perhaps not go so far in this matter as to suggest that power should not be developed in small installations by petroleum; but certainly it is the case that the use in large quantities of petroleum adapted to produce light for power production through the steam boiler cannot be defended from the point of view of conservation and the future of the nation. And even for the production of power in the small installation it is likely that in the future alcohol will be largely substituted for petroleum, since alcohol may be made through the indefinite future. 


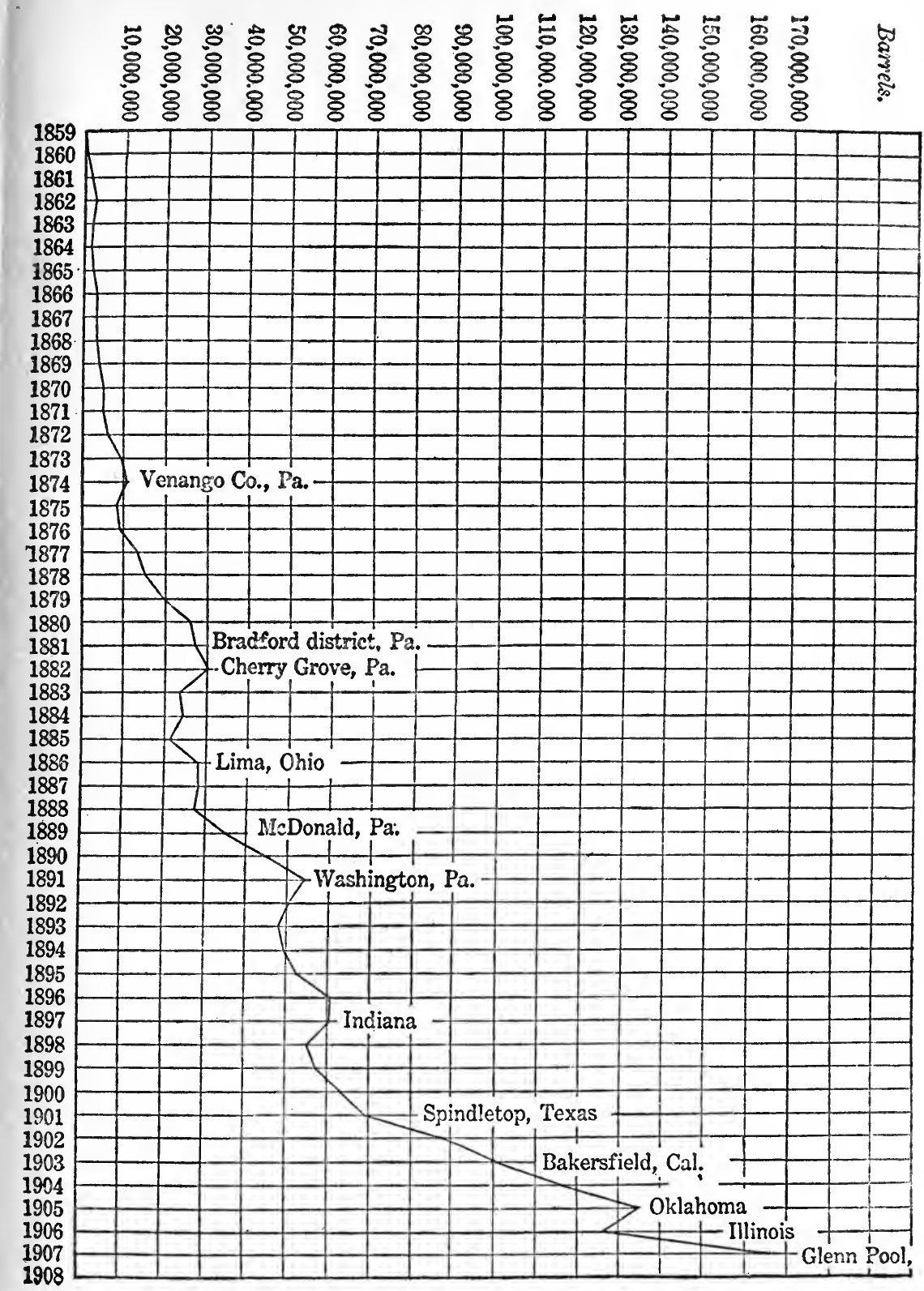

FIG. 4. - The annual production of petroleum from 1859 to 1908 , after Day. 
Decrease rate of petroleum exploitation.

At the present time more than one fifth of the petroleum taken from the ground is exported. The question should be raised as to whether exportation of a product which is likely to last so short a time should be permitted. It has become almost a maxim with us in this nation that the thing to do is to develop and use our natural resources as fast as possible. In general the men who have taken possession of and exploited rapidly our resources, have been commended for developing a new country. This view has had a certain justification in the past, but the time for preaching such a doctrine in this country has now passed. With reference to each of our natural resources, the question should be now asked as to whether it is wise to encourage further exploitation, or on the contrary to reduce the draft upon the product. It seems to me that in the case of petroleum the answer is clearly that not only should an increased rate of exploitation cease, but a decreased rate should be demanded. This generation should leave in the ground as much petroleum as possible, in order that succeeding generations may have the advantage of this most valuable product for those special purposes for which it is absolutely necessary.

There is little question that if the good of the country demands it, exportation of petroleum may be prohibited. If the general welfare of the nation demands that a natural resource be retained here for the use of our people, Congress may prohibit its exportation under the clause of the Constitution giving that body power to regulate interstate commerce.

Reduce amount of petroleum exported.
Therefore, I raise the question if laws should not be passed by Congress which require gradual reduction in the amount of petroleum which may be exported, perhaps allowing, the first year after the law passes, the exportation of nine tenths as much as the previous year, the next year eight tenths as much, and each year one tenth less, so that exportation shall cease altogether at the end of ten years. Ten years for the change is merely suggested as illustrative, as showing the principle which should be adopted. I would not advocate the radical procedure of stopping all exportation of petroleum at once; 


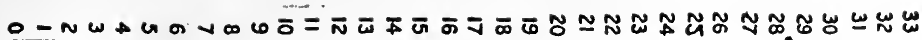

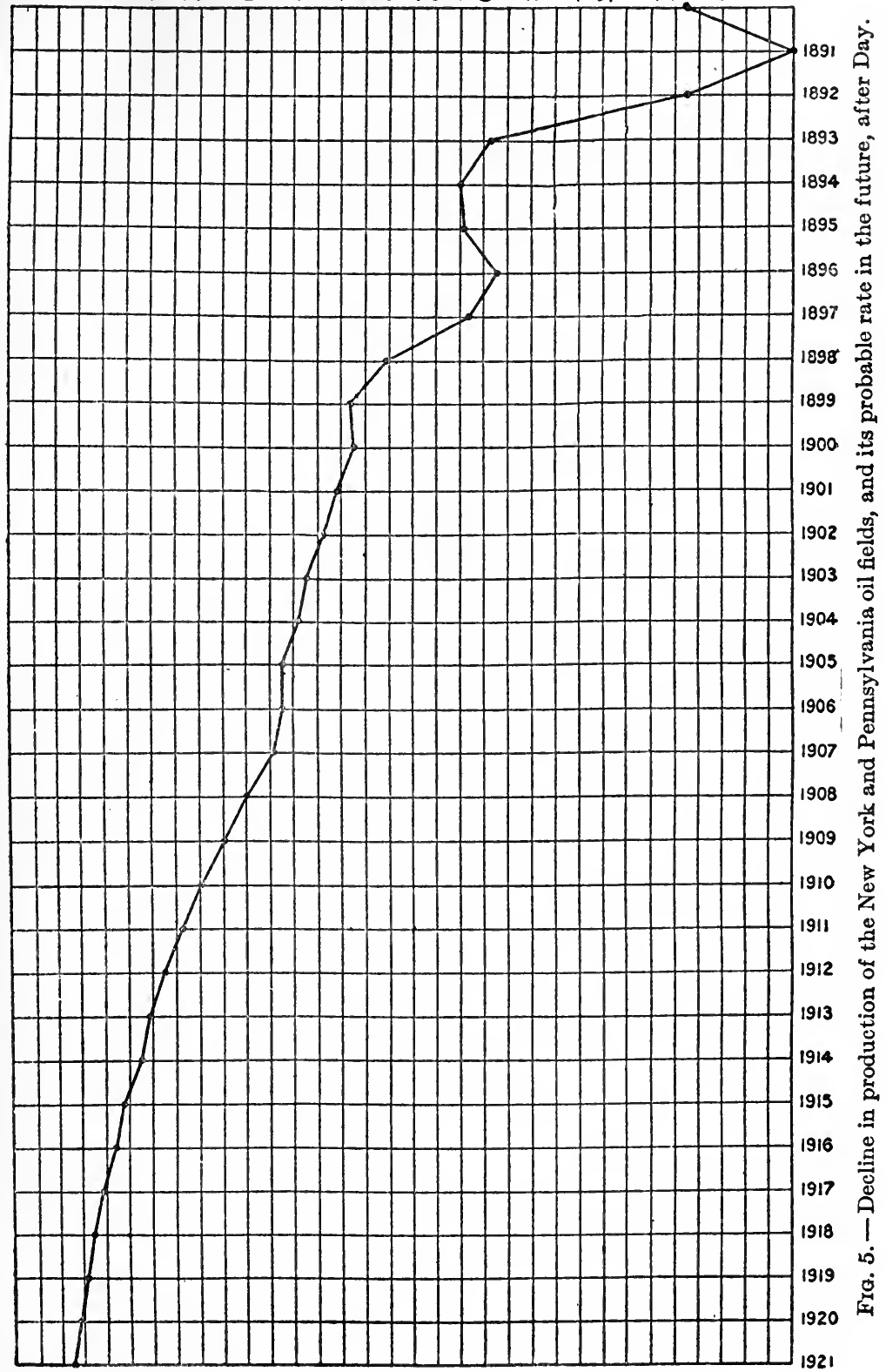




\section{CONSERVATION OF NATURAL RESOURCES}

but gradually and yet somewhat quickly the exportation of this product should cease.

With- Since the output of petroleum from lands privately owned drawal of petroleum lands. is now more than adequate for all legitimate demands of the people of this country, all public petroleum lands should at once be withdrawn from private entry and held to be operated upon the lease system when in the future the output from lands already in the hands of private parties becomes so small as to require the production of petroleum from the public lands. Under President Roosevelt's and President Taft's administration, oil lands have been withdrawn temporarily from private entry in Colorado, Wyoming, California, Utah, and Oregon. March 4, 1910, the amount of such land was $3,487,076$ acres.

C. W. Hayes, chief geologist of the United States Geological Survey, states that most of the oil lands which have passed from the public domain have been entered under the placer mining law. A location under the placer law is valid if based upon actual discovery; but in the case of oil there can be no discovery except by expensive drilling. Other methods of obtaining oil land are its location under the guise of a gypsum claim, or for agricultural purposes.

Mr. Hayes calls attention to the fact that any proper law must recognize that oil is mobile, in consequence of which it may pass underground from lot to lot. It follows, therefore, that oil should be disposed of only as a commodity, and not in terms of acres like other minerals. This difference is so plain that the leasing system is practically universal on oil lands which are in private lands. It is clear that it will be equally advantageous for the government to "adopt the plan which has been worked out through long experience, and, where the holdings are sufficiently large, found thoroughly satisfactory, both to the oil operator and to the private landowner. Why should not the government as a landowner deal directly with the producer rather than through the intervention of a middleman to whom title to the land has passed?"

These views are embodied in a bill drawn up by $\mathbf{R}$. A. 
Ballinger, Secretary of the Interior, and approved by President Taft. This bill as submitted to Congress authorizes the withdrawal of all petroleum lands from sale, and conPetroleum lands to be leased. tains among other provisions the following: that the petroleum lands be leased in tracts of not more than 320 acres each, for a period not to exceed ten years, but with authority to renew for periods of five years, the royalty for the first lease not to exceed 15 per cent of the gross value of the output at the point of production, with a yearly rental upon the land, the same however to apply on the royalty. This act also directs the lease to "fix the maximum prices or rates beyond which the lessee shall not charge the public" for oil.

By the various steps proposed, the substitution of other products than petroleum for power, prohibition of exportation, and the retention by the government of its public petroleum lands, it is probable that this material will be available for its most essential purposes for a much longer time than ninety years; we may perhaps hope several times ninety years. But looking at the matter from any point of view, in the not distant future there is likely to be a severe shortage in petroleum, and especially in material for lubricating purposes.

\section{NATURAL GAS 1}

Natural gas is the most perfect form of fuel which nature has furnished us; it is indeed the ideal fuel. This becomes evident when it is recalled that the best known way to produce power from coal is to transform it into "producer" gas, before it is burned to produce energy either below the steam boiler or in the combustion engine. This is true, although the manufactured gas used for power is mixed with much inert nitrogen. The natural product is practically free from the element nitrogen, and thus has a much higher efficiency than producer gas.

1 The data for this section are mainly from "Natural Gas Resources of the United States," David T. Day, N. C. C., Vol. III, pp. 465-475, and the papers and reports of Professor I. C. White.

Natural gas ideal fuel. 
Extent of gas fields.

Increased production of natural gas.

Short life of natural gas.

The United States is blessed with greater fields of natural gas than any other country. The aggregate is something like 10,000 square miles, which is distributed over twenty states, including eastern, southern and western states.

According to Hill, ${ }^{1}$ the production of natural gas has gone through several cycles. "It rose rapidly from a value of $\$ 215,000$ in 1882 to $\$ 22,629,875$ in 1888 , fell gradually in the next eight years to $\$ 13,002,512$ in 1896 , a little more than doubled in five years to $\$ 27,066,077$ in 1901 , a little more than doubled again in the next six years to $\$ 54,222,399$ in 1907." The output in 1907 was $406,622,119,000$ cubic feet and in 1908, 402,140,730,000, a slight falling off.

It is impossible accurately to estimate the amount or the future life of natural gas, but it is certain to be short. According to Day it cannot be expected that it will last for more than twenty-five years. That the supply of natural gas will not last long is shown by the fact that the older wells have been exhausted and others are yielding a diminishing flow. Not only is this so, but whole districts have been practically exhausted in a score of years or a few decades. Only a few years ago from the gas fields of Indiana great quantities of natural gas were piped into the city of Chicago to be used for manufacturing and for heating purposes. The supply has gone down until the amount which comes into that city at present from this source is insignificant.

\section{WASTE OF NATURAL GAS}

Notwithstanding the extreme value of natural gas as a fuel, notwithstanding that it is the most perfect product for this purpose, notwithstanding that it is severely limited in quantity, there is no natural resource which has been so carelessly used and recklessly wasted by the American people as this one.

Natural gas has also been used extensively in an uneconomic way. Thus it has been used for the production of

1 "Natural Gas," by B. Hill, "Mineral Resources of the United States," Part II, Non-metallic Products, 1908, U. S. Geol. Survey, p. 317. 
power through steam. A much more economical use of natural gas for power is in the combustion engine as an explosive mixture with air. If there is economy in making power by transforming coal into gas for the combustion engine, then certainly a product which is in the form of gas to begin with, so far as it is to be used for power, should be in such an engine. By the use of natural gas in the gas engine for power instead of under a boiler, it is estimated that its efficiency will be increased twofold or threefold.

The uneconomical use of natural gas has been relatively unimportant as compared with its absolute waste. This waste has been going on for many years, indeed since the first discovery of the product. The waste has occurred in various ways :-

First, there has been much loss from high pressure wells. In the early days of the use of natural gas, when bores reached the reservoirs of the material, sometimes the pressure was so great that the drillers did not know what to do, and they were not able to cap the wells. But methods have now been developed so that the greatest pressure may be controlled.

Often there has been complete indifference in reference to the waste of natural gas. Many bores have been made into the gas reservoirs in exploration for oil; and often, if oil Waste of natural gas by flaming was not found, the wells were lighted and allowed to flame heavenward in the open air. In some cases a well has been thus allowed to burn for twenty years. At some burning wells the rock outside of the casing has sunk and the gas has escaped not only through the tube, but over a considerable area. Thus have been produced burning caldrons of gas, - "giant flambeau." This situation is well illustrated by Louisiana. In that state some of the wells have been allowed to burn until the rock has caved so extensively as to have become veritable flaming lakes. The largest may be seen by night a score of miles away illuminating the sky. It is estimated that in the Caddo field alone of that state some 70,000,000 cubic feet per day of gas are wasted, burned without doing any good in any way to anybody. This is sufficient to light ten cities the size of Wash- 
Waste through oil wells.

Law needed against waste of gas.

Total waste of natural gas. ington, or is equivalent to the daily waste of 10,000 barrels of petroleum. And this is going on year by year with no attempt whatever upon the part of the state of Louisiana to stop this enormous loss.

Another of the inexcusable and vast wastes of natural gas has been in connection with oil wells. Nearly all oil wells are also gas wells; but frequently the oil producer has not cared for the gas, and so he has allowed it to escape into the air without any attempt to utilize it. Not only so, but he has successfully resisted all laws which have been attempted to be passed to prevent this practice, save in a single state.

In addition to the great waste in natural gas at the well, there has been large loss in transmission. Many of the pipes through which the gas is carried are carelessly constructed, and there is much leakage from the joints; this is a loss which ean be made wholly preventable.

A decision of the United States Supreme Court (see p. 363 ) holds that no one has the right to waste a natural product; and there is no question that the above objectionable practices may be prevented by law. Indeed, this has been done in the state of Indiana, where in 1891 there was enacted a broad law, providing for a gas inspector, whose duty it is to prevent leakage in pipes, decide upon the kind of pipes which may be used and the pressure they may carry, to provide for plugging of wells when not in use, plugging of abandoned wells, and for the prevention of waste of gas while extracting other products. This comprehensive law has been upheld by the highest state courts.

It has been seen that in 1907 there were utilized some $400,000,000,000$ cubic feet of natural gas. Dr. Day places the waste of this material at an equal amount. Professor I. C. White of West Virginia, says: "At this very minute our unrivaled fuel is passing into the air from uncontrolled gas wells, from oil wells, from giant flambeaus, from leaking pipe lines, and the many other methods of waste at the rate of not less than $1,000,000,000$ cubic feet daily and probably much more." "The heating value of $1,000,000,000$ cubic feet of natural gas is roughly equivalent to that of $1,000,000$ bushels 
of coal. What an appalling record to transmit to posterity!" Professor White further states that the waste of gas in West Virginia is equivalent to the waste of coal, if, at the rate of a car a minute, "not for one week only, or for one month, but for twenty years, a forty-five ton car of coal had been dumped into an abyss from which it could never be recovered."

For some reason it has been impossible in other states than Indiana to secure effective legislation to stop the enormous waste of natural gas. Year after year laws have been introduced for this purpose in the various states but without avail. The situation may be illustrated by West Virginia. Professor I. C. White, state geologist, said in a recent address: "For ten years your speaker has appealed in his official capacity as State Geologist to the Legislature of West Virginia to put some check on this frightful waste of our State's most valuable resource. Three patriotic Governors, including our present able Executive, Governor Dawson, have in every biennial message besought the Legislative branch to end this criminal destruction by appropriate legislation; but some unseen power greater than Governor or Legislature has so far thwarted and palsied every effort to save to the State and the Nation this priceless heritage of fuel, so that although five successive Legislatures have attempted to deal with the question in biennial sessions, not an effective line has yet been added to the statutes - and at this very hour not less than 250,000,000 cubic feet of gas, and possibly more than double that quantity, is daily being wasted in this one State alone, 80 per cent of which is easily and cheaply preventable." Further, according to Professor White, nine tenths of the waste of the gas in West Virginia is in connection with the oil industry. This is probably a larger proportion than for the country as a whole, but the gas lost in connection with petroleum amounts to one half, and possibly 75 per cent, of the total waste. This loss occurs because with few exceptions the operators for oil permit the accompanying gas to escape into the air without separating the two. This is perfectly feasible, and if done the gas as well as the oil could be utilized. 
Oil operators responsible for waste.

Waste of gas reflection on our intelligence.
Necessity for immediate action.
The various oil operators are responsible in this matter in proportion to the product which they take out. All alike should be compelled by law to save and utilize the gas which comes from the ground with the oil.

Of all the pieces of extravagance of which the American people have been guilty, perhaps their reckless and wasteful use of natural gas is the most striking - not the most important - but the most striking. This product, severely limited in quantity, which can last only a few years at most, has been handled by us as if it were illimitable. No serious attempt has been made in any other state than Indiana to control the awful waste which has been described.

Of the various episodes of wanton extravagance in the waste of our natural resources, this of natural gas is least favorable to our intelligence. We hear of American progress; we hear of the position America has taken in the history of the world; we proudly boast of our leadership; and yet in wasting our resources we have been guilty of more stupendous folly than any other people in the civilized world. How long shall this waste be continued? How long shall there be allowed to escape into the air daily a billion of feet of natural gas?

Certain it is that if we wait another score of years before effectively handling the question of this waste, there will be no necessity for handling it at all. For if past practice is continued, the amount of natural gas which will be available at the end of another twenty years will scarcely be worth consideration. Immediate action on the part of legislatures is required in all those states producing this material. Every session gone by without action represents a great and irreparable loss. It stands as evidence that one more legislature has been incompetent to administer the trust that is imposed upon it by the people.

Secretary of the Interior Ballinger, with the approval of President Taft, has presented a bill to Congress authorizing the withdrawal from sale of all natural gas lands and the leasing of the same on terms identical with those which obtain in reference to petroleum. (See pp. 54, 55.) 


\section{CONCLUDING STATEMENT}

In conclusion, with reference to coal, peat, petroleum, and natural gas, once extracted from the ground, they are soon used; and once used they are destroyed forever. Therefore the problem of conservation with reference to these mineral resources is slow extraction and economical use, reducing the amount drawn upon to the minimum absolutely necessary. As far as possible, substitutes for the mineral fuels should be used, so that these products may last long into the future in order that a large number of succeeding generations may have their fair share of this precious heritage.

\section{THE METALLIC RESOURCES}

The principle of conservation in reference to metallic resources is very different from that in reference to fuel. The ores of the metals when taken from the ground and reduced to the metallic form are capitalized. Two tons of iron ore in the ground capable of producing one ton of metallic iron are less valuable as ore than as metallic iron. Therefore in taking the ores from the ground and transforming them to the metallic state, we are performing a service to mankind. We are doing a thing analogous to building bridges and making cities; we are taking a natural resource and transforming it to a more valuable product; so far as this is accomplished it is of advantage to man.

After the metals are once extracted, we should keep them as nearly intact as possible, use them over and over and over again, reduce the losses by wear and dissipation to Conservation principle applicable to metals. a minimum. It is doubtless true that some gold now in circulation was mined centuries ago. It is reported that there exists at Delhi, India, an iron monument which was manufactured before the earliest written history of that country.

Metals should be used many times. 
Thus it is plain that the metals may be preserved; they may be kept indefinitely after they are once reduced; this is the problem of conservation of the metals.

\section{Classification of the Metals}

For the purposes of conservation the metals may be divided into two classes, those that are important, and those that are subordinate. This is an entirely different classification from a chemical or geological one. It is a classification based on usefulness.

The first group, the important metals, include iron, copper, lead, zinc, gold, and silver. The second group, the subordinate metals, include aluminum, manganese, chromium, nickel, cobalt, tin, platinum, mercury, vanadium, tungsten. The other metals are so subordinate in importance, at least for use in the metallic form, that they are neglected.

Each of the important metals will be separately considered.

Iron the most important of the metals.

\section{IRON}

Of all of the metals, iron is the most important. Indeed, it is certain that with the present practices of the world we could better spare all the other metals than iron. Frequently the idea is held that the thing is most valuable which is dearest; but on the contrary, those useful things which are cheap and abundant are those most valuable to civilization. For instance, soil, which is far more abundant and cheaper than fuel or any metal, is the most valuable of our resources. Therefore iron, because the most abundant of the metals which can readily be reduced to the metallic form and possessing the essential qualities of strength, ductility, and flexibility, is the most valuable of the metals. Iron furnishes us road metal for railways, steel for bridges and buildings, reënforcement for concrete, material for all kinds of machinery and implements. For certain purposes where extraordinary strength or toughness or some special quality is required, iron is advantageously alloyed with other metals, such as nickel, manganese, vanadium, or tungsten. 
Next to coal, iron is clearly the most important of the subsurface products.

\section{THE IRON ORE RESOURCES}

In giving estimates of our resources of iron ore, I shall follow the statements of Dr. C. W. Hayes, ${ }^{1}$ chief geologist of the Geological Survey, who with collaborators, engineers, and geologists, has recently published a careful analysis of our iron ore reserves. He believes that for something like 85 per cent his estimates are within 15 or 20 per cent of being right. For the remaining 15 per cent he thinks that his estimates are not closer than 100 to 200 per cent. If he is correct in his conclusions, we probably know within a factor of error of one-quarter in reference to our supplies of iron ore.

For the purposes of conservation the ores may be classified into two divisions, those which are available under present conditions, and those which will become available eventually.

Available and unavailable

By available ores are meant those which are of such a character and in such a position in reference to commercial demands, transportation, contiguity to coal, etc., as to be exploitable with profit either now or in the near future. As showing the importance of location it will be readily appreciated that an ore which might be very valuable under present conditions, if located in Pennsylvania, would be wholly unavailable at present if located in New Mexico. Since, however, it is impracticable in a classification of the ores upon the basis of availability to take all of these factors into account, the division into available and unavailable is upon the basis of composition only. In considering the composition there are two factors, the percentage of iron, and the character of the associated material, or gangue. Iron ores are of two general characters with reference to the associated material, those in which it is calcareous and those in

1 "Iron Ore of the United States," C. W. Hayes, N. C. C., Vol. III, pp. 483520. See also " The Production of Iron Ores, Pig Iron, and Steel in 1908 " by E. C. Harder, Bull. U.S. Geol. Survey, Mineral Resources of the U.S. for 1908. 
which it is silicious; that is, ores in which associated with the iron compounds is calcium carbonate, or limestone, and those in which the associated material is silica or quartz. The calcareous ores are available with a smaller percentage of iron than the silicious ores. Those having as the gangue material, calcium carbonate or limestone, are regarded as available if they contain as much as 30 per cent of metallic iron. The silicious ores are regarded as available if they contain as much as 50 per cent metallic iron. The available ores are given upon this basis. It is believed that in the future the calcareous ores will be available if they contain as much as 20 per cent metallic iron, and the silicious ores if they contain as much as 35 per cent metallic iron.

Using these data as a basis, Dr. Hayes estimates the iron ore supplies as follows: available ores, 4,788,150,000 long tons; low grade ores, those not now available under existing conditions, but which may become available in the future, approximately $75,116,070,000$ long tons.

The distribution of these amounts in the different parts of the country is shown by the following table.

\section{TABle showino Distribetion of Inon Ores}

Commercial Districts

1. Northeastern

2. Southeastern .

3. Lake Superior

4. Mississippi Valley

5. Rocky Mountain

6. Pacific Slope
Avathable

Long tons

$298,000,000$

$538,440,000$

$3,510,000,000$

$315,000,000$

$57,760,000$

$68,950,000$

$4,788,150,000$
NoT AVATLABLE Long tons

$1,095,000,000$

$1,276,500,000$

$72,030,000,000$

$570,000,000$

$120,665,000$

$23,905,000$

$75,116,070,000$
Available iron ores mainly in Lake Superior region.
Total

These figures show that of the total available iron ore of the United States almost three fourths is in the Lake Superior region. Since the Lake Superior ores contain a higher iron content than the average for the remainder of the country, more than three fourths of the metallic iron of the available ores is in that region. Also it is to be noted that of the iron ore reserves which are likely to be available 
in the future, the great preponderating mass, more than $72,000,000,000$ tons, is in the Lake Superior region; whereas in all of the remainder of the United States there are not known much more than $3,000,000,000$ tons of the low grade ore. It is therefore clear that the great center with reference to iron ore exploitation in the United States is the Lake Superior region; and this is so whether the matter be looked at from the point of view of the ores which are available at the present time or those available in the future.

Of the available ores of the country, it is certain that the United States Steel Corporation owns more than 50 per cent, and some estimates place the holdings of the company as high as 75 per cent.

In considering the ore reserves which may be drawn upon by this country we should perhaps take into account adjacent countries, and especially Canada, Cuba, and Brazil, where it is estimated there are considerable quantities of iron ore, some of which is being exported into the United States at the present time. The Canadian geologists estimate that in the Canadian region, and mainly adjacent to Lake Superior, there are some 20,000,000,000 tons of ore which will ultimately be available. But a small proportion of this is of a character to be available under present conditions. Probably not more than $75,000,000$ tons of such material is known. Thus the Canadian ores mainly belong to the class available in the future rather than that now available. In Cuba it is estimated that there is some $3,000,000,000$ tons of known ore, of which approximately one half is available under existing conditions. In Brazil are very large deposits of high grade ore; but no estimate of the tonnage is available.

\section{EXPLOITATION OF IRON ORE}

In the exploitation of iron ore there has been the same astonishing increase as in the exploitation of coal. The United States was not a producer of iron ore until in the nineteenth century, and the production between 1810 and 
1850 was unimportant. The production of iron ore to 1869 and during the last four decades is shown by the following table:-

Production of Iron Ore in the United States prom 1810 to 1869, AND FROM 1870 to 1909 BY Decades, estimated from Pig Iron Production

\begin{tabular}{|c|c|c|}
\hline & Long tong & Percentage of increase \\
\hline $1810-1869$ & . $\quad 49,656,000$ & - \\
\hline $1870-1879$ & $43,770,527$ & - \\
\hline $1880-1889$ & $91,043,854$ & 108.0 \\
\hline $1890-1899$ & - $163,989,193$ & 80.1 \\
\hline $1900-1909$ & . $386,857,102$ & 135.2 \\
\hline Total & . $735,316,676$ & \\
\hline
\end{tabular}

Of the total production of iron ore of the United States, from 1810 to 1909 inclusive, $460,986,042$ tons, or considerably more than half, came from the Lake Superior region. Since the Lake Superior ores are of considerably higher grade than those of the other states, the amount of iron from the Lake Superior region to the present time is more than two thirds of the total produced in this country.

Rapid increase in iron ores mined.

The table above shows that before 1850 the drafts upon our iron ore were small, and that the great drafts have been during the last thirty years. The rate of increase in exploitation has been so rapid that during the decade ending 1909, more than half, 52.6 per cent, of all of the iron ore mined in the United States was extracted. Also the product of any one of the previous three decades is equal or nearly equal to the product of all previous decades.

Not only has there been a great absolute increase in the production of iron ore, but there has been a rapid increase in production per capita. According to Harder this has been as follows: in 1870, 180 pounds; in 1880, 313 pounds; in 1890,560 pounds; in 1900,806 pounds, and in 1907, 1344 pounds. Thus the amount per capita in 1907 was more than seven times as much as in $\mathbf{1 8 7 0 .}$ 


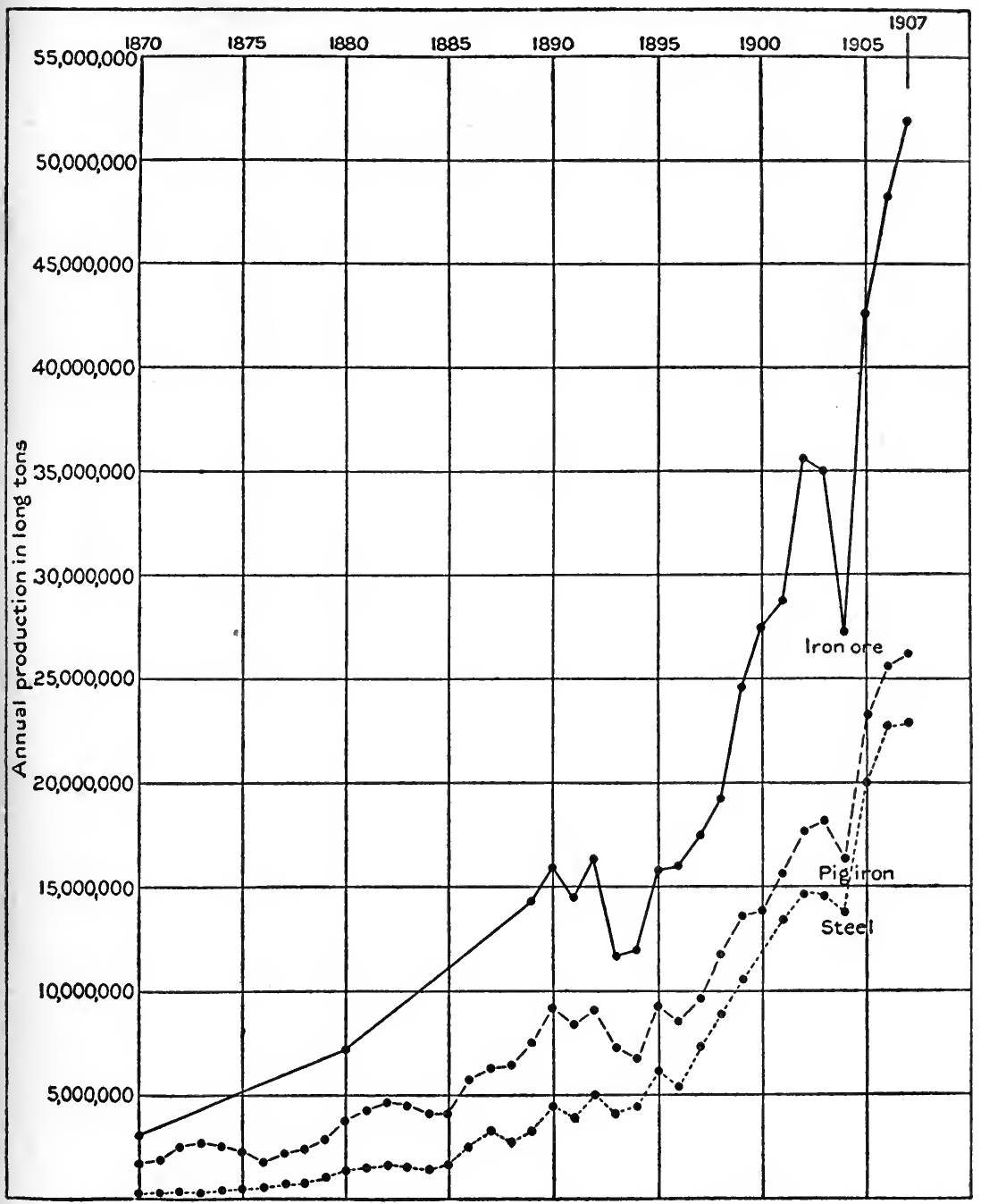

Fig. 6. - Curves showing the production in long tons of iron ore, pig iron, and steel in the United States, from 1870-1907, after Hayes. 
Life of iron ores.

Economy in mining iron ores.

If the rate of increase of exploitation of iron ores of the three past decades be continued, the high grade ores of the United States, those that are now available, would be exhausted in about three decades more. However, it is believed that high grade iron ores will be available for a longer period for the following reasons:

1. Greater care will be taken in mining ores. In the early mining of iron ore a considerable portion of the deposits was wasted; only the high grade material was taken out; large quantities were left as pillars. In some cases much of the material left has been or will be mined; but in other cases the ground has caved and the ore left, both that of moderately high grade and that of low grade, cannot be profitably won.

The iron ore deposits in the Lake Superior region have largely passed into the hands of great corporations who realize fully the limited supply of high grade product, and therefore are handling it with very great efficiency. From many of the great deposits of the Mesabi Range, the overlying drift is stripped. This makes it unnecessary to lose any ore through supporting pillars. Where underground mining is necessary, by the sinking method, which is somewhat complex, and into the details of which I cannot go here, a very large percentage of the product, frequently more than 95 per cent, is taken out, so that the waste is reduced to a minimum. If associated with the high grade material is low grade ore, which must be taken out but cannot now be used, it is stock piled. The parts of the deposits in which the low grade ores predominate are not worked, but are left as a solid mass to be handled in the future. Little legitimate complaint can be made at the present time of a lack of realization of responsibility on the part of the iron ore owners of the Lake Superior region. To a considerable extent the same thing is true of the iron ores of other districts of the United States, although in these regions the mining methods have not been developed to quite the extent they have in the Lake Superior country. According to Harder the more important losses are in the bedded de- 
posits which are mined underground and especially those of Clinton age. Often in the mining of these ores unnecessarily large pillars are left; and not infrequently two contiguous beds occur separated by rock, in which case one bed may be neglected. Thus with the Clinton ores the losses are of the same kind as those which occur in the mining of coal. Harder estimates the recovery of this class of ores to vary from 75 to 90 per cent, the estimates of reserves being upon the former basis. It is certain that by improved methods of mining the recovery may be increased to the higher figure.

2. New ore deposits will be discovered. The United States has not been fully explored with reference to iron ore. It has been the fact up to the present time that more high grade ore has been discovered in any one year than has been extracted that year, so that each succeeding estimate of the ore reserves has been an increasing and not a decreasing amount. In Minnesota, especially, there are large areas which are difficult to explore and which are likely to contain important deposits. In Michigan and Wisconsin, also, there are considerable areas to be explored in which ore deposits will be found. However, we should not take too sanguine a view of the situation. There is no reason to believe that the ores which will be discovered in the future are anything like so important in quantity as those which have been already discovered. The discoveries of each year are now declining and it will not be many years before the amount exploited will exceed the amount mined; and when this time comes, the known reserves will be a decreasing amount.

3. Another factor which will extend the life of the high grade ores is the substitution of stone and cement for iron. Early in the history of this country the great majority of the bridges were largely constructed of wood. Then there came the time of bridge-building of iron, and we are now turning to cement and stone reënforced with iron. The amount of iron required for the reënforcement of cement is but a small fraction of that required for iron bridges. The

Discovery of new iron ore deposits.
Substitution of stone and cement for iron. 
Limitation of supply and price.

Use of low grade ores.

use of cement and stone is rapidly increasing also in buildings and in other structures. Thus in various ways cement and stone may be substituted for iron; this should be done wherever it is possible, for the amount of these materials is inexhaustible.

It should be stated, upon the other hand, that iron is now being largely introduced in the manufacture of railway cars and other articles which formerly were made mainly of wood. The substitution of iron for wood during the coming decade, or coming score of years, will make a very large demand upon this metal. Iron is much stronger and more permanent than wood; also the danger of a shortage of wood is even greater than that of a shortage of iron; so that where the use of wood can be decreased by the substituting of iron, this should be done. It is a step in the direction of the conservation of our resources.

4. It is to be noted that the knowledge of the limitation of a supply has an effect upon its price. Indeed, this effect is already felt in the case of iron ore. A few years ago when there was keen competition among a large number of holders of iron ore and it was believed that the ore was inexhaustible, the prices often were very low. But since the iron ore has largely passed into the hands of a few large companies that own furnaces and desire to continue in the iron industry through centuries to come, the price of ore does not fall extremely low when there is a serious falling off in the demand for iron, because the companies see that it is the part of wisdom to hold the ore to meet future demands rather than to part with it at a loss.

5. It is certain that long before the high grade ores are exhausted, lower grade material will be used in increasing quantity to mix with the higher grade products. It was only a few years ago that in the Lake Superior region anything below 60 per cent metallic iron was regarded as unmarketable. At the present time material from 50 per cent is regarded as marketable. Indeed, some ore has been sold as low as $\mathbf{4 0}$ per cent metallic iron which is high in silica and low in phosphorus. Increasing use of low grade ma- 
terial for mixing with the high grade ore will greatly prolong the life of the latter.

6. The extent to which imported ores will be substituted for domestic ores is uncertain. It is clear that such ores are to be used in an increasing amount, and especially those from Cuba, and possibly from Brazil. It is probable that they will be a somewhat important factor in prolonging the life of the high grade ores within the United States.

7. The store of metallic iron is increasing by enormous amounts each year. Indeed, the saving and re-using of iron once used is the most important point in the conservation of iron. In the not distant future the new needs of any year will be sure to be met in considerable proportion from the re-use of iron already made, rather than by the mining of ore and its reduction; and it may be that finally the larger source of iron for new uses will be the metal utilized for some other purpose, or else reworked for the same purpose.

8. It is a question whether the great era of structural expansion is not near its climax. It is certain that we shall not go on building railroads and other structures at the same percentage of increase as in the past. Therefore we should expect that the percentage of increase in the demand for iron from ore will not continue indefinitely in the future because the great structural work of the country will be largely done. After a city is made it does not require so much iron as it does in the process of making. Similarly, when the railroads are once constructed, their efficiency can be increased without a corresponding increase in the quantity of iron required.

Therefore, for the various reasons given, it is believed that three decades will not see the end of the supply of high grade iron ore, or even a close approach to it; and the danger of exhaustion of all low grade ores is remote. This, however, is no reason why the greatest care should not be taken to economically mine ore and the utmost pains used to conserve the iron reduced; for thirty years or ten times thirty years are insignificant compared with the length of time that the people of this country will require large supplies of iron.

Construetional work near climax
Life of iron ore. in store of metallic iron.

Use of imported ores. 
Protection of iron from rust.

\section{THE PRESERVATION OF IRON}

Iron is utilized in three forms, - pig, steel, and wrought. These three products differ among themselves in their speed of deterioration under different circumstances. It is plain that the product should be used which will best resist corrosion under the conditions in which it is to be placed. The great loss of iron is by rust when in position; this there are various ways to prevent.

In the first place it has been found that homogeneous iron is less likely to rust than that which is irregular. Iron which is heterogeneous becomes an electric battery having a positive and negative pole, and therefore is subject to solution where electric currents pass through it, as they are likely to do under our modern conditions of civilization.

Also it has been found that pig and wrought iron are much less subject to rapid corrosion than steel, and they therefore should be preferred for all underground purposes, such as culverts, pipes, etc., where it is impracticable to renew a protective coating. It has been found as a matter of experience that when steel pipes are placed underground and used for water purposes they corrode very rapidly. Until a comparatively few years ago the great quantity of iron used was in the form of pig or wrought, because these were cheaper; but since the discovery of the Bessemer process, steel has become very cheap, so that steel is less expensive than wrought iron. Recently there has been a very rapid development of the so-called open hearth steel, and metal manufactured by this process may be made to approach close to wrought iron. This material has greater resisting power than Bessemer steel; therefore if steel is used at all for underground work where oxidization is especially likely to take place, open hearth rather than the Bessemer steel should be used.

Investigations by Hambuechen and Burgess ${ }^{1}$ show that iron and steel when in a state of strain are much more readily

1 "The Corrosion of Iron from the Electrochemical Standpoint," Presidential address of C. F. Burgess, for the American Electrochemical Society, April 30, 1908. 
corrodible than when in an unstrained condition; therefore so far as iron is placed in a position where it is subject to corrosion, it should be in an annealed condition, not under a condition of strain. Further, Burgess has shown that inequalities of temperature result in increasing corrodibility of iron.

Wherever possible, iron should have a preservative coating. These coatings are of several classes.

First, there are coatings of zinc or tin and, to a much smaller extent, of copper or lead. Iron coated with tin is ordinarily called tin plate or simply tin; iron coated with zinc is called galvanized iron. Galvanized iron and tin plate are used for many purposes, - roofing and sheathing of buildings, wires, nails, tanks, and many kinds of utensils. Metal coatings are reasonably permanent and greatly prolong the life of the iron. But it is to be remembered in this connection that the zinc and tin used for coating iron are very largely lost. They are put in a form in which the recovery is relatively small, and while from the point of view of iron their use is very favorable to conservation, from the point of view of zinc and tin it draws heavily upon them, how heavily will be seen when we reach those metals (see pp. 82, 86).

Second, iron may be coated with paint, bitumen, or cement. One of these should be and indeed is generally applied wherever the iron is exposed and the metallic coatings are not Coating iron with paint. used. For structural iron and steel in bridges, decorative iron work, for locomotives, etc., it has been found a matter of good economy to keep the iron surfaces exposed to the weather well protected by a coating of some kind.

Third, iron may be coated with lacquers, japans, and enamels. These, however, are expensive, and therefore are used only for small implements, such as gun barrels, philosophical instruments, and other objects having a relatively high value.

While a protective covering should be applied to iron whenever practicable, there are certain uses in which that is not possible; as, for instance, in the case of steel rails for

Coating iron with other metal. 
Waste of iron.

Relation of use of iron to use of coal.

railroads. The rails are of necessity exposed to the weather and wear, and the loss is therefore relatively heavy. After a certain number of years, the rails become so oxidized and worn that they cannot be longer used safely and are replaced by new ones. The remainder of the old rails is worked over into some other form of steel or into new rails, as the case may be.

A very considerable loss of iron in this country is that of simple waste. Before iron became so common, every piece of iron or steel was treasured, kept and sold to a gatherer of scrap, who turned it over to a manufactory to be again used. Among the barbarous people, where iron is scarce, this is still done, but the very cheapness of iron under the modern conditions has led to great carelessness in this respect. This unnecessary waste should cease. All that need be done is simply to take the trouble to pile and keep the refuse material. There is always a sale for scrap iron at some price, and in most cases the trouble, even from the point of view of present advantage, will be justified.

Finally, it is to be remembered that the smelting of iron ores is one of the heaviest drafts upon coal; and, therefore, in proportion as iron once extracted is conserved, coal also will be conserved. To produce the $25,000,000$ long tons of pig iron of last year, required $1 \frac{3}{4}$ tons of coal each, or some $45,000,000$ tons of high grade coal. Hence conservation of iron is demanded equally for the conservation of coal.

\section{Copper, Lead, Zinc, Gold, and Silver}

Before considering copper, lead, zinc, gold, and silver separately, there are certain remarks which may be made that apply to them all. The ores of these metals are so irregular in their occurrence, and so widely dispersed, that it has not been possible to make any accurate estimates of the known stores of them, or even of the developed reserves, as has been done with coal and iron. Indeed, it is rather exceptional for a copper, gold, silver, lead, or zinc mine to have the property opened up so that there is in sight a re- 
serve of some years. While this is true in general, it should be said that some of the larger mines do have their deposits thus developed. But it certainly could not be asserted that there is in sight the equivalent of the probable output of the next decade. By this it is not meant to imply that the reserves are not greater than this; but that they have not been opened up, developed sufficiently so that an accurate estimate can be made of their future life.

One reason which makes it impracticable to make any accurate estimate of the probable reserves of copper, lead, zinc, gold, or silver is the fact that as methods of mining have been improved and methods of extraction advanced, lower and lower grade ores have been commercially handled. A few years ago it was comparatively rare to work copper ores which yielded less than 2 or 3 per cent of metallic copper. At the present time ores are profitably worked which yield less than 1 per cent, or twenty pounds to the ton. Gold ores are profitably worked from which is extracted less than one eighth of an ounce of gold per ton. That is, 2000 pounds of material are taken from the ground, mined, run through breakers, and the gold extracted, all for the recovery of a $\$ 2.50$ gold piece. This well illustrates the remarkable improvement of recent years in the exploitation of ores and the extraction of the metals.

It is probably true, as with iron, that the known reserves of copper, lead, zinc, gold, and silver are larger than at any previous time. The ore deposits of these metals have been opened up faster than they have been exploited, notwithstanding the amazing increase in output. But that this is true is due to our ability to handle a steadily decreasing grade of ore. If at the present time the available reserves were limited to the grade of copper, lead, zinc, gold, and silver ore commercially handled a few years ago, it is certain that they would be very limited. 


\section{COPPER}

In the United States the production of copper until 1845 was unimportant. The yield in gross tons of metallic copper for that year and for selected years is given in the following table:-

Table Showing Metaluc Copper Prodjced in Selected Years

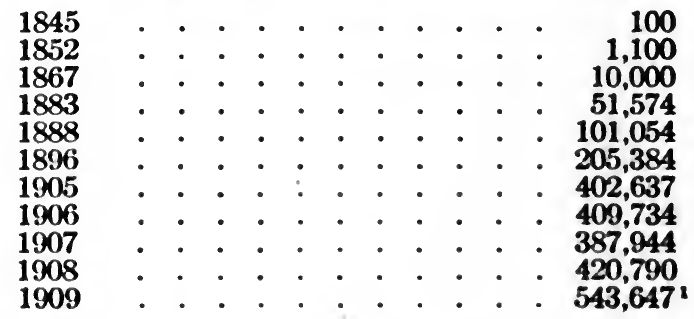

Rapid increase in copper production.
This table shows that copper first began to be heavily drawn upon in 1867, when 10,000 tons of metallic copper were produced. From 1867, the product increased fivefold in the sixteen years to 1883; in five years more, to 1888 , it again doubled; again it doubled in eight years from 1888 to 1896; and once more doubled in nine years, 1896 to 1905 . From 1905 to 1909 , four years, the increase was 30 per cent to 543,647 tons, which far surpasses the output of any previous year.

Of the total yield of the United States, including 1909, amounting all together to $6,400,780$ gross tons, $3,672,921$, or 57.3 per cent, were produced in the last ten years of the. period. Also the output of either of the two previous decades more than equaled the entire product of all of the previous decades. Thus in this respect there is a parallel between copper and iron. While the output of copper is still rapidly rising, it is very doubtful if the rate of increase of the past three decades will be kept up even for another ten years.

Since 1895 the United States has produced from 50 per I Approximately only. From Mining World, Jan. 22, 1910. 


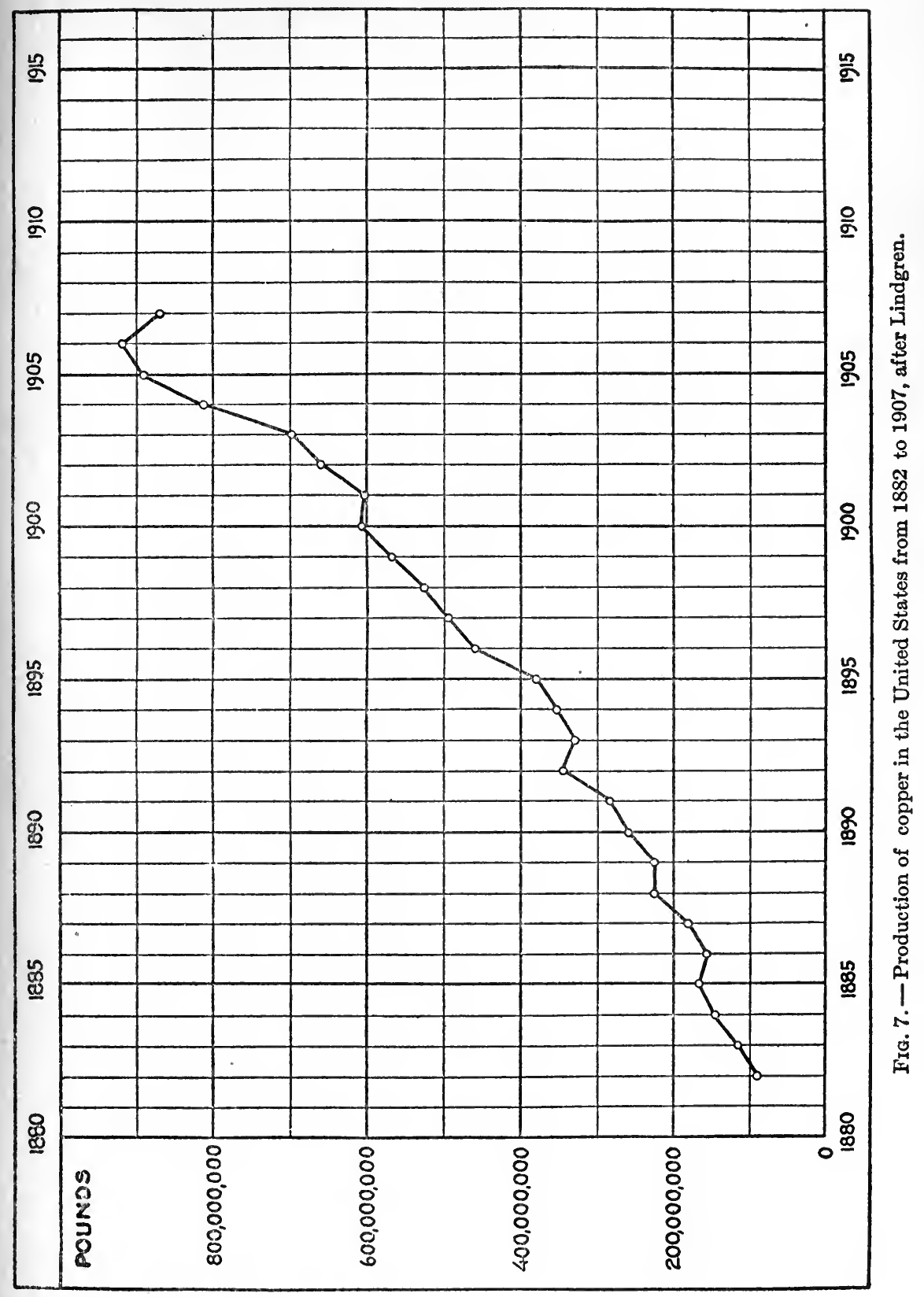


Known reserves of copper.

Increase of price will increase available ore.

Lose of copper.

cent to 55 per cent of the copper of the world, and according to the Mining World, in 1909, 72.6 per cent. The chief copper producing states are Michigan, Montana, and Arizona. In 1909 they produced respectively 236,000,000, $311,000,000$, and $294,000,000$ pounds of copper. The state next in importance is Utah, which in 1909 produced $108,000,000$ pounds.

In Michigan the grade of ore has steadily declined, until in 1907 the average metal received from the rock of the famous mines of the state was only 1.1 per cent, or twentytwo pounds of copper per ton.

Upon the basis of thirteen cent copper, according to Lindgren, the known reserves of this district are not more than fifteen years, and it is doubtful if in Montana and Arizona the known reserves exceed ten years. But as in the case of iron, the discovery of copper ores has gone on faster than exploitation, so that the present known reserves, while very moderate, are larger than ever before. Further exploration will extend ore bodies now known and will lead to the discovery of new deposits, and thus prolong the life of copper ores of the grades now used.

If in the future the price of copper rises to fifteen cents or twenty cents per pound, or to a higher amount, it will be possible to work ores of a lower grade. While no estimate can be given as to the quantity of very low grade copper ore, it is known that the amount is relatively large. But even the most sanguine can hardly hold out the hope that copper can be profitably produced at the present rate for fifty or one hundred years, and this is a very short time as compared with our future need for this metal. Hence there is the greatest necessity for conservation of it in every possible way.

At the present time the production of copper is mainly in the hands of large companies, and little complaint can be made as to wastefulness in mining or extraction. The greatest loss is in concentration, especially of the sulphides; according to Lindgren the losses in such cases sometimes reach 30 per cent. Wherever the amount of metals which 
goes into the tailings is considerable, they should be stored.

The uses of copper are mainly for wire and sheet and brass castings. All of these uses are such that the material may be again utilized. At the present time a considerable portion of the domestic consumption is from scrap copper. To some extent copper is used for chemical purposes, and when thus used, is rarely available more than once. Copper is sufficiently valuable so that little complaint can be made of mere waste of material in the metallic form. This metal differs from lead and zinc in that only a comparatively small part of it goes to a purpose which, when once used, dissipates it.

\section{LEAD}

The lead smelting industry in the United States, as an important one, goes back farther than that of any other metal. We have estimates for the amount of lead produced by the United States as far back as 1825, whereas the earliest years for which figures are available for any other metal are the decade of 1840 to 1850 .

The production of metallic lead in short tons from domestic ores for selected years is shown by the following table:-

Table Showing Metallic Lead Produced in Selected Years

$$
\begin{aligned}
& 1825 \text { • • . • • • . . • . } 1,500 \\
& 1832 \div \div \div: \div \div \div: \div \div \div 10,000
\end{aligned}
$$

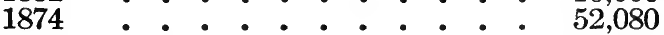

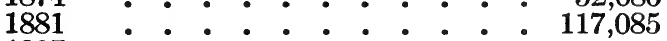

$$
\begin{aligned}
& 1897 \div . \div . \div . \div . \div . \div 207,365 \\
& 1907 \text { •............ . . } 337,340 \\
& 1908 \text { • . . . . . . . . . . 298,672 } \\
& 1909
\end{aligned}
$$

The table shows that it took forty-two years, from 1832 to 1874 , for the lead produced to rise from 10,000 tons to 50,000 tons; but to go from 50,000 to over 100,000 tons

Rapid increase in production of lead. required only seven years, from 1874 to 1881 ; and to rise to above 200,000 tons required sixteen years more, from

1 Approximate only; does not include lead from base bullion. From Mining World, Jan. 22, 1910. 
1881 to 1897 . Beginning with 1830 , the total output of the United States, including 1909 , was $8,595,672$ short tons. Of this, $3,063,047$ tons, or 35.6 per cent, were produced during the closing decade. Thus while the output of lead has increased very rapidly during the past fifteen years, the rate of increase has not been so great as in the case of iron and copper, for which metals the product of the past decade was more than 50 per cent of the total.

\section{LOSSES OF LEAD}

Loss of lead in mining ore extraordinary.

In the mining of lead the losses are always considerable and sometimes are excessive. Frequently the low grade ores are left in the mines under conditions which make it difficult to raise them. In the southeastern district of Missouri, under the best practice, not less than 15 per cent is left in the mines, and this is less than the average amount. However, the greatest losses in the production of lead are in the concentration and smelting of the ore. In the better practice the losses in concentration approach to 15 per cent, and in the poorer practice they are much higher than this. The loss in smelting of the concentrates frequently amounts to from 15 to 20 per cent. A conservative authority states that in southeastern Missouri the losses in mining, concentration, and smelting aggregate under the best practice from 35 to 40 per cent, whereas the loss for the district for the whole is in the neighborhood of from 45 to 50 per cent. That is, there is finally recovered as metallic lead a little more than one half of the material of the ore in the ground. This does not take into account the low grade ores which under present conditions cannot be commercially handled. So far as such low grade ores are left in the ground, this should be under such conditions that they may be mined in the future. Conservation demands improvements in the methods of mining, concentration, and smelting of lead. Probably satisfactory results will not be secured until there are comprehensive and rigid mining laws which control the methods of mining, milling, and 


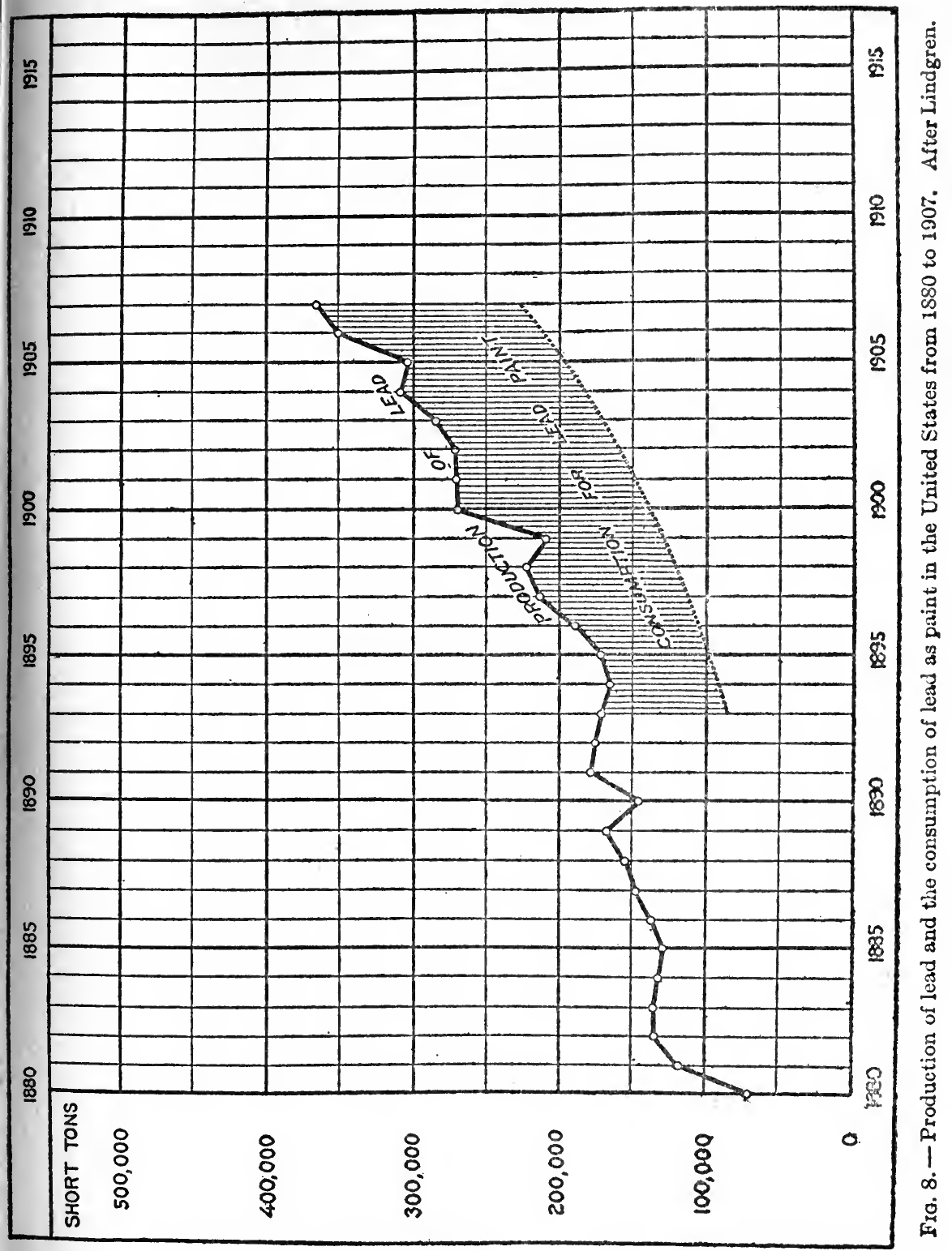


Use of lead for paint. smelting of the lead ores. Such laws must include, provisions for a mining inspector with ample authority to enforce the provisions of the law.

\section{THE USES OF LEAD}

Of the lead which is produced, one third is made into white lead for the manufacture of paint. In 1907 there were thus used 135,000 tons. Lead made into paint has but one service, since its recovery is impracticable. The use of lead for paint places this metal to that extent upon the same basis as coal, which, when extracted and used, is gone forever.

So far as possible, it is clear that, for paint, other substances should be substituted for lead. Of these, iron oxide and barytes are the most available. It is admitted that paints made of these substances are not so good as white lead paint; but because the amounts of them are large and because they do not draw upon the metals, the quantity of which is very limited, we should encourage as rapidly as possible the substitution of these metals for white lead.

\section{ZINC}

The production of zinc in large quantity in the United States is comparatively new. Statistics are available only since 1873. The production of metallic zinc in short tons for selected years is shown by the following table:-

Table Showino Metaluic Zinc Prodeced in Selected Yeaba

Rapid increase in produc-

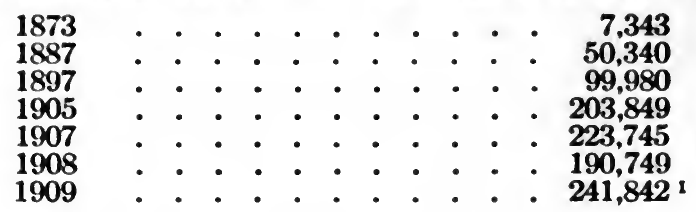
tion of zinc.

The figures in the table do not include the zinc white made directly from the ore. This table shows that from 1873 to 1887 , fourteen years, the output of zinc increased

1 Approximate only. From Mining World, Jan. 22, 1910. 


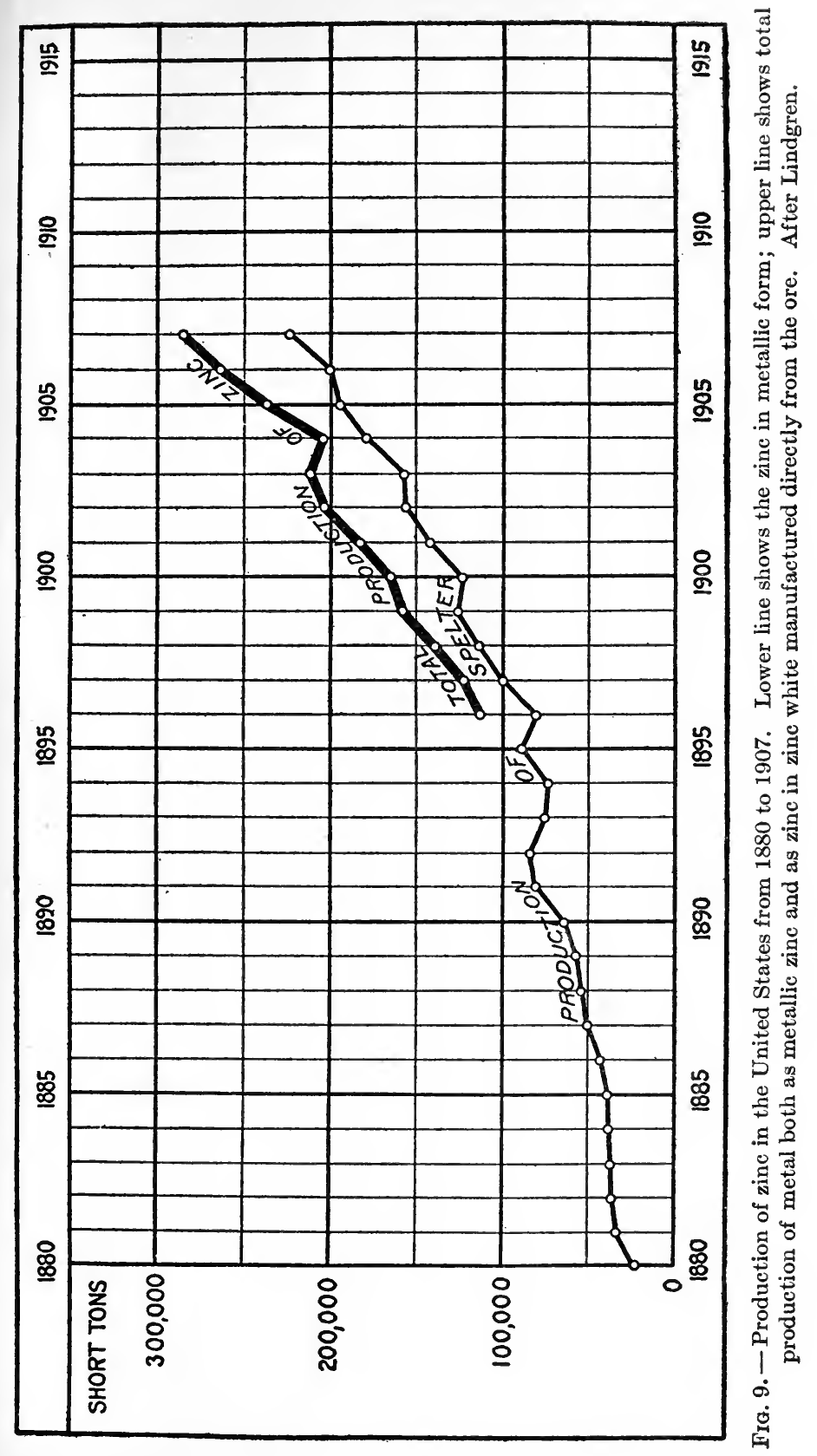




\section{CONSERVATION OF NATURAL RESOURCES}

more than sixfold; it doubled again by 1897 , that is, in ten years; and doubled again in 1905, that is, in eight years. Of the entire production since 1873 to 1909 inclusive, $3,271,630$ short tons, $1,827,435$ tons, or 55.9 per cent, were produced in the closing ten years. Thus zinc is again a product the output of which for the last decade more than equaled the entire output of the previous decades.

\section{THE WASTE OF ZINC}

The wastes in mining and smelting of zinc are great. Often as much as 15 per cent of the zinc ore is left in the mine. After the ore is taken out of the mine the loss of metal in concentration is large.

Loss of sinc in mining and extraction.

Not only is there great loss in the mining of zinc and in its concentration, but there is very great loss in smelting. Zinc is a peculiar metal in one respect. Iron, copper, gold, and silver, when reduced from the ore to the metallic form, are liquid. In the furnace, zinc does not give up the oxygen combined with it except at such a temperature as to be a vapor. Hence the smelting of zinc presents the problem of its condensation from that form. Notwithstanding the greatest care upon the part of the smelters, the losses are great. It is very rare indeed that there is obtained more than 80 per cent of the metal in the ore treated. It is difficult to altogether avoid this loss of 20 per cent or more, but it is clear that the manufacturers should use every precaution to improve metallurgical processes for zinc, and thus increase the percentage of metal extracted.

It is probable that putting together all the losses in mining, concentration, and smelting of zinc, they amount on the average to at least 40 per cent of the metal in the ore. In Missouri,. which state produces about one half of the zinc of the United States, the waste is almost beyond belief. The most conservative estimates place the loss at from 30 to 35 per cent ; and it is estimated by some men who know the conditions that the losses amount to 70 per cent. By those making the latter statement, it is held that the extraction of the ore from the ground is not to exceed 70 per 
cent; that 60 per cent is a more probable figure; that in the concentration and smelting of the ore, 50 per cent of the zinc in the ore taken out of the ground is lost. This would make the recovery of metal not more than 30 to 35 per cent of the amount in the ore.

The very great losses in Missouri and other states are in Loss of large measure due to the high royalties exacted of the miners by the fee holders. The great majority of the ores in Missouri and Wisconsin are not mined by the men who own the land. The properties are leased to miners upon the condition of a royalty of 10 or 15 per cent of the gross output of the concentrates. Very frequently the man who makes the first lease sublets to another party at a 10 or 20 per cent royalty. In such cases the subleases are small and the mining installations poor and inefficient. Thus under this system the total royalties amount from 20 to 35 per cent. The inevitable consequence of excessive royalties is that the operator, bound to get a profit - the largest possible profit in the shortest time - takes out of the mines the high grade ores and leaves the low grade material. It is to the operator's interest to mine and concentrate rapidly and cheaply even if a large amount of the metal does remain in the mine and go into the tailings. He will thus get the largest returns on his investment.

It is clear that the fee holder should put into his leases a condition requiring clean mining and handling the deposit so that the low grade material may be mined in the future; it is clear that he should require the best methods of concentration in order to reduce the losses of milling. It is believed that such losses may be reduced to one third or one fifth of the present amount. In order to require these things from the operator, it will be necessary for the fee holder to reduce the royalties. This procedure may temporarily lessen his income per year from a mine; but there is no doubt that the total income derived from a property will be increased both to the fee holder and to the operator by wise provisions in reference to the methods of mining and extraction and liberal conditions as to royalties.

Conditions of lease should require conservative mining. 
Zine used for paint.

Zinc used for galvanizing.

Zinc used for brass.

Rapid increase in production of gold.

\section{THE USES OF ZINC}

Zinc, like lead, is used for the manufacture of white paint. In 1907 more than 60,000 tons of zinc white were made, containing more than one sixth of the total output of zinc. This material made into paint and used is gone forever. The same principle here applies as in the case of lead, - we should substitute non-mineral and iron paints for zinc white.

The largest use of zinc is for galvanizing iron. In 1905 there were used for this purpose 100,000 tons; in 1906, 124,000 tons; and in 1907, 149,000 tons. Thus, for galvanizing, in 1907, was required two thirds of the metallic zinc produced. This use of zinc is one in which the proportion of metal dissipated is very large. Probably, under the most favorable circumstances, it will never be true that half of the metal used for galvanizing will be available a second time. Recovery from galvanized iron in 1907 amounted to about 13,000 tons.

The remainder of the zinc is mainly used for sheet zinc and for brass, an alloy of which it and copper are the constituents. So far as possible, zinc should be conserved for these permanent uses. Brass is a very important product for many purposes. If we are to have a sufficient supply of zinc in the future for the manufacture of sheet zinc and for brass, so extensively used.in the arts, we shall finally be obliged to discontinue largely or wholly its use as a paint and for galvanizing iron.

\section{GOLD}

Gold production in the United States was relatively unimportant until 1850. With the discovery of gold in California came a phenomenal increase in the output. From 1850 to 1897 there were produced each year between $1,500,000$ and $3,000,000$ troy ounces of the metal, each representing a value of $\$ 20.67$. In 1905 the $4,000,000$ ounce mark was passed, there being produced that year 4,265,742 ounces. In 1908 the production reached 4,574,340 ounces, and in 1909 approximately $4,889,524 .^{1}$ The total gold production of

${ }^{1}$ From Mining World, Jan. 22, 1910. 


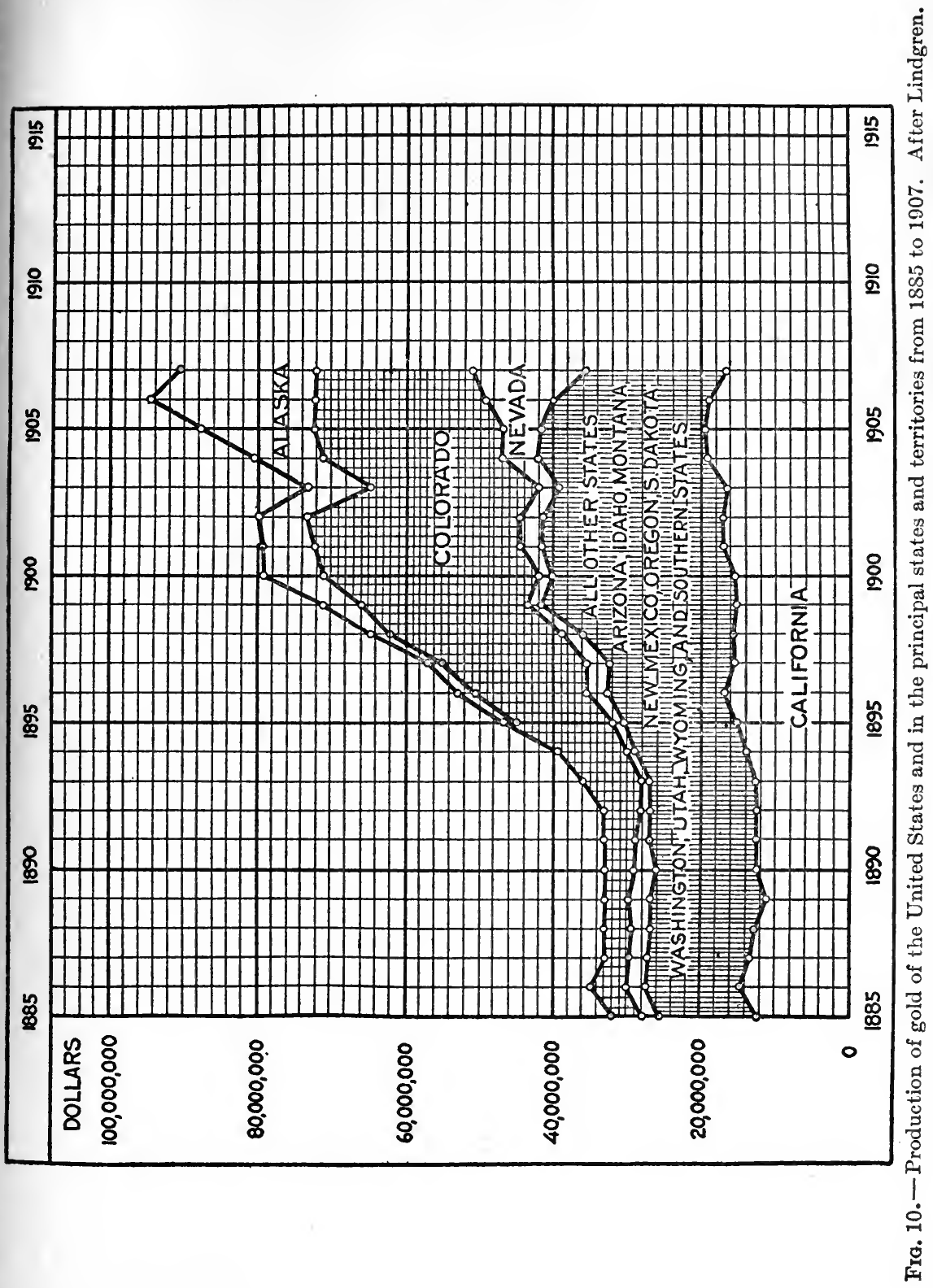


the United States to 1909 was $153,129,703$ ounces, of which $41,627,643$ ounces, or 27.2 per cent, were produced during the decade ending that year. In recent years the output of gold has not increased nearly so rapidly as the base metals.

The chief gold-producing states are Colorado, California; and Nevada. Each of these states contributes from $\$ 15,000,000$ to $\$ 20,000,000$, or nearly $1,000,000$ ounces of gold per annum.

Reserves of While the reserves of gold ore are large, they cannot be gold ore. appraised with anything like an approach to exactness. Lindgren, who is an expert upon this metal, thinks it is not likely in the United States in the near future, unless important fields are discovered in reference to which we know nothing, that the output of gold will go beyond $\$ 110,000,000$ per annum; nor does he think that it will sink below $\$ 60,000,000$ per annum. How long it will be before the maximum production is reached and a decline sets in cannot be predicted, but this may occur within twentyfive years or less.

The increasing output of gold has only been possible, as in the case of copper, by the discovery of new fields and a great decrease in the average grade of ore which was treated. It seems in the case of gold, where in some instances two thousand pounds of material are being mined and milled to get an eighth of an ounce, that we must be near the limit as to lowering of grade of ore. Certainly we cannot expect in the future that the grade of the product can go much lower.

\section{LOSSES OF GOLD}

Gold losses in mining and extractions.

In the early days of gold mining in the United States there was great waste in the mining and extraction of gold; and the losses are still large in Alaska. At present, gold exploitation is mainly by large companies. The limitations of the amount of good ore are appreciated, and in recent years there has been much lessening of the waste. The mining methods are excellent, and the ore taken out so nearly 
approximate to the full amount available that there is little cause for complaint from the point of view of conservation.

Also the loss in extraction has been greatly reduced in recent years. Formerly the loss in the tailings was large. The stamp mills were small and the methods of extraction crude, so that there went down to the gulleys, to be washed into the streams, great masses of material which contained a considerable percentage of the gold of the ores. How great the losses were in the past is shown by the fact that large quantities of tailings, so placed as not to be washed away, have been worked over with profit by modern methods. Even at the present time it is advantageous to store the tailings from the mills, for future improvements may make possible further recoveries.

But in general, in consequence of the improvements in the methods of milling and the discovery of the so-called chlorination and cyaniding methods of extracting the gold from the base concentrates, there is reasonable extraction of the metal. The greatest percentage of losses is in the low grade base ores. According to Lindgren, the loss in the concentration of such ores is still 3 per cent; but in the combined processes of amalgamation and concentration with treatment of concentrates by cyaniding or chlorination, the loss is not more than 1 per cent. So far as the gold is extracted from the ore by a smelting process, there is practically no loss.

\section{THE USES OF GOLD}

The uses of gold, unlike those of the metals which we have heretofore considered, are mainly of kinds which preserve it. Gold well illustrates the principle that when the Reduce gold losses by use of certificates. metallic ores are mined and the metal extracted, the metal is capitalized. The larger proportion of the gold taken out of the mines goes into coin and bullion. There is no loss from the gold in the subtreasuries and banks, but from that in circulation there is loss by wear and also loss of the coin itself. The amount of gold coin in circulation should there- 
Gold coin in circulation.

Amount of gold coin and ore.

fore be reduced, for the wear of gold as a circulating medium is the greatest loss of this capitalized product. This reduction may readily be accomplished by an extension of the use of gold certificates. When the certificates become worn, they are replaced; if lost, the government and therefore the people are the gainers. If gold certificates are substituted by the nations of the world for circulating coin and the equivalent gold kept in the treasuries, the loss by wear will be reduced to an inappreciable amount.

\section{It probably will not be practicable for a number of years} to altogether take gold out of circulation. In this country we have gone farther in this respect than most other countries. The gold actually in circulation at the present time is mainly restricted to the Pacific coast states and particularly California. In the central and eastern parts of the country we seldom use gold coin, its place being taken by gold certificates. In other countries, England, France, and Germany, etc., there has been no such development in this direction as in the United States. It is advisable from the point of view of conservation that other countries adopt the plan of substituting certificates for gold coin.

At the end of 1907, according to the director of the mint at Washington, there was gold in circulation, and coin and bullion in the subtreasuries of the world, to the value of $\$ 7,014,600,000$. $^{1}$ During the twelve years 1896 to 1907 , inclusive, there were produced by the world $\$ 3,648,878,800$ worth of gold, or more than 50 per cent of the total amount in circulation and in the sub-treasuries of the world at the end of the period.

During those twelve years, prices for all other commodities have increased on the average about 50 per cent. The connection between the two is obvious. Gold has depreciated in value during those twelve years. In making this statement it is not meant to imply that the increase of the gold supply is the only factor in rising prices; it is only one among a number.

${ }^{1}$ Annual Report, Director of the Mint, for the fiscal year ending June 30; 1908 , p. 68. 
Gold, besides being used for money, is also used in the arts, especially for table wear, for ornamental objects, for Gold used in arts. jewelry, and to some extent for chemical purposes. It is estimated that the amount of new gold used in the United States during the year ending June 30, 1909, for these purposes, had a value of $\$ 29,647,000$, or somewhat more than a quarter of the output of the United States, and that in addition to this, old material was re-used and coin drawn upon to the value of $\$ 10,000,000$.

\section{SILVER}

The production of silver in the United States until about 1830 was unimportant. From that date it gradually increased until in 1880 there were produced more than $30,000,000$ ounces. In 1889 the amount had reached $50,000,000$ ounces, from which time it has varied between that amount and 60,000,000 ounces, with the exception of two years. In 1892 and 1893, the production was respectively $63,500,000$ ounces and $60,000,000$ ounces. The total production of silver in the United States to the end of 1908 is estimated at 1,783,149,000 ounces, of which 556,683,300 ounces, or 31.2 per cent, were produced in the closing ten years. Apparently for silver the crest of production has been passed, being reached in 1892, some seventeen years ago. Probably in the future the yield of silver will be below rather than above that of 1892, and in the not distant future there may be a gradual decline in the amount of silver produced.

The chief silver producing states are Colorado, Montana, and Utah, each of which yields more than eleven million ounces per annum. Nevada and Idaho come next, the yield - of each being about eight million ounces.

\section{THE USES OF SILVER}

Silver, like gold, when taken from the mines and extracted from the ore, has been largely conserved, because its main Silver for coin. use in the past has been for money. According to infor-

Production of silver not increasing. 
mation furnished me by Dr. T. S. Adams, silver is still the standard of value in a number of countries, - China, Hongkong, Indo-China, Bolivia, Salvador, Persia, Guatemala, Nicaragua, and Honduras. In India it is the basis of circulating currency, but is given a definite value as compared with gold by limiting the coinage. In other countries a bimetallic standard prevails, as in France, Spain, Servia, and Bulgaria; but in these countries there is strict limitation in the coinage to keep the silver at a par with gold. In all other countries silver is used as a subordinate coin. It thus appears that, notwithstanding the tendency for gold to replace silver as the standard of value, silver still maintains a very important place as a circulating medium.

Use of certificate saves silver.

Like gold, the use of silver as a coin results in wear and to some extent in the loss of the coin itself. There can be little doubt that the wear of silver as coin is the chief cause of the dissipation of this metal. Instead of silver itself being used, the certificate may be issued by the government and the silver kept in the mint, and thus the loss by circulation prevented. In this matter different parts of this country have different habits. In the Middle and Far West the silver dollar is extensively used as current coin. In the East this coin is only occasionally met with in circulation, being replaced by the silver certificate. The use of the silver certificate is increasing in the Middle and Far West, and this should be extended until the circulation of the silver dollar ceases. In other countries also the loss by wear of silver in circulation may be greatly reduced by the substitution of the silver certificate for the larger silver coin. It is probable that silver for fractional currency, the half and quarter dollar and the dime, will be used in this country for a long time to come; also similar subordinate silver coins will continue to be used in other countries.

Silver used in the arts.

As with gold, a large amount of silver is used in the arts. At the present time it is estimated that something like $20,000,000$ ounces, or more than one third of the entire product, goes into this use. Of these 20,000,000 ounces, $4,000,000$ ounces or one fifth come from old objects which 


\section{4 \\ CONSERVATION OF NATURAL RESOURCES}

have been remelted and worked into a new form. Like gold, the use of silver in the arts is in a large measure of a kind which conserves the metal. That is, it is used for utensils, for ornamental objects, and for silverware. To a greater extent than gold, however, silver is used in the chemical arts; for instance, in connection with photography and as a chemical reagent. While uses of these kinds are legitimate, once so used, the saving of only a small part of the silver is practicable.

\section{The Subordinate Metals}

The subordinate metals include manganese, aluminum, mercury, chromium, molybdenum, nickel, tungsten, uranium, vanadium, tantalum, platinum, antimony, bismuth, tin, and cadmium.

A number of these metals are important for various purposes, especially for alloys and for use in the arts. However, in this brief course of lectures it is not possible to consider each one of them from the point of view of conservation. To do so would take too much time. Therefore, recognizing the incompleteness of treatment, only a single one of the subordinate metals will be considered; this is aluminum.

\section{ALOMINUM}

Abundance of aluminum.

Difficulty of extracting aluminum.

Aluminum is selected for consideration because of its abundance; indeed, aluminum is by all odds the most abundant of the metals. It is the only one which is contained in the rocks in so large a percentage as to make the amount practically illimitable. The entire crust of the earth contains on an average over 8 per cent aluminum, and in many rocks there are from 20 to 30 per cent of this element.

Not only is aluminum abundant, but it has properties which make it valuable for many purposes. It does not readily corrode; it is light, strong, ductile, and has a high electrical conductivity. Hence the question arises why it is that it does not have a more important place in our econ- 
omy. The difficulty is in the expense of its extraction. The greater amount of the aluminum of the world is united with silica in compounds, called silicates, and from them it is extremely difficult to extract the metal. It can be done, but at the present time the expense is prohibitive. For the most part the aluminum extracted is from an ore called bauxite, in which the aluminum is united with oxygen. The amount of this particular ore is very limited, - much more so than iron ore. And even from this oxide of aluminum it is difficult and expensive to extract the metal; indeed until a few years ago, almost no aluminum was produced in this country except as a chemical curiosity.

In 1883 in the United States, the total production of aluminum was eighty-three pounds. With the invention of a process for electrical reduction of the ore, using water for power, the production of aluminum became important. The amount in 1891 reached 150,000 pounds; in 1896, 1,300,000; in $1898,5,200,000$; in $1905,11,347,000$; and in 1907, $17,211,000$. The total production of the United States to the end of 1908 was $111,682,779$.

Because aluminum has a high electrical conductivity, is strong and does not readily corrode, it may replace copper Uses of aluminum. for transmission of electrical energy; and because of its lightness and strength it may replace iron for many purposes.

But even with the use of water power and electrical reduction of aluminum, the cost is still high. At the present time prices range from thirty-five to forty cents a pound, or thirty-three cents a pound in ton lots. Hence, notwithstanding its abundance, this metal is more than twice as costly as copper. So long as no method is discovered to greatly reduce its cost, it cannot be expected that aluminum will be widely used as a substitute for iron and copper.

\section{Concluding Statements in Reference to the Metals}

In conclusion, in reference to the metals, certain general statements should be made. 
Losses of metals.
Laws

required to reduce lose of metals.
Use of byproducts.

We have seen that the losses in the production of metals are threefold. First, there are losses in connection with mining. We have suffered much in the past by neglect of the low grade material and by leaving behind a considerable part of the high grade ore. Second, there are losses in extraction. These losses have been greatly reduced in recent years, but are still very large for some metals and especially zinc. These losses are mainly in the tailings but partly in the slags. Third, there are losses of by-products, especially arsenic and sulphur. For instance, it is said that at Butte, Montana, the loss in arsenic by neglect of this element is equivalent to 10,000 tons a year, which at the rate of fifteen cents a pound for arsenic trioxide, represents a loss of $\$ 1,000,000$ a year.

\section{REMEDIAL LEGISLATION}

These facts suggest remedial legislation. There should be legislation to prevent loss in mining; and where there are low grade ores not at present available, the laws should require the ground to be so left that these products may be mined in the future. There should be legislation in reference to concentration and smelting, requiring that the losses be reduced to a minimum. When the tailings contain any considerable residuum of metal, the law should require that they be stored. There should be laws requiring that by-products be saved. We have already seen (pp. 28-29, 56-61) how enormous are these losses in the cases of natural gas and the manufacture of coke.

In general, proposed laws requiring the utilization of by-products have been resisted by the parties concerned. That fact has already been mentioned with reference to the gas wasted in connection with the extraction of petroleum. But sometimes when a law has been passed requiring the utilization of by-products, this has been found to be commercially profitable. It is believed that this will be true of further improvements. Too often operators have been too conservative in introducing improvements. According 
to James Douglas, ${ }^{1}$ the Vivians, great smelters of Swansea, Wales, admitted that as early as 1881 they had in one year recovered 47 per cent of the sulphur, which had produced 3660 tons of sulphuric acid at a great profit. Yet the regulation which compelled them to do this was passed against their bitter opposition.

Thus it is clear that the opposition of interested parties to the savings advocated is no sufficient reason for not passing the laws suggested. The sole criterion in reference to this matter is, - do the principles of conservation demand that it shall be done? Do the needs of coming generations require that the valuable products be saved? It is often very difficult to make a business man appreciate this point of view. Indeed, some of the ablest and strongest business men of the country in charge of very large enterprises have often been exceedingly shortsighted in this respect. Not infrequently the directors of a corporation ask that they have large returns, "results," from their manager; and results mean the dividends declared that year. They do not appreciate that the demand for large returns the current year may be a mortgage upon the results to be secured next year or a few years hence.

In this connection the question should be considered whether the losses are larger among small or great corporations. There has been a marked tendency in recent years for the size of holdings of mineral lands to increase. This is very decided, Comparative losses by large and small indeed, in the case of iron and copper. It is estimated that at least iwo thirds of the high grade iron ore of the United States is owned by the United States Steel corporation. Much of the copper ore is held by a few large companies. What is true for iron and copper is true to a less extent for lead, zinc, silver, and gold, although there is no such approach to monopoly as in the case of iron ore.

What is the relation of large holdings to conservation? It is certain that the larger companies have been far less wasteful than the smaller ones. Managements of some of the great

1 "Conservation of Natural Resources," by James Douglas, Trans. Am. Inst. M. E., May, 1909, p. 441. 
Segregation of mineral lands.
Early leasing system abandoned. companies are considering not simply the coming year, or five years, or ten years, but the coming fifty years or hundred years. One of the best illustrations of this farsightedness is the United States Steel corporation.

I fully realize that there are two sides to the question of consolidation. The danger is that the great corporations will practice extortion upon the people if once they control a product by a monopoly or a community of interests. But, as has been indicated (pp. 44-46), such extortions may be controlled by regulation; and in case of existing large holding to regulation we should look to protect the people rather than to subdivision of holdings and competition.

Another class of laws which should be passed is in reference to the classification and segregation of the public mineral lands. In this connection it is necessary to give very briefly an outline of the mineral land laws of the United States.

By an ordinance in 1785 , in reference to the mineral lands of the "western Territory," there was to be reserved to the government, " one third part of all gold, silver, lead, and copper mines, to be sold, or otherwise disposed of as Congress shall hereafter direct."

In 1807 a provision was passed authorizing the leasing of lead mines in Indiana Territory. Thus there was a beginning in this country of leases for mineral property. In 1816 it was provided with reference to the public lands of the United States that where land applied for contained a lead mine "no permission to work the same shall be granted without the approbation of the President of the United States." In 1829 the first steps were taken to abandon the leasing policy of mineral properties before the same was fairly inaugurated; for in that year a law was passed for the sale of the reserved lead mines and contiguous lands in the state of Missouri.

The abandonment of the leasing system was furthered by a message to Congress of President Polk in 1845, which recommended the repeal of the leasing system for mineral lands and their sale "upon such terms as Congress in their wisdom may prescribe." President Polk, however, added the clause, "reserving to the government an equitable percentage of the 
gross amount of mineral product." To that time about $1,000,000$ acres of mineral land had been reserved from sale. Congress accepted the first clause of this recommendation but most unfortunately paid no attention to the second clause.

In 1846 mineral lands in Illinois, Arkansas, Wisconsin, and Iowa were ordered by Congress to be disposed of by public sale at a minimum price of $\$ 2.50$ per acre. In 1847 the President was authorized to dispose of the mineral lands of the Lake Superior district at a minimum price of $\$ 5$ per acre; and in 1850 an act was passed by Congress ordering the mineral lands of the Lake Superior district, including Michigan and Wisconsin, to be sold at public sale in the same manner as other public lands, and with the same rights of preëmption. In other words the distinction between mineral lands and nonmineral lands for that region was wiped out. By these acts Congress surrendered the rights of the people in the enormous deposits of Lake Superior iron and copper. No one can estimate their value; but it is certain that had the royalties gone to the government which have been paid by individuals or companies to fee holders, and equivalent amounts from operators who own their own fees, the total royalties would already have been more than $\$ 100,000,000$; and upon the basis of present known reserves, the total royalties which the government would receive in the future would greatly exceed $\$ 1,000,000,000$. And there is no reason to believe the exaction of moderate royalties by the government would have prevented the development of the Lake Superior country; for why should a royalty paid to the government be a greater deterrent to development than a royalty paid to an individual or corporation?

The early laws concerning the western part of the United States exempted mineral lands from entry under the ordinary land laws. This was true of the acts of 1841, 1851, and 1853. With the discovery of gold in California there grew up local regulations in reference to the mining claims which gradually settled into custom. These customs were later recognized by the courts and in many cases formulated into

Western mineral land laws. 


\section{CONSERVATION OF NATURAL RESOURCES}

law by the territories. It was not until 1866 that Congress passed a general law in reference to the acquiring of mineral lands in this western region. This act was supplemented and amended by the general mining act of 1872 .

Under these acts, in the western region, lode claims were sold at the rate of $\$ 5$ per gere, and placer claims at $\$ 2.50$ per acre. A lode claim may nit be more than 1,500 feet in length nor more than 600 feet wide; and no placer claim for any one person or association of persons may exceed 160 acres. In 1897 petroleum and oil lands were ordered to be disposed of under the same laws as placers.

Neither the lease system nor the royalty system was attempted in the Far West. Thus, as in the Mississippi Valley and in the Lake Superior district, the mineral lands were allowed to pass into private hands with no reservations. Had the wise recommendation of President Polk been adopted and the mineral lands disposed of subject to even a very moderate royalty, this would have meant to the government and to the people enormous sums of money. Since the year 1900, excepting one year, the mineral products of the United States each year have had a value of more than $\$ 500,000$,000 , and in 1907 of over $\$ 900,000,000$. This of course is the value of the smelted product and not of the ore, but had a moderate percentage of the value of the ore been exacted as a royalty, the income to the government in recent years would have been many millions of dollars per annum.

Government mineral lands should be permanently retained.

Certainly the time has now come when the land belonging to the United States should be classified and the mineral land segregated. The geological surveys of the various states and of the United States government should make investigations so that the mineral bearing areas may be exactly outlined and the amount of each mineral determined as accurately as possible. And finally all of the mineral lands now retained by the government or the states should be held perpetually as public property. Much the greater part of the mineral lands formerly belonging to the government or to the states has passed into private hands. The remnant belonging to the United States is mainly in the Rocky Moun- 
tain region and in Alaska. The mineral lands retained by the government should be operated upon the lease system. The advantages of such retention have been fully explained with reference to coal (see 41-44), and the same principles apply to each of the metallic ores.

These conclusions follow from the facts mentioned at the opening of the treatment of the metals, that for their manufacture was required the building of the world; man cannot either add to or subtract from them, and therefore, so far as they have not passed from the government, they should be retained by it for the people of all generations.

Before concluding with the metals, the question of exportation should be considered. At the present time a very large part of the copper produced and relatively small amounts of Exportation of the metals. lead and zinc are exported. Of the copper produced in this country, there were exported in the year 1908 over 660,000,000 pounds, or about 70 per cent. The chief exportations of zinc were 26,108 tons of high grade ore valued at $\$ 877,745$ and 8,405 tons of zinc dross valued at $\$ 467,403$.

Since our supplies of metals are not likely to be sufficient to last the people of this country for centuries to come, the question certainly should be raised as to whether there should be control of exportation. At the present time it is not advocated that the amount exported should be limited, but certainly much more accurate estimates should be made than are now available as to the probable future life of our ores and the probable future demands for the metals in this country, in order that we may have available the data upon which laws with reference to exportation may be formulated.

In extending the life of our metals, it is clear that in addition to the above suggestions every other possible improvement should be made. The reduction of the losses of recent years has come largely as a consequence of investigations. Investigations should be continued by the nation, the states, and the Investigation to promote conservation of metals. individuals. Says Holmes: "The common purpose of all these investigations must be to indicate $(a)$ how we can prevent waste; (b) how the mineral products may be mined, treated, and used with greatest efficiency; $(c)$ how the more abun- 
Many nonmetallic resources inexhaustible.
Nonmetallic materials should be substituted for metals.

dant materials may be substituted for the rarer and more costly materials." ${ }^{1}$

\section{THE NON-METALLIC RESOURCES}

The non-metallic resources include structural materials such as cement, lime, sand, gravel, stone, slate, clay; abrasive materials such as mill stone, emery; chemical materials such as arsenic, borax, gypsum, salt, sulphur; pigments such as barytes; and miscellaneous materials such as asbestos, asphalt, graphite, magnesite, etc.

The quantities of many of these products, unlike the mineral resources, are very large; indeed, some of them, from the point of view of mankind, are inexhaustible. For instance, in the salt mines of the United States, in the salt lakes, and in the ocean, is a sufficient supply of salt. Similarly, the supply of stone, gravel, and sand is inexhaustible; also the materials for making lime and cement. To these products the principles of conservation do not require any limitation in their use. This statement should be qualified to the extent that the richer deposits should not be recklessly handled or wastefully used.

It is entirely impossible in this brief course to treat separately each of the non-metallic products; and indeed, because of their abundance such treatment is not necessary. The chief point which need be made in reference to them is as to their widest use and development, - to substitute them for other materials which are limited in quantity, so far as this can be done. Thus it is clear that structural materials, such as stone and cement, being practically illimitable in quantity, should be substituted so far as possible for materials which are limited in quantity. Our bridges should be made of stone and concrete instead of iron, although there may be a certain amount of iron reënforcement in the concrete. Our houses should be made of stone and cement and brick and not of wood. We are the only civilized country which uses wood extensively for that purpose. This we have done in the

1 " Production and waste of mineral resources," J. A. Holmes, An. Am. Ac. Pol. and Soc. Sci., Vol. XXXIII, No. 3, p. 686. 
past because wood has been so cheap, but in the future wood is to become more expensive; and even from an economic point of view it will be cheaper to construct buildings of stone, cement, and brick. However, we should not wait until that time to develop the sentiment that the abundant and permanent non-metallic materials be used for all buildings, and thus save our wood supply.

Of the various substances mentioned, some are exhaustible, Sulphur and in such cases careful use is required. One of these sub- limited stances limited in quantity is sulphur. Sulphur is required for the manufacture of sulphuric acid, a compound which is very important in the arts. Sulphur occurs in this country combined with the metals as sulphides. When the metals are extracted the sulphur should be saved as a by-product.

The only other non-mineral products which I need to mention are the nitrates, the potassium compounds, and the phosphates. These are used as fertilizers, and primarily concern the soil. Therefore they will be treated in connection with that part of the subject rather than with the metals (see pp. 316-339). 


\section{PART II}

\section{WATER '}

Water the most important of the nonorganic resources.
Large amount of water required by organisms.
$\mathrm{W}$ ATER, while not ordinarily thought of as a mineral, under the broadest definition of that term is included. Whether water be classed as a mineral or placed by itself, it is by far the most important of all the non-organic products of the world, - more important even than coal or iron, - more important from the point of view of mankind, indeed, than all of the metals. Water is the basis of life. On the average the plant tissue of annuals is three fourths water, and of perennials, three eighths. Animals, including human beings, are 80 per cent water. The very brain is four fifths water; the cerebellum, about 80 per cent, the white matter somewhat less than 80 per cent, but the gray matter, supposed to be the thinking part, 83.5 per cent, $-\mathrm{a}$ larger proportion than in the average of the body. This, of course, is a commonplace with students of biology; but it is worth reflecting about that the brain which has developed in man through thousands of years, the animal, the first in this world that has asked the meaning of the order of nature, and has asked the significance of his own destiny, is mainly composed of water. Not only are organic tissues in very large measure composed of water, but for their production is required many times their weight in water. According to Erlanger, the average man of 150 pounds ingests each year about 264 gallons of

1 The facts in reference to Part II are largely derived from three sources: the Annals of the American Academy of Political and Social Science, Vol. XXXIII, pp. 521-602; The Report of the National Conservation Commission, Vol. I, pp. 39-49, and Vol. II, pp. 10-178, Washington: Government Printing Office, 1909; Preliminary Report of Inland Waterways Commission. Washington: Government Printing Office, 1908. 
water or 35 cubic feet, the weight of which is more than a ton.

According to Stoddart, to produce a bushel of corn requires through necessary evaporation from the soil and transpiration of the plants, from 10 to 20 tons of water. According to King, in Wisconsin, the amount of water required for evaporation and transpiration to produce one pound of dry matter for various crops varies from 270 pounds to 576 pounds, with an average for six kinds of crops of 446 pounds. To produce a ton of dry clover requires 576 tons of water. According to McGee, to produce a pound of beef requires directly, and indirectly through the feed, 15 to 30 tons of water. Thus we see not only is water the most important constituent of organisms, but for their development vastly more water is required.

Water is so common in the humid regions that the in- In arid habitants do not appreciate its importance. One must go to the arid land to get a proper conception of the value of water. There it is the limiting factor of life. As many plants grow as the scanty water can supply with drink; they are separated from one another by open spaces. The animals, likewise, are relatively few. Trails converge from various directions; we expect to find a city, - we find a water hole or a spring. I remember well my amazement at the unbounded enthusiasm of an inhabitant of the arid region when I visited with him a clear mountain stream. For the first time I appreciated the importance of water. When I returned to the humid regions and saw our lakes and rivers full of water largely unused, it seemed reckless extravagance.

Until I had experience in an arid region, I had no conception of the force of the imagery of the Bible, "Let him that is athirst come; and whosoever will, let him take of Water and the imagery of the the water of life freely." "My soul thirsteth for thee; my flesh longeth for thee in a dry and thirsty land, where no water is." "My soul thirsteth for God, for the living God." "As the hart panteth after the water brooks, so panteth my soul after thee, O God." It is to be remembered that 
Palestine is a dry region. The authors of the Scriptures, when referring to water, used the strongest figures furnished by their experience. In no other way could they so well express the intensity of their feeling.

\section{THE SOURCE OF WATER}

The ultimate source of water is the ocean. The water evaporates from the sea through the heat of the sun, is carried by the atmosphere over the land, and is precipitated upon the earth in the form of rain, snow, hail, and dew. Water once precipitated may be again evaporated and reprecipitated. And thus the water which leaves the ocean, before it returns to it through the streams, may have been evaporated and precipitated several times.

Supply of water ever renewed.

Water is different from all the other minerals in that its supply is ever renewed; that is, as fast as it goes down to the ocean, it is restored to the land through evaporation and precipitation. While there are very slow climatic changes by which a region once humid may become arid, or an arid region become humid, these changes are so slow as to be negligible; and therefore, as a matter of practical expediency, we may consider the supply of water available as permanent and unchanging. Hence our duty concerning water is very different from that in reference to other minerals; we should, so far as possible, substitute it for other materials. The problem of the conservation with reference to water is its fullest utilization.

\section{THE AMOUNT OF WATER}

In estimating amounts of water, different units have been used, - the cubic foot, cubic mile, acre foot (that is the amount of water required to cover an acre to the depth of one foot), the cubic meter, and the kilostere or 1000 cubic meters. ${ }^{1}$ One kilostere equals about 1000 tons, or four fifths of an acre foot.

1 The statements below as to the precipitation in the different parts of the United States are taken from Water as a Resource, by $\mathbf{W} \mathbf{J}$ McGee, An. Am. Ac., Vol. XXXIII, No. 3, pp. 521-534. 
The mean annual rainfall of the United States is about thirty inches. Using this as a basis for calculation, it follows that the total quantity of water falling upon the United States, including the water areas, is $215,000,000,000,000$ cubic feet. This is equivalent to about 1500 cubic miles, or $6,000,000,000$ kilosteres, or $5,000,000,000$ acre feet, or putting it another way, equivalent to ten Mississippi Rivers.

Of this precipitation more than half is east of the 95th meridian; that is, it is in the humid region of the United States. For this region the average precipitation is forty-eight inches, and the quantity is estimated at $140,000,000,000,000$ cubic feet, or 1000 cubic miles, or $4,000,000,000$ kilosteres.

Between the 95th meridian and the $103 \mathrm{~d}$ meridian is the semi-humid region. There the average precipitation is thirty inches; and this aggregates $40,000,000,000,000$ cubic feet, or 285 cubic miles, or 1,140,000,000 kilosteres.

The remainder of the United States, about two fifths of the country west of the $103 \mathrm{~d}$ meridian, includes the arid lands. The average precipitation of this region is only about twelve inches per annum, which amounts to $35,000,000,000,000$ cubic feet, or 250 cubic miles, or $1,000,000,000$ kilosteres.

This great quantity of water is received each year. The question arises as to what becomes of it. Of the water which falls upon the land, substantially one half soon evaporates, and this by McGee has been called the fly-off, because it almost directly is returned to the atmosphere. About one sixth of the water is consumed by the plants, or goes far enough below the surface to join the underground water; this McGee calls the cut-off. The remaining one third of the water passes into the rivers and thence into the sea; this is the run-off.

I shall consider each of these divisions, 
Influence of fly-ofi on humidity.

\section{THE FLY-OFF}

The fly-off comprises about $110,000,000,000,000$ cubic feet, or 750 cubic miles, or $3,000,000,000$ kilosteres. While this amount, as has been said, evaporates with no direct use by man, or indirect use by him through the plants, it does have an influence upon the humidity of the atmosphere. If it were not for this enormous amount of water supplied by the land, the quantity supplied by the ocean would be entirely inadequate to give conditions of humidity to the atmosphere, resulting in abundant precipitation. Therefore the great service of the fly-off is that it, passing into the atmosphere and added to the water directly received from the ocean, makes the conditions favorable for precipitation. The fly-off is thus restored in large measure to the soil, to be again divided between the fly-off, cut-off, and run-off. It is plain that if the total precipitation is as has been given, and only one third of it goes to the sea in streams, approximately two thirds of the total precipitation is derived from water which once falls and again goes into the atmosphere, for the run-off is the measure of the amount which is newly contributed by the ocean.

Evaporation dependent upon various conditions.
The speed of evaporation depends upon the nature of the surface, upon the temperature, and upon the humidity of the atmosphere. Where the surface is porous and the openings are moderately small, so that capillary action readily takes place, the water is continually drawn to the surface and evaporation goes on with extreme rapidity. If, on the other hand, the upper part of the ground has openings larger than those of eapillary size, the water is not so rapidly drawn to the surface and evaporated. This is the principle which controls the action of the farmer who, immediately following a rain in those regions where water is a limiting factor in agriculture, cultivates the land and so breaks up the capillary openings near the surface. This practice is general in the fruit orchards of California. The best results are reached if, after the surface is broken so as to give coarse openings for a short distance below, 
a roller or drag is used, heavy enough to make a smooth, layer of soil-dust at the top. Under these conditions capillarity draws the water to the subsurface where the roots of the plants feed, but its rising to the surface is largely prevented by the thin zone of material where the openings are of supercapillary size.

The amount of evaporation also depends upon the temperature. In those parts of the country where the average temperature is high, evaporation goes on much more rapidly than in the colder regions. Finally, the amount of evaporation depends upon the humidity of the atmosphere. In those regions where the atmosphere is very dry, evaporation goes on with great rapidity, whereas in the areas in which the atmosphere is often saturated with moisture, the evaporation is slow. It is thus plain that the very poverty of the arid regions in water makes their relative losses greater than in the humid regions, because of the greater dryness of the atmosphere.

\section{THE CUT-OFF}

The cut-off is $35,000,000,000,000$ cubic feet, or 250 cubic miles, or $1,000,000,000$ kilosteres. This is the water which goes underground. The water absorbed by the earth is consumed by natural vegetation or that produced through agriculture, or it joins the subterranean reservoir.

\section{THE USE OF WATER BY PLANTS}

The underground water is the medium which dissolves the earth's salts and conveys them to the roots of the living plants; it is the source of the plant circulation. The Transpiration of water by larger part of the water which goes underground is used in the growth of vegetation and is finally evaporated. This water absorbed by the roots is carried up the trunks of the trees and the stems of plants to the leaves, and by the leaves it is transpired. The amount of water evaporated through the medium of vegetation depends upon the density of the vegetation, upon the humidity, upon the tem- 


\section{CONSERVATION OF NATURAL RESOURCES}

perature, and upon the length of the growing season. It varies from a very large amount in the warm, humid regions such as the Everglades of Florida, to a very small amount in the arid regions where the vegetation is sparse. Indeed, the amount of water which is available to the plants is their limiting factor. Given proper conditions of temperature, if the water is sufficient, the vegetation is luxuriant. Often in the tropics where there is abundant rains, the forests are almost impenetrable. The same is true of the well-watered slopes of the Pacific ranges of Washington, Oregon, and California. According to Stoddart, the transpiration of the forests through the foliage in the growing season varies under different conditions from 1000 to 20,000 pounds of water per day per acre. The same authority states that the transpiration of the foliage of maize in the production of a bushel of corn probably averages about 5000 pounds.

Desert In the arid regions the plants are small in size and sparsely plants abstemious distributed. The bunch grass, the sage bush, the greasewater users. wood, the salt bush, the yucca, the paloverde, the cactus, are usually separated so far from one another that one can readily walk or ride between them. Also they are abstemious water users. A great many of them are leafless or nearly so, the stems of the plants having a green color and serving the place of leaves as in the case of the paloverde. And often when the plants have leaves they are small and narrow and hang in diagonal positions so that the rays of the sun largely strikes them on the edges rather than upon their faces. This sparseness of plant life is necessary because there is not enough water below the surface so that more may live; as many grow as can possibly find water. As we travel in the desert we find many of even these hardy and abstemious plants stunted and half dead from thirst. 


\section{THE RESERVOIR OF UNDERGROUND WATER}

The water which goes underground and is not evaporated through vegetation joins the reservoir of underground water. For the larger portion of this country, if a hole be bored into the earth, underground water will be found at a reasonable depth, in the humid regions comparatively near the surface, in the arid, much deeper. The place at which water is encountered is known as the level of ground water, or the water table. The level of underground water varies from the surface in the case of the swamps and marshes to hundreds of feet or even 1000 or more feet below the surface. Commonly, however, in the eastern humid part of the United States the level of underground water is found at depths less than 100 feet.

Below the level of underground water, all the cracks and openings of the rocks down to the depths in which there are practically no cracks are filled with water. In the more porous rocks the space occupied by the water may be 20 per cent or more of the volume. McGee estimates that the amount of water contained in this subsurface belt to the depth of 100 feet is equivalent to a solid mass of water over the United States 17 feet deep. He estimates that the belt contains over $1,400,000,000,000,000$ cubic feet, or 11,000 cubic miles, or $40,000,000,000$ kilosteres. This is equal to the entire rainfall of the United States for seven years, or the run-off for twenty years. The most conservative estimate of the entire amount of underground water in the outer zone of the earth to the depth to which fractures extend is that by Fuller. According to him this is equivalent to a solid belt of water ninety-six feet in depth. Other estimates exceed this by several to many times. It thus appears that on a very conservative estimate we have stored in the so-called zone of fracture of the earth at least the equivalent of the total precipitation from the atmosphere for a period of forty years and the equivalent of the run-off for more than one hundred years. 
Underground water source of springs and wells.
The extent of roots.

The underground water is the source of all the springs and wells, cold and hot, natural and artificial. The inestimable importance of the underground water supply is appreciated when it is known that probably three fourths of the population of the country obtain their water for domestic purposes from this source. Also underground water, obtained by artesian wells or by pumping, is extensively used for irrigation. As states which well illustrate this use are Florida, California, Kansas, and the Dakotas. Mendenhall estimates that the total amount of water drawn from underground in the United States is equal to the volume of the Potomac River at Point of Rocks, Maryland, or the Colorado at Yuma, Arizona. This volume is somewhat less than one per cent of the total run-off of the United States.

The water used by plants, already mentioned, comes in good measure from this reservoir. You who have studied biology appreciate that wherever you see a forest above the ground, there is another forest of roots below the ground; where there is a corn field above the ground, there is a plexus of roots of almost equal magnitude below. Frequently, the plants in the arid region have a much larger volume of roots than branches and foliage. This is because of the necessity of extending their roots far and wide in their search for water. The roots of such plants as alfalfa go deep into the soil as compared with the height of the plant. Says Van Dyke, "The roots of the greasewood and the mesquite are almost as powerful as the arms of an octopus, and they are frequently three times the length of the bush or tree they support. They will bore their way through rotten granite to find a damp ledge almost as easily as a diamond drill; and they will pry rocks from their foundations as readily as the wistaria wrenches the ornamental woodwork from the roof of a porch. They are always thirsty and they are always running here and there in the search for moisture. A vertical section of their underground structure, revealed by the cutting away of a river bank or wash, is usually a great surprise. One marvels at the great network of roots 
required to support such a very little growth above ground." 1

It is estimated by McGee that, by injudicious farming and deforestation, the water table has been lowered in the eastern part of the United States by from ten to forty feet. Indeed, he estimates that of the shallow wells and springs in this part of the country, at least three fourths have failed. The springs have dried up; the small brooks have ceased to flow; the wells have been sunk to lower levels.

In this matter we have an exceptional situation with reference to water which is somewhat analogous to that of the minerals. We are using the supplies of the past and not restoring an equal amount. This we are doing to some extent because of our present need; but also more wells are drilled in many artesian areas than are necessary; and when they are not in use, which is often the larger part of the year, the water from them is allowed to run off freely. Usually it is not realized that such waste lessens the head and makes available a smaller amount when water is again needed. This waste of underground water is analogous to the waste of natural gas. Strange as it may appear, waste of this kind is allowed to continue not only in humid regions where water is not appreciated, but in arid regions where it is of such fundamental importance. Such waste should be prohibited by law and the law should provide means for its enforcement.

Already strict laws exist in a number of states of the West; this is illustrated by the state of California. It is clear that laws preventing waste of underground water are constitutional upon substantially the same grounds as are the laws with reference to waste of natural gas. This is clearly indicated by decisions which have been rendered in various courts. ${ }^{2}$

It is important to get into the ground a sufficient amount of water so that the water table will be maintained at a

1 John C. Van Dyke, "The Desert," p. 136.

2 "The Conservation of our Natural Resources and of our National Strength and Virility," A. A. Bruce, Pennsylvania Law Review, Vol. 58, pp. 149, 151, 159.

Lowering of water table.

Waste of underground water.
How to get water underground. 


\section{CONSERVATION OF NATURAL RESOURCES}

convenient depth. This is especially important in the arid and semi-arid regions; for there often the underground water is the only certain source of this element for domestic purposes and for irrigation.

In various places in the West, and especially where the underground water has been drawn upon heavily for irrigation, as in the fruit ranch district of southern California, the level of the underground water has been seriously lowered, in some cases as much as from ten to forty feet. In this region, notwithstanding national forests and great storage reservoirs, at times of flood a large amount of water has been allowed to go down to the sea. The streams gain their water in the mountains from which they emerge to the lowlands through cañons. At the mouths of the cañons are great coarse alluvial cones. Recently a concrete headgate has been placed across the Santa Ana, the largest of the rivers of the San Bernardino range, so that at times of flood the water may be diverted from its bed and spread over the sand and gravel of the cone; the water is rapidly absorbed by this coarse material and passes underground. In this way the level of the underground water in the San Bernardino basin has been raised a foot, notwithstanding the increasing demand upon the underground reservoir.' This method of preventing water from flowing to the sea in arid regions, where the streams come out of cañons at the mouths of which are alluvial cones, is likely to have a wide extension in the West.

The above is a somewhat special method of getting the precipitation underground. On a much wider scale increasing the proportion of precipitation which goes underground may be accomplished by covering the earth with vegetation, by contour plowing, and by cultivating in such a manner as to leave a rough surface.

Distribution In conclusion, in reference to the cut-off, it has been seen of cut-off. that it is the medium through which plants are fed, and that the larger proportion of the water escapes into the at666.

1 "The Water Savers," Walter V. Wœklke, Outlook, April, 1910, pp. 665, 
mosphere through vegetation. Another portion of it reaches the surface from the underground reservoir either naturally through springs, or artificially through wells, and is there evaporated or else joins the run-off.

From the foregoing it is plain that the undergound water has a continuous and extremely complicated circulation, and during its circulation performs various highly important functions. What has been given is no more than an exceedingly rough outline sketch of its work. Sooner or later the water which goes underground joins the fly-off or the run-off. The diversion of any given part of water from these forms may be very brief or it may be thousands of years.

\section{THE RUN-OFF}

The annual run-off of the United States is about $70,000,000,000,000$ cubic feet, 500 cubic miles, or $2,000,000,000$ kilosteres. One third of this escapes to the sea through the Mississippi River.

This run-off is available for the following purposes:-

1st, for water supply; $2 \mathrm{~d}$, for water power; $3 \mathrm{~d}$, for navigation; 4th, for irrigation.

The use of water for one of these purposes does not necessarily prevent its use for another. Thus the water used in cities usually goes back into the streams or the Use of same water for several lakes, and may be used for water power, irrigation, or navi- purposes. gation. Similarly, water which is used for water power may be used for domestic purposes, navigation, or irrigation. These various uses supplement one another. Mendenhall gives the Santa Ana River of southern California as an excellent illustration of the use of water a number of times. There the water is first used for power, then for municipal and irrigation purposes at Redlands and Highlands, then largely recovered by means of springs and flowing wells for San Bernardino and Riverside. A part of the water reemerges into the river at Riverside Narrows, where it is again used for irrigation; and after this a part of it is again recovered by pumping. But little of it reaches the sea.

Circulation of underground water.

. 
Frtent to which run-off is used.
Mendenhall thinks that the same particle of water, in its course from the headwater of the stream toward the sea, may have been used as many as eight times for power, irrigation, or domestic purposes, although of course the average use is less than this.

Of the run-off, it is estimated that one seventh of one per cent is used for municipal or community purposes. It is supposed that about 2 per cent of the whole of the run-off, or 10 per cent of that in the arid and semi-arid regions, is used for irrigation purposes. It is supposed that about 5 per cent is used for navigation, and that less than 5 per cent is used for water power. Thus it is clear that more than 75 per cent, and some estimates go as high as 85 or 90 per cent, of the run-off is not used for any of these purposes. It is evident, if this is true, even taking the conservative figure of 75 per cent, that there is opportunity for vast improvement in the utilization of the run-off.

\section{WATER SUPPLY}

Domestic purposes highest use of water.

Water supply of cities.
Water for water supply includes that used for domestic purposes, and also that used for manufacturing, street sprinkling, etc. This is the highest use of water. If there is a conflict between the use of water for water supply and any other use, water supply should take precedence. The most frequent conflict is with irrigation; but as has been said, it is frequently possible to use water first for domestic purposes and then for irrigation or some other purpose; but not infrequently its use for irrigation must be stopped until it has been used for municipal purposes. An illustration of this is at Los Angeles, where pumping underground of water in the Los Angeles River basin for irrigation was prohibited, since this lessened the flow of the Los Angeles River, the rights to the water of which the city owned.

According to Leighton, in 1908, there were catchment areas for water supply of cities aggregating $1,000,000$ acres, representing an investment of $\$ 250,000,000$. The population so supplied with water approached $10,000,000$. The 
annual consumption of this water for these catchment areas, he places at $37,500,000,000$ cubic feet, or one-twentieth of 1 per cent of the run-off. In these cities there are used upon an average 3750 cubic feet per inhabitant per annum, or more than 10 cubic feet per day.

At the present time there are in progress of construction great enterprises which well illustrate the expense which may be necessary to supply cities with water. The city supply of Los Angeles is to be conveyed from Owens River by an aqueduct 225 miles in length. Great reservoirs are to be built, one of the dams of which is 140 feet high. The cost of the work, exclusive of distributing system, will be $\$ 25,000,000$. The daily capacity will be $258,000,000$ gallons. Power will be developed along the line of the aqueduct to the extent of 49,000 horse power.

For San Francisco water is to be taken from Tuolumne River and Eleanor Creek and carried through an aqueduct 182 miles long. The area of the watershed is over 450 square miles. Two reservoirs are to be constructed, one of which is to have a dam 150 feet high. The estimated cost of this work, exclusive of the distributing system, is $\$ 30,000,000$. The daily capacity will be $60,000,000$ gallons.

The additional supply now being constructed for New York City will be derived from a drainage area of over 900 square miles. The works will furnish $500,000,000$ gallons per day. The estimated expense of all the work in connection with same is almost $\$ 100,000,000$.

It is related that once a group of Zunis visited the Eastern states and saw all the wonders of our civilization. When, The Zunis and water. after having seen everything remarkable that could be shown them, they were asked which was the strangest, they said that the most wonderful thing that the white man had accomplished was his ability to open a faucet anywhere and have flow from it a stream of water. Not infrequently the Zunis from their dwellings must climb down hundreds of feet into a cañon, and there place a jar under an opening from which slowly trickles the water, sometimes drop by drop. 


\section{THE WATER POWERS}

THE WATER POWER AVAILABLE

In 1908, according to the United States Census Bureau, there were developed in the United States $5,356,680$ horse power from water. The distribution of this power is shown by the following table from Leighton:-

Table Showing Number of Wheers and Developed Water Power in the United States

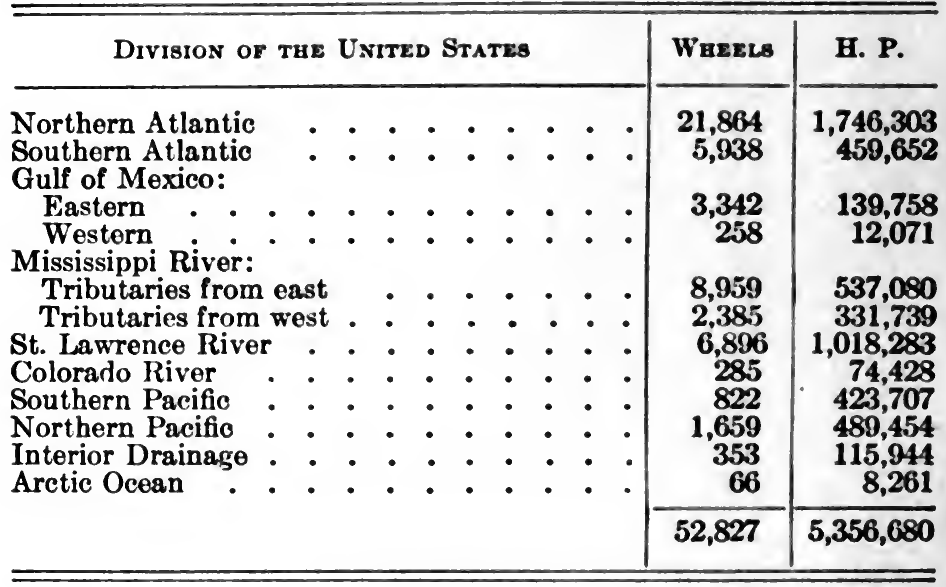

Leighton ${ }^{2}$ gives another table which shows the drainage areas, the flow of water of same, the primary horse power available, and the minimum available for the six high-water months.

1 "Water Powers in the United States," by M. O. Leighton, An. Am. Aa. Pol. and Soc. Sci., Vol. XXXIII, p. 555.

${ }^{2}$ Loc. cit., p. 549. 
Table Showing Estimate of Stream Flow and Water Power in the United States

\begin{tabular}{|c|c|c|c|c|}
\hline \multirow[b]{2}{*}{ Principal 'Drainages } & \multirow{2}{*}{$\begin{array}{c}\text { Drainage } \\
\text { AREA } \\
\text { SQ. MI. }\end{array}$} & \multirow{2}{*}{$\begin{array}{c}\text { FLOW PER } \\
\text { ANNUM } \\
\text { BILLION } \\
\text { CU. FT. }\end{array}$} & \multicolumn{2}{|c|}{$\begin{array}{l}\text { Horse Power } \\
\text { Available }\end{array}$} \\
\hline & & & $\begin{array}{l}\text { Primary } \\
\text { or } \\
\text { Minimum }\end{array}$ & $\begin{array}{l}\text { Minimum } \\
\text { of the Six } \\
\text { Highest } \\
\text { Months }\end{array}$ \\
\hline Northern Atlantio to & & & & \\
\hline $\begin{array}{l}\text { Cape Henry, Va. } \\
\text { Southern Atlantic to }\end{array}$ & 159,879 & 8,942 & $1,702,000$ & $3,186,600$ \\
\hline Cape Sable, Fla. & 123,920 & 5,560 & $1,253,000$ & $1,957,800$ \\
\hline $\begin{array}{l}\text { Eastern Gulf of Mex- } \\
\text { ico to Mississippi }\end{array}$ & & & & \\
\hline River. $\dot{\text { Gulf }}$ of & 142,220 & 6,867 & 559,000 & 963,000 \\
\hline $\begin{array}{l}\text { Western Gulf of Mex- } \\
\text { ico west of Vermil- }\end{array}$ & & & & \\
\hline í River main & ${ }^{1} 433,700$ & 12,232 & 433,760 & 829,650 \\
\hline str & $1,238,800$ & 21,940 & 147,000 & 335,000 \\
\hline $\begin{array}{l}\text { Mississippi River trib- } \\
\text { utaries from east }\end{array}$ & 333,600 & 12,360 & $2,472,590$ & $4,940,300$ \\
\hline $\begin{array}{c}\text { Mississippi River trib- } \\
\text { utaries from west } \\
\text { including Vermilion }\end{array}$ & & & & \\
\hline St. Lawrence River to & 905,200 & 9,580 & $3,948,970$ & $7,085,000$ \\
\hline Canadian line. . & ${ }^{2} 299,720$ & ${ }^{2} 8,583$ & $6,682,480$ & $8,090,060$ \\
\hline Colorado River, above & & & & \\
\hline Yuma, Arizona & 5,000 & 521 & $2,918,500$ & $5,546,000$ \\
\hline Point Bonita, Cal. . & (0, 00 & 2,193 & 3,2 & 300 \\
\hline Northern Pacific . & 290,400 & 15,220 & 12,9 & 24,7 \\
\hline $\begin{array}{l}\text { Great Basin } \\
\text { Hudson Bay }\end{array}$ & $\begin{array}{r}223,000 \\
62,150\end{array}$ & 614 & $\begin{array}{r}18,000 \\
75,800\end{array}$ & 212,600 \\
\hline Total & 4508,289 & 94,612 & $36,906,200$ & $66,449,310$ \\
\hline
\end{tabular}

By primary horse power is meant the amount which can be developed upon the basis of the flowage of the streams for a period of two weeks in which the flow is the least. Minimum available water power. According to the table, if all the installations in the United States were made to use as much of the water as is available the lowest two weeks of the year, and allow all the rest to escape without use, there would be developed 36,906,200 horse power; that is, approximately seven times the amount

1 Includes Rio Grande in Mexico.

${ }^{2}$ Includes drainage in Canada. 


\section{CONSERVATION OF NATURAL RESOURCES}

Possiblo water power available.

now produced. The primary power, according to McGee, " exceeds our entire mechanical power in use, would operate every mill, drive every spindle, propel every train and boat, and light every city, town, and village in the country." While this is true, because of the limited distance that power can be economically transmitted, it cannot be concluded that power produced by water can be more than partially substituted for power produced in other ways (see pp. 121, 124).

If wheels were put into the streams sufficient to use the water the highest six months of the year, there would be more than 66,449,300 horse power developed. Leighton believes that if the flood waters were stored, so that the streams were as fully utilized as practicable, it would be possible to develop in the United States 200,000,000 horse power. Others regard this estimate as too high and say $100,000,000$ horse power is nearer the truth. But even the smaller amount will furnish sufficient power from water to meet the needs of this nation for all purposes when the population of the United States is $250,000,000$ people.

When a century or two centuries hence the amount of coal has become much diminished in quantity, and has become higher in price, none may estimate the importance to the nation of this water power. Certain it is that in the future he who controls this $100,000,000$ or $200,000,000$ horse power controls the industries of the nation.

In this estimate no account is taken of the tides. Theoretically there is available in the tides a very large amount of power, but for the most part the head is small. Each day there are two periods of high and low water, with intervals of little or no flow; this results in extremely irregular heads and intermittent energy. These defects may be remedied to some extent by the use of storage batteries; but at best tidal installations to produce a large amount of power must be very expensive in proportion to the energy furnished. The difficulties in the use of the tidal flow for power are so great that at the present time there remain but a few small installations of this kind in the United States. 
It may be said that other sources of power will be developed which will render water power less dominant in its influence upon industrial development. For instance, there are available the power of the winds, and the direct energy of the sun.

The winds are a great source of energy which if entirely utilized would be extremely important. Wind power is extensively used for small installations, and especially for pumping water; but for large installations the wind has the irremediable defect that for any given place it is extremely variable. To some extent, this may be neutralized by batteries in which power may be stored to be used when the wind does not blow; but this will involve great expense. For these and other reasons, so far as we can predict, the wind cannot become a serious competitor of water for the production of power in large quantities.

Theoretically there is a possibility of using the direct energy of the sun as a source of power. This has actually been done in a small way in the arid regions where there is a large average of sunshine. But like the tides and the winds, the sun is not available as a continuous source of power, since upon the average one half of each day he is below the horizon. It is yet to be proved that the sun can be economically utilized as an effective source of energy in a large way.

Until very recently the development of water power was slow and the installations small. This was the situation because it was necessary to use the power derived from water near its source. But with the rapid development of the transmission of energy through electricity the radius of a water power has steadily increased. At the present time power in California is transmitted more than 200 miles, and in the case of the Central Colorado Power Company, 300 miles. Where such long distance transmission is practiced the rates that are charged are necessarily somewhat high. It is doubtful if power can be carried such distances as these in competition with power developed from cheap coal. If we suppose that the average of the present economic

Area tributary to large water powers. 
use of water were only 100 miles, a water power, if sufficient to do this, could serve more than 31,400 square miles, or nearly the area of Connecticut, Rhode Island, Massachusetts, New Hampshire, and Vermont. A radius of 200 miles would give an area of more than 125,000 square miles, or more than the states of Georgia and Wisconsin, or more than any one state in the Union save California, Montana, and Texas. A radius of 300 miles would give a subject territory of 270,000 square miles, or nearly one tenth of the United States. Thus, wherever there is a water power of sufficient magnitude, it may be available to millions of people. The value of their property is in a measure tributary to it.

With the extension in the radius of use, the magnitude of the installations and the size of the wheels have steadily increased. At the present time the average amount of water power developed per wheel is not more than 100 , but in some of the great new installations single wheels are being installed to develop 10,000 horse power and in a single plant 100,000 horse power or more. Doubtless in the near future the majority of the installations on the large streams will be of great magnitude.

\section{ADVANTAGES OF WATER POWER DEVELOPMENT}

It is clear that the advantages to the nation from the development of water power are almost beyond measure.

Water power and manufacturing industries.

Easy subdivision of electrical energy.

First, the development of water power is a factor of prime importance in obtaining leadership in the manufacturing industries of the world. There is no other large nation in a more favorable position as to available water powers than the United States. This great source of energy is by its cheapness a factor of prime importance in the industrial competition in the world.

Not only is electrical energy superior to all other forms for large installations, but it has an inestimable advantage over all others in its capacity for ready subdivision. It may be carried to the small shop, to the home, to the barn. Already in cities, where electrical energy is furnished cheaply, 
it is running the sewing machine, cleaning the floors, and doing other heavy work of the household. Similarly, on the farm, it may do much of the heavy work, both indoors and outdoors. For certain lines of industries, it may be the means which will keep them in the small shop instead of being concentrated in the large factory.

Not only is electricity destined to play a larger and larger Power rôle in the industries, but it is to furnish the power in increasing degree for transportation. The development of transporfrom water for tation by land through the railroad is the greatest of the revolutions of this modern age. Thus far, in this country, steam has been used almost exclusively for trunk-line railways; but already the era of railway transportation by electricity has been begun, and it is certain that it will rapidly extend. Some of the larger railroad companies of the West have acquired extensive water power rights in order to provide for transportation by electrical energy. With the extension of the range of electrical transmission of power has come the electrical railway, which has supplemented the steam railway. Already a network of such railways exists in the more densely populated parts of the country, as, for instance, much of New York, New Jersey, and New England, and is rapidly extending to other parts of the country. The street car in cities is almost altogether driven by electricity. A large amount of this electrical energy is now produced from water power and an increasing proportion is to be thus developed; for there are great economies with reference to the future in using the power of water directly rather than the wasteful methods of developing power from coal.

A qualification should perhaps be made in reference to the coal-producing regions. Along the Youghiogheny River in Pennsylvania, coal is so cheap that at the present time the manufacturer can obtain energy from this source at a lower price than he could by developing water power on that river. It is clear that in such cases as this the question of ultimate economy should be considered, but we must expect that the manufacturer will produce the power he needs in the cheapest way possible, "whether that be by the use of coal or water. 
Light

from water power.

Substitution of water power for that from coal.

Water power in Switzerland.

For light, electricity developed by water is the ideal solution of the problem; and not many years can elapse before light will be produced from water power wherever such energy is available within reasonable distances.

As coal becomes dearer in the future and is turned to other uses than the production of power, the predominance of one nation over another in manufactures and transportation will depend to a larger extent than at present upon water power. Indeed, this factor is likely to be more important than any other. It is plain that it is difficult to overestimate the extreme importance of water powers to the future progress of the nation.

At the present time in the United States $26,000,000$ horse power are developed by coal. It is believed by Leighton that $15,000,000$ horse power could be more economically developed by water, although he does not hold that the substitution to this extent can take place at once, nor that every unit of it will give an economic advantage. But he believes that, under existing conditions, with the present price of coal, at a fair rate of interest upon the capitalization, this substitution on the average would give an economic advantage of $\$ 12$ per annum per horse power, or $\$ 180,000,000$ a year. He bases this estimate upon figures furnished by the New York Water Supply Commission. But this is not the most important saving. Every time one horse power is developed by water, which is now produced by coal, at least ten tons of coal are saved; and therefore, if the $15,000,000$ horse power developed by coal be produced by water, there will be saved each year $150,000,000$ tons of coal in addition to the $\$ 180,000,000$ gained by the substitution. This is about one third of the output of the coal of the United States and this alone will greatly lengthen its life. The term "white coals" for water power is certainly appropriate.

Switzerland ' is likely to be the first country to gain fully the enormous advantages which come from the utilization of "white coal" for power and for light. In another place it is p. 151.

1 "The White Coal of Switzerland," F. C. Howe, Outlook, Jan. 22, 1910, 
pointed out that the national government has been granted authority to control the water for power (see p. 141). Already in that state "practically all of the street railways and the great bulk of the industrial energy now comes from water power." Also the railways which heretofore have had steam locomotives will derive their energy from water. Not only is electrical energy for light and power distributed to the large cities, but to the towns and villages, and even to the isolated farms. The loom of the lacemaker and the machine of the watchmaker in the home is being driven by electrical energy. Water-produced power even goes into the barn of the peasant. "Grain is being threshed, milk is being churned to butter, water is being pumped, food for the cattle is being prepared, and the farmer is being relieved of his most arduous labor."

\section{CONDITIONS FOR SATISFACTORY DEVELOPMENT}

In order that power from water be satisfactory and effective, the developed streams should maintain a uniform flow. If a stream has a flow which will develop 10,000 horse power for a small portion of the year and for the remainder only 1000 , it would be unwise to place an installation for much more than the minimum amount. Therefore the question arises, if water is to be fully utilized for power, how a uniform flow may be obtained.

Those who are not engineers, or have not studied meteorology, or geology, probably do not appreciate how unequal is the precipitation and how unequal the flow of streams. It not infrequently happens that the larger part of the precipitation of one year comes within two or three months; indeed, for large areas of the country this is the normal condition of affairs, and sometimes the major portion of the precipitation occurs within a few days. In a single great storm the larger part of the precipitation of one year may fall. The run-offs from these great storms produce floods. It will be appreciated that in consequence of the extreme inequality of rainfall most of the streams have a very uneven flow under natural conditions. It is therefore necessary to consider what shall be

Great variation in stream flow. 
Reservoirs promote uniform flow.
Natural reservoirs of the Niagara and the St. Lawrence.

done to hold back the storm waters and thus secure a uniform flow.

I agree with those who hold that a very important factor in accomplishing this is the retaining of forests at the headwaters of the streams. (For discussion of this point see pp. 245-252.) But the maintenance of the forests is not sufficient to equalize stream flow. While a forest will restrain the movement of water and will hold back for a long time an amount up to its absorptive capacity, this is not unlimited in quantity. And even when there is flood precipitation in excess of the absorptive power of the forest, it will still act as a restraining influence, and distribute the excess through a short time. Even a delay of hours is of the utmost importance so far as flood damages are concerned, but it is not adequate to maintain a nearly uniform flow. Hence it is necessary to supplement forests by reservoirs, at the headwaters of the streams, which will store and hold the excess of storm waters until they can be utilized. This is one of the great improvements now before our people.

Before considering reservoir extensions it may be advisable to give illustrations of streams with natural reservoirs. The great examples of streams having lake reservoirs are Niagara and the St. Lawrence, the former having a reservoir area of 88,660 square miles, and the latter 95,660 square miles - areas not equaled by the reservoir systems of any other streams in the world. The maximum flow of the Niagara is about 35 per cent more than the minimum, of the St. Lawrence $\mathbf{5 0}$ per cent. As compared with ordinary streams this is a wonderful approach toward uniformity, and this on streams of enormous size. It is not surprising that there should be strong pressure to develop the power at Niagara.

The river that never changes.

Another stream which has a uniform flow, due mainly to the slow melting of the snows upon the mountains, and to underground storage, rather than to surface reservoirs (although it does have along its headwaters a number of lakes) is the Deschutes of Oregon. This stream and all of its numerous western branches rise in the lofty plateau and high mountains of the Cascade range, upon which great quanti- 
ties of snow fall each year to melt slowly and uniformly during the summer. Also, the Cascades are built of volcanic rocks which are broken and porous, and are capable of absorbing great quantities of water and slowly emitting it in springs. The result is that the Deschutes is referred to by those who live along its banks as "the river that never changes." It has a drainage area of nearly 9000 square miles; it has a fall from where it is large enough to be used for water power to its mouth of over 3000 feet. According to I. N. Teal, chairman of the Oregon Conservation Commission, it is capable of developing a million horse power, - over three times that at present developed at Niagara Falls. Unfortunately, a large part of the power of this river is unavailable because of the construction of two railroads in the cañon of the Deschutes. The water power sites of this stream are all within 100 miles of Portland. When in the future these railroads are displaced and the water power developed, no one can measure what this shall mean to the development of that eity.

These wonderful streams, the Niagara and Deschutes, are given as illustrations of nearly ideal conditions for water power furnished by nature itself. But for the great majority of streams such conditions do not exist. They present the problem of producing artificially a uniform flow. The solution of that problem lies, aside from the maintenance of forests in essential areas, and so carrying on agriculture as to get into the ground the largest possible percentage of the precipitation, in the building of reservoirs.

Reservoir systems have been established in the arid region, in the Upper Mississippi Valley, and in the northeastern part of the United States. I have already said that the people Extent of reservoir systems. of the arid region have a much higher appreciation of the importance of water than those of the humid region. It is therefore natural that in this western region where water is so valuable, and where its use is so necessary not only for water power but for irrigation, that extensive reservoir systems should have been constructed to save the storm waters. Many millions of dollars have been spent for this purpose in the West by private parties and by the government, primarily with 
Reservoirs in areas of glacial deposits.
Cost of an Ohio reservoir system.

reference to irrigation and subordinately with reference to water powers.

In the humid regions there has not as yet been an extensive development of reservoirs, but it is certain that in the future the people of these regions will follow the example so well set by the inhabitants of the arid country. To the present time reservoirs in humid regions have been mainly confined to the Upper Mississippi Valley and to the northeastern part of the United States.

In Minnesota reservoirs of large capacity have been constructed by the government with reference to the navigation on the Mississippi. These reservoirs have a present capacity of $96,000,000,000$ cubic feet, and it is planned to extend them so as to store $175,000,000,000$ cubic feet. Incidental to the development of navigation, the water powers from Pokegama Falls to St. Paul have been greatly improved and their value largely increased. By the board of engineers appointed to investigate the matter, the direct value of the reservoir system to present and prospective mill interests for that distance, is placed at $\$ 500,000$ per annum; but it is added that a large proportion of this benefit is conferred upon the general public.

On the headwaters of the Wisconsin River an important series of reservoirs, sufficient to store not less than $2,000,000,000$ cubic feet of water, have been built for equalizing the flow for water power purposes. In New York and New England a series of reservoirs have been developed or proposed, which Leighton estimates are adequate to care for 10 per cent of the surplus storm waters. It is to be noted that both of these regions are a part of the great area of the recent glacial drift upon which are numerous ponds, lakes, and meandering streams. In such regions it is possible to construct a system of reservoirs of large capacity with a minimum expenditure of money.

In other parts of the East the conditions are very different and the expense far greater. Leighton has studied the Ohio with reference to the necessary reservoir system to control floods and develop navigation. This stream has its headwaters in the mountainous region. The Alleghany, the Mo- 
nongahela, the Cumberland, and the Tennessee are the principal tributaries. He estimates that an adequate reservoir system will cost $\$ 125,000,000$; but he does not insist that this estimate is accurate; it may be too small. He thinks that there will be a possible additional water power in consequence of such reservoirs amounting to 110,000 horse power, which if developed would yield $\$ 20$ each per annum. This would give an income of $\$ 2,200,000$ per annum, of which probably one fourth, or $\$ 550,000$, would be profit. If this amount were capitalized at 5 per cent, it would represent $\$ 11,000,000$. This amount is sufficient to pay only a fraction of the cost of the reservoir system; and clearly, if the investment be made, it must be on the basis of other advantages which are to accrue in addition to water powers (see pp. 181-184).

In order that reservoirs shall be effective, it is very necessary that forests be preserved on the headwaters of the streams feeding them. Otherwise the great quantities of silt brought down at times of flood rapidly fill the reservoirs with débris. Reservoir systems can only be successful when in conjunction with forests. Thus the maintenance of uniform flow and the controlling of floods does not depend upon forests alone, nor upon reservoirs alone; it can only be successfully solved by their combination.

\section{VALUE OF WATER POWER}

The question of the value of water power is a complicated one and no general statement can be made which applies to the country as a whole. The value of a power depends upon the cost of construction per horse power developed, distance to market, nature of the market, and many other factors. Such facts will be presented as are available as to the cost of developing power in the various parts of the country and the profits which are derived from the same.

According to the reports of the Ontario Hydro-Electric Cost of Power Company, power is produced at Niagara Falls at about $\$ 10$ per horse power per annum. In this cost are included op- Niagara. erating expenses, maintenance and repairs, depreciation and 
Cost of steam power.

Price of power in East.

interest at 4 per cent upon the capital invested. That is, the entire cost of the maintenance of the plant, plus 4 per cent interest on the capital invested, may be secured if power is sold at the astonishingly low rate of $\$ 10$ per horse power per annum. The Niagara is a large installation, under very favorable circumstances; and it may well be that in installations of moderate size, and under less favorable circumstances, the annual cost per horse power, including interest on capital, may be double this amount for the eastern part of the United States and even more than this in the western region.

The lowest estimate of cost per horse power from steam in large installations is $\$ 15$ per annum, and from this it varies to four times this amount, and for smaller installations is even more than this.

In discussing the question of expenditure warranted in developing water power, it would be advantageous to know the cost of production for the various plants of the United States from which an average could be obtained. Data, however, are not available for such an estimate, but it is pretty safe to say that upon the whole, power is not being sold anywhere on a large scale cheaper than it is produced. Thus, if we have no exact information as to reasonable rates we have a base which is high enough.

In New York State, where fuel is comparatively cheap, power is supplied from hydro-electric plants at the rate of $\$ 20$ per horse power per annum, with 24 -hour service. In North Carolina and South Carolina water power is furnished at the rate of $\$ 15$ per horse power per annum with 66-hour service per week, which corresponds with $\$ 38$ on the basis of continuous service. It is probable therefore that in the humid glacial regions of America, which include New England, New York, and the Middle West, \$20 per annum per horse power at the plant will on the average pay expenses and depreciation and give a good return on the investment. In the Appalachian district, south of the glacial drift, to construct reservoirs is more expensive, and the cost per horse power is greater on the average than in the glacial region."

In California the rate for even the largest consumers is 
$\$ 40$ per annum per horse power, and small consumers often pay more than twice that amount. It is rather safe to say that such charges give large profits.

According to Mead, the cost of installing water power plants varies from $\$ 40$ to $\$ 300$ per horse power, the first on exceptionally cheap high-head plants with power delivered at the wheel shaft, and the latter on low-head plants with electrical equipment and long distance transmission with power delivered at the substation or at the consumer's switchboard. Operating expenses are also relatively much higher per horse power on small plants than on large ones. Therefore it is not possible to make any general statement with reference to the cost of producing power by water which will be applicable to individual cases, and the broad statement below made must be considered as a rough approximation of the minimum value of water power rather than a statement which can be applied in a given instance.

The New York Water Power Commission estimates a saving over steam in the state of New York by the development of additional power through reservoirs at $\$ 12$ per annum. ${ }^{1}$ If upon the average we estimate this saving for the country as a whole at only one half of this, or $\$ 6$ per horse power per annum, and this seems conservative, the wealth gained each year by the substitution is five times the number of horse power used. For the 5,000,000 horse power now developed, this would be a saving of $\$ 30,000,000$ a year, which if capitalized at 5 per cent would represent a value of $\$ 600,000,000$. If $15,000,000$ additional horse power were substituted for steam power, and this is likely to be possible in the near future (see p. 124), this would result in an annual saving of $\$ 90,000,000$, which would give a 5 per cent income on $\$ 1,800,000,000$. These figures are presented to show that even on the most conservative basis, making all the assumptions as to the saving being a minimum, very large expenditures are justified in the development of the reservoir system of the country even for the purpose of water powers alone, without any consideration of the other

${ }^{1}$ Fourth Annual Report, N. Y. State Water Supply Commission, p. 234.

Saving by substituting water for steam power. 
Calculated profits in Illinois.

Extension of hydroelectric power.
Calculated profits at Muscle Shoals.

benefits which may come from the development of storage reservoirs.

The above calculations, which seem to warrant large investments for the development of water power, may be illustrated by one instance. It is proposed in the state of Illinois to extend the drainage canal of Chicago so as to make a fourteen-foot channel to the Mississippi River along the Illinois River at an estimated cost of $\$ 20,000,000$. Incidental to this development the state will produce 140,000 horse power, of which 100,000 horse power will certainly belong to the state. It is estimated that at the outset this will have a value of $\$ 25$ per horse power per annum, and thus will yield an annual income of $\$ 2,500,000,-$ a sufficient amount to extinguish the debt with interest in seventeen years, with a surplus of $\$ 167,000$. After that time it is estimated that the annual net earnings of the water power alone will be not less than $\$ 2,750,000$, which at the rate of 5 per cent is equivalent to a paid-up capital of $\$ 55,000,000$. This will represent the gain to the state from the project at the end of the seventeen years in addition to the great saving each year in freight rates and increased commerce,- the primary purposes of the improvement (see p. 161).

The profits from water power have resulted in the rapid extension of hydro-electric installations. The census bureau estimates that during the years 1900 to 1905 the increase of electric power was 270 per cent, of which much the larger part unquestionably has come from water. Localities having large water power have great advantages in commercial development. This is illustrated by Buffalo, which receives some 40,000 horse power from Niagara Falls, one half of which goes into industrial and manufacturing enterprises. The recent extremely rapid growth of that city has been largely due to this fact.

Another illustration is that of Muscle Shoals on the Tennessee River. ${ }^{1}$ According to Newell, at this locality there may be developed a minimum net horse power for the driest years of 51,000 , and for the average year 99,875 . According

'Electrical World, Vol. III, pp. 1397-1398. 
to Ball, if this power be developed and delivered to the districts where cheap coal is available, as, for instance, Birmingham, Alabama, allowing for all proper charges, including depreciation, "the saving in favor of the water power would be 60 per cent."

Other benefits from the development of reservoirs are not less important than for powers. Some of these are the improvement of navigation, reduction of flood losses, decrease in denudation, and irrigation. These aspects of the subject are subsequently treated.

\section{THE CONTROL OF WATER POWERS}

Water powers should be controlled by the public; I do not say owned or operated by the public. The elastic word "controlled" is used because the amount of control which is advisable or necessary is different in different cases. The North American Conservation Conference of 1909, composed of commissioners from the United States, Mexico, Canada, and Newfoundland, agreed unanimously upon the principles which should obtain as to the control of water powers. Therefore these principles may very well serve as a starting point in the discussion of the subject. "We regard the monopoly of waters," said the commissioners, "and especially the monopoly of water power, as peculiarly threatening. No rights to the use of water powers in streams should hereafter be granted in perpetuity. Each grant should be conditioned upon prompt development, continued beneficial use, and the payment of proper compensation to the public for the rights enjoyed; and should be for a definite period only. Such period should be no longer than is required for reasonable safety of investment. The public authority should retain the right to readjust at stated periods the compensation to the public and to regulate the rates charged, to the end that undue profit or extortion may be prevented.

"Where the construction of works to utilize water has been authorized by public authority and such utilization is necessary for the public welfare, provision should be made

Public control of water powers. 


\section{CONSERVATION OF NATURAL RESOURCES}

for the expropriation of any privately owned land and water rights required for such construction."

The principle of public control of waters was more concisely expressed by the Fourth Lakes-to-the-Gulf Waterway Convention, held at New Orleans, in 1909, to which convention there were over 500 accredited delegates, representing forty-six states of the Union, and including a majority of the governors, the President and Vice President of the United States, several members of the Cabinet, and a large number of senators and representatives. The representatives of the convention declare "that the waters belong to the people, and maintain that this right of the people is inherent and indefeasible; and while recognizing the necessity for administering this invaluable possession of the people by state and federal agencies, each within its appropriate jurisdiction, we deny the right of municipalities or of state and federal governments to alienate or convey water by perpetual franchises or without just consideration in the interests of the people." The same declaration of principles was made by the First National Conservation Congress at Seattle, and the Seventeenth National Irrigation Congress at Spokane, both held in 1909 .

Principle upon which

What is the fundamental principle upon which these public control based. declarations are based? It is that a resource which originated from a wide area, but is available at a particular point, is the property of all the people concerned. To illustrate, the area of the Great Lakes, excluding Ontario, is 88,360 square miles, and the areas of their drainage is 241,560 square miles. The rainfall of this vast region escapes from Lake Erie through the Niagara River. At one place, Niagara Falls, the water is available for the development of enormous power. Is the position to be taken, if it so happened that the adjacent lands were owned by private parties, that in consequence of this fact they own the water power, for which they paid nothing, and which if they were allowed to develop fully would be worth incredible sums? The answer is clearly in the negative. If this be the correct answer in reference to Niagara Falls, the same principle 
applies in the case of lesser streams which may have drainage areas of only a few hundred or a few thousand square miles, but which are available for the development of power at only a few favored sites.

It is clear that originally the public owned the water powers. In certain localities by law or by judicial decision they have been allowed to pass into private hands. In all cases they should be subject to public control. What are the advantages which come from such control? Some of them are as follows: -

First, public control is necessary to secure reasonable charges.

Herbert Knox Smith, Commissioner of Corporations, states that already a large proportion of the water powers, especially the best and largest ones, are owned by a few corporations. He says that the General Electric Company controls at least 250,000 horse power and partly controls 420,000 more; that the Westinghouse Company controls absolutely 180,000 horse power, and partly controls 100,000 additional; that eleven other companies control 875,000 horse power, - making a total in the control of thirteen companies of $1,825,000$ horse power, or more than one third of the entire development of the United States. Not only do these companies control adjacent powers, but by a system of coupling up they obtain a high state of efficiency. Since it is advantageous to have the power uniformly used and the calls for the maximum amount of power occurs at different times in different places, by coupling up a large number of plants a much higher average use of the power is possible than if each plant were separately operated. This concentration is economically advantageous. Therefore, conservation requires us to encourage concentration and coupling in order that we may get the greatest efficiency of the water. But if we permit this, the users can only be protected by public control. Hence the conservation principles with reference to water powers are concentration and public control.

In connection with this question of concentration another principle is to be considered. While there may not be

Consolidation of water powers. 
District monopoly possible.
Speculative control of undeveloped water power.

monopoly now, or in the near future danger of monopoly, for the water powers of the United States as a whole, there is now at various localities monopoly for individual districts. The distance to which power can be economically transmitted is limited. It has been said that the usual maximum is now not more than two hundred miles. Therefore if a given company controls all the good water powers within a certain radius, power from other waters cannot compete because of the cost and loss of long distance transmission. If a company, or a community of companies, has the water power of a district, it has a monopoly for that district. As illustrating this principle, I quote Herring, ${ }^{\prime}$ of the United States Forest Service, in reference to the conditions which obtain in the West. He says that already in the northwest, "Owing to the low cost of power and the distance to which it can be transmitted, such sites" (that is, sites for water powers) "are in demand and it is almost impossible at the present time to find a suitable site within a reasonable distance of a market for such a plant in the northwestern states, or on the west side of the Sierra Nevada Mountains, which has not already been appropriated."

Also Herring says in reference to California: "On four of the rivers in northern California, where there is a possible development of over 800,000 horse power, only 20,000 has been actually utilized, while speculative water rights are held on these streams from which over 566,000 horse power could be developed; or in other words 75 per cent of the power possibilities on these streams have been alienated from public ownership and less than 2 per cent utilized for useful purposes."

"The extent to which the control of such plants is passing into the hands of a few of the larger companies is also well illustrated in California, where four of the largest companies have a combined capital of $\$ 55,000,000$ and operate 30 hydroelectric plants and 18 steam plants. The largest one of these companies supplies power to 26 individual lighting com-

1 "Applications of Water Power," by W. E. Herring. Preliminary Report Inland Waterways Commission, 1908, p. 448. 
panies and 12 electric railway companies, in addition to a number of cities and towns where it has its own substations."

Thus it is plain we cannot wait until it is proven that monopoly of water power exists in the United States or even in a state. Each district has to be considered by itself, and the facts ascertained as to whether or not in it there is monopoly.

Therefore, the economic advantage which comes from Public large holdings and from coupling, combined with the fact that monopoly of water power does already exist in various parts of the country, and is likely to exist elsewhere in the control necessary to secure near future, make it absolutely necessary for the public to control the prices which may be charged for water power. The companies must not be allowed to decide the rates which they levy. If this be done extortion will be practiced.

Second, if the argument given on pp. 133-135 is sound, that the use of water for power is a public right, a tax should be levied when a franchise is granted to develop a power in fair price. order that the entire people may gain the advantage of a national or state resource. It has sometimes been said that the control of rates through a public utility commission, or in some other way, is sufficient; for under such circumstances the company developing a water power could be prevented from gaining more than a reasonable profit. This is true, but if no franchise tax be charged the advantage of a great resource will go wholly to those who develop and utilize it, not to the people as a whole. The waters which flow through a single stream may have fallen upon an entire state or even on several states. The waters in the streams belong to the nation and to the states except so far as they have parted with them. Hence a franchise tax upon the companies that develop power belonging to the states is equitable and just. Where there is adequate public control, whether or not such a franchise tax is charged is of no consequence to the company. If such a tax be levied it is a just charge which must be taken into account in fixing the rates. This additional charge is imposed upon the consumer. The consumer who gains the advantage of the

Tax on water powers fair. 
Public control and full development.

Public control of reservoirs. cheap power resulting from a natural resource can well afford to pay the franchise charge to the state, and thus in a measure distribute the advantages of a great natural resource. Third, under public control each stream may be so handled that full development of its water power may be secured. Not infrequently it happens that when private parties locate dams here and there, as their interests may require, the locations are not such as to give complete development. Therefore, before any franchises for dams are granted on any river, a careful investigation of the entire stream and all its tributaries should be made by competent engineers, and the sites and heights of dams at each site be designated in order that full efficiency of that stream system may be developed with the smallest expenditure of capital. This is only possible through public regulation.

To illustrate: There may be a possible water power site where A. B. is the riparian owner. There may be another site on land below owned by C. D., the full development of which would back the water so that the power site on the land of A. B. is worthless. In this case, whether there shall be one or two water powers developed, should be determined by the resulting economy and efficiency. If concentrating the full possible power of the two sites at the lower one will give the best results, this should be done.

In order that there shall be full development, it is necessary that there be public control of the reservoir sites; for, as has been shown (pp. 128-129), this is only possible by the use of reservoir systems. Since the benefits of a reservoir on the headwaters of a stream are not for one power simply, but for all the water powers below, one owner or operator cannot afford to construct the reservoir. And for the full improvement of a stream system the problem is not the construction of one reservoir, but often many reservoirs situated on different branches. Moreover, the drawing of the water from these reservoirs must be considered as one complex problem in order to give as nearly a uniform flow as possible to the different water powers below. Hence the construction and operation of a system of reservoirs on 
a river system must be a unit from the headwaters" of the many branches to the lowest place at which water may be used for power. Even with reference to water powers alone this can only be accomplished by government or state control.

But in the humid regions reservoirs are constructed and operated not only with reference to power, but with reference to navigation; and navigation is under the control of the government. As an illustration may be mentioned the Mississippi River, the headwaters of which are in Minnesota and Wisconsin. The existing reservoirs in these states have been in part constructed with reference to navigation and in part with reference to water powers (see p. 128). For such a great system of reservoirs the only agency which can satisfactorily control the manner of drawing off the water from the different storage sites and adjust the charges proportionally to the benefits, is some public authority, the nation or the state, or the two in coöperation.

It will be seen (pp. 149, 173) that already the government Public has applied the principle of ownership of reservoirs both with reference to navigation and with reference to irrigation; and recently the Secretary of the Interior, with reference to water powers, has recommended that all remaining reservoir sites upon the public domain be reserved permanently as the property of the nation.

Fourth, the public has the right to require that those who control water power resources shall develop them on a scale sufficient to meet the needs of the people.

Without public control, water power sites may be acquired and held indefinitely without development, the purpose being to prevent the competition of others, or to gain monopoly for the district. It has been stated that in California on four rivers holding companies have sites capable of developing 566,000 horse power, on which only 20,000 horse power have been developed; and yet in that state an extremely high charge is made for power sold (pp. 130-131).

In the California case, each decrease in rate will increase the amount of power used. Increase in the amount of

ownership of reservoirs.

Public control secures adequate development. 
Public control necessary for public safety.

power used will result in larger and therefore more economical installations. Thus there is action and reaction. This should continue until there is the largest development of power economically possible at the lowest reasonable rates.

Many cases could be cited where a water power is not fully developed, and a great excess of water is flowing over the dam unused, while a high rate is being charged for power furnished. The public may require as a condition of a franchise that construction shall be begun within a reasonable period and that the power shall be developed as rapidly as it is needed and at a reasonable rate.

Fifth, an additional reason for public control is public safety. I need only to call your attention to the Johnstown disaster, which resulted from the break of a dam too weak to hold back the waters at the time of a flood. A reservoir was built on the Little Conemaugh River above Johnstown, capable of storing $480,000,000$ cubic feet of water. This reservoir, after belonging to the state and to the Pennsylvania railroad, was sold to the South Fork Hunting and Fishing Club of Pittsburg. In May, 1889, there was a flood rainfall upon the headwater of this stream from 2.5 to 7.8 inches. The spillways of the dam had been somewhat obstructed by screens placed across them to prevent the passage of fish. When the flood came the dam broke and a great mass of water, estimated in height at thirty feet, passed down over the various towns above Johnstown, and so on to that city. Some towns were entirely destroyed, and it is estimated that 30 per cent of the inhabitants of Johnstown perished. While the loss of life was never known, it was estimated at the time from 10,000 to 18,000 . The loss of property has never been accurately estimated, but it was certainly many millions of dollars. Merely to clear up the débris, covering some thirty acres above the masonry bridge of Johnstown, required three quarters of a million dollars.

It has sometimes been said that public control of dam construction is unnecessary, since the parties building the dams should be responsible for the resulting damage. Is it 
likely that the South Fork Hunting and Fishing Club of Pittsburg was responsible for one hundredth part of the damage to property which resulted from the broken Conemaugh dam, saying nothing of the appalling loss of life? Therefore it is not sufficient to say that those who built dams are responsible for them. Every dam which is constructed in such a position that if it breaks, its loosed waters will menace life and property, should have the approval of a state engineer. Only so are we even reasonably safe. It is natural for those furnishing capital to desire a large return on their investment. They, therefore, sometimes take a chance and in the construction introduce too small a factor of safety. Under public control it would be the duty of the state engineer to introduce a sufficiently large factor of safety so that the greatest flood which will come shall not carry away the dam and thus destroy life and property below. It is an imperative necessity to the safety of the people that the control of water powers rest with the public.

Now that the reasons have been presented for public control of water powers, facts will be presented as to the extent to which such control has been assumed.

\section{Control in Foreign Countries}

In the Province of Victoria, Australia, water may be diverted only by license. The licenses are for a limited period and the charge is apportioned to the amount diverted and its value to the user. Upon the average for the development of hydro-electric power the franchise charge is $\$ 5$ per horse power per annum.

In New South Wales the government retains the ownership of a strip of the land sixty-six feet wide along all the water fronts. Thus this country not only retains the water but the riparian rights. Hence it owns the water absolutely for all purposes, water supply, water power, irrigation, navigation, fishing, etc.

In Switzerland, in 1908, an amendment to the constitution was adopted, granting to the federal government con- 
Public control in Switzerland.

trol of franchises to utilize water powers. Under this act the federal Congress regulates "the disposal and terms of water right concessions, as well as the transmission and delivery of electrical energy, so far as the protection of public interests and the proper development of these resources require such regulation." Where federal interests do not require regulation the water is under the jurisdiction of the cantons. But whether it be by the federal government of Switzerland or by the cantons there is public regulation including a franchise charge.

According to Howe, fully 70 per cent of the power generated in Switzerland is either owned by public authorities or is under public control through ownership of stock in the operating companies. At the present time the cities and cantons are constructing for their own use and for distribution very large installations, one of them being expected to develop 60,000 horse power.

Public control in France.

In France ${ }^{1}$ streams are divided into two classes, navigable and non-navigable. The navigable streams belong to the public domain and therefore the nation has the entire disposition of the water. It grants permission to develop hydraulic plants and to use the water for other purposes upon a rental. The right of the use of water for the development of hydraulic power on non-navigable streams is recognized as belonging to the riparian. The bed of such water courses belongs to the proprietors. In this respect French law is like that of Wisconsin (sce p. 158). Various bills have been proposed to regulate the development and use of hydro-electric power on non-navigable streams by concessions and payments for the use of the power, but as yet no such law has been enacted.

Public In Italy ${ }^{2}$ under a law of 1884 concessions are granted for control in Italy. the development of water power, which concessions include "the conditions of diversion, withdrawal, use, and restoration of the waters, the rental, etc." A concession cannot

1" The Public Utility of Water Powers and their Governmental Regulation," by René Tavernier and Marshall O. Leighton, Water Supply Paper 238, U. S. Geol. Survey, pp. 74-92.

${ }^{2}$ Loc. ci., pp. 46-47. 
be granted for a period greater than thirty years, but may be renewable in favor of the first concessionaire for another period of thirty years. The rentals are fixed at three francs per horse power per annum for industrial diversions.

For a large part of Ontario a strip of land four rods wide Public along the water fronts is reserved to the government. However, I am informed by Frank Denton, Esq., of Toronto, control in Ontario. that in some parts of the province, and particularly where the townships are small, i.e. six miles square, no reservations have been made. Apparently there is no easy explanation of why reservations have been made along water fronts in parts of this province and not in others. So far as such rights have been retained, and this is true of a large part of the province, the situation with reference to riparian rights is exactly the same as in Victoria, - the waters are public for all purposes.

In 1907 the legislative assembly of Ontario passed the power commission act to provide for the transmission of electrical power to municipalities and creating the hydroelectric power commission of Ontario. This commission has authority to appoint engineers, accountants, a secretary, and other officers as may be necessary. It has authority to expropriate water powers which have already been developed. It may operate water powers. It may furnish power to municipalities; and municipalities may in turn use the power for heat, light, and power, and may sell power to private parties. The commission may contract with railways for distributing power, or for right of way. It may charge for power sufficient to pay for the cost of operation, maintenance, repair, and renewing, for forming a sinking fund sufficient to extinguish the capital account in thirty years, and to pay interest at the rate of 4 per cent on the money invested: to carry out the provisions of the act the lieutenant governor in council may loan money on the credit of the province. There is no limit to this authority.

By an order-in-council of the government of Ontario, January 16,1907, general regulations were made as to the 


\section{CONSERVATION OF NATURAL RESOURCES}

control and development of water powers, exceeding 150 horse power at their average low stage. Under this order the right to develop water powers may be granted to private parties. The locations and all plans and specifications in reference to same are to be fully approved by a competent engineer satisfactory to the minister of lands, forests, and mines. No lease shall be granted for a longer term than twenty years, with privilege, however, of renewal for two successive terms of ten years each. For leases, rentals are fixed by the minister. The rights of running logs, fishing, and navigation are fully protected. Power must be developed within a definite period to a specified portion of the energy available. The rates which may be charged other parties for power are controlled by the hydro-electric commission. At the expiration of the lease, the property, with all permanent improvements, excluding machinery, becomes the property of the crown; provided, however, that if the province makes appropriations therefor, the hydro-electric commission may pay the lessee by way of compensation such sums as they may deem proper for such improvements. Non-payment of rental for ninety days, or neglect to operate or produce power for one year, may result in cancellation of the lease.

Even the above does not give the full provisions for the control of water powers in Ontario; but the summary made is sufficient to show that the principles advocated by the North American Conservation Conference are there fully applied. In the handling of water powers, the people of the province of Ontario have shown greater wisdom than the majority of the states of the Union.

\section{Control in the United States}

In treating public control of water powers in the United States it is advisable to mention the origin of the public rights in navigable streams. This information I have derived from a brief furnished by Professor E. A. Gilmore, of the Law School in the University of Wisconsin. 
In England, tidal waters are public waters, and public for all purposes. Since in England few streams that are not tidal are navigable, tidal waters and navigable waters are Law of public usually interchangeable terms. But in those cases, where waters not tidal are navigable, it has been held that in fact the test as to whether waters are public is their navigability. The common law of England passed to this country. Here are numerous large streams which are navigable and not tidal. Consequently the modification in the principle of tidal waters above given is of fundamental importance. It has been held in this country that waters which are in fact navigable are public waters, are a part of the community or collective property of the state or nation.

It is held by Gilmore that the fact that the public waters have been mainly used for navigation, fishing, and ice does not prevent them from being public for other purposes. Only recently has there been great development of hydroelectric power; hence the attention of the people has not in the past been directed to this use of the water. They are now claiming this use as a public use, whereas heretofore such use has been often by private parties without public control. Hence differences of opinion have arisen as to the extent of the public right in water. Those following to its logical conclusion the common law hold that the development of hydraulic power on all navigable streams may be held to be a public use and may be controlled by the public. Now, how far has this theory been applied?

\section{Control by the United States Government}

The United States Constitution gives Congress the right to regulate interstate commerce, and this involves the complete control of navigation.

Charles Edward Wright, ${ }^{1}$ assistant attorney of the Secretary of the Interior, holds that under this right, where the gov-

1 "The Scope of State and Federal Legislation concerning the Use of Waters," by Charles Edward Wright. An. Am. Ac. Pol. and Soc. Sci., Vol. XXXIII, pp. 566-582. 
General law of United States as to dams.

ernment produces a water power for the improvement of navigation, "it owns what it produces, and it may sell or lease the right to utilize its creature."

Mr. Wright goes farther and holds that the control of navigation empowers the government to do anything necessary in order to secure the conditions for navigation, including if necessary the control of the headwaters of navigable streams, the building of dams upon them to make reservoirs, as well as building dams upon main streams.

Special acts by Congress, permitting the construction of dams across navigable rivers, are subject to a general act, ${ }^{1} 1906$, which places the control of the construction in the charge of the chief of engineers, giving him power to protect all the public interests of navigation, fisheries, etc. "In approving said plans and location, such conditions and stipulations may be imposed as the chief of engineers and the secretary of war may deem necessary to protect the present and future interests of the United States."

The law contains the very important provision "that the right to alter, amend, or repeal this act is hereby expressly reserved as to any and all dams which may be constructed in accordance with the provisions of this act, and the United States shall incur no liability for the alteration, amendment, or repeal thereof to the owner or owners or any other persons interested in any dam which shall have been constructed in accordance with its provisions."

Under this general act seventy-eight special acts have been passed. ${ }^{2}$ It appears probable that if Congress in the future decides to permit the construction of dams only as an incident to navigation with the condition that a charge be made for the privilege, this may be done.

An act approved March 3, 1909, provided for the acquiring by the government of water powers already developed at Sault Ste. Marie, Michigan, and authorizes the Secretary

${ }^{1}$ U. S. Rev. Stat., Ch. 3508, Vol. 34, p. 386.

2 "The Public Utility of Water Powers and their Governmental Regulation," by René Tavernier and Marshall O. Leighton, Water Supply Paper 238, U.S. Geol. Survey, p. 125. 
of War to lease the water powers developed, with the provision "that a just and reasonable compensation shall be paid for the use of all waters or water powers now or hereafter owned in St. Mary's River by the United States, whether utilized in said river or in any lateral canal, such compensation to be fixed by the secretary of war."

Also under the same act the Secretary of War "is authorized and empowered to grant leases or licenses for the use of water power created by the government dam on the Wabash River at Mt. Carmel, Illinois, at such a rate and on such conditions, and for such periods of time, as may seem to him just, equitable and expedient, the said leases or licenses to be limited to the use of the surplus water not required for navigation and for a period not exceeding twenty years; and he is also empowered to grant leases and licenses not exceeding twenty years for the occupation of such land belonging to the United States on said river as may be required for millsites or other industrial purposes, not inconsistent with the requirements of navigation." The moneys collected from such leases or licenses go into the United States treasury.

According to the chief of engineers, in 1908 power generated on government dams was sold to the amount of 3243 horse power, the revenue derived from the same being some $\$ 5600$. The power sold is principally on the Muskingum, Green, and Kentucky rivers, in the Ohio Valley. ${ }^{1}$

We thus see that the principle of payment for water power on navigable streams has been put into force by the United States government in reference to dams and water powers which it creates as an incident to navigation.

The acts above cited leave open the question as to whether the United States government can make a charge for the use of water power on a navigable stream when the dams and improvements are made by private parties. Upon this point Attorney-general Wickersham, in an opinion recently given, holds that under the act of June 21, 1906, the chief of engi-

Sale of

water power developed as incident to navigation.
Law does not authorize charge when dam constructed by private parties.

1 "The Public Utility of Water Powers and their Governmental Regulation," by René Tavernier and Marshall O. Leighton, Water Supply Paper 238, U.S. Geol. Survey, p. 137. 
Power of Congress to impose franchise charge. neers and the Secretary of War are not authorized "to require as a condition to a license for the construction of a dam across a navigable river the payment of a sum or sums by way of compensation for the privilege granted, although they may require such payment or assumption of expenses as are necessary or proper to insure the navigability of the stream." This opinion was given in reference to a proposed dam at Prairie du Sac on the Wisconsin River.

The opinion of the attorney-general does not cover the point as to whether Congress may impose a franchise tax upon water powers developed on navigable streams by private expenditure. The opinion simply holds, that under the law of 1906, Congress did not contemplate such charge.

The possibility that Congress may in the future make a charge for the use of water power which is developed by the investment of private capital is foreshadowed by an arrangement made in reference to the construction of a dam at Rainy River, Minnesota. In 1908 a bill was passed by Congress extending the time of construction of this dam, the owning company having agreed in advance that the chief of engineers should emboly the following conditions and agreements in the approval of the plans and specifications of the company:

"First, such reasonable limitations as to the time for such grant as the Secretary of War shall impose, conditioned that the United States shall not be subjected to any expense in the removal of such or any obstruction or improvement caused by said company either at the expiration of said grant, or at any other time that the United States may direct the same to be removed.

"Second, that the said Rainy River Improvement Company has agreed and will agree to the payment of such charge to the United States as may be required by the Secretary of War, either under the present law or as may be hereafter determined by authority of Congress.

"Third, that this grant is expressly made subject to any impositions hereinafter authorized or directed by Congress embodied in any general law or special modification or change

' H. R. 60th Congress, 1st Session, Report No. 1767. 
of this or other Acts, and that a special reservation to this effect shall be an essential part of such approval of said plans by the Secretary of War and Chief of Engineers.

"Fourth, that any application of said company for the approval of its plans and specifications whenever made, shall be agreed by said parties to be within the purview of a part of and as authorized by the pending act of Congress whenever the same shall become a law; and that all the provisions of the approval of the Secretary of War and Chief of Engineers to said plans and specifications and all conditions as a part thereof shall be a part of the authority of said officers now or hereafter conferred by general or special acts of Congress with reference to this project."

Thus in the case of the development of water powers on navigable streams in which the improvements are made by private parties with the consent of Congress and the Secretary of War, it is not yet determined whether the United States may impose a franchise tax under the authority to regulate commerce. It seems to me to be extremely probable that if Congress should authorize the construction of a dam as an incident to improving navigation and with the condition that a franchise charge should be made for the privilege, the $\mathrm{Su}-$ preme Court would be very slow to overturn it. This, however, is an individual expression of opinion.

Where water power sites are on the government domain, there is no question that a franchise charge for water powers may be imposed.

The first reservation of reservoirs by the United States government was not made primarily with reference to water powers, but with reference to irrigation. Under laws passed in 1888,1890 , and 1891 , the reservoir sites which were selected by the United States Geological Survey primarily with reference to irrigation, were reserved from entry. Under these laws reservoirs in various states were selected by the irrigation division and have been reserved from entry. Where irrigation projects have developed power which is not required with reference to irrigation, the Secretary of the Interior may lease the surplus power produced for a

Power developed in connection with irrigation may be sold. 


\section{0 CONSERVATION OF NATURAL RESOURCES}

period not exceeding ten years, giving the preference to power for municipal purposes. The money received from such power goes into the reclamation fund and is placed to the credit of the project from which the power is derived.

During the latter part of President Roosevelt's administration in 1909, a large number of sites on 29 streams were withdrawn directly with reference to power instead of with reference to irrigation. Under President Taft's administration an even larger number of power sites have been withdrawn, covering 97 streams not heretofore withdrawn, making a total of 126 streams along which withdrawals have been made. March 4,1910 , the acreage of the power sites withdrawn amounted to about $1,300,000$ acres of public land and 200,000 acres of entered land.

Water power concessions in national forests.]
Proposed laws as to water powers in public domain.

The United States Forest Service is granting water power concessions in the national forests under a series of elaborate provisions, which comprise the application of the principles advocated by the North American Conservation Conference. Among these conditions are the requirement of construction within a reasonable time, a construction charge in proportion to the land occupied to such time as the plant is put into operation, and "annually thereafter a net operation charge fixed by the forester," based upon the amount of electrical energy developed. The charge for the first year is nominal, - two cents per thousand kilowatt hours, but gradually is increased until from the forty-sixth to the fiftieth year it is thirty-two and a half cents per thousand kilowatt hours. The contracts further require continuous operation for a reasonable fraction of the full power capacity of the site, termination of the permit at the end of fifty years, with the privilege of renewal on such conditions as the government may impose, and forfeiture in case of becoming part of a combination or trust. As a final step by the government toward securing returns for the water powers of the public domain, R. A. Ballinger, Secretary of the Interior, with the approval of President Taft, has presented to Congress a bill embodying among others the following features: The Secretary of the Interior is authorized to withdraw from entry the parts of the public domain which 
are more valuable for power development than for other uses. He may grant leases for the development of water power for a term of not exceeding forty years, the lessee being allowed five years to construct all necessary works and to develop at least 25 per cent of the power. For such lease a charge is to be made in proportion to the power developed and may be increased every ten-year period during the lease. Each lease shall fix the minimum payment to be made each year by the lessee, independent of the power developed, but this minimum may be increased at the end of each ten-year period. The leases shall contain provisions which shall fix the maximum price beyond which the lessee shall not charge the public for power developed. At the end of the lease a new lease will be offered to the original lessee on equitable terms based upon an appraisal value of the privilege. In the event that such lessee shall decline to renew his lease the same is to be sold at public auction "at an upset price to be based on the appraisal of the privileges and improvements, and the original lessee shall thereupon be entitled to be compensated to the extent of the sum received for the improvements only." Of the money received from the leases, one third is to be paid to the state or territory in which the power exists, to be expended for roads and schools in the county where the leaseholds are situated, and the other two thirds is to go to the general fund of the United States treasury.

If Congress acts favorably upon the recommendation of the Secretary, the water powers now a part of the public domain will be perpetually retained as the property of the nation. Bills are pending in Congress which provide for the transfer to the western states of all water power sites now owned by the federal government. It is to be hoped that none of these bills will be enacted into law. It would be far easier for those interested in acquiring water powers and operating them without restraint to secure this under state than under federal control.

It is apparent that since the movement for conservation began two years ago, there has been an astonishing development of public sentiment in reference to the control of the water 
Develop- " powers of the United States, and that the expression of public ment of sentiment as to public control of water powers. sentiment has resulted in putting into operation principles which have been advocated by the various conservation congresses and associations. Already we have in force the principle that water power developed by the government may be subject to a proper charge. We have the question raised as to whether water power developed by private parties upon navigable streams in the United States may be subject to a franchise charge. We have all the limitations recommended by the North American Conservation Conference imposed upon the development of water power in the national forests. Finally, the Secretary of the Interior has withdrawn from private entry all water power sites which still remain a part of the public domain, and recommends to Congress that these be permanently held by the United States so that they may be forever the property of the people.

\section{Control by States}

The next subject to be considered is the control of water power by states. So far as the right to the water is not retained by the government under the general authority to control commerce, and so far as the government does not retain the land where water power may be developed, the water rights have passed to the states or to individuals, - in part to the states and in part to individuals. The question at once arises as to how far these rights are vested in the states, and how far they are vested in individuals. According to Assistant Attorney Wright, except so far as necessary for navigation, "the water in theory is the property of the state and not of the nation."

Etreams in more than one state.

This general statement leaves unsettled the question as to the exact extent to which the United States government will assume control under the authority to regulate commerce. Probably it may be assumed that where streams declared to be navigable by the government run through more than one state, or are between two states, or both, such streams are wholly under the control of the United States government; and if a 
franchise charge be imposed for the development of water powers, such charge will be by the government, since in such cases no dam or other construction can be built without the consent of Congress. When Congress gives such consent, that body will doubtless attach franchise charges if this be deemed advisable.

A second class of streams, declared to be navigable by the United States government, lie wholly within a single state. Under such circumstances a dam may be built across the Streams wholly within a river without a specific act of Congress, and the chief of engineers and Secretary of War may approve the construction of such a dam provided the consent of the legislature of the state concerned be first secured. In such cases, since the legislative enactment is by the state, it is probable that any franchise tax which may be charged would be levied by and would go to the state.

In the third class of cases, streams have been declared navigable by state enactment or by state courts which are not regarded as navigable from the point of view of the United States. In such cases it seems clear that any franchise charges imposed in connection with the same would be by the state.

I shall not attempt to present an exhaustive statement of the extent to which public control of water powers has been assumed by the states, because to take up each state separately would unduly extend this part of the subject; but I shall give some illustrations of the exercise of state control.

The constitution of the state of Colorado, adopted in 1876, Colorado. states: "The water of every natural stream, not heretofore appropriated, within the state of Colorado, is hereby declared to be the property of the public, and the same is dedicated to the use of the people of the state, subject to appropriation as hereinafter provided." 1

The constitution of the state of California, adopted in 1879, declares: "The use of all water now appropriated, or that may hereafter be appropriated, for sale, rental, or disPublic control in California. tribution, is hereby declared to be a public use, and subject 
to the regulation and control of the state, in the manner to be prescribed by law. ..." Further, the civil code of California declares that "the state is the owner of all land below tidewater, and below ordinary high-water mark, bordering upon tidewater within the state; of all land below the water of a navigable lake or stream; of all property lawfully appropriated by it to its own use; of all property dedicated to the state; and of all property of which there is no other owner." ${ }^{2}$

North

Dakota.

Washington.

Wyoming.

Idaho.

The constitution of North Dakota, adopted in 1889, states that: "All flowing streams and natural water courses shall forever remain the property of the state for mining, irrigating, and manufacturing purposes." 3

The constitution of the state of Washington, adopted in 1889, declares: "The use of the waters of the state for irrigation, mining, and manufacturing purposes shall be deemed a public use. ${ }^{4}$

In Wyoming, the constitution adopted in 1889 contains the following clause: "The water of all natural streams, springs, lakes, or other collections of still water within the boundaries of the state are hereby declared to be the property of the state." 5 Also the constitution declares that, "water being essential to industrial prosperity, of limited amount, and easy of diversion from its natural channels, its control must be in the state, which, in providing for its use, shall equally guard all the various interests involved." These constitutional provisions are put into effect by a law in conformity to them passed in $1909 .^{7}$

In Idaho, the law declares: "Water being essential to the industrial prosperity of the state, and all agricultural development throughout the greater portion of the state depending upon its just apportionment to, and economical use by, those making a beneficial application of the same, its control shall be in the state, which, in providing for its use, shall equally

${ }^{1}$ Article XIV, Section 1.

${ }^{2}$ Civil Code of the State of California, Section 670.

${ }^{3}$ Article XVII, Section $210 .{ }^{3}$ Article VIII, Section 1.

4 Article XXI, Section $1 . \quad{ }^{6}$ Article I, Section 31.

${ }^{7}$ Chapter 68 of the Session Laws of Wyoming, 1909. 
guard all the various interests involved. All the waters of the state, when flowing in their natural channels, including the waters of all natural springs and lakes within the boundaries of the state, are declared to be the property of the state, whose duty it shall be to supervise their appropriation and allotment to those diverting the same therefrom for any beneficial purpose. ..." 1

The state of Oregon in 1909 passed ageneral law controlling Oregon. the water of the state. This act, among other provisions, contains the following: "All water within the state from all sources of water supply belong to the public. That every person, firm, or corporation, except municipal corporations (hereinafter called the appropriator), who shall appropriate water after the passage of this act, for the purpose of applying the same to the development of power, shall during the life of such appropriation as fixed herein pay to the state of Oregon not less than 25 cents or more than $\$ 2$ per annum in advance, on or before the second day of January of each year, for each and every horse power represented by the said appropriation. . . . The appropriator thereof shall own and enjoy all of the uses thereof so long as he pays the annual fees therefor, herein required, for a term not exceeding forty years from the date of appropriation, and shall have a preference right to reappropriate such water under such conditions as may be prescribed by law at the expiration of such term of years provided all fees have been paid. ...." 2

In 1907, only two years ago, the principle of making a New York. charge for the granting of a franchise for water power was introduced in New York. The Long Sault Development Company asked for a franchise for the development of water power on the St. Lawrence River. The bill granting the franchise was only approved by Governor Hughes upon imposing a charge. The amount of such charge is $\$ 15,000$ for the year 1910, $\$ 20,000$ for the year 1911, and after that time so much per horse power, with, however, a fixed minimum

${ }^{1}$ Section 3240, Revised Codes of Idaho, 1909.

${ }^{2}$ Chapter 221 of the General Laws of Oregon, 1909. 
Defects of New York law.

of $\$ 25,000$ per annum. The rates which are to be charged are 75 cents to 25,000 horse power, 50 cents from 25,000 to 100,000 horse power, and 25 cents in excess of 100,000 horse power.

While the Long Sault law is a great advance over the past practice of granting franchises without compensation, it is far from meeting the conditions recommended by the North American Conservation Conference. The charge per horse power for the amount first developed is higher than for additional amounts. There probably should be an increased charge instead of a decrease with increasing amount of power, since in large installations power can be produced more cheaply than in smaller installations. In the second place the franchise is unlimited as to time and the act specified gives the corporation perpetual existence; whereas a franchise should not be given for a longer period than forty years. How serious is this perpetual franchise will be understood when it is appreciated that in the future the value of this power may be several or many times the amount paid, indeed, probably will be; and yet the company has the use forever of the great power at the Long Sault at the extremely low rates above given.

The general problem of the control of water supply has also been taken up in New York. In 1905 the State Water Supply Commission was established. In 1907 this commission was directed " to devise plans for the progressive development of the water powers of the state under state ownership, control, and maintenance, for the public use and benefit, and for the increase of the public revenue."

In consequence of this authority the commission has formulated a comprehensive plan for the improvement of the water powers of the state, and especially those on the Hudson, Genesee, and Raquette rivers.

On the Hudson it is proposed to construct reservoirs having a capacity of $64,000,000,000$ cubic feet; on the Genesee one of 18,000,000,000 cubic feet; and on the Raquette a series of reservoirs with a total capacity of $20,000,000,000$ cubic feet. 
At the present time there are developed in the state of New York about 620,000 horse power. It is believed by the reservoir system proposed, and through other improvements, that there may be developed no less than 1,500,000 horse power in that state, exclusive of the Niagara and St. Lawrence rivers; or roughly, 1,000,000 more horse power than are now developed. It is believed by the commission that the minimum profit from such development will be $\$ 12$ per horse power per annum, or a gain of $\$ 12,000,000$ a year, without considering any of the indirect advantages, such as the saving in coal, the lessening of floods, the improvements in navigation, etc. The water to be stored in the reservoirs is to be sold, leased, or rented; and thus pay for the cost of maintenance and operation, the interest on bonds, to provide a sinking fund, to provide a fund to make further improvements in the waters of the state, and finally to be a source of income to the state for general purposes. In order to accomplish these results a constitutional amendment will be required permitting the flooding of about one sixth of the state lands in the Adirondack forest, 20,000 acres all together, and to permit bond issue to furnish funds to construct the storage reservoirs.

It thus appears that the state of New York has made one very important advance in the matter of water powers in the past few years and may make another in the near future.

While the New York act in reference to the Long Sault Development Company is very defective, the law is of great importance, in that an old state has introduced the principle that in the granting of a franchise for the construction of a dam to develop water power, a charge is made. Further, under the plans of the State Water Supply Commission, the state is to gain the advantage of the franchise charges by the existing water power users, as a result of the furnishing of additional water to them by the storage reservoir system.

The example and experience of New York in handling the water power problem should be of great advantage to other states now considering the subject. The situation in

Profits of reservoir system. 


\section{CONSERVATION OF NATURAL RESOURCES}

Navigable streams of Wisconsin.

Relation of ownership of bed of streams and water rights.

Franchises subject to amendment or repeal.
New York is analogous to that in a number of states, and doubtless the principles worked out by that state may be used by them to advantage.

Wisconsin may be considered briefly as illustrative of a great group of states in which the question of the public control of water power has been raised, but has not yet been settled. In that state the principle of complete public ownership for all waters, with the exception of rivers, has been held by the state Supreme Court. The legislature by enactment has enumerated a considerable number of navigable streams, and the Supreme Court has held that all streams are navigable which will float to market the products of the soil for some portion of the year, and "some portion" of the year has been held to be a period approximately of six weeks. Hence under the law and under the action of the Supreme Court navigable waters in Wisconsin are precisely defined. A stream upon which logs can be run at high water is navigable.

'The Wisconsin Supreme Court has also held that since the rivers are nontidal, the beds are vested in the riparian proprietors. But, notwithstanding the fact that the soil beneath the river, by judicial decision, not by legislative enactment, has been declared to be the property of the riparian owner, the court has also held that "such ownership is of such a qualified character as not in any way to interfere with the character of the stream as public waters; not public in the sense of such rivers as at common law were merely subject to the right of passage, but public by the common law test of navigability." Also, the Supreme Court has held "the right of the riparian owner . . . does not ... depend upon his ownership of the soil under the water, but upon his riparian ownership, and the right of the state to control the waters of such stream in the public interest is the same whether the ownership under the water be in the state or in the riparian owner."

To and including the year 1907, the legislature of Wisconsin has, from time to time, granted franchises for the construction of dams for the improvement of navigation and for the 
development of water powers without charge. Such franchises, with the exception of a few of the earlier ones, contain the provision that they are subject to amendment or repeal. Also, the state constitution provides in reference to corporations without banking powers or privileges that "all general laws or special acts enacted under the provisions of this section may be altered or repealed by the legislature at any time after their passage."

Finally, the power of eminent domain has been given with many such franchises, it being necessary in order that they may be useful to give the power to flow other land. "The mill dam act of 1840 was upheld on the ground that the land flowed by virtue of it was devoted to the public use." This power of eminent domain is related to the selection of sites to which franchises are given, mentioned on p. 138. If in the case of two adjacent water power sites, the development of the lower of which will destroy the upper, the flowage rights take away the value of the upper water power. This is justifiable if the power developed by the water belongs to the state; but clearly it is not justifiable to merely pay for the land flowed, if, as has been claimed by some, the power which may be developed at a given site belongs to the riparian. The fact that the state has granted the right of eminent domain to individuals and corporations would seem to make it reasonable to impose special conditions, including charges, for special concessions.

The State Conservation Commission has recommended that hereafter the franchises for water power be granted under a general statute, that the issuing of such franchises be placed with a commission, that such franchises be in the Recommendations of Conservation Commission. nature of leases for a long term of years, at low rentals, renewable on equitable terms. The question of what the state should do in reference to those water powers where franchises have already been granted is not touched by the commission.

The recommendations of the commission have been strongly opposed by riparian owners. They hold that the riparian owner has the right to the use of the water of streams flow- 
Rights of state should be preserved.

Reservoirs in

Wisconsin.

ing by or over their land, for developing power without compensation to the state. The entire question of the control of water powers is now before a recess committee of the legislature for consideration and recommendation.

Since I do not profess law, I shall not venture to present a brief for either side of the case. The main principles have been summarized, so far as they have been clearly determined. What the legislature and the courts of Wisconsin may finally decide as to the relative rights of the state and the riparian in the water powers, the future can only determine; but certainly it is the case, if the principles of conservation herein advocated are well founded, that the state should hold for the people all rights in water powers which it still holds in law and in fact.

In Wisconsin there is one other development with reference to water powers which needs to be mentioned, since it illustrates an important principle. In 1907 the legislature passed an act giving to the Wisconsin Valley Improvement Company the right of acquiring reservoir sites and developing them on the Wisconsin River and its tributaries, for the purpose of maintaining a uniform flow. In order that this authority should be effective the company was granted the right of eminent domain. The company was required to develop reservoirs to store a minimum of $2,000,000,000$ cubic feet of the surplus water. The company is allowed to pay 6 per cent interest on the capital invested, which is limited to actual expenditures. This interest on the expenses for maintenance and operation is assessed as toll upon the users of the water for the development of power. The plans for the reservoirs must be submitted to and approved by the State Board of Forestry. To this board is given the power to determine to what heights the water may be raised in the reservoirs, the level to which it may be lowered, and the manner in which it may be drawn off. To this end they may employ at the expense of the company a hydraulic engineer. The company is to maintain fishways and free passage for logs, and is to conform to all other general regulations of the state concerning dams. The right is reserved 
to the state to repeal or amend the act at any time. Finally, the state may take over the company's plant at any time for the actual value of the paid-up capital, no allowance being made for franchise or good-will.

It would probably have been far better for the state to construct this reservoir system and to impose a charge on the water power users benefited as is proposed in the state of New York. This was not possible in the state of Wisconsin, for the constitution has a provision that no internal improvements shall be undertaken by the state. To protect the future interests of the state the clause was inserted in the bill giving to the state authority, at any time that this is constitutional, to purchase the reservoir system.

As already indicated in another place (see p. 132), it is proposed that the state of Illinois construct a channel from the end of the Chicago drainage canal to the Mississippi River, following the Illinois River, incidental to which there will be developed about 140,000 horse power; of this certainly 100,000 belongs to the state. In order to do this a constitutional amendment was passed; but the legislature has not yet taken action putting the same in force. Since the state is to create the water power, the right to charge for the same is beyond question.

In conclusion, it should be said, in applying the principle of leases for water powers, that the terms should be so fair that capitalists will be encouraged to put money into their development; for, as has been fully explained, the principles of conservation require the rapid development of the water powers, not only for the increased economy resulting from the use of otherwise wasted energy, but, more important than this, to save coal.

The subject of water powers well illustrates how rapid has been the advancement of public sentiment and law in the past few years in the direction of public control of a natural resource limited in quantity. It, perhaps better than any other, verifies the statement made in my opening lecture that in calling the White House Conference the President of the United States made the voice of conservation the voice of the nation. 


\section{NAVIGATION 2}

The waterways of the United States for domestic commerce include the coast waters and bays, the Great Lakes, the rivers, and canals.

In 1906 the freight moved by water in American vessels, excluding harbor and raft traffic, amounted to $177,519,758$ tons. A small part of this was foreign commerce. Of this 42.6 per cent was on the Great Lakes. If the harbor traffic were included, the amount would be $265,000,000$ tons.

\section{THE COAST AND BAYS}

The coast line of the United States aggregates 5700 miles in a straight line along the border of the country. The meandered length of the coast line is over 64,000 miles. The ocean is extensively used for coastwise trade and through the deep indentations of Long Island Sound, Delaware Bay, Chesapeake Bay, and Puget Sound, water transportation at various places goes well inland. The traffic of the Atlantic and Gulf coast, excluding harbor traffic, was $65,361,000$ tons. In addition to this there was a large traffic on the Pacific. Some of the more important articles carried were coal, lumber, and petroleum.

\section{THE GREAT LAKES}

The Great Lakes are the most important group of inland waterways in the world. The United States shore line is 2760 miles, with a meandered length of 4329 miles. The lakes, above Lake Ontario, are connected by channels and canals twenty feet in depth.

The chief bulk commodities carried on the Great Lakes are iron ore, grain, coal, and lumber. In 1907 the total traffic amounted to more than $80,000,000$ tons, of which

1 The facts included under navigation are largely taken from "Transportation by Water," Herbert Knox Smith, Report National Conservation Commission, Vol. II, pp. 13-56; and Preliminary Report of the Inland Waterways Commission, Washington, 1908. 
$45,500,000$ tons were iron ore. This iron ore is east-bound traffic. The most important item of the west-bound traffic is coal, which in that year amounted to over 21,000,000 tons. More than half of the vast traffic of the entire lakes passes through the locks of St. Mary's River, which from the opening of the season to the close of navigation are active day and night.

In 1907 the freight that went through this canal amounted to $51,751,080$ tons, about 80 per cent of which was east bound, and about 20 per cent west bound. ${ }^{1}$

"The east-bound business was mainly: iron ore, 35,357,042 tons; wheat, 84,271,358 bushels; other grain, 54,341,155 bushels; flour, 6,495,350 barrels; copper, 107,633 tons. West bound: bituminous coal, 7,728,255 tons; anthracite coal, 1,011,275 tons; general merchandise, not comparatively heavy, but of relatively large value."

It is seen that the larger proportion of the traffic of the Great Lakes is raw material carried in great bulk, in which time is not an important factor in transportation, and which therefore is handled at such low rates by water as to exclude railway competition.

\section{RIVERS}

There are 295 rivers which are used for commercial purposes in the United States, with an approximate total length of 26,400 miles of navigable water. Most of these streams are adapted only to light draft boats. But one tenth of this mileage has a ten-foot channel. Another one tenth gives a navigable depth of from six to ten feet during a part of the year. Thus the great majority of the streams do not furnish a navigable channel of more than six feet. The longest system, the Mississippi, has about 2500 miles of navigable waters having a depth of six feet or more. The traffic of this entire system in 1906 was only about $19,000,000$ tons.

1 "Transportation on the Great Lakes," by Walter Thayer, An. Am. Ac. of Pol. and Soc. Sci., January, 1908, Vol. XXXI, pp. 127-146. 


\section{CaNaLS}

According to Herbert Knox Smith, $\mathbf{4 5 0 0}$ miles of canals have been constructed in the United States, of which 2444 miles, costing \$\$0,000,000 have been abandoned. There are sixteen private canals in operation in the United States of more than local importance, with an aggregate length of 632 miles. State canals are maintained in New York, Ohio, Illinois, Louisiana, with a total mileage of 1360, constructed at an estimated cost of $\$ 156,983,538$. The great majority of these are towpath canals with a depth rarely exceeding seven feet and commonly are not available for boats having a greater draft than six feet. Traffic by towpath canal is necessarily very slow. Canal traffic has decreased from $16,000,000$ tons, in 1880 , to $6,600,000$ tons, in 1906.

\section{COMPARISON OF RAILWAY AND WATER TRANSPORTATION}

In the United States, June 30, 1908, were 237,389 miles of railway track, which during the year ending that day carried approximately $1,532,981,790$ tons of freight, a decrease of $185,460,810$ tons as compared with the previous year; the ton mileage for the year was $218,381,554,802$. The number of passengers carried was $890,009,574$ and the passenger mileage 29,082,836,944. At that time the par value of the railway capital of the United States was estimated by the Interstate Commerce Commission at $\$ 16,767,544,827$. In 1904 the value of the railroads was estimated at 10.5 per cent of the entire wealth of the nation. Of our entire production for the year ending June 30, 1907, amounting to about $\$ 10,000,000,000$, about one fourth of the value, $\$ 2,589,000,000$, was given by railway transportation. Since in the figures given with reference to water transportation (p. 162) the ocean traffic to foreign points in American vessels is included, it appears that not more than one tenth of the commerce within the United States is carried by water; and this is so, notwithstanding the fact that we have 
a better distributed and more extensive system of inland waterways than any other nation of the world.

The question naturally arises, why is it that there has been in this country so small a development of water transportation? According to McGee the cost of transportation by water does not exceed from one fourth to one third that by railway.

Mr. James J. Hill says railroad transportation cannot be performed at much less than one half a cent a ton per mile. The season of 1909, rates on the Great Lakes for iron ore were less than one mill per gross ton per mile, whereas the Comparison of railway and water freight rates for ore by rail were about one cent a ton per mile, or ten times as much. Ore is only a single commodity, but it is the largest one in inland water transportation, and therefore illustrates the situation for heavier commodities.

The railroads in recent years have been congested, have actually been unable to handle the traffic of the country during the busy season of each year. The failure of the railway system to meet the needs of commerce first markedly appeared in 1906. Since that time, whenever the business is at the maximum, the railroads are far behind in handling the freight. This was well illustrated in the winter of 1909-10, when, according to Mr. Hill, Chicago was practically blockaded and shipments were generally from ten to sixty days behind time.

Mr. Hill, who probably in this country is second to no man as an authority upon this subject, estimates that to develop the railroads so that they will be able to handle the traffic in the near future will require the additional expenditure of some $\$ 6,000,000,000$. He holds that the economical way to remove the congestion and to provide adequate transportation facilities is to develop the waterways.

\section{IMPROVEMENTS OF RIVERS}

The rivers may be very greatly improved in two ways: the channels which are at present navigated may be deepened so as to permit vessels of larger draft, and the distance which is navigable may be extended, - perhaps be doubled. 
Increase in size of boats.

The deepening of the navigable channels is of the utmost importance with reference to cheapness of water transportation, and therefore with reference to its development. In the ocean-going traffic there has been in recent years a very rapid increase in the size of the vessels. It is not so many years ago that a freight vessel capable of carrying 1500 or 2000 tons was considered a large boat. At the present time there are boats engaged in freight and passenger business which carry 30,000 tons or more.

About twenty-five years ago the largest of the Great Lakes boats had a carrying capacity of only about 3000 tons of 2240 pounds. At the present time, according to W. J. Olcott, president of the Oliver Iron Mining Company, there are seventy boats on the Great Lakes having a capacity of 10,000 gross tons, and several ships have carried from Lake Superior to lower ports somewhat more than 12,000 gross tons. In proportion as a boat becomes large the investment in the vessel, the engine, and labor, per ton capacity, is lessened; and therefore there are great economies with increase in the size of the unit of water transportation.

"A modern ocean carrier of 5000 tons displacement requires 1000 indicated horse power to drive her at a speed of 10 knots, and a carrier of the same type symmetrically enlarged to 10,000 tons displacement requires only 1587 horse power to drive her at the same speed; that is, the cargocarrying capacity is doubled at the same speed with an increase of little more than 50 per cent for fuel. The increased expense for labor is less than 1 per cent, and the superiority of the large carrier in adverse weather is very marked." 1

But if the economy resulting from large vessels is to be gained in the case of the rivers, it ean only be accomplished by deepening the channels. We have already seen that for the greater number of streams the depth is not more than sufficient to carry vessels of six feet draft; whereas oceangoing vessels have a draft of thirty feet or more, and those upon the Great Lakes go to twenty.

${ }^{1}$ Preliminary Report of the United States National Waterways Commission, Washington, D. C., 1910. 
It is estimated by the Inland Waterways Commission that to develop adequately the inland waterways of this country will cost somewhere between $\$ 500,000,000$ and $\$ 800,000,000$. This amount seems large - very large - but it is to be noted that it is only one tenth the amount which Mr. Hill estimated will be required to develop the railroads so as to handle the traffic of the country. Also, it should be remembered in this connection that transportation by water costs only one third to one fourth as much as by rail. While in any case large additional extensions of railways will be required, it is safe to say that, allowing for this, the development of waterways will result in an enormous saving in the capital invested for this purpose, and also an immense saving each year in the amount paid for transportation. If the cost of transportation is lessened, the price of commodities will be lower.

\section{THE SITUATION IN EUROPE}

The situation in this country is in somewhat remarkable contrast with that in Europe. According to Herbert Knox Smith, the entire federal appropriations for the improvement of rivers and canals, excluding harbors, to 1907 was $\$ 250,000,000$; and much of this money has been very unwisely expended. According to Welliver, ${ }^{1}$ in recent years there have been developed in an area of about 800,000 square miles, in Austria, Hungary, Belgium, France, Holland, Germany, and Italy, a great system of interior waterways, which cost the governments of those countries not less than $\$ 1,000,000,000$, or $\$ 200,000,000$ more than the maximum estimate for the necessary improvements of the waterways of the United States. Some of the more important rivers which have been greatly improved are the Danube, the Rhine, and the Rhone. Even smaller countries, such as Holland and Belgium, have a series of canals and waterways which connect the important cities, center-

1 "Relations of Waterway and Railway Traffic in Europe," by J. C. Welliver, Preliminary Report Inland Waterways Commission, pp. 377-435.

Cost of improving European waterways.
Relative improving waterways and railroads. 
ing in the case of Belgium at Antwerp. The countries above mentioned have become convinced that it is economical for them to solve their problem of transportation by the development of waterways as well as railways, and their experience has shown that such development has not injured the railroads. In fact, the railroads have been handling practically all the freight that they could carry. Simultaneously with the development of waterways there has been also expansion of the railways. Also, because of the competition of the waterways, there has been great reduction in the freight charges. In Germany the amount of river transportation increased from 1875 to 1905 more than fivefold, the very period during which river transportation in the United States has steadily declined.'

Finally, in this connection, it is to be noted that the countries in which the government largely owns the railways have been those making great investments of money for the improvement of the waterways. And we in the United States have been content to see our waterways decline as instruments of transportation during the period in which great expansion has taken place in Europe.

\section{WHY WATER TRANSPORTATION HAS NOT DEVELOPED}

The question should here be considered as to why it is in this country, during the time of the extremely rapid development of our railroads, not only has there not been development in river transportation, but actual decadence. Those who have read Mark Twain will recall the busy scenes on the Mississippi in the days of Tom Sawyer. Many freight and passenger boats plied up and down that impressive stream, which was the great artery of commerce of the Mississippi Valley. At the present time the passenger transportation and freight traffic upon the Mississippi above St. Louis is almost negligible. The same is true of the Missouri. About the only remnant of a large freight traffic

1 "The Present Significance of German Waterways," by Walther Loets, An. Am. Ac. of Pol. and Soc. Sci., Vol. XXXI, January, 1908, p. 252. 
is on the Ohio and Lower Mississippi. This is mainly coal going to points downstream.

\section{Channels Shallow, Crooked, and Shifting}

The first of the causes of decline of water transportation is that the improvement of the river channels has not been commensurate with the necessities of a rapidly increasing commerce. The existing channels are shallow, crooked, and shifting. The boats are necessarily small and their progress is often slow. Under these circumstances it has not been possible for river traffic to compete in a large way with railroad traffic rapidly advancing in power and efficiency.

\section{Illegitimate Competition of Railroads}

Second, the decline has been caused by the active efforts of the railroads to reduce the water traffic and if possible to destroy it. The efforts have been along various lines. Canals owned by railway Wherever there is competition between the waterways and the companies. railroads the railroads have uniformly made lower than the average rates. Frequently such rates have been so low as to have been unprofitable, or even resulted in a positive loss. Such destructive competition has often continued until the water carriers have been driven out of business, after which the rates were promptly increased. The railroads have also prevented the development of water transportation by securing the water front terminals. They have gained control of many of the competing canals and vessels. Some of the canals owned or controlled by the railroads of the country are the Delaware and the Raritan, the Morris, the Lehigh, the Chesapeake and Ohio. Other canals have been purchased by railroads in order that they should be put out of business entirely. Among these are the canals in Pennsylvania owned by the Pennsylvania Railroad. Further, it has been shown that the railroads own a considerable portion of the stock or have complete control of various packet lines on the rivers. 


\section{0 \\ CONSERVATION OF NATURAL RESOURCES}

Refusal of railroads to prorate.

Forced to ship by railway.

Another method that the railroads have pursued to break down water competition is to refuse to prorate with them. If, for instance, there are two railways which jointly make a through route, say from Chicago to New Orleans, they will unite to give a rate which may be lower than that which would obtain if goods were shipped to the terminus of the first road and reshipped on the second. But the first road, which we may suppose extends to St. Louis, will not prorate with the boat lines from St. Louis to New Orleans. Says Herbert Knox Smith in reference to this matter: "The railroads of the country, by refusal to prorate, can, and in large measure do, prevent the rivers and canals from becoming a part of the whole transportation system of the United States, or else they extend their control over the waterway system by prorating only with favored affiliated water lines."

Also, rebates have been given to break down water transportation. Finally, not infrequently the manufacturers have been compelled to use railroads when they would have preferred to ship by water. A manufacturer is located on a river. A part of his business is such that he necessarily uses the railroads; he wishes also to use the waterways; he is informed by the railroads that they can handle all of his business. If he does not consent to the suggestion, there is a shortage of cars, or some other difficulty, until finally the shipper is practically driven to ship exclusively by the railroads.

The above facts in reference to illegitimate competition on the part of the railways are all taken from government official documents, the Preliminary Report of the Inland Waterways Commission and the Report of the National Conservation Commission. This point is mentioned in order that it may be fully understood that the above statements are not merely my personal opinions.

Illegitimate competition not permitted in Europe.

In some countries in Europe illegitimate competition by the railroads of the kinds mentioned above is not permitted. In France such methods were pursued until the government 1 Report National Conservation Commission, Vol. II, p. 52. 
was obliged to interfere to protect the canals and give them a fair share of the business. Indeed, "in many cases the railways are now forbidden by the state to make as low rates as the canals."

Also, in Europe, to insure effectiveness of water transportation, there is frequently public ownership of water fronts and wharves. To some extent there is such public ownership in this country, but this is exceptional.

\section{COÖPERATION OF RAILWAYS AND WATERWAYS}

The ideal system of transportation is that in which waterways and railways perfectly coöperate. It is comparatively easy to require such coöperation where the government owns both systems. But in this country, where the ownership of the railways rests exclusively with private corporations, the securing of coöperation in place of illegitimate competition will be far more difficult, but laws must be enacted which will accomplish this.

\section{CONTRAST BETWEEN GREAT LAKES AND RIVERS}

The situation upon our streams with little passenger transportation and, with few exceptions, unimportant freight transportation, is to be contrasted with the situation on the

Development of Great Lakes traffic. Great Lakes, where there is adequate depth of water and where illegitimate methods of railway competition have not been possible. There navigation has developed at an astonishing speed. Great freight boats in large numbers are plying in and out of the ports of Duluth, Superior, Chicago, Milwaukee, Detroit, Toledo, Cleveland, and Buffalo; and even the small towns, Conneaut and Ashtabula, have a vast tonnage of iron ore. Also, a fine passenger service by several lines is maintained. On the Great Lakes there is real competition both as to freight and passenger service; and, consequently, the rates are very reasonable.

The situation on the Great Lakes illustrates that which should obtain upon our rivers and canals; they should be 
How rivers may become arteries of commerce.

great arteries of commerce. At the present time there is being carried on a great campaign to improve the inland waterways. A National Rivers and Harbors Congress has held six annual conventions to promote this movement. An appropriation of $\$ 50,000,000$ a year for ten years is asked in order that the improvements proposed by the Inland Waterways Commission may be carried out; this would involve an expenditure of $\$ 500,000,000$. It is proposed to meet this expenditure by issuing bonds. If this development is undertaken, it will be necessary that the railways and waterways coöperate, as they do in Europe. And since the principle has been adopted in this country, within the past half-dozen years, that it is the function of the nation and the state to regulate railroads, to inquire into their rates, to see that traffic is not transported at one time lower than its cost and at another time at an excessive rate, to prevent the giving of rates to one shipper different from another, and to make other reasonable regulations; it will now be possible, although difficult, to prevent unfair competition of the railroads. Therefore, if the waterways are improved so as to make possible economical transportation, there is no reason why there should not be seen on the rivers and canals a large traffic similar to that of the Great Lakes.

\section{DIFFICULTIES IN IMPROVEMENTS}

Shifting of channels and silt.
There are, of course, difficulties in carrying out the plans of the Inland Waterways Commission. The question will be raised as to whether the investment is warranted. There is the difficulty of the great inequality in the flow of the streams. There are engineering difficulties because of the shifting of the channels and the carrying into them of enormous quantities of silt by the headwater streams. There are great difficulties in the adequate decpening of the channels. In many places it will be necessary to build dams and levees, and in certain cases it will be necessary to canalize the rivers or some portion of them. 
The greatest difficulty of navigation is the unequal flow of the streams. At one time a stream is in flood, overflowing its banks, rolling down with great velocity toward the sea; at another time it is comparatively small, indeed often being divided into several small streams trickling over its bed. The conditions in either case are not favorable to navigation; in the first, because of the velocity of the stream, and in the second, insufficient depth to carry a vessel. In the projected improvements, according to Leighton, the first and most important step is to so control the streams as to get a nearly uniform flow.

The holding of flood waters, and therefore securing greater regularity, may be accomplished to a considerable extent by levees on each side of the river bank at some distance from the low water river channel, so as to make a basin. At times of flood the water rises above the banks, and so makes between the levees a long, narrow, temporary lake which may require several days to fill and empty. Such intermittent levee reservoirs prevent damage from floods and to a reasonable extent regularize the flow of the stream.

In many cases, in addition to a system of levees such as indicated, it will be necessary to construct at the headwaters of the great navigable streams adequate systems of Reservoirs of Upper Mississippi. reservoirs. We have seen that the development of reservoirs is of immense importance with reference to water power. Also, it is of equal importance with reference to navigation. The construction of reservoirs as an aid to navigation has not been done extensively in this country. Indeed, there is but one case in which large plans are being carried out for this purpose. Upon the Upper Mississippi, in Minnesota, five reservoirs, capable of holding 96,000,000,000 cubic feet of water, have been constructed, and these reservoirs have undoubtedly tended to lessen the fioods at St. Paul and below. However, only about 11 per cent of the drainage areas above St. Paul is controlled by these reservoirs, and naturally the results are not fully satisfactory. It is believed that the Upper Mississippi reservoir system in Minnesota and Wisconsin may have a capacity of

Unequal flow of streams. 
Cost of reservoir system.

Power of government to construct reservoirs.

$175,000,000,000$ cubic feet. Reservoirs of this capacity would doubtless very much ameliorate the situation along the upper part of the Mississippi.

But the great flood streams of the Mississippi are the Ohio and Missouri. To control these streams will involve very large expenditures. I have already pointed out that in Wisconsin and Minnesota it is comparatively easy to develop a reservoir system. To develop a system on the Ohio adequate to control the headwaters of the Monongahela, the Cumberland, the Tennessee, the Kanawha, will cost, according to Leighton, something like $\$ 125,000,000$.

This amount will by no means cover the expense of the reservoir system of the Mississippi; for, with reference to the floods of the lower reaches of the river, the Missouri, the Arkansas, and the Red rivers are to be considered. Reservoir systems for other streams than the Mississippi will be far less expensive, but still will be large.

But the question arises, can the government legally undertake the construction of reservoirs on the headwaters of streams? There is no doubt as to this in the minds of some lawyers who have carefully considered the matter. The government has the power to regulate and develop interstate commerce; and if for that purpose it can be shown, as it can be, that it is necessary to control the headwaters of the streams, this can be done. In fact, as already indicated, reservoirs have been constructed in Minnesota, because it has been found that this is one of the cheapest ways to develop navigation on the Upper Mississippi; and if this can be done in Minnesota, it can be done in other parts of the country. The work by the United States government will doubtless be supplemented by the states; also, it will be supplemented by the companies that build reservoirs to develop water power.

Other expenses of improvement.
The reservoir systems are only one part of the expense of the improvement of the waterways. There will be the cost of constructing levees and revetments, of making wing dams, of dredging channels, of deepening the canals, and of enlarging the locks. But upon the other side it is believed that the development of reservoirs will make unnecessary a large part 
of the cost of building the levees higher and higher. The expense of maintaining levees in the past has been very large. Frank M. Kerr, chief engineer of Louisiana, says that state has spent for that purpose from 1865 to the first of January, $1910, \$ 34,500,000$; and in addition to this since 1882 the United States has spent something like $\$ 12,000,000$. He estimates that the annual expenditure for levee work in the state of Louisiana is now about $\$ 800,000$.

In carrying on improvements of the waterways, it is necessary to have standard units; that is, for a given stream system, as, for instance, the Mississippi, the channel for a certain part may be fourteen feet, for another part nine feet, for another part six feet. Upon other river systems these same units should be used. The importance of having standard units for river navigation and on the canals is that boats may be constructed of a standard size and form adapted to definite reaches of a river system, and may be transferred from one part of the system to another, or to an entirely different river system.

\section{IMPROVEMENTS PROPOSED BY INLAND WATERWAYS COM- MISSION}

The inland waters may be divided into the following systems: first, the Great Lakes; second, the Atlantic system; third, the Gulf system, in which the Mississippi River and its tributaries occupy a dominant position; and fourth, the Pacific coast system, confined to the Colorado, the Sacramento, the Columbia, and their tributaries.

The more important projects of the Inland Waterways Commission for improving these systems are as follows:-

First, they propose to connect the Atlantic Ocean and the Great Lakes by a deep channel. At the present time the Hudson River is navigable 100 miles above its mouth for boats having approximately twenty feet of draft. The Erie Canal is at present time adapted only to small boats, the channel being only seven feet deep. However, it is now being deepened to twelve feet, at an expense of more than

Standard units of depth desirable.
Deep channel between New York and Great Lakes. 
Inner

Atlantic channel.

Improvement of Mississippi.
$\$ 100,000,000$ to the state of New York. By the. Inland Waterways Commission it is proposed to connect the Great Lakes with the ocean by a deep channel. If this canal were made twenty feet, this would standardize this canal with the other canals and rivers connecting the Great Lakes. It would thus enable New York freight to reach all the lake ports by an all-water route, and vice versa. The advantage of including New York and the Hudson as a part of the Great Lakes system of traffic cannot be overestimated.

The second of the great enterprises which the Inland Waterways Commission propose is an inner channel extending from New England to Florida. For much of this distance there are, outside of the mainland, barriers and islands with an inner channel of varying depth. By the utilization of these channels and the bays, such as the Chesapeake and Delaware, it will be possible to construct a deep channel which would be navigable for the ocean-going boats engaged in the coastwise trade. Such a channel would be of vast importance to commerce, because it would be largely independent of the storms. Also, in case of a foreign war, if that emergency should arise, it would be a great source of strength, because the naval forces adapted to the inner channel could concentrate at any point. To some extent, for defense, it would serve the same purpose as the inner sea of Japan.

The third great project, in geographic order, of the Inland Waterways Commission, but first in importance, is the development of the gulf system of rivers, especially the Mississippi. It is proposed to connect the Gulf of Mexico and the Great Lakes by a fourteen-foot channel. Such a channel at the present time would do much to develop commerce; but when the Panama Canal is finished it would be of vastly greater importance, for through it the commerce of the Orient could get by water to the heart of our country, including all the lake ports by an all-water route, and vice versa.

This project, so far as it is in Illinois, has already begun to take definite shape. In accordance with the recommendations of Governor Charles S. Deneen, the legislature submitted to the people a constitutional amendment to allow the state to 
be bonded for $\$ 20,000,000$, in order to construct a deep waterway from Chicago along the Des Plaines and Illinois rivers to the Mississippi near St. Louis. This proposal was approved by the voters November 3, 1909; but, while the senate of the state legislature of 1910 passed a bill providing for the construction of the canal, this bill failed in the house; and, therefore, favorable action upon the matter is not possible before 1911. The plans of the Internal Improvement Commission of Illinois provide that at first the channel be only fourteen feet deep; but the locks are to be so constructed as to permit of the deepening of the channel, without rebuilding the locks, to twenty-four feet. (See pp. 132, 161, in reference to water powers.)

President Taft, in 1910, definitely recommended to Congress that the Ohio River from Pittsburg to Cairo be improved so as to maintain a minimum depth of nine feet, and thus make possible a great increase of its tonnage, which even under present conditions is large, the port of Pittsburg having a traffic in 1906 of nearly 13,000,000 tons. He further recommended that the Upper Mississippi from St. Louis to St. Paul be improved to maintain a constant depth of six feet; that the channel of the Missouri from St. Louis to Kansas City have the same depth; that in the Mississippi from St. Louis to Cairo a depth of eight feet be maintained; and that below Cairo a depth of nine feet be maintained. $\mathrm{He}$ indicates that in the future these depths may be increased as commerce shows the necessity. President Taft's proposal does not go so far as that recommended by the Inland Waterways Commission, but if carried out would undoubtedly result in vast improvements in the condition of the Mississippi River system.

A fourth project is to connect the Columbia River and Puget Sound. Puget Sound is an inner sea for the state of Washington, serving the ports of Seattle, Tacoma, and other cities. Columbia River and Puget The proposed canal would connect the commerce of this inner sea with Portland and with the traffic of the Columbia and Willamette.

Fifth, it is proposed to deepen the waters of the Sacra- 
Study of projects required.

Lakes-tothe-Gulf deep waterway.

mento River and the San Joaquin, so that commerce may go by water to the heart of the state of California and reach Sacramento, Stockton, and other cities.

Sixth, there are many other systems upon which improvements should be made. In these streams channels will be constructed for boats of relatively shallow draft.

While the above proposals are made by the Inland Waterways Commission, it is not advocated that they all be undertaken at the present time, or that any one of them be undertaken until there is a most careful study of conditions. They are all feasible; all may be executed with the expenditure of sufficient money. The question, however, arises whether the expenditure demanded for a particular improvement will be warranted by the results. This question in any given case cannot be answered until an exhaustive study has been made of the entire problem by competent men. There should be available to Congress the results of such an investigation in each case as a basis for action.

The above statement does not apply to the Lakes-to-theGulf fourteen-foot waterway. That project has been declared to be feasible by a special board of engineers, created by Congress; and all necessary surveys and working plans have been made so that construction may begin as soon as appropriations are available. The Fourth Lakes-to-the-Gulf Deep Waterways Convention at New Orleans expressed the conviction that the improvement of the Mississippi River system is the first of the great projects for the improvement of the inland waterways which should be undertaken. They say that the great interior region drained by the Mississippi River comprises about half the area of the United States; that this is by far the most productive portion of the country; and that in this area are nearly $60,000,000$ people, the commercial needs of whom have increased very much more rapidly than in any other portion of the country.

Probable future development of waterways.

Doubtless during the next twenty-five years there will be great improvements upon our rivers and our canals. Probably these improvements will continue through the coming hundred years. I have little doubt that before the end of this 
century most of the improvements suggested, and doubtless others, will become accomplished facts. If the population and commerce of the present time are not sufficient to warrant them, it is certain that the population and the commerce of the future will do so, - exactly as was warranted the expenditure of $\$ 1,000,000,000$ in improving the rivers of 800,000 square miles in Europe.

Finally, a brief statement should be made in reference to the Panama Canal. ${ }^{1}$ While this is not an inland waterway of the United States, it is so connected with the development of those waterways, and especially those of the Mississippi River, that it should be considered. This canal is to be 40 miles between shore lines, and nearly 50 miles between the 41 -foot contours of the bays of Lyman and Panama. It is to have a channel 42 feet deep, and a minimum width of 300 feet at the top, and 200 feet at the bottom. The summit is to be made by a large lake 55 feet above mean tide, with three locks on either side, each one to be not less than 1000 feet long, 100 feet wide, and 40 feet deep. The total cost of the canal, as estimated in 1909 by Chairman Goethals, is $\$ 375,201,000$. It is expected that it will be ready for commerce in 1915. The completion of this canal cannot but give a powerful impetus to commerce between the eastern and western parts of the United States, and especially between the Mississippi Valley and the Pacific coast states. Its completion will give water competition with railway competition between the east and west. The effect of this canal upon foreign commerce is not discussed, since this subject is not included within the scope of these lectures.

INFLUENCE OF WATER TRANSPORTATION ON FREIGHT RATES

Even with the present very imperfect development of the waterways, competition of water transportation has been a most important factor in lowering the freight rates on railWaterways and freight ways. This has been especially true of the Great Lakes traffic,

The Panama Canal.

1 “Present Status of the Panama Project," by Henry L. Abbot, An. Am. Ac. of Pol. and Soc. Sci., Vol. XXXI, No. 1, pp. 19-20. 
the influence of which has not simply affected the lake ports, but has extended to a considerable distance inland. Thus the price of anthracite at Minneapolis, St. Paul, and many other interior cities is much lower than if the coal had necessarily an all-rail haul. If the projects proposed were carried through, so that there would be a 20 -foot channel between New York and the Great Lakes, and a 14-foot channel from the Gulf to the Great Lakes, no one can estimate the effect that this would have upon freight rates. The railroads could not charge, for heavy commodities in which time in transportation was not an important factor, a greater rate between New York and the lake ports and points within a reasonable distance from the lakes, than the boat companies, or by the boat companies combined with the railways. Indeed, it is probable that a 20-foot channel between New York and the Great Lakes would result in a large part of the more bulky and cheaper commodities going by water. This would decrease the congestion of the railroads between the East and Chicago, and would enable them to handle, without great extensions, the traffic in which the articles are more valuable and in reference to which time is an important factor. Such commodities bear a relatively high freight rate.

Transshipment necessary.
The same argument applies to the great north and south traffic of the Mississippi Valley, and this traffic will be enormously increased when the Panama Canal is completed.

Some of those who have been most sanguine in reference to the improvement of inland waterways have held that their development would enable ocean-going boats to reach the heart of the country. However, this can hardly be expected. We have seen that ocean-going boats are steadily increasing in size; and a large part of the freight is already carried on boats having a draft greater than twenty feet. It is therefore to be expected that the foreign commerce must bear one transshipment; but the inner channels should be developed so that only one transshipment should be necessary. This a twenty-foot channel between New York and the Great Lakes and a fourteen-foot channel from the Gulf to the Great Lakes would accomplish for a large part of the country. 
The advantages resulting from the development of the waterways may be recapitulated as follows:-

In the first place, the freight rates will be reduced for a large part of our traffic. It is impossible to estimate, even approximately, the amount per annum of such reductions; but if we suppose that there will develop on the rivers of this country a traffic at all comparable with that on the Rhine and the Danube, the reduction in freight rates alone would justify the necessary expenditure.

In the second place, water development will relieve the congestion of the railroads and render it unnecessary to spend a vast sum of money to develop the railways sufficiently to handle the traffic of the country, estimated by Hill at about $\$ 6,000,000,000$. But in any case a part of this expenditure will be necessary, for railway transportation is sure to grow rapidly, and this will require expansions and improvements of the railway system.

Third, the storage of storm waters in reservoirs would make the water of the streams less impure. The waters would be better both for domestic supply and for manufacturing. Many lines of manufacturing require pure water. This is illustrated by the paper industry. Often a large part of the cost of the water supply of a city is occasioned by great systems of filtering plants to separate the silt and mud. If the storm waters are held at the heads of the streams in reservoirs, so that there are no great floods, and the streams maintain an equal flow, the expense in connection with supplying cities with water from rivers will be lessened. No estimate can be made as to this saving, but it will be many millions of dollars. This is entirely apart from the increased healthfulness of the waters, due to their being neither heavy with silt at time of flood, nor so scanty at times of low water as to become contaminated.

Fourth, there will be an immense reduction in flood damages. By "flood damages" is meant the actual losses which occur along the streams to constructed property in cities, country homes, railroad bridges, etc.; they have no relation to agriReduction of flood damage.

Reduction of freight rates.

Relieve congestion of railways.

Advantage of storing storm waters. 


\section{2}

Mother

Gunga

eats great allowance.
Amount of flood damages. culture, - the land itself. I do not know how many of you have seen a great river in flood; it is a most impressive sight. The stream normally occupies but a relatively little of the cut between its banks. At a time of flood the cut is filled to the brim, and often overflowing, extends across the valley, from terrace to terrace, sometimes several miles in width. Crops and houses are washed away; cities at some of the great floods are inundated; and enormous damage is done.

Doubtless the greater number of my listeners remember that Kipling's "Bridge Builders" were constructing a bridge across the Ganges. Although the piers had been sunk many feet below the shifting bed of the stream, Peroo, the native assistant, in discussing the matter with the chief engineer, said: "Mother Gunga eats great allowance. There is always room for more stone on the revetments." When Mother Gunga got up, all the stone so placed by the industrious assistant was sorely needed. In this story Kipling depicts with fidelity and insight the enormous power and impressive majesty of a mighty river in flood.

At the present time the flood damages of the country are enormous. Leighton, after a careful consideration of the facts, estimated them, in 1908 , at $\$ 237,800,000$. If one fourth of this loss were prevented, as a result of completing the storage reservoirs and developing navigation, it would be more than sufficient to pay for the entire improvement proposed of $\$ 500,000,000$ during the next ten years. As already noted, at the present time reservoir systems are only partially developed in a few regions. In the northeastern part of the United States and in New York, it is estimated that 10 per cent of the flood waters are retained by reservoirs. I have already mentioned that there is a beginning of the development of reservoir systems in Wisconsin, Minnesota, and the far West in connection with irrigation and water powers. Leighton estimates that for the United States as a whole not more than 1 per cent of the excess of the storm waters is held back in the reservoirs; and he believes, as a result of his careful investigations, that for two thirds of the country, reservoirs may be constructed which will hold from 
55 to 60 per cent of the storm waters. This being the case, it is very conservative to conclude that when this is done, flood damages would be lessened by one fourth; possibly they would be lessened by one half, or even two thirds.

Fifth, if the storm waters were restrained in reservoirs, there would be great reduction in the denudation of the land. This point I shall not further consider at this time, but shall Reduction of denudation. take it up in connection with land (see pp. 245-252).

Sixth, an incidental result of the storing of storm waters will be that large areas of land now flooded and made swamps or marshes will be reclaimed.

Seventh, the storing of the storm waters would greatly improve the water powers which have already been developed and would develop new water powers of large magnitude (see pp. 126-129).

Reservoirs are one of the more important methods of storing storm waters and preventing floods, but other measures are necessary. One of these is the preservation of the forests upon the headwaters of the streams, and especially the steep slopes of the mountains, to be mentioned later (see p. 245). The general law in reference to floods is that barren conditions without land protection or cultivation result in increasing floods. The removal of the forests lead to such conditions. Where under natural conditions there are no forests and the grasses are sparse, cultivation may have a tendency to decrease floods. As an illustration of this may be mentioned the Red River in the southwest. The development of agriculture on the headwaters of that stream has resulted in getting a larger proportion of the precipitation into the ground and has decreased the amount of floods.

If the floods are decreased, the amount of silt which is carried by them to the streams will be greatly reduced, and this will result in lessening the expense of maintaining channels for navigation.

McGee's estimate of the gains which will result from the expenditure of $\$ 500,000,000$ distributed through ten years for the improvement of the waterways is as follows: He says Incidental improvement of water powers.

Reclamation of wet lands. powers. 
Taxation as an investment.

$\$ 250,000,000$, an annual saving from flood damage of $\$ 150,000,000$, an annual saving from forest fires of $\$ 25,000,000$, an annual benefit from cheapened power of $\$ 75,000,000$, an annual saving of soil erosion of $\$ 500,000,000,-\mathbf{a}$ total of $\$ 1,000,000,000$ per annum. The proposed expenditure is at the rate of $62 \frac{1}{2}$ cents per year per capita. The saving is at the rate of $\$ 12.50$ per capita, or twenty times as much.

McGee's figures may be erroneous. The savings may be only ten times the cost of the improvement. But, even so, it is certainly true that here is an opportunity for wise investment by the government for the benefit of the whole people. But the situation with the government and the states is that the money must be raised by taxation. The profits go to the people, not the government directly, and therefore it is difficult to secure the required appropriations. The cry - we are increasing the national debt; we are increasing taxation-scares the politician. Neither the politician nor the citizen who raises the cry stops to consider that as the result of the increase in national debt, and hence an increase in his taxes, he will receive ten or twenty fold the amount in increased income. This is somewhat apart from the proper field of conservation, but those who profess political economy should carry on a campaign of education upon taxation as an investment. He is not a statesman who stands before the public and cries, "Economy! If you put me in office I shall reduce the expenditures." He is a statesman who says, "I shall reduce unnecessary expenditures; but I shall advocate all those necessary public expenditures which will prove a wise investment for the people." Very few of our public men, to the present time, have had the courage to rise to this level. We are now hearing much about economy of expenditure, but very little about making great fundamental improvements. In this respect the governments of Europe are far in advance of us. During the past few years, as we have seen (see pp. $167-168$ ), the people who occupy an area of 800,000 square miles have put in $\$ 1,000,000,000$ on the improvement of their waterways, well realizing that this vast expenditure would be justified by their increased wealth. From their increased 
income only a small fraction need be taken in taxation to pay for the improvements.

These broad statements are well illustrated in the case of the Illinois Deep Waterway, which, careful plans show, can be constructed so as to be paid by the water power developed in seventeen years; and from that time the state will have the improved navigation and the water power as a great perpetual source of wealth (see p. 132).

Conducting this part of the subject, it is manifest that improving the waterways is one of the great fundarnental questions of conservation. Improvement in navigation will not simply accomplish improvement in transportation; it will result in several other advances of the first order, among which are the lessening of flood losses, purifying the waters, lessening denudation of the land, reclaiming the swamps, and increasing the water power.

\section{IRRIGATION 1}

Irrigation is the artificial transfer to the land of water for the purposes of agriculture. Irrigation is advisable, indeed necessary, for the best results wherever the annual rainfall is twenty inches or less, or when there are frequent droughts during the crop season.

The ancients, imitating the natural inundation of the rains, practiced the art of irrigation thousands of years before the Christian era. Some of the larger countries which The ancients and irrihave long practiced irrigation are Assyria, Egypt, Persia, China, and India. At the present time there are in some of these countries immense areas under irrigation. Indeed India has the largest area of irrigated land of any country in the world. In the year 1900 the area irrigated was $31,544,000$ acres, or one third of the cultivated land of that country.

1 The chief sources of information for this chapter are: the Report of the National Conservation Commission, Vol. II, pp. 59-85; "Irrigation," F. H. Newell, Crowell \& Co., New York, 1902; "Irrigation and Drainage," F. H. King, The Macmillan Co., New York, 1899; and personal information furnished me by F.H. Newell, director of the U.S. Reclamation Service, and others. 
Egypt practiced irrigation as early as two thousand years before Christ, and probably much earlier. In ancient times the area that could be irrigated in any one season depended upon the height to which the Nile rose. In years of abundant rainfall along the headwaters of the Nile, the river rose sufficiently high to irrigate a large area; such years Egypt was prosperous. Other years in which the rainfall was small, the Nile rose but little, and the area irrigated was small; those were lean years in Egypt. And the fat and lean years have alternated in that country from Biblical times until recently. Egypt is now under the control of England. In 1902 the original Assuan dam was completed at the first cataract of the Nile, creating a storage reservoir having a capacity to irrigate a large acreage. This dam is now being increased in height, and when this work is completed, the area which can be irrigated as a result of its construction will be 950,000 acres. At the present time there are more than $6,000,000$ acres under irrigation in Egypt.

Early irrigation in the United States.

The Mormons.

In the United States irrigation is not a recent art. There are evidences of ancient irrigation in the southwestern part of the United States, especially in Arizona and New Mexico. However, the first modern extensive irrigation in this country was done by the Mormons in the eastern part of the great basin by the Wasatch. After the Mormons had moved for the fourth time to Illinois, and the conditions had become such that they could no longer remain there, they decided to move west to an area beyond the control of the United States. Utah, then a part of Mexico, was chosen by Brigham Young. Young men were sent out in advance to raise a crop, and the people of the faith later followed to assist in the reaping. Hundreds of wagons, with more than a thousand people, made their weary way across the prairies and great plains, across the plateaus and along the gulches of the Rocky Mountains, and at last wound down through the Wasatch Mountains into the superb eastern part of the Great Basin. The snow-clad Wasatch rises to the east like a wall from the plain which slopes gently westward to Great Salt Lake. Abundant rains fall upon the Wasatch, and out of them flow numerous 
streams, some of them strong, like the Weber and the Bear, and others of smaller size. It was an ideal site to begin modern irrigation in the United States. By the Mormons the waters of the streams were turned on to the land between the Wasatch and Salt Lake, and the desert was made to blossom like a rose. The Mormons were among the great pioneers of the United States.

\section{IMPORTANCE OF IRRIGATION}

The importance of irrigation cannot be overestimated, since it transforms lands which are semi-arid or arid and almost worthless to a more highly productive condition than any lands where irrigation is not practiced. Irrigation is therefore of fundamental importance from the point of view of conservation. It makes available a great resource which otherwise would be relatively unimportant. The irrigated lands have extraordinary value for the following reasons:-

(1) The arid lands are very rich in the mineral plant foods. The potassium and phosphorus have not been dissolved and washed away. They have continuous sunshine during the day.

(2) By irrigation there may be perfect adjustment between the requirements of the crop and the amount of water furnished. In humid regions, where dependence is upon natural Adjustment between water and precipitation, there may be too much or too little water. Often for extensive regions the water for a part of the season is in excess; at other times the rainfall is below the normal and the crops dry up. These conditions are wholly avoided by irrigation. At any time the amount of water may be adapted to the condition of the crops; when abundant water is needed, it is there; when at another stage of growth less water is advisable, less water is used.

(3) For the warmer parts of the United States two or three crops may be raised in a single year. Not infrequently three or even five crops of alfalfa are produced. In other cases a crop of one kind and another of a different sort are produced in a single year. 
Productivity of irrigated lands.

Value of irrigated land.

(4) Since in the arid regions the water is turned upon the land and only exceptionally is there abundant precipitation upon the fields, erosion is reduced to a minimum. Indeed, in the arid regions, in general, the natural conditions are such as result in accumulation of the soil rather than in its destruction.

It naturally follows that under the ideal conditions above disclosed, the productivity of the land is far beyond that where irrigation is not practiced. Not only is this so for the ordinary crops, but by the control of water it is possible to raise crops of the highest market value. Some of the classes of crops raised under irrigation are: (1) grains, hay, alfalfa; (2) truck, including potatoes, onions, beets, beans, peas, asparagus, lettuce, and other vegetables; (3) fruits, including apples, pears, peaches, apricots, prunes, oranges, lemons, grape fruit, olives, etc.; (4) berries, including strawberries, raspberries, blackberries, etc.; (5) nuts, such as walnuts, pecans, etc.

McGee graphically describes the increased productivity of the arid lands by the statement that, "under irrigation one hundred heads of grain replace the blade of grass, and one hundred head of kine graze where an antelope or two wandered before." "

It naturally follows that as soon as water is placed upon lands in an arid region they have a value varying from $\$ 50$ to $\$ 500$ or even $\$ 1000$ per acre. A common value is from $\$ 100$ to $\$ 150$ per acre. The higher figures apply to lands which are adapted to fruits. For irrigated lands on which there are bearing fruit trees a not uncommon price is $\$ 1000$ or more an acre; and at Grand Valley, Colorado, bearing fruit orchards have been sold at more than $\$ 4000$ per acre. These high prices are warranted because the net profits may reach several hundred dollars per acre per annum.

1 McGee, W J, "Soil Erosion" 


\section{AREA OF IRRIGABLE LANDS}

The facts given make it clear that the area of irrigated land should be extended to the highest practicable limit in order that the largest possible area of rich soil of the arid region may be utilized. The total area of land in the United States which should be irrigated is not less than $750,000,000$ acres; that is, at least this amount of land has a position, altitude, and precipitation which would make irrigation very advantageous.

The question arises, what proportion of this land can be irrigated? It was supposed a few years ago that the larger Rainfall of arid region. part of it could be supplied with water. Indeed it was thought by some at one time that rainfall could be produced by big explosions or other devices; and attempts of this kind were made in Texas, I believe. But as yet no means have been found to increase the rainfall. The average precipitation of the area of the United States below 20 inches is less rather than more than 15 inches. If, as has been seen, more than one half of this fall is almost immediately evaporated, and if another portion of it goes underground to be later evaporated in part, then the average run-off which is available for irrigation cannot be more than a fraction of 15 inches.

The United States reclamation projects are upon the basis of from $1 \frac{1}{2}$ acre feet to $5 \frac{1}{2}$ acre feet, or 18 inches to 66 inches in depth over the whole surface per annum. In the northern Amount of water required. part of the country, and in areas where the precipitation is moderate, the water required may not be more than $1 \frac{1}{2}$ feet, - as at Milk River and at Sun River, Montana. More commonly, however, from 2 to $2 \frac{1}{2}$ feet are required, and occasionally 3 feet. In the hot districts of the southwest allowances are usually from $3 \frac{1}{2}$ to 4 feet. The Salt River, Arizona, project is on the basis of 4 acre feet and the Yuma on the basis of $5 \frac{1}{2}$ acre feet per annum at the land.

The above allowances of water are liberal. In some cases, especially where the precipitation is relatively large, not more than one foot may be necessary. The amount required depends not only upon the rainfall, and upon the temperature, 
One tenth of arid land irrigable.

People to be supported by irrigated land. but also upon the kind of crop, upon the number of crops raised in a year, upon the character of the tillage, upon the presence of trees to serve for windbreaks, upon the skill of the irrigator, etc. McGee points out that if four acre feet be taken as the normal amount of water required for the soil for efficient productivity, its weight each year will be about two and one half times that of the first foot of soil, the specific gravity of the latter being taken at one and one half. ${ }^{2}$

Regarding the western arid region as occupying two fifths of the United States, this would be an area of approximately $1,200,000$ square miles, or $768,000,000$ acres. It is probably safe to say that $500,000,000$ acres of this area have an altitude and surface of a kind so that it would be advantageous to place water upon them if this were practicable. But under the most favorable circumstances it will not be possible to irrigate more than a fraction of this vast area. According to Fortier, who has carefully studied this problem, the area capable of irrigation is not greater than about $45,000,000$ acres, or less than one tenth of the land which could be irrigated to advantage.

At the end of 1908, in the far West there were under irrigation some $13,035,700$ acres of land, or approximately between one third and one fourth of the amount which will be irrigated in the future. When the full $45,000,000$ acres are irrigated, they will support a great number of people. It is safe to say that five acres of irrigated land will support at least one person under present conditions, and 45,000,000 acres will support $9,000,000$ people. I have no doubt whatever that in the future $20,000,000$ or more people will be supported directly or indirectly from irrigated land.

If only one tenth of the land which should have more water can be irrigated, this leaves nine tenths available for dry farming and for ranching purposes. This part of the subject will be treated under soils (see pp. 274-277). 


\section{THE RELATION OF IRRIGATION TO FORESTS AND TO RESERVOIRS}

It has already been pointed out that the forests at the headwaters of the streams act as a restraining influence on Forests and the flow of water and, therefore, distribute it more uniformly. Hence the preservation of forests at the headwaters of the more important streams, and especially those in the mountains, is extremely advantageous for irrigation, exactly the the same as for water powers.

Also, the same principles and ideas apply with reference to reservoir sites and the storage of waters for irrigation that apply to water powers. The development of reservoirs for irrigation has been undertaken upon a great scale by the United States Reclamation Service.

\section{SOURCES OF WATER}

The sources of water for irrigation are wells, springs, tanks, and canals.

In India, in 1899-1900, 13,644,460 acres of land were irri- Irrigation gated by canals, $4,388,375$ by tanks, and $12,287,218$ by wells. These figures are given to show the surprisingly large acreage irrigated by wells, which requires the artificial raising of the water to the surface. This is due, in India, to the extraordinarily dense population, cheap labor, and the small holdings of land. Irrigation from wells is there possible on a scale which could not be approached in America under present conditions.

In the United States, irrigation is subordinately by wells and springs, but mainly by canals. Irrigation by wells has become of increasing importance. The artesian well is an by wells. important source of water for irrigation. The use of such wells is perhaps best illustrated in the Dakotas, especially in South Dakota. In that state are several formations which are water bearing, the most important being the Dakota sandstone. These formations come to the surface and are

The artesian well. 
Pumping of water.

filled with water in the neighborhood of the Black Hills. East of the Missouri and along the Missouri Valley, at distances of from 150 to 200 miles, are more than a thousand wells, the aggregate flow of which is estimated by Darton at $7,000,000$ gallons a day. ${ }^{1}$ Many wells yield from 1000 to 1500 gallons per minute, with an occasional one reaching as high as 2000 gallons or more, although much the larger number yield less than 1000 gallons per minute.

Where the water is comparatively near the surface, it is often profitable to pump for irrigation. This is especially true for the more intensive crops, such as fruit and truck. This is very well illustrated in the Arkansas Valley of Kansas and in southern California, in both of which areas pumping of underground water for irrigation is done on an extensive scale. The greater irrigation projects of the United States supply water through canals. At the present time large expansions of canal irrigation are taking place. Also, where cheap power from water is available, water may be pumped from the streams to lands that cannot be reached by gravity canals.

\section{THE IRRIGATED LANDS}

It has already been noted that in the United States are more than 13,000,000 acres under irrigation. This land has been reclaimed in small part by individual action. That is, a man has taken up a homestead, and by his individual effort has conducted from a stream, usually a small one, water to irrigate his farm.

But much the larger part of the irrigation work has been done by combination. Most irrigation projects are too large to be undertaken by one man. At the present time irrigation is mainly being extended through four plans: -

(1) By coöperation of farmers and by small corporations;

(2) By the creation of irrigation districts;

(3) Under the Cary Act;

(4) By the Reclamation Service. p. 64.

"Geology and Underground Waters of South Dakota," N. H. Darton 


\section{(1) Coopperation and Corporations}

The aggregate acreage of land irrigated by the coöperation of individual farmers and by small corporations is very large. This was the method of irrigation in its early development in this country, and according to Newell the larger number of existing ditches have been built by such organizations. He thinks the total acreage irrigated in this way is as large or larger than that produced as a result of forming irrigation districts and the Cary Act, considered below.

\section{(2) Irrigation Districts}

In the western states a group of people get up a plan to make a certain area an irrigation district. The plan must have the affirmative vote of the people concerned, often a majority, but in some cases two thirds. The cost of the construction of the ditches, etc., is assessed upon the land benefited by the improvements. The necessary money is raised by bonds upon the land. Usually in such cases the interest only is payable for the first ten years, thus affording the people for a time an opportunity to put the main part of the income into improvements. The second ten years the bonds are extinguished by partial payments. Thus, ultimately, the canal and all the water works in connection with the improvements become the property of the landholders.

\section{(3) The Cary Act}

The Cary Act, which was passed Aug. 18, 1894, provides for reclamation by coöperation between the nation, state, corporation, and individual. Under this act the states of Colorado, Idaho, Montana, Nevada, Oregon, Utah, Washington, and Wyoming were each given 1,000,000 acres of land, provided they complied with the conditions of the act. To Wyoming and Idaho, each, in 1908, there were an additional 1,000,000 acres granted. The method of development is similar to that of the irrigation district. A company forms 
a project. This is submitted to the state authorities. If approved by the state, the government at Washington is requested to withdraw the land from entry, and give the control of it to the state. These two things done, the individual owners enter into contracts with the water company for the water rights, and they have a perpetual interest in the irrigation works. Commonly the land is sold by the state to the individual at a very low price, - in Wyoming, at fifty cents per acre. Under this act the government has patented 293,000 acres and has approved plans but not patented 1,716,000 acres. Also there are many other projects before the government for approval. The Cary Act is therefore likely to result in a large increase in the irrigated land of the West.

\section{(4) The Reclamation Act}

Money from sale of lands dedicated to irrigation.

Variety of business of reclamation service.

But the most notable of the recent steps in progress for irrigation has been made under the reclamation act of June 17, 1902. Under this act money from the sale of the public lands in the West was made a reclamation fund. Congress definitely committed itself to dedicate the funds derived from the sale of the western public lands to irrigation. The act gives to the Secretary of the Interior large discretion in the disbursement of the reclamation funds for irrigation works. Sometimes it has been said that the government should not engage in business, because to do so is socialistic. But under the reclamation act (I do not say this was considered by Congress at the time the act was passed) the government has engaged in many kinds of business.

According to Director Newell, the reclamation service has made some 350 miles of roads; has built about 1000 bridges, having an aggregate length of about five miles; has engaged in manufacturing various articles for storage dams and other works, including the making of bricks and cement. It has run general stores to supply workmen and their families; it has established and maintained extensive board- 
ing houses, the number fed varying at different times of the year from 1000 to 5000; it has built houses for the engineers; also various other activities have been entered into. In short, the reclamation service has done all the kinds of business necessary to irrigate the arid fields in districts where no, or only a few, people lived. These business enterprises were absolutely necessary if the great dams, the long tunnels, the immense ditches, required to reclaim the arid region, were to be constructed.

The reclamation fund, to June 30,1909 , had reached the sum of about $\$ 58,582,000$, and to that time there had been spent in reclamation work $\$ 45,750,000$. According to the Secretary of the Interior water could be supplied to 767,958 acres of land, making 12,198 farms. Actually at that time water has been supplied to 424,549 acres and to 7970 farms.

In 1908 there were thirty projects in various stages of construction, which when completed will irrigate 3,037,961 acres of land. It is not possible in these lectures to describe in detail these projects, but certain features of some of them may be mentioned to illustrate their magnitude.

The Salt River project of Arizona is to have the great Salt River Roosevelt dam, 280 feet in height,' with a storage area of 16,320 project. acres, and a capacity of $1,284,000$ acre feet. The main canals are to be 119 miles in length and the laterals 208 miles. Water power to the extent of 4400 horse power will be developed. On the basis of the duty of water of four acre feet per annum, 240,000 acres of land will be irrigated. The products are to be semi-tropical fruits, sugar beets, and alfalfa.

The Sun River project of Montana has one large reservoir. Canals are to be constructed as follows: 0.3 mile with capacSun River project. ity greater than 300 second feet, 17 miles with capacity less than 300 second feet and greater than 50 second feet, and 88 miles with capacity less than 50 second feet. With a duty of water of two acre feet per annum, 276,000 acres of land are to be irrigated. The principal products will be hay, grain, and vegetables.

The Truckee project of Nevada and California uses as 
Truckee project.

Rio

Grande project.

Cost of the thirty projects.

Issue of bonds.

Cost to be repaid by settlers. its natural reservoir superb Lake Tahoe, having an area of 125,000 acres. Canals are to be constructed as follows: 104 miles with capacity greater than 300 second feet; 79 miles with capacity less than 300 and greater than 50 second feet; 487 miles with capacity less than 50 second feet, - making a total of 670 miles. With the duty of water of three acre feet per annum at the farms, 206,000 acres are to be irrigated. The principal products are alfalfa, grain, potatoes, and onions.

The Rio Grande project of New Mexico and Texas is to have a reservoir with an area of 40,000 acres, with a dam 265 feet high, and a capacity of 2,538,000 acre feet. This will be the greatest capacity of any reservoir in the world. With the duty of water of two and one half acre feet per annum, 180,000 acres of land are to be irrigated.

The cost of the thirty projects, now either finished or in process of construction, is estimated at $\$ 119,555,000$. The estimated value of the land without improvements when irrigated is $\$ 239,435,600$. Since the land has comparatively little value without irrigation, this represents a profit to the farmers who get the land of not less than $\$ 100,000,000$. This takes no account of the vastly greater profits to the nation to be derived from the products of more than $3,000,000$ acres of land which otherwise would give a very small return. If these profits be figured at the very conservative amount of $\$ 25$ per acre per annum, it would amount to $\$ 75,000,000$ per annum.

In order that the projects under construction may be carried to completion as soon as possible, President Taft has recommended to Congress that authority be given to issue not to exceed $\$ 30,000,000$ of bonds, the proceeds to be applied to the completion of these projects, and to be repaid from the reclamation fund. The bonds are to run for ten years, and it is estimated that the income from the completed enterprises will retire the bonds within the time specified.

The cost of any given project is assessed against the land benefited, and it is to be paid for in ten years. Thus the $\$ 45,750,000$ invested by the United States government will be returned to the reclamation service, to be again used in the 
further development of irrigation projects. Also, the fund is being continuously increased by the sale of public lands. Therefore we may expect in the not distant future that if this wise reclamation law remains unchanged, the irrigable land of the West will be reclaimed. So far as the development of our resources is concerned, the reclamation act is one of the greatest which Congress has enacted or is likely to enact.

Reclamation work by the government was first strongly advocated by Major J. W. Powell, the one-armed soldier, who in 1869, first among men, went down the cañon of the Colorado. His studies of the arid region, begun that year, continued through the following years. Ten years later, in 1879, appeared his report on the lands of the arid region of the United States.

This report contains the first comprehensive account of this region. Major Powell clearly saw that the lands of the arid region should be divided into three classes, irrigable lands, pasture lands, and forests. He advocated that special laws should be formulated, adapted to each of these classes. Almost every fundamental point now understood with reference to the character of these lands was appreciated by him, with the exception that dry farming was not then known. After Major Powell's report on the arid lands was published, another decade of advocacy by him for reclamation was required, before in 1888,1890 , and 1891 acts were passed by Congress making appropriations for an irrigation survey, and authorizing the withdrawal from private entry of reservoir sites selected by the Geological Survey for water storage.

From the irrigation survey of 1888 resulted the reclamation act of 1902. To Major Powell is due the credit of being a great pioneer in this movement of such immeasurable importance to the nation. I well remember a conversation with Major Powell fully twenty years ago; he then in substance said: "The people of the West think it possible to irrigate a large part of the arid land (or as they prefer to call it, the semihumid land), but I believe that probably not more than one tenth can be irrigated." This broad judgment, made without accurate computations, but with comprehensive knowledge 
Loss by reckless use.
Loss due to law of prior appropriation.

of the region, has been completely confirmed by recent accurate studies.

\section{LOSSES DUE TO CARELESS USE OF WATER}

Since at best it is possible to reclaim only a fraction of the arid region, it is important that the highest efficiency of the water shall be secured. At the present time there are great losses in the water due to the following causes:-

1. Many of the contracts for irrigation are based upon the number of acres to be irrigated rather than upon the amount of water. The contracts say a sufficient amount of water shall be furnished to irrigate a certain tract. Under these circumstances there is no stimulus to economy. The farmer uses water freely, recklessly, as his fancy dictates, without any reference to anything but the crop of that year. If, however, the charge was, in all cases, upon the basis of the amount of water used, this resource, like any other valuable commodity, would be used economically.

2. There is great loss of water under the law of prior appropriation. The law says that the prior appropriator may take a sufficient amount of water to irrigate the area upon which he filed and applied water. Again there rises exactly the same situation as in the case of a contract with a company. The man uses water freely, often more than necessary, and without reference to the needs of later appropriators.

Loss due 3. There are great losses because of imperfect application to imperfect application.

of the water. Fields are poorly prepared, so that the water does not spread over them uniformly, and more water is used than is really required. This waste will be corrected in large measure as soon as the payment for water is upon the basis of the amount used; for then there will be an incentive to prepare the fields properly and so use the water economically.

Loss by seepage.

4. There is large loss of water in many cases by seepage through the canals. Many of the canals are cuts in open, porous soil. The soil in the West is not commonly of the clayey kind which can be puddled and made practically impervious. The seepage under those circumstances is very great in the canals. This loss can be remedied by the construction of 
cement canals, but such construction is very expensive and can only be possible where the water is very valuable.

Fortier says that in different cases the loss of water in irrigation varies from 10 per cent to $33 \frac{1}{3}$ per cent, and he thinks Estimate of the probable loss upon an average at the present time is 25 per cent. If this figure be correct, and it were practicable to eliminate this loss, the $13,000,000$ acres at present irrigated could be augmented by $3,250,000$ acres. If the value of the land were thereby made $\$ 100$ per acre, there would be an increase of wealth of $\$ 300,000,000$, without considering the products raised by the enlarged acreage.

But the waste of water is not the only or principal loss resulting from careless use. The water from leaky canals and from seepage dissolves the alkalies, carries them to the lower ground, where, rising to the surface by capillarity, the water is evaporated and the salts in solution deposited. Also, excessive seepage renders the land swampy. Many thousands of acres of good land have been thus destroyed. These results are illustrated in the Yakima Valley of Washington by extensive alkali marsh flats, - lands originally desert, then made valuable farms, and now ruined.

\section{IRRIGATION IN SUBHUMID REGIONS}

Between the humid region and the arid region, there is a great semiarid or subhumid region, call it which you will, running from approximately the 98th or 100th meridian to the $103 \mathrm{~d}$ or 105 th meridian. This area, roughly about one fifth of the United States, 600,000 square miles, or $384,000,000$ acres, lies mainly in the states of North Dakota, South Dakota, Nebraska, Kansas, Oklahoma, and Texas. This is the eastern part of the great plains, which forty years ago used to be called, on the schoolroom maps, the great American desert. This is the debatable ground. In years of abundant rainfall there is enough water to raise a crop. In dry years there may not be enough rainfall to raise a crop satisfactorily, although dry farming has improved the conditions very much. In this region, from 1876 to 1885 , the precipitation was much above 


\section{CONSERVATION OF NATURAL RESOURCES}

normal. During these years the people drifted out into this area, and there were times of prosperity. Following these years were several dry years, 1886 to 1901 , during which the precipitation was below normal. For extensive areas, when the seed was put into the ground, the wheat or corn would start to grow and then would come the drought with the hot winds, and the crops would wither. One of the greatest tragedies of the western movement of our people came at that time. Many thousands of people who had drifted out into this area, taking with them all that they had, came back with nothing, gaunt and discouraged. With 1902 again began a period of more than ordinarily humid years, and again the people have settled this area. They have had several years of prosperity. But the dry years are sure to come again, probably not with such disastrous consequences as the dry period of 1886 to 1901 , for there has been considerable accumulations of property and dry farming have been discovered. By this practice in western Kansas, Nebraska, and the Dakotas a crop can be raised under conditions of such scanty rainfall as formerly would have resulted in complete failure.

\section{IRRIGATION IN HUMID REGIONS}

Irrigation advisable in humid region.
The eastern humid region comprises two fifths of the United States, or roughly an area of $1,200,000$ square miles, or $768,000,000$ acres. While irrigation has not been generally practiced in this region, there is no doubt that it will be there greatly extended in the future. In regions in which the average precipitation is more than twenty inches, regions in which if that amount of water fell each year and was favorably distributed it would be ample to raise a crop, irrigation is often advisable. Frequently the water is very unequally distributed during the year. Where the average precipitation is thirty inches or more, in exceptional years the precipitation may fall far below this amount, may in some cases not exceed more than one half of the normal fall. Indeed, there is scarcely a year in most of the areas of the United States in which some crop at some season does not suffer from lack of rain. Con- 
sequently, irrigation in humid regions is an advisable supplement to precipitation; it may be regarded as a form of insurance of success. As the population increases and as the need for food grows, there will be great extensions of irrigation in humid regions. If in arid regions, where water is perfectly controlled, it is possible to produce much more prolific crops than in humid regions under normal conditions, why not in humid regions add water to the land when it is deficient, and so make the crops in such regions as nearly as possible match those in the irrigated western areas? In some cases, for intensive crops, such as truck and fruits, which should perhaps return $\$ 200$ or $\$ 300$ per acre, or more, in a dry season, may return no more than $\$ 100$ an acre. Also, for ordinary crops in dry seasons the yield will be much increased by irrigation.

Already these facts have begun to be recognized in some regions with reference to some crops. In New England, at the present time, orchards are being irrigated somewhat extensively. In the truck farms which extend from New Jersey to Georgia irrigation is practiced at various points, but usually in a small way. In the Gulf country of Louisiana and Texas, especially on the rice fields, irrigation is practiced. In most cases the water for irrigation is derived from small streams, springs, or wells. One reason for this is the difficulty with riparian rights which long hampered irrigation in the West, and which have there been disposed of or greatly modified (see pp. 202-204).

In the Upper Mississippi Valley, the great garden of the world, where the conditions of precipitation and fertility are unsurpassed, as yet little has been done in the way of irrigation; but doubtless the development which has been begun in the East will extend to this region.

The crops to which irrigation has been applied in the humid regions, to the present time, are mainly the intensive kinds; such as fruit, including cranberries, apples, peaches, berries, etc.; and truck, including celery, asparagus, onions, beets, etc. 
Common law of water not applicable to arid regions.
New wine in old wine skins.

The first in time the first in right.

\section{IRRIGATION LAWS}

The facts given naturally lead to a brief consideration of irrigation laws. It is clear that the laws controlling water in the regions where irrigation is required, must be different from those in humid regions. The common law coming over from England to this country is adapted to the eastern humid part. It is the standard law of the humid regions that water must not be permanently diverted from its bed. In an area requiring irrigation the one thing that must be done is to divert the water from the natural channels. A part of it may by seepage go back again, but the remainder is used up by evaporation and by the transpiration of the crop. Therefore the common law principles controlling water, built up in humid England upon the common needs of the people living there, were found wholly unadapted to the conditions in the West, where the common needs of the people are widely different. Had England been an arid country instead of a humid one, it is safe to say that the common law there developed would have followed the needs of an arid region. It is absurd to attempt to apply the water law of a humid region to an arid one.

Therefore it has been necessary, by legislative enactments, to make new laws, or by judicial decisions to put new interpretations on old laws. Truly, the latter has been putting new wine into old wine skins; but law fiction under judicial rulings has sometimes been found equal to the task. The common law, which should truly represent the needs of a people, has been so interpreted that it is now recognized in the western states that the water can be diverted from its bed. In order to accomplish this, the privileges of the riparian owners have been greatly curtailed.

The fundamental law in reference to water which has grown up in the West is this: The first in time is the first in right; that is to say, he who first files on water for a definite beneficial purpose and uses it for that purpose has the first right to it. No man may later go above him and divert that water and so make the property of the prior appropriator valueless. 
This law is modified by the condition that the use shall be continued. In order to retain the right of appropriation, it must be continuously exercised, or exercised at reasonable intervals.

The principle of the prior appropriator of water has been upheld by the United States Courts as between the states. If, for instance, water is first appropriated by Kansas on a stream which heads in Colorado, then the people in the state of Colorado must allow a sufficient amount of water to go by to meet the needs of the prior appropriators in the state of Kansas.

Says the Supreme Court in reference to the claims of Kansas: "It is obvious that if the depletion of the waters of the river by Colorado continues to increase, there will come a time when Kansas may justly claim that there is no longer an equitable division of benefits, and may rightfully call for relief against the action of Colorado, its corporations and citizens, in appropriating the waters of the Arkansas for irrigation purposes." 1

It has been indicated already that the law of riparian rights as in force in the East required modification to meet the western conditions. In many of these states riparian rights have been practically obliterated or limited by beneficial use, and in some states altogether ignored. For instance, in the state of Nevada the principle of riparian rights was first accepted by the Supreme Court, but finally in 1885, after a review of the entire situation, the court of that state decided that the doctrine of riparian rights "was entirely unsuited to the conditions existing in that state, and therefore never was and never could be the law for that jurisdiction." 2 Similarly, the Supreme Court of Oregon recently decided that this doctrine was not applicable to that state. $^{3}$

1 "Conservation of our Natural Resources and of our National Strength and Virility," by A. A. Bruce, Pennsylvania Law Review, December, 1909, p. 154 .

${ }^{2}$ "Reclamation of Lands by Irrigation," by Morris Bien, An. Am. Ac. of Pol. and Soc. Sci., Vol. XXXIII, No. 3, p. 673.

${ }^{3}$ Loc. cit., p. 674. 
Modification of law of riparian rights.

In other states, where riparian rights have been recognized by the courts, the same principle has been applied to them as is applied in the case of the diversion of water; that is to say, the riparian rights extend only to the degree of beneficial use. If a riparian owner has had water sufficient to serve a thousand cattle, a sufficient amount of water must be allowed the riparian to meet the use. But the principle that the riparian owner shall have the use, at any time in the future, of all the water which originally flowed in the bed of the stream, as has been held in the humid region, has been wholly abandoned in the West, partly by statute, partly by judicial decision. Public sentiment demanded of the courts that the laws be interpreted to meet the needs of the people rather than by maintaining rigidly the principles developed in other countries and not adapted to their needs. This question, which has been fought out in the West, will be sure to be raised in the East with reference to water for irrigation; and can we doubt that law and judicial decision will finally modify the rights of the riparian owner, so as to give the greatest good to the greatest number? But where the riparian rights have been long recognized, as they have in the East, and the public needs require their modification or extinguishment, this should be done by due process of law with just compensation.

That this is possible is clearly indicated by the pronouncement of the United States Supreme Court as follows: "Few public interests are more obvious, indisputable, and independent of particular theory than the interest of the public of a state to maintain the rivers that are wholly within it substantially undiminished, except by such drafts upon them as the guardian of the public welfare may permit, for the purpose of turning them to a more perfect use. This public interest is omnipresent wherever there is a state, and grows more pressing as the population grows. It is fundamental, and we are of the opinion that the private property of riparian proprietors cannot be supposed to have deeper roots."

1 "Conservation of our Natural Resources and of our National Strength and Virility," by A. A. Bruce, Pennsylvania Law Revicw, December, 1909 , p. 155. 
In order that the law of prior appropriation shall give satisfactory results, great care is required in its execution. We have already seen that the defect in this law is that the prior appropriator may divert more water than is necessary, may use the water carelessly; therefore it is necessary to control the general principle by careful legislation. The great difficulties in reference to the recognition of prior appropriation have led in some states to prorating of waters by groups. For instance, it does not seem just that a man who has appropriated water on one day shall have all that he needs, and even an excessive amount, for the tract of land which he wishes to irrigate, and the man who comes along the next day shall have no water. This condition of affairs has led in certain states to classifications of appropriations. The state of Utah has been mentioned as one in which irrigation wás first extensively practiced. In that state there has been full recognition of all appropriations prior to 1870 . The appropriations between 1870 and 1880 are made a second lien and those since 1880 a third lien.

In some states, however, and under some conditions, the law has developed even farther than this; that is, the question has been taken up broadly as to what use of the water will really best serve the greatest number, and the water has been apportioned among the users. This principle cannot be extended too far, since the amount of land which is irrigable is far beyond the amount which can be adequately supplied with the water.

State control has led usually to satisfactory results. One of the best examples is Wyoming. In that state the right to use the water can only be obtained by application regularly State control advisable made to the state engineer, who ascertains whether there is unappropriated water. If there is no unappropriated water, the rights of the applicant are not recognized; if there is unappropriated water, his rights are recognized. The water in a given district is then prorated among those who are recognized as having water rights.

In the past there have been great abuses in reference to the development of waters, especially by ditch companies. 
Abuses of water rights.

Water the property of the state.

In many instances a ditch company has agreed to furnish water for a much larger acreage than practicable by their water rights. In such cases, and especially in years where the rainfall is below the normal, the result has been that farmers who have bought land with the condition that water was to be furnished, have been unable to secure the water. Great wrong has been done in thousands of cases in this way. Such cases make it clear that state regulation is necessary. Exactly as no individual should be allowed to file a water claim if there is no unappropriated water, similarly a ditch company should be obliged to confine itself in its obligations to the area which the water controlled by the company can feed; and that determination should be made by an uninterested party, - a representative of the state.

In conclusion, with reference to the state laws, we see that they should provide against waste of water; they should provide for the sale on the basis of the amount furnished rather than the area irrigated; they should provide for the control of appropriation.

The western states, probably better than any other region, illustrate the fundamental principle which has been recognized in common law, that the water is not the property of the individual, but is a part of the common property of the people. The land may be owned; ditches and flumes may be controlled by private parties; but the water itself in the streams and ditches, the corpus, is originally the property of the state, and only passes from the state to individuals as laws and customs permit that passage. This principle is clearly recognized in the judicial decisions. It is understood perfectly of the public domain of the West that the water belongs to the national government; and, therefore, that originally a man who was a riparian owner had no possession of the water, merely its use for certain purposes. The question, of course, in any state is, how far that commodity which was originally the property of the people as a whole has passed into private hands, - the extent to which this right has been given up; and here is abundant 
ground for difference of opinion. The situation is different in different states, and different solutions of the problem will be reached, each more or less well adapted to the conditions of a particular state.

At the outset of this course of lectures I called attention New conto the fact that when there are new conditions, it may be that rights of the public, long unasserted, may be asserted. ditions result in When it is supposed that there is an illimitable supply of a commodity, then we do not especially stress the public rights. When, however, because of the growth of the population and increasing demands, there is necessity for more of a particular resource than can be furnished under the changed conditions, we begin to ask the question, how far has the public a right in this commodity? And it is clear, under such circumstances, that the government and the state will assert all of the rights which they have not regularly allowed to pass from them; and properly so. This statement is no forfeiture of the recognition of the rights which have actually been transferred to individuals or corporations. So far as this is the case, and they are again necessary to the public under the new conditions, they should be legally expropriated by condemnation with just compensation. new laws. 


\section{PART III}

\section{FORESTS 1}

7 HE United States originally had a forest which for 1 extent and value was not equaled by that of any other civilized nation; indeed, it is doubtful if anywhere else in the world in an area of 3,000,000 square miles was contained a forest so valuable for all purposes. The United States, located in the temperate region, includes the great area most favorable to coniferous growth; and therefore contained vast quantities of soft wood, timber which for constructional purposes has exceptional value.

\section{THE ORIGINAL FORESTS}

The original forests of the United States are classified in five great divisions: ${ }^{2}$

First, there was the great northern forest. It included New England with the exception of Connecticut and Rhode Island; the larger part of New York and Pennsylvania; an extension from Pennsylvania along the Appalachian Ridge to northern Georgia; and more than one half of Michigan, Wisconsin, and Minnesota. This forest was the home of the white pine; with it were red pine, spruce, hemlock, cedar, balsam, fir, birch, black cherry, sugar maple, and other hard woods. It is estimated that this forest contained originally $150,000,000$ acres, with not less than $1,000,000,000,000$ feet of board measure ${ }^{3}$ of merchantable saw timber.

1 The information concerning forests is mainly from the Report of the National Conservation Commission, Vol. II. pp. 179-686.

${ }^{2}$ U.S. Dept. of Agriculture, Forest Service, Circular 166, by R. S. Kellogg. thick.

3 A foot board measure is a piece of wood one foot aquare and one inch 
Second, the great central forest lies between the northern and southern forests, into which it merges on either side. It was the great hardwood forest; it contained walnut, oak, elm, hickory, cottonwood, maple, basswood, chestnut, sycamore, red gum, and ash. The central forest contained about $280,000,000$ acres, and the merchantable saw timber is estimated at 1,400,000,000 feet board measure.

Third, the great southern forest extends from southern New Jersey along the coast nearly to Mexico; it includes large parts of Delaware, Maryland, Virginia, the Carolinas, Georgia, Alabama, Mississippi, and Texas, all of Florida and Louisiana, and parts of Arkansas, Oklahoma, and Missouri. This was a great coniferous forest, yellow pine predominating; with the pine were cypress, gum, magnolia, yellow poplar, oaks, and other varieties of hardwood. This forest contained something like 220,000,000 acres, with not less than 1,000,000,000,000 feet of board measure of merchantable timber.

Fourth, the Rocky Mountain forest was chiefly coniferous. Yellow pine was the most important species; lodge pole pine, larch, spruce, Douglas fir, western red cedar, and other soft woods were abundant. This forest contained not less than 110,000,000 acres, with 400,000,000,000 feet board measure of saw timber.

Fifth, the Pacific forest of Washington, Oregon, and California was almost exclusively coniferous. It consisted of western Douglas fir, yellow pine, redwood, western red cedar, sugar pine, and other firs and spruces. This forest had 90,000,000 acres, and contained not less than $1,400,000,000,000$ feet board measure of saw timber.

I do not know how many of you have seen the great forests of the coast ranges of California and the Sierra Nevada. Those who have not, have a great pleasure before them. We who live in the central or eastern part of the country, even in the areas where the forests are fine, can gain no conception of the magnitude of the trees in those areas, or the density of the forests. The Douglas fir, the redwoods, the sugar pine, have diameters from six to fifteen feet, and ex- 
ceptionally even more. They range in height from 150 to 300 feet, or even in exceptional cases to 350 feet. It is indeed most impressive, in the open forest in the Sierras, to wander about among those giant trunks and look up to the great tops which seem almost to be a part of the sky.

The original forests of the United States contained not less than $850,000,000$ acres, having not less than $4,800,000$,000,000 feet of merchantable saw timber. In addition, in the United States were probably about $150,000,000$ acres of scrubby forest and brush land not containing merchantable timber, making altogether approximately $1,000,000,000$ acres once forest-covered.

This was our magnificent original heritage. The United States as a nation has existed a century and a quarter, and what have we now? In that brief time approximately one half of the value of our forests has gone. In the northern forest there are some $90,000,000$ acres, or 60 per cent of the original area; in the central forest $130,000,000$ acres, or 46 per cent; in the southern forest $150,000,000$, or 68 per cent; in the Rocky Mountain forest 100,000,000 acres, or 91 per cent; and in the Pacific forest $80,000,000$ acres, or 89 per cent. Thus the forests still cover some $550,000,000$ acres, or one fourth of the United States.

\section{THE EXISTING FORESTS}

While these figures show about 65 per cent of the original forest still standing, since the best timber has been cut, and the existing forests have been damaged by fires and in other ways over extensive areas, it is certain that we do not have more than one half of the merchantable saw timber originally possessed by the United States. Of this remaining forest, which still is vast compared with the wood property of most other nations, about one fifth is owned publicly, and four fifths is in private hands. 


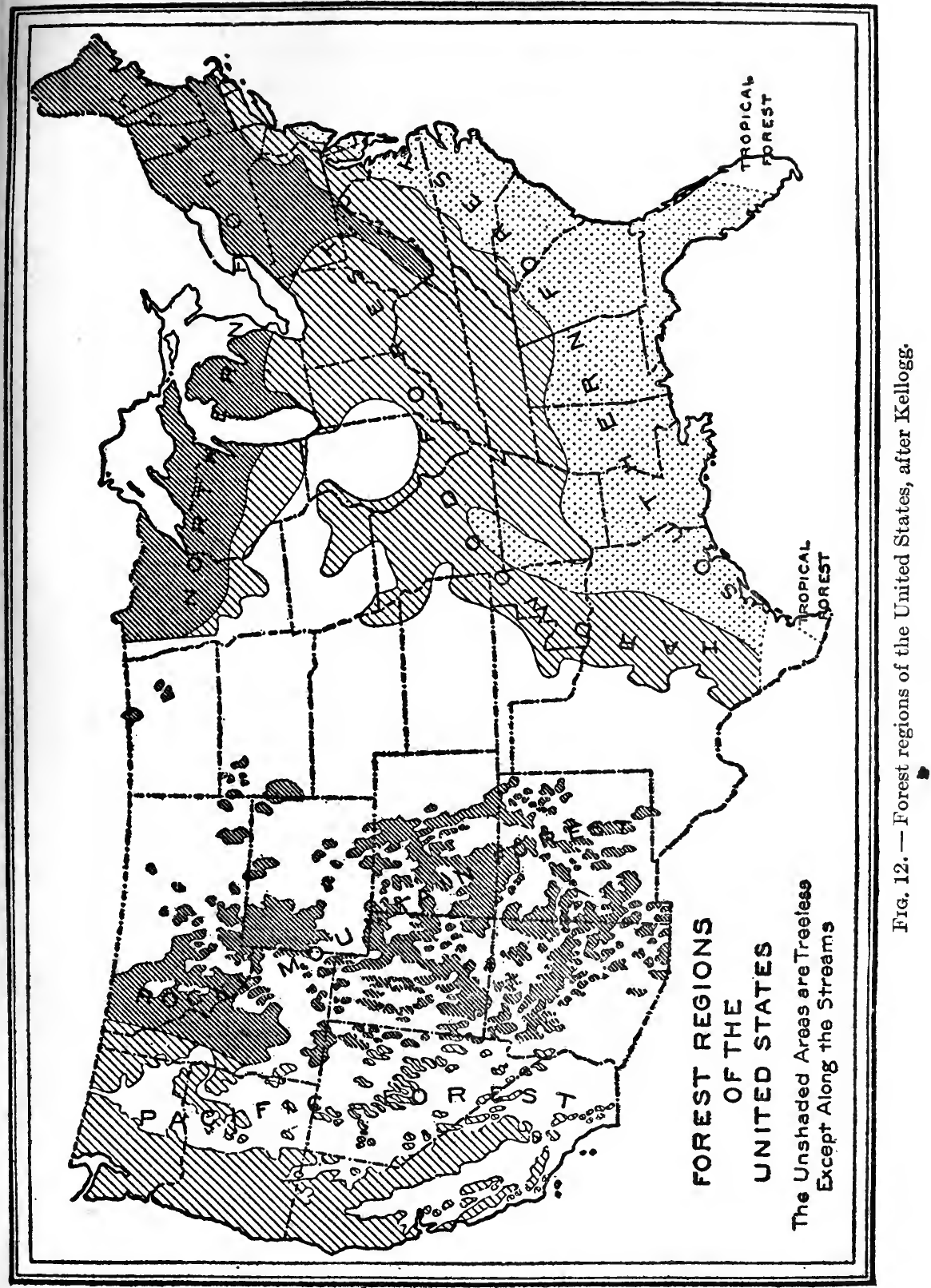




\section{THE PRIVATE FORESTS}

The privately owned forests fall into two classes, the small and the large. The small holdings are for the most part the farmers' wood lots. These wood lots have been culled so that the lumber upon them is not so valuable upon the average as it was originally, but still it is estimated to contain some $300,000,000,000$ feet of board measure of saw timber and about 1,500,000,000 cords of wood. These wood lots cover in the neighborhood of $200,000,000$ acres, or 95 per cent of the forests east of the great plains. The large holdings, corporate and individual, are estimated to contain $1,700,000,000,000$ feet of saw timber. Since the corporations have very naturally taken the best timber available, this privately held timber is by far the most valuable of the wood resources in the United States.

\section{THE PUBLIC FORESTS}

The history of the first forest reserve.
The public holdings ${ }^{1}$ of timber are fortunately still large. The early reservations by the United States government were for military purposes and for national parks. Under Harrison's administration began the withdrawal of the timber lands of the West as forest reserves, later to be called national forests. The origin of the movement which resulted in the national forest may be traced back to a paper read before the American Association for the Advancement of Science at Portland in 1873, by Franklin B. Hough. This paper showed a remarkable appreciation of the evils which have come to other countries as the result of the removal of the forests, and especially the removal of the forests in the mountainous regions. Hough pointed out the great advantage to the nation of withholding from sale the forest lands of the West, especially those in wild unbroken regions. He fully appreciated the influence of the forests in maintaining a

1 "The Public Holdings of Timber." "Standing Timber in Posession of the Government," G. M. Homans. "Standing Timber Owned by the States," I. Girvin Peters, N. C. C., Vol. II, pp. 191-195. 


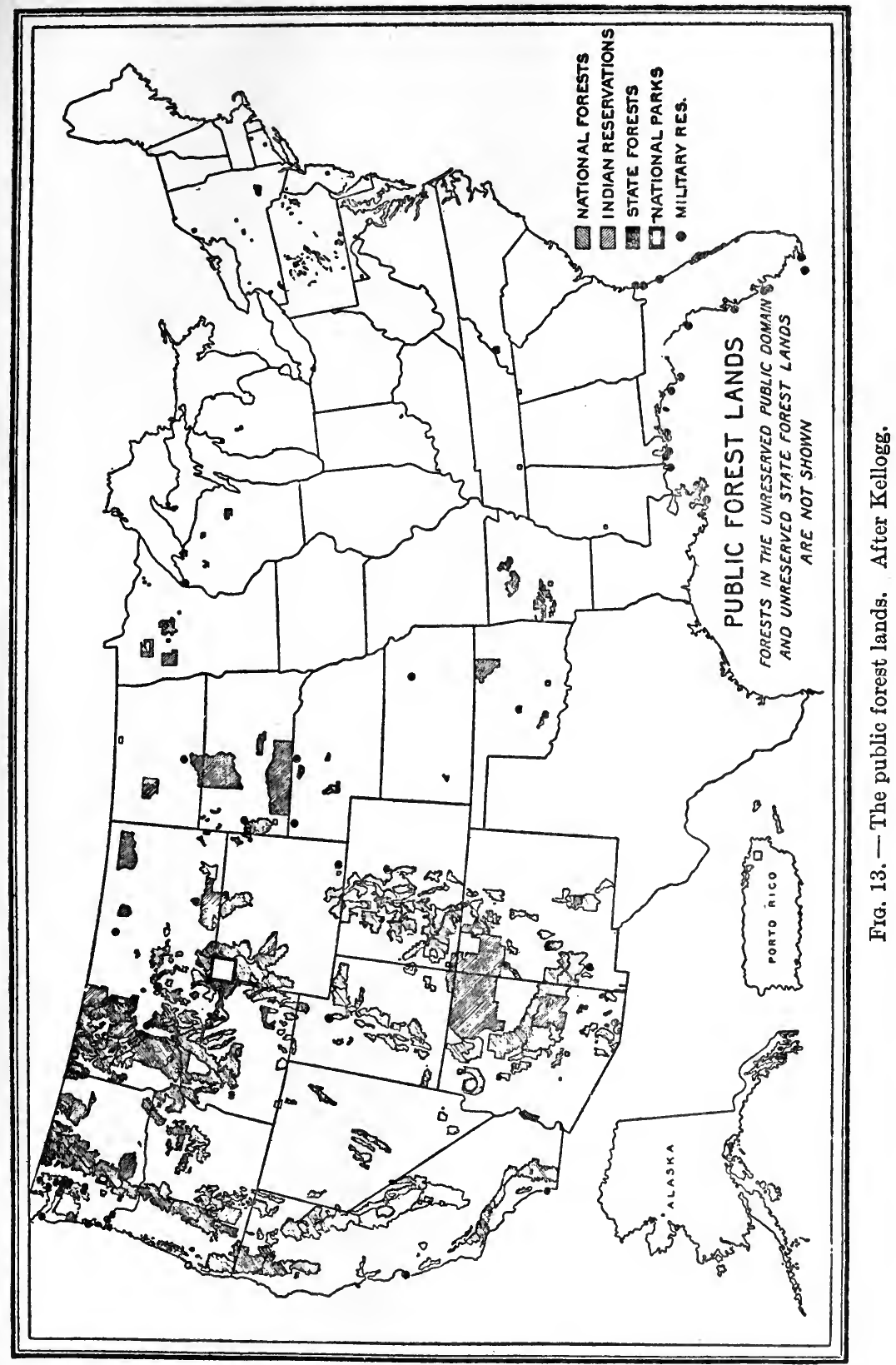




\section{CONSERVATION OF NATURAL RESOURCES}

uniform flow of streams, but indicates that to give such uniformity forests will need to be supplemented by reservoirs.

National forests result of work of scientific men.

In 1874 a memorial was presented to Congress by a committee of the American Association for the Advancement of Science, Mr. Hough being chairman of the committee. This memorial resulted in the establishment of the division of forestry in the department of agriculture in 1887. However, it was a memorial to the President of the United States presented by the American Association for the Advancement of Science in 1890 that led to the first forest reserve. This memorial, presented by a committee of the association, with T. C. Mendenhall as chairman, recommended that a commission of competent men be employed to "investigate the necessity of preserving certain parts of the present public forest area as requisite for the maintenance of favorable water conditions"; and also recommended that "pending such investigation all timber lands of the United States be withdrawn from sale and provision be made to protect the said lands from theft and ravages by fire, and to supply in a rational manner the local needs for wood and lumber until a permanent system of forest administration be had." '

Honorable J. W. Noble, Secretary of the Interior under President Harrison, clearly indicates that it was this memorial that led him to recommend that Congress pass adequate legislation to prevent the rapid and needless destruction of the great forest areas. ${ }^{2}$ In accordance with this recommendation, Congress in 1891 enacted a law stating, "That the President of the United States may, from time to time set apart and reserve, in any state or territory having public land bearing forests, in any part of the public lands wholly or in part covered with timber or undergrowth, whether of commercial value or not, as public reservations, and the President shall, by public proclamation, declare the establishment of such reservations and the limits thereof."

1 Proceedings Am. Assn. Adv. Sci., 39. Indisnapolis, 1890, p. 28.

2 Address on the occasion of the unveiling at Indianspolis of the statue of Benjamin Harrison, pp. 13-14. 
Finally, the enlargement of forest reservations and the organization of the administration of the national forest was taken up by the National Academy of Science, as a result of the request of the Honorable Hoke Smith, when he was Secretary of the Interior. This report gives a comprehensive plan for the extension and development of the forest reservations. As recommended by it, in 1897, a bureau was established in the agricultural department, and Gifford Pinchot was made its chief in 1898. This position he held until 1910.

It was the simple provision of the law secured by Secretary Noble in 1891 which has made possible the magnificent national forest. The lands which surveys have Withdrawals by different shown are more valuable for timber than for agriculture have been withdrawn from time to time. Under Harrison's administration there were withdrawn $13,416,710$ acres; during Cleveland's administration the national forests were enlarged to $39,103,030$, this being an increase of 25,686,320; during McKinley's administration the national forests were further enlarged to $46,153,119$, an increase of 7,050,089; under Roosevelt's administration came the great period of withdrawals, the national forest being enlarged to $194,500,043$, a splendid addition of 148 ,346,925 acres during his term. When President Roosevelt went out of office the larger part of the great forests in the Pacific and Rocky Mountain states which still remained a part of the public domain had been made national forests, to be held perpetually as the property of the people and to be administered in their interest.

Of the national forests, 149 in number, it is stated that on May 27, 1909, 167,677,749 acres were in the United States, 26,761,626 were in Alaska, and 65,950 were in Porto Rico. While this forest is scattered through twenty-two states and territories, its greater value is in the Far West. It is estimated that of the merchantable timber some 70 per cent is in the states of California, Oregon, and Washington, 18 per cent in Montana and Idaho, and only 12 per cent in all the remaining states. 


\section{CONSERVATION OF NATURAL RESOURCES}

Timber in national forests.
Of the national forests it is estimated that some 750,000,000 acres contain merchantable saw timber, totaling $390,000,000,000$ feet board measure; of the Indian reservations 10,541,900 acres contain about 34,000,000,000 feet board measure of saw timber; of the national parks about $2,540,000$ acres contain some $11,000,000,000$ feet board measure; of the military reservations 69,000 acres contain 200,000 ,000 feet board measure of saw timber; and of the unreserved public forests, 4,448,500 acres contain about $14,000,000,000$ feet board measure of saw timber. The national forests vary greatly in their value. In selected areas on the west slopes of the Cascade Mountains there are sometimes per acre 100,000 feet board measure of Douglas fir. Probably, however, the average of the forest land owned by the government does not exceed $\mathbf{4 0 0 0}$ feet board measure of merchantable timber.

The states also have made a beginning in forest reserves. It is estimated that twenty-two own some $9,460,622$ acres, which contain of merchantable timber some $35,474,050,000$ feet board measure. The distribution is given in the table opposite.

Other states have important holdings. For instance, Wisconsin, which once had one of the most splendid stands of white pine in the Union, and which received from the United States government grants of swamp lands, as have other states, at the present time has only 324,000 acres of forest, and the amount of merchantable timber contained is not large; with the exception of a few relative small areas.

Fistory of state park in

Wisconsin.
It was only in 1903 that Wisconsin definitely established the policy of acquiring a state forest. In 1878, all of the state lands in Vilas County and a part of them in Iron County on the headwaters of the Wisconsin and Chippewa rivers, were withdrawn from the market and made a state park. An attempt was made to obtain from the United States the remainder of the lands in this area, but the government did not make the grants asked to the state, and the lands were placed on the market in 1897. The larger part of them, in the very heart of the white pine forest of 
Table showing Acreage of Forests and Amodnt of Saw Timber owned by Twenty-two States and Territories

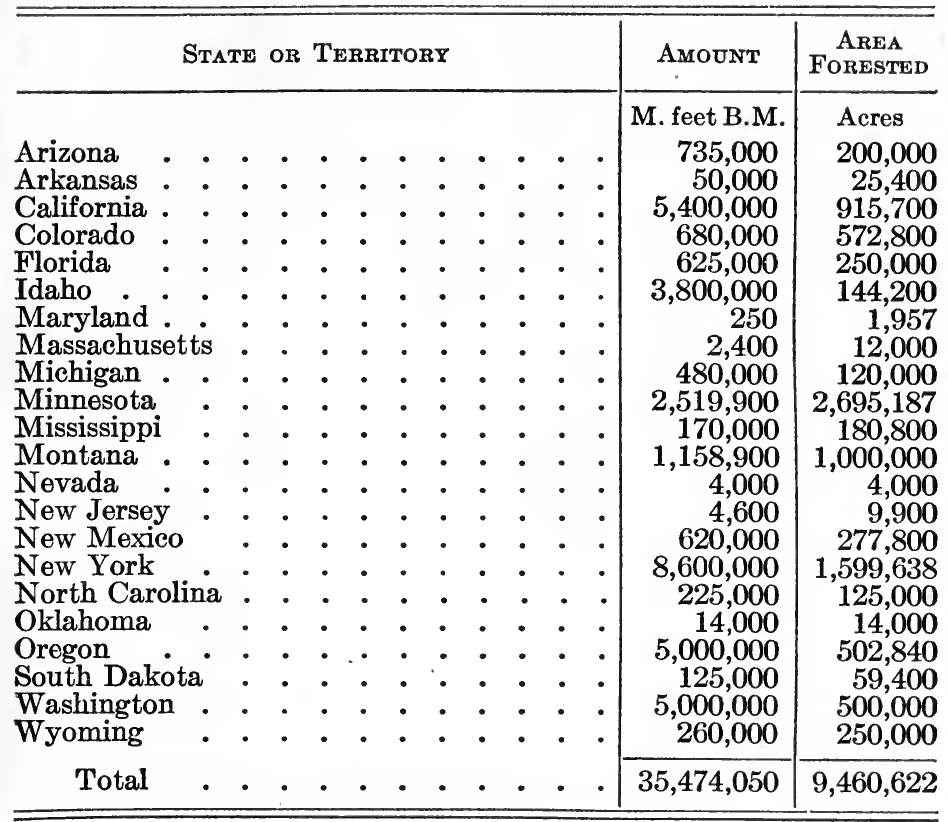

Wisconsin, were sold at prices ranging from $\$ 4$ to $\$ 60$ per acre, only the poorer remnants being left to the state. Ten years later, after the pine was cut and the fires had burned the slashings and the younger growth, the state began buying back the denuded lands to make forest reserves at prices varying from $\$ 2.50$ to $\$ 3$ an acre.

About 71,000 acres have been purchased within the area set aside as the state park, and a considerable percentage was land formerly owned by the state. In the place of the splendid white pine, these lands are now mainly clothed with cherry, poplar, and other scrub material, although in some places there is a young growth of pine. The repurchase of the lands in this area was necessary because they are upon the headwaters of the two chief rivers of the state, the Wis- 
consin and the Chippewa. This action of Wisconsin is given as an illustration of common practice in this country when the pernicious theory was held that the resources of the country were illimitable.

\section{THE CONSUMPTION OF THE FOREST}

Amounts of materials from forests.
Three eighths of timber in final product.

The consumption of the forest is due to two causes, - use and waste.

Use. The amount of wood used is enormous. At the present time it is estimated that there are being taken from our forests each year $23,000,000,000$ cubic feet of timber. This amount is sufficient to make $40,000,000,000$ feet of board measure of lumber, shingles, and laths; $1,000,000,000$ posts, poles, and fence rails; $118,000,000$ hewn railroad ties; $1,500,000,000$ staves; $133,000,000$ sets of headings; $500,000,000$ barrel hoops; $165,000,000$ cubic feet of round mine timber; $100,000,000$ cords of firewood; $3,000,000$ cords of pulp wood; and 1,250,000 cords of wood for distillation. The value of this material is estimated at $\$ 1,280,000,000$. Of this, three fifths is in lumber, shingles, and laths, and about one fifth in firewood. None of the other products have more than ten per cent of the total value.

Waste. The waste of timber is enormous. The first of the wastes is in manufacturing. At the present time it is estimated that in the logging operations in the forests, for every 4000 feet of timber logged, at least 1000 feet (or one fourth) are lost. The remaining three fourths goes to the mill. The lowest estimates place the losses there at one third, and in some cases the losses run as high as $\mathbf{5 0}$ or $\mathbf{6 0}$ per cent. Using the lower figure, of the original timber in the woods, one half would leave the mills as lumber. After the timber goes to the factory there is a further loss of one fourth; this leaves three eighths. Thus, as compared with standing wood of merchantable quality, capable of making saw timber, three eighths only goes into manufactured articles. Another of the great losses, in the southeastern and 
FOREST PRODUCTS IN 1907.

FOREST MATERIAL REQUIRED

CLASSES

BILLIONS OF CUBIC FEET

FIREWOOD

-

LUMBER AND SHINGLES

POLES, POSTS, AND RAILS

HEWED CROSS-TIES.

COOPERAGE STOCK.

PULP-WOOD.

ROUND MINE TIMBERS.

DISTILLATION WOOD.
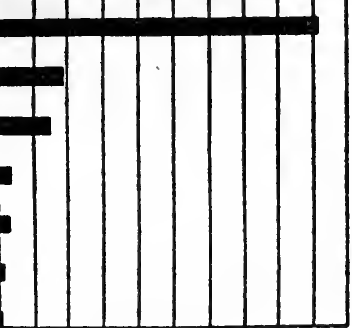

Fig. 14. - Forest products in 1907. After Kellogg.

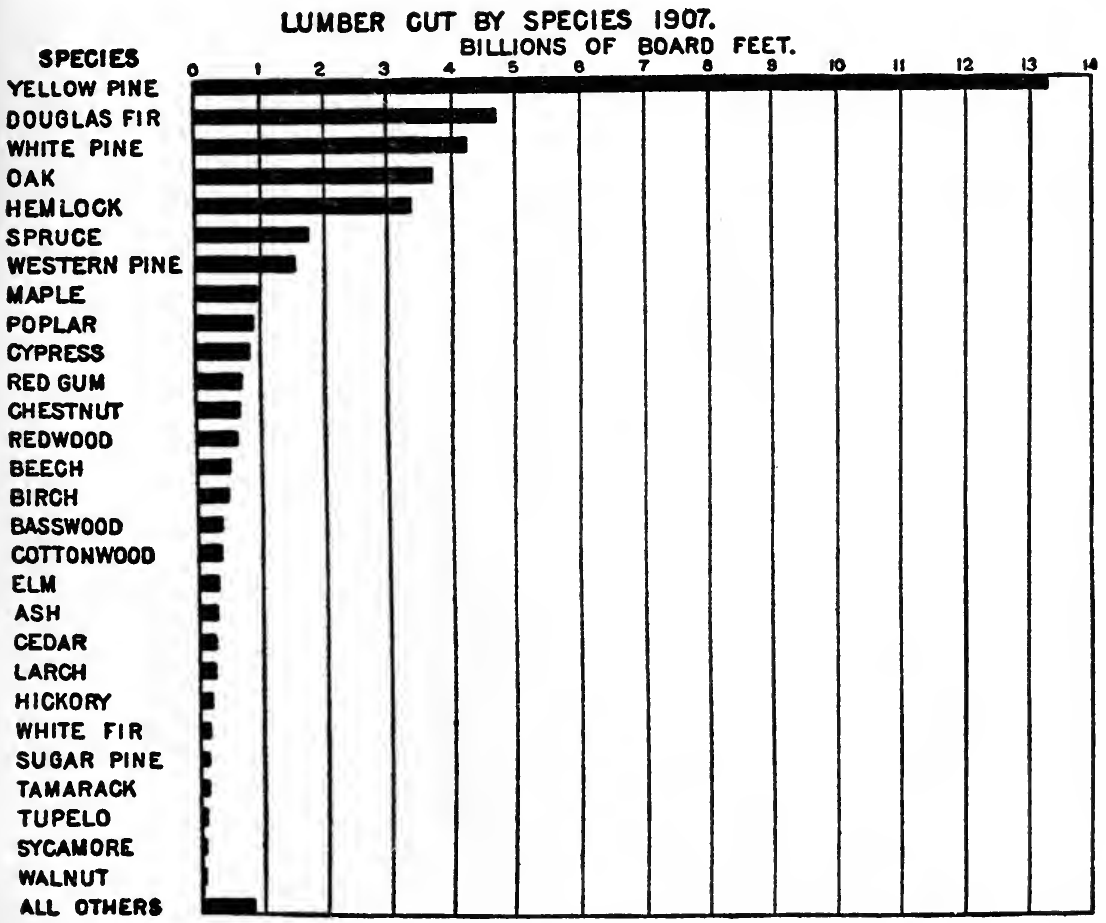

Fig. 15. - Lumber cut by species, in 1907. After Kellogg. 
southern parts of the country, is by turpentining. This industry as carried on destroys the trees at the end of four or five years or leaves them so weak that they are likely to be blown down.

Loss by fire.

Finally, there is appalling loss by fire. The loss due to this unnecessary cause has been practically the same as the amount of timber used. You, who in the early part of the year have traveled in the Rocky Mountains or Pacific ranges will remember the wonderful dark blue of the atmosphere. If you climb a mountain peak and look up, the sky is ultramarine. You gaze from range to range and see the details of the peaks 100 miles away. But in June or July, usually the latter, a haze appears. This haze becomes thicker and thicker until the peaks are wholly obscured. As you stand upon one peak you cannot see its neighbor. The whole region is under a pall of smoke; and this has gone on year by year, decade after decale.

Substantially the same situation has obtained in the great northern forest, except that there the fires have been more catastrophic. Not every year, but at intervals, dry years come in which there are great fires. This is illustrated by the Peshtigo fire of 1871 and the fires of 1908.

Age of forest trees.

The result, whether west or north, is the same, - destruction of a resource of inestimable importance which it has taken hundreds of years to produce. Nearly all of the timber of first quality is more than 100 years old. The great sugar pines and Douglas fir and redwood of the West are hundreds of years in age, and some of them more than 1000 years; and it is believed that some of the old great sequoias were trees before the beginning of the Christian era. And yet, wholly disregarding the length of time that it took for nature to manufacture this magnificent forest resource, we have destroyed as much of it by fire as we have by use. No other nation in the world has so dreadful a responsibility to succeeding generations. This recklessness has come about from the fact that this continent has been taken possession of rapidly. Heretofore, as a people have overrun a country, 1 “Forest Products," R. S. Kellogg, N. C. C., Vol. II, pp. 196-202. 
LUMBER CUT BY STATES 1907.

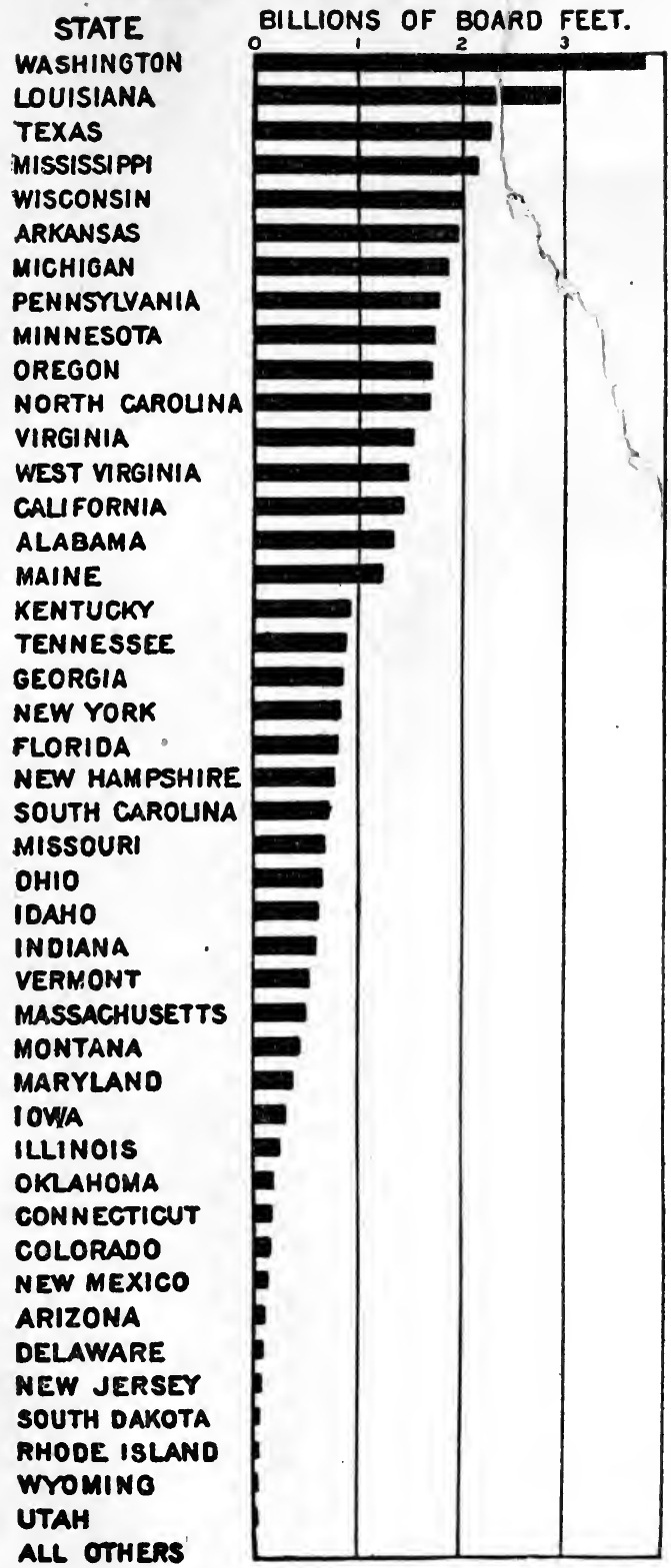

Fra. 16. - Lumber cut by states in 1907. After Kellogg. 
Average increase of $\mathrm{I}$ wood per acre.
Consumption of wood must be reduced to production. or developed in it, the process has been gradual, extending through centuries. Much the larger part of this country has been occupied in a little more than a century. Due to this fact, combiner with the feeling that the resources were illimitable, more than enough for all, there has come this relative Lumber gloouction recklessness, this wastefulness, IN TEN STATES IN ESOAND IgOT

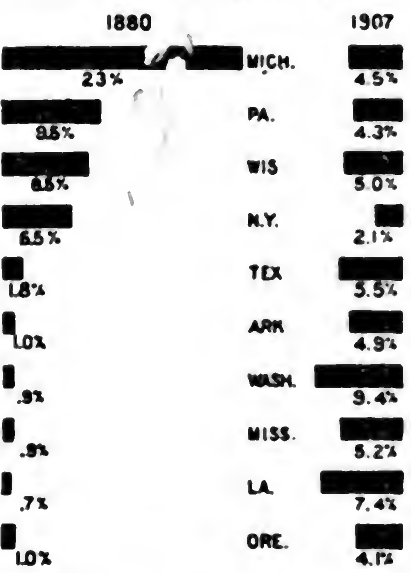

Fio. 1\%. - Relative lumber production in ten states in 1580 and $190 \%$. After Kellogg. which is unmatched in the history of the world.

At the present time we are using 260 cubic feet of wood per capita; Germany uses 37 and France 25, one seventh and one tenth as much respectively as we use.

It is estimated ${ }^{1}$ that upon the best stands of forests the increase per annum is from 30 to 100 cubic feet, with an average, however, not greater than 28 cubic feet per acre per annum for the 240,000,000 acres of growing forest. But it is to be remembered that there are 250,000,000 acres of timber which are partly cut or burned over, and 100,000,000 acres cut and burned over, so that the average growth upon the $550,000,000$ acres of forest is not greater than 12 cubic feet per annum per acre. But we are taking upon the average 40 cubic feet per acre. Thus you see at the present time we are cutting our timber more than three times as fast as it is produced.

It is clear that our consumption must be reduced to our production, since it cannot be expected that we shall be able more than temporarily to secure timber by importation. Already the densely populated countries are importing timber, instead of exporting it. It is true, in some of the large undeveloped countries, such as Siberia, Canada, Brazil, and parts of Africa, timber is being exported. But this will

1 "Rate of Forest Growth," E. A. Ziegler, N. C. C., Vol. II, pp. 203-269. 
not long be the case; for as soon as these countries are fully occupied, they will need all the timber they can grow, and consequently in the future we shall be obliged to depend upon what we produce. Since in the near future we must reduce our consumption to our production, the question arises as to what we must do to accomplish this. The answer is a twelvefold one, each element of which will be considered separately:-

1. We must reduce waste in cutting.

2. We must reduce waste in milling and manufacture.

3. We must reduce loss in turpentining.

4. We must extend the life of timber by preservative treatment.

5. We must utilize by-products.

6. We must reduce fire losses.

7. We must reforest areas burned over.

8. We must maintain forests on essential areas.

9. We must maintain areas stocked so as to produce larger growth.

10. We must battle with insect pests.

11. We must substitute other products for timber.

12. We must reform our tax laws.

\section{REDUCTION OF WASTE IN CUTTING ${ }^{1}$}

It has already been said that the loss by careless cutting is not less than 25 per cent. On our national forests, where modern methods are practiced similar to those which are in force in other enlightened countries, the loss has been reduced to 10 per cent or less, or to two fifths of the amount on private holdings. But the loss in the timber cut is only a small part of the damage to the forests as lumbering is at present practiced by private parties. Where forestry is practiced the precautions given below are taken to maintain the forests.

(1) There should be care for the young growth. Under the present methods of logging, the trees are often felled

"“C Conservative Logging," Earle N. Clapp, N. C. C., Vol. II., pp. 512-546.

Destruction of young growth in logging. 
Lack of seeds prevents reforestation.

Extravagance of cutting young timber. with no thought of the young timber. A log is thrown down where it seems best for that $\log$ and with reference to other logs which are to be cut; indeed, in some cases the very young timber is deliberately used as a cushion for the falling trees. In skidding and handling the logs the young timber is often disregarded. Also chains or cables attached to the immature trees frequently tear off the bark, and even injure them so that they are worthless. Thus a large part of the timber which is so small as not to be merchantable is destroyed during the removal of the merchantable timber.

(2) Seed trees should be left. If every tree capable of bearing seed is cut, then no seeds are produced to reforest the cut-over area. Because of lack of seed trees, combined with other facts to be considered, extensive areas in the northwest, which once were heavily timbered with white pine, or other valuable coniferous trees, now have no second stand of these species. This could have been avoided had there been occasional trees left for seed. Leaving seed trees is universally practiced wherever the forests are under the control of the government and modern methods are used.

(3) The immature trees should not be cut. At the present time the almost universal method of cutting in the United States is to take everything which will produce a log; even young growth, scarcely more than poles, six or eight inches in diameter, is cut. When an area has been gone over, there is nothing left of the species which the contractor is taking out except the shrubs and saplings. It is an advantage to the growing trees to cut the mature trees, which, if allowed to stand, may deteriorate, or if not deteriorate, are of an age such that improvement is not rapid; but the young timber of intermediate size is at the period of most rapid growth, most rapid annual addition of material. This is wholly disregarded and everything is swept clean. Only by leaving the immature and rapidly growing timber can we hope to make the future growth equal to our needs.

(4) Clean work must be done in the forests. Clean work involves a number of factors: -

(a) Preceding cutting, well designed logging plans should be 
prepared. The habit of the past was to go into a piece of forest and begin to cut, just as it used to be the practice of one in charge of a mine simply to begin to take out ore: But modern methods, both in forestry and mining, involve a careful scientific examination of the timber area to be cut, or the mine to be worked, and carefully wrought out plans so that exploitation may not only be efficient, but economical.

(b) All the timber which is cut should be removed. Not infrequently short logs and small logs are left. Indeed, I have seen areas in the North where the timber has been cut, and either by mismanagement or change of hands the logs left on the ground to rot. The sight is always a distressing one. The cutting of timber and leaving a part or all in the woods is indeed wanton destruction.

(c) The timber should be removed in inaccessible places when an area is cut. Not infrequently on the steep side of a hill, or in a ravine, where the timber is rather hard to get at, it will be left. This is especially likely to occur under the contract system of cutting, where the pay is in proportion to the amount taken out. The leaving of mature timber in inaccessible places is extravagant; for to go in an area a second time for logging operations involves large additional expenditure. When an area is cut over all of the mature timber adapted to the market should be taken.

(d) The cut should not be limited to the choicest timber, but the inferior trees, and especially the inferior species, which stand in the way of the better species, should be removed and thus give the latter an opportunity to grow. In the past it has been the common practice in the North and in the Pacific forests to remove only the white pine, Douglas fir, and redwood, leaving all the hemlock and in the northern forests the hardwood. Under new conditions this situation is being changed. If, when a tract is to be cut, all of the mature merchantable timber of every species except seed trees be removed, the young timber will be given favorable conditions to reforest the area.

(e) Not infrequently it is the case that an area contains dead or blown down timber in large quantities, perhaps as a 
Utilize dead and down timber.

Waste of hemlock and chestrut.

High stumps.

Use tops of trees. result of fire or cyclone, or the two combined. This timber may not be of as good quality as that growing, but it should be removed and utilized for the purposes for which it is adapted.

(f) Where there are inferior species and inferior trees which are not merchantable they should be utilized for the construction work incident to cutting. A certain amount of timber is always needed for making roads and skids and the other forest work.

(g) The trees should be cut for all the material which they furnish. Only a few years ago great hemlock trees were cut down by the thousands from which only the bark was taken for the tanneries, the logs being left to rot in the woods. How great the loss of timber was by wasted hemlock it is impossible to say, but it was enormous. To some extent, chestnut has been the subject of similar practices. At the present time, with the increasing value of timber, this particular waste has practically ceased.

Low cutting should be practiced. Under contract work especially there is a temptation to cut above the butt expansion. The contractor's price is so much per thousand feet; he does not care whether there is left a butt several feet high, containing much good timber. Careless cutting in this respect has resulted in large losses, especially in the great redwood forests of the West, where stumps seven or eight feet high are not uncommon. In the pine forests in the North the winter stumps average not less than five feet. Low cutting should always be required as one of the conditions of the contract, so that the timber shall be saved as near to the ground as possible. Except in special cases stumps need not be higher than eighteen inches and often they may be even lower.

The tops of the trees should be used for saw timber so far as practicable and the remainder for cord wood and other purposes. At the present time, in the lake states and the West, the tops of the trees, including the branches of considerable size, are left in the forest, no attempt being made to save them. This is not only a great loss of material, but is a menace to the forest by furnishing fuel for forest fires. 
By variation in the lengths of logs and by using short lengths, a larger proportion of the trees may be made into saw timber. Use short logs.

Too frequently in the past only those logs have been taken out which will yield twelve, fourteen, sixteen feet or longer lumber. The shorter length logs, eight or ten feet, should be saved.

(h) Great saving may be made by careful operation, which includes felling, transportation, and driving. An inexperienced or careless cutter often falls his $\log$ so that the tree is shattered or broken, whereas with an experienced and careful Loss from careless work.

man this will rarely happen. The use of the axe where the saw should be used has resulted in large losses in the past. Very frequently by careless driving the streams are imperfectly cleaned up and many logs are lost. Booms are so poorly made that at times of flood or wind they break and the logs are scattered far and wide. Also the booms of log rafts, being towed, break with grave disaster. The result is that on almost every large lake in the North there have been important losses of logs. You who have traveled along the shore of Lake Superior will remember that the lake is bordered with logs half buried in the sand or piled on the beach. These logs have broken from rafts or have escaped from the rivers. This loss has been enormous. Not infrequently a great boom in a river holding millions of feet of lumber has broken and the whole gone down at a time of flood to Lake Superior, Michigan, or Huron, or some other of the lesser but still large lakes. In such cases a part of the logs are recovered, but only a part. A large number of them get beyond recovery and join the zone which borders so many bodies of water in the lake country.

\section{REDUCTION OF WASTE IN MILLING AND MANUFAC- TURE ${ }^{1}$}

According to Margolin, in milling the following are the losses of the entire volume of the logs: bark, 13 per cent; kerf, or Total losses. sawdust, 13.5 per cent; edging and trimming, 8.7 per cent; slabs, 8.7 per cent; careless manufacture and accidents, 3.5 per cent; requiring standard lengths and widths, 1.7 per " "Waste in Milling," Louis Margolin. "Waste in Use of Timber," McGarvey Cline, N. C. C., Vol. II, pp. 547-580.

Lake shores bordered with abandoned logs. 
Use thin saws.

Good material in waste heap.

Use of small picces.

Various losses in use. cent; making a total loss, from all sources in the mill, of 49.1 per cent. This, Margolin holds, is the average practice at the present time.

This enormous loss can be reduced in the following ways:(1) For half the timber sawed gang saws are used. The use of such saws, each of which has to be thick, should be abandoned, and thin band saws used. It is calculated that this substitution would increase the lumber from the logs now cut by $2,250,000,000$ board feet, all of which now goes into sawdust. For many purposes round timber could be used. If those in control of the market would not insist upon having all the lumber squared up, and the round-edged lumber were used for certain purposes, this would give a large saving.

(2) If the market requirements and usages could be so modified as to use odd lengths and short lengths for various purposes, this would result in great saving. You who have seen a sawmill at work must have been amazed at the number of pieces which, because somewhat short of the standard minimum length of the market, go into the waste heap. For many purposes these short lengths could be used, and if only the trouble were taken to put them on the market, they would readily find a sale at a lower rate than that charged for standard lengths.

(3) The pieces which are so small as not to be used for short boards could be used for matches, toothpicks, excelsior, and novelties of small size. As a matter of fact, however, even for minute objects, such as matches, the largest and best timber is extensively used.

(4) After lumber is milled into standard forms there are still further losses in its utilization. These are of three kinds; those due to seasoning, those due to manufacture, or factory loss, and those due to improper uses.

In the building trades it is estimated that the loss in seasoning and in use amounts to 15 per cent or $3,600,000,000$ feet board measure; in furniture making, it is estimated that the loss in seasoning and factory amounts approximately to 25 per cent, which represents an annual loss of 1,710,000,000 feet board measure; in making boxes it is estimated that the loss 
is approximately 20 per cent, which represents an annual loss of $692,000,000$ feet board measure; in making bridges and cars the loss is about 10 per cent, which represents an annual loss of 282,000,000 feet board measure; in the manufacture of vehicles and agricultural implements the loss amounts approximately to 25 per cent, or an annual loss of $482,000,000$ feet board measure; in ship-building and other miscellaneous uses the loss is at least $\mathbf{1 5}$ per cent, which represents an annual loss of $157,000,000$ feet of board measure. Thus the total loss in adapting to its final use milled timber in 1907 was 17 per cent, or 6,803,000,000 feet board measure. This loss is mainly in sawdust, shavings, and small blocks. Even under the best of conditions this loss can only be reduced; it cannot be altogether avoided. Therefore the term "loss" better describes the situation than "waste." Indeed, the materials, sawdust, shavings, and small blocks, are used for packing, for fuel, and for other purposes, and thus are not wholly wasted.

\section{REDUCTION OF LOSS IN TURPENTINING ${ }^{1}$}

When I was a lad, one question in the geographies used to be, What are the chief articles produced in the Southern states? A part of the answer was, "Tar, pitch, and turpentine." When, Tar, pitch, and turpentine.

a schoolboy, I made this answer, I did not appreciate the tragedy involved in it. You who have traveled in the South, where the roads go through the great forests of long leaf pine, have seen many thousands of trees hacked four, five, and six inches deep for two thirds the way about the trees, and from one or two feet from the ground to as high as the ax can reach. The strength of the trees thus abused is reduced by one third to one half; and, greatly weakened, after a few years they fall. Becoming dry, they invite the fire, and then their destruction becomes a menace to the entire forest.

The average period during which tar, pitch, and turpentine are furnished by a given tree under the method of boxing comBoxing of trees. monly practiced in the South is not greater than four years.

1 "Conservative Turpentining," George B. Sudworth, N. C. C., Vol. II, pp. 498-511. 
The deep cut each year, for a fresh cut must be made annually, is fifteen or sixteen inches; in four years it is sixty or sixtyfour inches in height; then that tree is abandoned and another attacked.

Improved methods of producing naval stores.

The manufacture of pitch and turpentine, called in commerce naval stores, because in early days the tar and pitch were used for introduction between the planks to make the ships water tight, has been studied very closely by the United States Forest Service. New methods have been discovered for the manufacture of these products, which have been thoroughly tested and found satisfactory. The method now advocated consists of shallow uniform cuts in the trees, metal gutters to carry the products, and clay receptacles to catch them. By the old method, the cut in the tree was deep enough actually to make a box within the wood, which gathered the sap of the tree. By introducing the metal gutters to carry the sap to the clay receptacles, the cut can be made very shallow; and that gives a greater rather than a less yield. Also the cuts need not be made in any one year more than three and one half to four inches in height. The life of a tree, instead of being three or four years, is thus increased to fifteen or twenty years. Also the method gives an increased yield of about 30 per cent. Finally, by it the trees are not seriously injured; and if the cutting is discontinued for a series of years, they may be again utilized. The question of tar, pitch, and turpentine may strike you as a small matter; these commodities are not commonly considered important; but the effect of their production upon the forest, as methods have been practiced in the past, has been most disastrous. There are no available estimates of the extent of the beautiful long leaf pine forests of the South which have been destroyed by boxing, but there is no doubt that, if figures were available, they would be appalling.

Probable future of naval stores.
If the present methods of producing naval stores continue, the forests will not furnish them at the rate demanded by commerce for more than twenty-five or thirty years. If, however, the new methods advocated by the Forest Service be introduced, and if in addition to the yellow and slash pine of the South, other pines are used for this purpose; and es- 


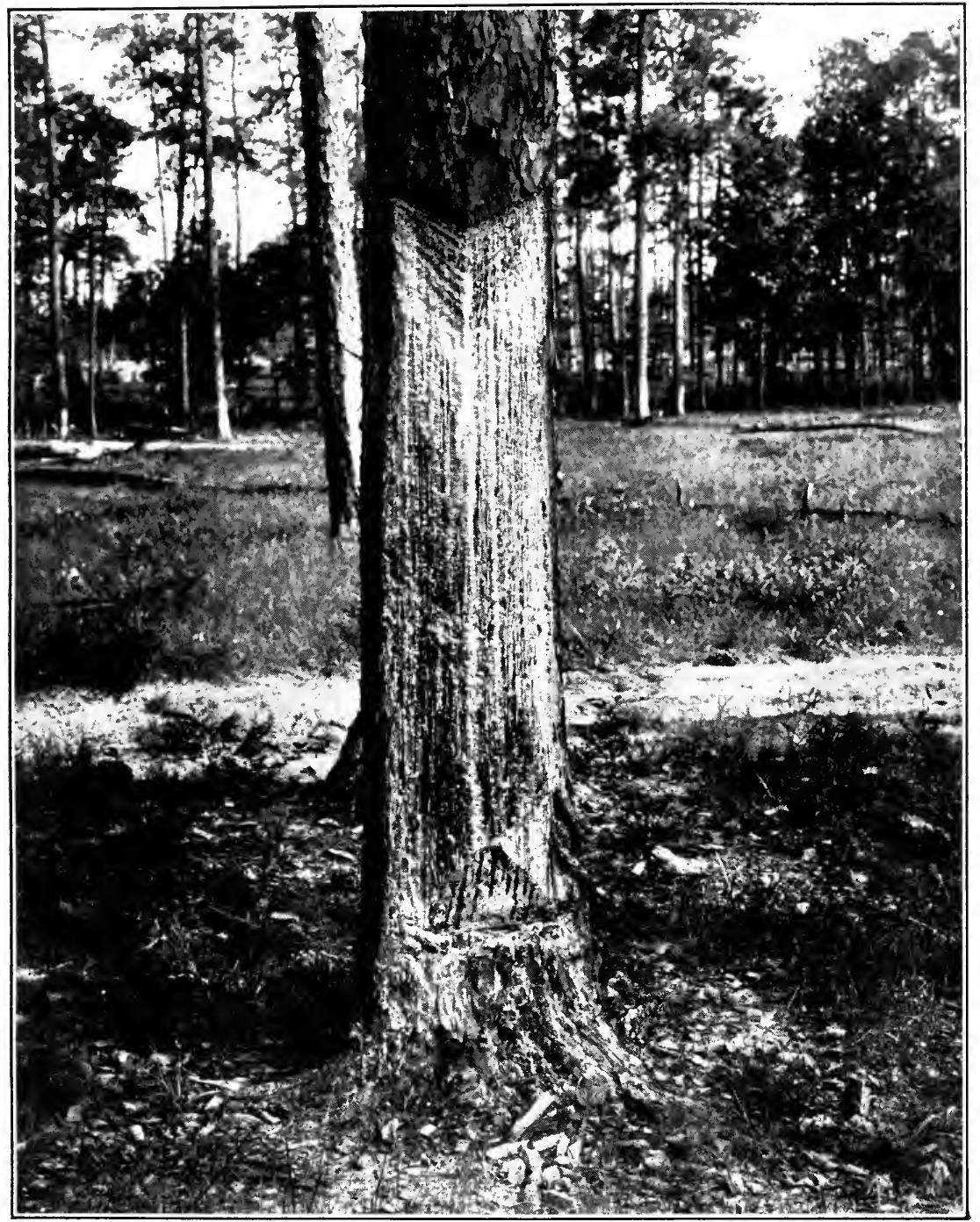

Plate I. - Pine boxed for three years, near Ocilla, Georgia. Photo by Forest Service. 



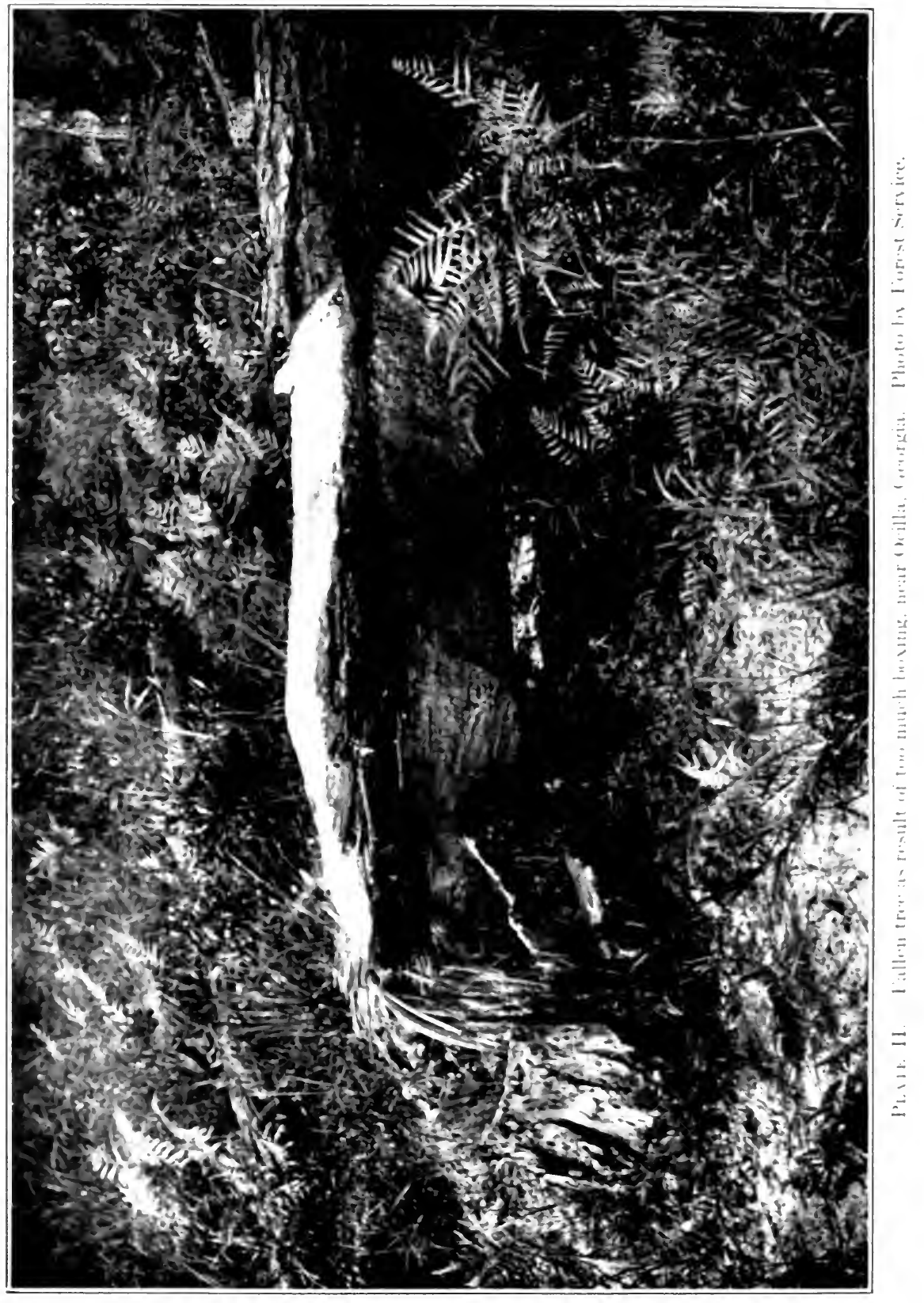


pecially if this process be combined with lumbering, it will be possible to produce a sufficient amount of naval stores through the indefinite future. A tree when near its maturity is in the best condition to yield the largest amount of tar, pitch, and turpentine. A forest may be drawn upon for these purposes for fifteen or twenty years; and then, before the trees are so greatly weakened as to result in windfalls and danger by fire, that forest may be cut for timber. By thus uniting the production of naval stores and lumber in a single plan, there will result a great saving of valuable timber.

\section{EXTENSION OF LIFE OF TIMBER BY PRESERVATIVE TREATMENT}

The next of the methods of lessening the demand for timber is preservative treatment. ${ }^{1}$ This consists in treating wood with creosote or zinc chloride, so as to make it less susceptible to destruction by decay, by insects, marine borers, mechanical abrasions, and fire. It is believed that these factors annually destroy not less than $9,750,000,000$ feet board measure of timber. At the present time there are in operation about sixty plants in the United States for preserving timber. Their output is something like 1,250,000,000 feet board measure, only a small fraction of the total timber used. Preservative treatment adds to the life of timber by from ten to eighteen years. Experiments on railroad ties, poles, posts, piles, mine props, shingles, and export lumber fall between these extremes.

If preservative treatment were applied to all merchantable timber, it is estimated that this would involve a saving per annum of $6,000,000,000$ board feet of timber, or 12 per cent Saving by preservative treatment. of the timber used. Thus by treating wood so as to prolong its life we could reduce by that one process the demand upon our timber from $40,000,000,000$ feet board measure to $34,000,000,000$ feet per annum.

Not only does preservative treatment prolong the life of durable species of wood, such as have been used in the past;

1 "Wood Preservatives," by W. F. Sherfesee and H. F. Weiss, N. C. C., Vol. II., pp. $658-667$. 


\section{CONSERVATION OF NATURAL RESOURCES}

Preservative but it prolongs the life of inferior and cheaper woods, so as to treatment makes available inferior wood. make them useful, which heretofore have had small value. Tamarack for railroad ties without treatment has so brief a life as not to warrant its use for this purpose; but treated tamarack ties have reasonable durability. The economy of preservative treatment is not confined to the saving of timber; there is also saving in the amount of constructive work. If the railroad ties last longer by ten or twelve years, then the number of ties to be replaced each year is reduced by many millions. If the life of the timber in a mine is prolonged ten years by treatment, the work of retimbering is greatly reduced. It is estimated that the cost of the work in maintaining wood structures as a result of introducing preservative treatment would be lessened by $\$ 72,000,000$ per annum.

\section{UTILIZATION OF BY-PRODUCTS :}

The next subject to be considered is the utilization of byproducts. At the present time in wood manufacturing the enormous amount of refuse formed is utilized only to a small extent; its utilization can be very greatly increased. The refuse comprises tops, stumps, butts, cull logs, slabs, edgings, trimmings, barks, shavings, sawdust. In what ways can these materials become of use?

Chemical byproducts.

Saving of turpentine.

First, chemical products may be manufactured from them. By the sulphite process of making pulp great quantities of socalled sulphite liquor are produced which contains much sulphur. As yet no way has been devised to save this byproduct. By the distillation of pine wood large quantities of pyroligneous acid are produced. In Germany from this material acetic acid and wood alcohol are made; but in this country these by-products have not been obtained.

About 30 per cent of the Southern yellow pine is treated in the dry-kiln. It is calculated that there is produced in this process something like one gallon of turpentine per thousand feet board measure. This amounts to 4,000,000 gallons per

1 "Utilization of Wood Waste by Chemical and Other Means," by $\mathbf{H} . \mathbf{8}$. Bristol and L. F. Hawley, N. C. C., Vol. II, pp. 645-657. 
annum. Improved processes have been proposed which will materially increase this amount. Some way should be devised to save this wasted turpentine.

Not only could chemical products be saved which are incident to adapting wood to its use, but they could be produced from refuse. If the waste stumps, slabs, and fragments of various kinds of the Southern pine and the sawdust formed were distilled for turpentine, it is calculated that there would be available for this purpose a sufficient amount of material on the basis of two and one half gallons per cord to make $36,500,000$ gallons of turpentine, or more than is produced in the United States at the present time by the extravagant process of extracting it from the living trees. Also a large amount of turpentine could be obtained from the waste material of the Douglas fir and other trees.

Another great loss is in the manufacture of charcoal. Where charcoal is made in the ordinary kiln, all of the distilled products pass into the air and are wasted. Incident to the manufacture of charcoal a large amount of creosote, wood alcohol, and acetic acid are formed. There are in this country a few scientifically constructed plants for the saving of all of these products. This is illustrated by the establishment of the Cleveland-Cliffs Company of Marquette, Michigan. Such a plant involves a considerable investment. It is necessary to bring the wood to a central plant to char it; and in addition to special kilns an expensive auxiliary plant is required to save the by-products.

We have already seen that in the past a very large amount of tannic acid for the tanning process has been obtained from the bark of hemlock, the wood itself being wholly neglected. Chestnut wood contains much tannic acid. Bristol and Hawley estimate that if the refuse chestnut wood of 1907 had been utilized for making tannic acid, there would have been available 50,000,000 cubic feet, which would have yielded about $312,500,000$ pounds of extract, or more than twice the amount of tannic acid used in the tanneries of the country.

A great possible saving is by making refuse into wood pulp.

Byproducts from charcoal manufacture.

Tannic acid from wood now wasted. 


\section{CONSERVATION OF NATURAL RESOURCES}

Wood pulp from wood now wasted.

Utilisation of sawdust.
One of the questions continually before the foresters and the manufacturers of paper is, how long will the supply of pulpwood be available? At the present time the material for making paper is almost exclusively derived from spruce, hemlock, and poplar. The trunks of these trees are cut into cord wood and sent to the pulp mills. But practically all of the soft woods can be made into pulp. If the slabs and tops of the hemlock, spruce, poplar, cottonwood, and the Douglas fir had been used for pulpwood; and to this had been added the waste material from yellow pine, Western pine, and Douglas fir; it is calculated that in 1907 there would have been available 22,600,000 cords of material, or five and one half times the amount used for pulpwood. Thus it is clear that in refuse now burned or left to rot in the wood there is an entirely adequate supply of wood for paper-making.

In the milling of logs and in the adapting of the lumber to its final purpose, a very large amount of sawdust is produced; indeed, this is one of the heaviest losses in wood manufacture. Sawdust is adapted for various uses: chemically, it may be used for the manufacture of oxalic acid, and for ethyl or grain alcohol; mechanically, it can be used for packing material, for a non-conductor in walls, as an absorbent, as for instance in making nitro-glycerine, and to mix with clay for making porous brick, the sawdust being burned out when the brick is burned, thus making a brick which is an excellent non-conductor. Also it can be used with a binding material for making wood substitute adapted to flooring and for various other purposes. Woor substitutes are already manufactured in France and in some other countries, but have not as yet been introduced into this country because of the cheapness of wood. Finally, sawdust may be used for fuel and power. This use is mentioned last because it is the least important, and only the residuum not available for other purposes should be thus used.

Griffith gives "as an illustration of how large concerns are utilizing what has heretofore been considered waste, the case of a prominent concern in its operation of a sawmill and chemical 
plant. After the timber suitable for manufacturing lumber is cut on the tracts owned by the company, all the small and defective hardwoods are felled, and together with the tops of the trees down to a $1 \frac{1}{2}$ inch limb, are cut into lengths easy to handle and hauled to the chemical plant. The wood is then treated and from one cord is secured 60 bushels of charcoal, 10 gallons of wood alcohol, and 145 pounds of acetate of lime. Not only does the company enjoy a source of income from this phase of utilization, but the removal of the slash does much to prevent fires and promotes reforestation or settlement to agriculture as desired."

The recovery of by-products from refuse wood is likely to have a great development in the future. Such utilization has made comparatively little progress in this country, because Future recovery of by-products of the cheapness of wood; but with a decreasing forest area, with a limited amount of the higher grades of timber, we shall be obliged to turn to the refuse material to supplement our supply. This situation has led the United States Forest Service to undertake exhaustive investigations in reference to the utilization of refuse. This is one of the chief purposes of the establishment of a forest products laboratory by the government at the University of Wisconsin.

\section{REDUCTION OF FIRE LOSSES 1}

We have already seen that the fire losses are the greatest of those with reference to timber. It has been stated that up to the present time this loss has been substantially equal to the timber cut. It is therefore necessary to consider in some detail the question of forest fires.

First to be considered is the cause of forest fires. The favorable conditions which result in forest fires are forest Cause of forest fires. débris in the woods. The débris includes leaves, twigs, fallen timber, dead trees, and above all, slashings produced by cutting; that is, the residuum left which the lumbermen

1 "Forest Fires," by Clyde Leavitt, Report National Conservation Commission, Vol. II, pp. 390-468. 
do not take out, and which residuum, as we have seen, might be used to make by-products. The slashings left in the forest soon dry, and are ready for combustion. In addition are only needed the agents of ignition for disaster to follow. These agents include locomotives, campers, lightning, brush-burning. In the South the burning over of the forests to remove the leaves and twigs is done to improve the grass. Finally, the incendiary has his share in the destructive work; he has been a potent cause of fire in the West, especially in connection with the sheep and cattle industry to secure better grazing for the herds.

An investigation of these various agents in the Rocky Mountains showed that in 1907, of some 2503 fires, 641 were by locomotives, 638 by campers, 458 by lightning, 49 by clearing and brush-burning, 43 incendiary, 22 hunters, and 652 of various unknown sources. This list shows that the greater number of fires were set by locomotives, by campers, and by lightning.

Fires from lightning.

Indian fires.

You will doubtless be surprised to learn how numerous were the fires caused by lightning, -438 in one year. This explains some of the old fires, those of the time before settlement. Many of the most extensive fires in the Rocky Mountains and elsewhere have been thus produced. However, lightning is not the only cause of fires before the settlement of the country by the white man; the Indian had a habit of burning over the forest each year. Thereby the forests were made more open and the prairies extended at the expense of the forests. If the forests are kept free from fire, they soon become difficultly accessible, both to men and to beasts. In the South, for a similar reason, the white man burns over the forest lands each year in order to improve the grazing of his herd.

Forest fires cost both loss of life and loss of property. It is estimated that under the conditions that have prevailed to the present the average annual loss of life was fifty. From time to time the nation has been stirred by great forest fires which resulted in loss of life and the destruction of villages and towns. Among these was the great Peshtigo fire in Wis- 


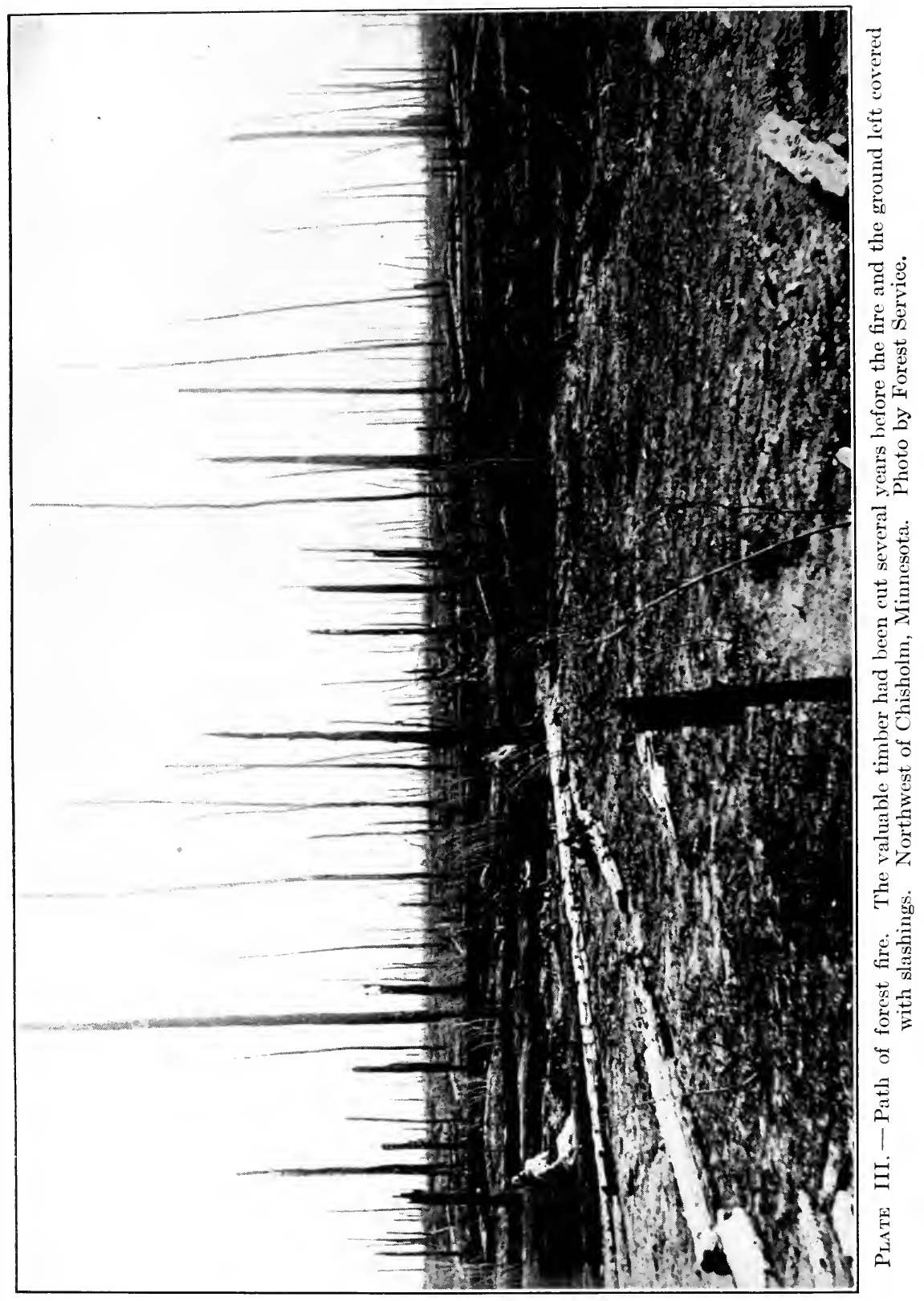



consin, in 1871, the Michigan fires in 1881, and the Minnesota fires in 1904 and 1908. In the Peshtigo fire 400 square miles was entirely devastated, 1000 people perished and 3000 left destitute. In the Michigan fire of 1881, 48 townships were burned over; a belt of timber 60 miles in length and 10 to 50 miles broad was destroyed, more than 1,000,000 acres all together; and 138 people perished.

The destruction in the forests by fire is of various kinds. First is the destruction of the mature timber. The mature trees, if dead, may be partly or completely burned; and the amount thus destroyed is large. But more important than that is the killing of the mature green timber. The flaming slashings and débris burn the bark of the trees, and they die. Even where the trees are not damaged so badly as to die within a short time, they may be greatly weakened. This is well illustrated in the turpentine region, where there is exposed to the flames the unprotected parts from which the bark has been removed.

It is estimated that between 1880 and 1896 the average annual loss of merchantable timber had a value of $\$ 50,000$,Amount of 000 , varying in different years between $\$ 25,000,000$ and $\$ 100,000,000$. This estimate does not take into account the killed timber which was later removed. If the timber after having been killed but not burned is cut within a short time, it may be made available; and a large amount of burned timber is thus saved. For instance, after the great fires of 1908 in Minnesota, Wisconsin, and Michigan, the larger part of the merchantable timber that was killed was saved; but there were remote and detached burnt areas from which it is not practicable to get the timber. This material remains, after a time falls, and becomes a further menace to the forest.

But the most serious loss by fire is not in the destruction of the mature trees, for as we see a large number of these are saved; it is in the destruction of the young and growing, Immature timber killed. immature timber. This loss we cannot estimate accurately, because it is difficult to determine the potential value of young forests which will furnish timber of merchantable size twentyfive or fifty years hence. A minimum estimate may be made fire loss.

Green timber killed. fire 


\section{CONSERVATION OF NATURAL RESOURCES}

on the basis of the cost of replanting. It does not cost less than $\$ 10$ an acre to plant an area; and each year there is a new area of burned forest of about 5,000,000 acres; and many millions acres in addition, in which the fires have run one or more times, are burned over again. The loss on the minimum basis of reforesting the newly burned areas would be $\$ 50,000,000$ per annum. But this is an underestimate, because the timber which is destroyed is not three or four years old, as is the case with new plantings; but varies from a few years in age to ten or fifteen, or even fifty. The destruction of the young timber was nothing short of appalling during each of the great fires mentioned on a preceding page.

But the destruction by fire is not limited to the mature timber and the young growth. The forest fires have a deleterious effect in the distribution and composition of the forest. The more combustible and valuable timbers are the ones likely to be destroyed to the greatest extent; and the less

Fires encourage poorer woods.

Burning of humus of soil. combustible to be perpetuated. Thus it is, where fires have run two or three times in the north or northwest, that great areas, originally valuable white pine, are not reseeded with that species, but with birch, poplar, cherry, and soft maple. Similarly in the south, in place of the long leaf and loblolly pine are often the huckleberry, the laurel, and the greenbrier. Many have the mistaken conception that pine will not reseed itself. This belief is due to the facts which have just been mentioned. If seed trees are left, or even if a fire runs but once, a forest will reseed itself with valuable timber; but if the fire runs once and kills the mature trees, then again when they fall, and especially if it runs a third time to take the last vestiges of the forest, the young seedlings are destroyed, the humus and the ungerminated seeds are burned, and the area does not reseed itself with valuable timber.

Another serious result of forest fires is the deterioration of the soil. The fires do not simply confine themselves to the timber, but they burn the humus in the soil itself. Frequently, after a great forest fire, and especially if the fires run over the same area two or three times, there is left of the soil, sand and the other minerals, but little or no organic 
material. In this case there must again begin the slow process of accumulating a sufficient amount of organic material in the soil before a good growth of forest trees can be secured. This requires scores of years at the very least. You who are familiar with areas where there have once been extensive valuable forests, and on which there have run repeated fires, appreciate the barrenness of the soil. In the Lake Forest belt such areas are often so poor that jack pine and worthless brush occupy them. Also such soil is almost useless for agricultural purposes.

Another result of forest fires is injury to stream flow. Unequal This point is to be considered in another connection. It stream will be shown that where forests are preserved on the headwaters of the streams, this favors uniform flow. Where forest fires have removed the timber, inequality of flow is promoted.

Another loss resulting from the destruction of forests by fires, which it is difficult to estimate, is the increased price of forest products. At the present time high-grade lumber is several times as expensive as it was a few years ago. Indeed, clear white pine, which was so abundant as to be used for many purposes, is now so expensive as not to be available except for special demands. If there were now available, not only the present stand, but as much timber as has been cut, the price of the forest products would not have so rapidly increased. The cost of the timber to the people would be less by many millions of dollars a year; we cannot tell by how many, but certainly by many millions of dollars.

Finally, there is the indirect loss which comes from the Relations of destruction of a natural resource. Where natural resources are abundant and available, they are an easy source of wealth resources and towns. to the people. The timber reserves of the country have led to the establishment of hundreds of villages and towns, which have been supported by timber manufacture. As a farther result the general wealth of the country was increased. Already in the northern lake country many lumber towns have become stationary; and some of them have already begun to go back, because of a deficient supply of material

Increased value of wood. 
for the basal industry upon which they were founded. Were the timber which has been burned still available, the life of these towns would have continued through many years in the future. This great loss of a natural resource we cannot estimate, but we know that for the nation as a whole it has been enormous.

\section{THE CONTROL OF FIRES}

We shall next consider the control of fire. The forest fire record of the past is appalling; shall we continue that record, or shall we rise to the emergency and stop this criminal waste? As showing the possibilities in this matter it may be said that of the 7,000,000 acres of forest in Prussia, the average area burned over each year is only 1400 acres, or one fiftieth of one per cent. What must be done to obtain a similar condition in this country?

Forest patrol.

First, and most important, is a regular patrol of the forests during the fire season. It is not sufficient to have fire wardens whose duties in reference to forest fires are only incidental. There must be in each of the great forests a regular patrol, just as there is in the city a police patrol to maintain conditions of peace and safety in the streets. A regular patrol has been found to be the only effective method of checking and controlling forest fires. Such a patrol has been found to cost, not to exceed two cents to three cents per annum per acre. Where there is a patrol, the cautionary laws can be enforced upon those who travel in the forest; and when, notwithstanding this, an exceptional fire occurs, the rising smoke, seen for many miles, gathers the patrolmen from all directions to take part in putting out the fire. An effective patrol system requires that cabins be constructed at regular intervals for the use of the rangers. These cabins should be well supplied with tools necessary to fight fire. As supplements to the above, there should be a system of trails and roads, telephone lines, and in some districts watch towers.

Fire lanes. Notwithstanding all these precautions an occasional fire may get started which it is impossible or very difficult to check. 
Hence there should be belts on which the fight may be made. Such a belt is the fire lane - a lane in the woods from which everything is cleared for a width of 15 to 100 feet, depending upon the conditions of the forest. In highly inflammable woods of great height the lane must be wide; if the forest is small the lane may be narrow.

Where the conditions are as advocated, when a fire breaks out, it is possible to converge a force to put out the fire at once; or if, in a rare case, it gets beyond control, it can be checked at a fire lane. We in the United States may well learn from Ontario. All the great forests which still belong to that province are regularly patrolled during the summer months. There is a well distributed system of rangers' cabins with connecting trails and water routes. The result is that the fires are few, and rarely does one become extensive.

In the second place, slashings should be burned. The greatest menace in the forest is the accumulated débris, and Burning of slashings. especially the slashings from lumbering. The lumberman goes into the woods, takes out the logs, and leaves the tops, limbs, and twigs. In the future, as has already been explained, we should use these materials for their by-products; but until this is practicable from a commercial point of view, they must be burned. If we could keep out the fires, it would be better to let the débris remain, because by their decay they add to the organic material in the soil; but as a matter of practical expediency, they are so serious a source of danger that this advantage does not at all compensate for the danger to the living forest.

As a result of actual experience it has been found that the cost of burning slashings from soft wood may be from as low as 15 cents or 20 cents per thousand feet of board measure to 50 cents or more, depending upon the character of the forests. The slashings of a clear Norway forest can be very cheaply burned. To burn the slashings of white pine is more expensive. As yet there is little experience as to the cost of burning the slashings of hemlock and hardwood forests. Some estimates are as low as 40 cents per thousand feet board measure, and others exceed $\$ 1$ or more per thousand feet. 


\section{CONSERVATION OF NATURAL RESOURCES}

Railroads and fires.

Camp fircs. There should be laws forbidding the making of camp fires at dangerous places, or leaving fires burning. The carelessness of the eamper is most surprising. Intelligent people with good intentions on a camping trip make a fire close to or in contact with débris. Oftentimes the fire spreads beyond their control. Also campers often leave their fire burning when they break camp. Such reckless acts are very reprehensible, not to say criminal. Against such practices there are laws in most of the forest states; but in order to make them effective the forests must be patrolled and the forest rangers and fire wardens must have ample authority to enforce them. They should have full police power, and should arrest and prosecute violators of any of the laws necessary to protect the forest.

In the national forest reserve the burning of slashings is compulsory. The same is true by order of the Department of the Interior in reference to the Chippewa Indian lands in Wisconsin The state of Minnesota has also passed a comprehensive law which requires the burning of slashings of all classes of timber. This law prescribes not only that the slashings shill be burned, but the conditions under which this shall te done, especially with reference to the time of year, 
so as to reduce injury to the standing timber and to lessen the danger of fires spreading.

It is clear that appropriate laws in reference to the burning of slashings should be passed in each state. No definite form can be enunciated, since the conditions vary in different states with reference to humidity, character of forest, value of timber; and laws which would be reasonable under one set of conditions would be unreasonable under another. Probably the best solution for a given state will lie in a general law declaring that slashings shall be burned so far as practicable, and authorizing a commission to make suitable regulations adapted to the conditions. Such regulations could vary in reference to the kinds of timber and be different in those parts of the state where the forests are continuous from where they are detached areas.

What are the results which have been accomplished where the measures and regulations above mentioned have been introduced and made effective? As yet this is only Fires in national forests. the case in the United States in the National Forests. There within the last two or three years we have reached an efficiency approaching that of Prussia. The United States Forest Service has a forest patrol; it has rangers' cabins; it has fire lanes; it has telephone communications; it has watch towers; it has in force regulations as to the burning of slashings, of camp fires, etc. In 1904 the area burned over in the national forests was .66 of 1 per cent; in 1907 the improved efficiency of the department had reduced the area to .02 of 1 per cent, the standard of Prussia. Then came the dry year of 1908 , in which there was an increase of forest fires, the stand destroyed being .06 of 1 per cent.

As yet the states, with one or two exceptions, have done comparatively little toward the control of fire. In New York and New Jersey there are efficient fire laws. A beginning has been made in Pennsylvania, Minnesota, Wisconsin, Maine, Maryland, Connecticut, Washington, and California; but none of these states have an efficient patrol; and only one of them requires the burning of slashings, which is absolutely essential in order to make a fire patrol effective. 


\section{CONSERVATION OF NATURAL RESOURCES}

Coöperative control of fire.

Cost of patrol.
In the protection of the forests from fires it will be most advantageous in those states where both the government and state own public forest for the two to coopperate; also it will be advantageous for the government and states to coöperate with the larger private holders. By such coöperation the cost per acre of the forest patrol and other necessary steps for protection will be reduced. Already such cooperation has been entered into by the United States government with some of the larger timber owners of the states of Washington, Oregon, California, and Idaho.

As yet only a few of the largest and most enlightened of the private owners of forests have a fire patrol. It is estimated that of the $450,000,000$ acres of forest owned privately not more than 1 per cent has an efficient system of fire protection.' Such a system is not needed in the case of the isolated woodlots which cover 200,000,000 acres; but is necessary in the case of the large and extensive holdings, and especially those in which the soft woods predominate. Experience has shown in the case of a few large companies that have introduced fire patrol, in the states of Idaho, Washington, and California, that the cost is at the rate of about 2 cents per acre per annurr. Had a fire patrol been in force in the lake states in the yea. 1908 , undoubtedly many times the cost would have been saved to the lumbermen in the reduction of their fire losses. Taking the years as they come, wet and dry together, had the lumbermen many years since introduced at their own expense a system of fire patrol in all of the great coniferous forests, it would have been immensely profitable to them; it would have been the best investment they could have made.

\section{REFORESTATION ?}

Area requiring reforestation.
It is necessary in order to increase our wood production to do extensive planting. We have seen that where a fire has run only once, where seed trees of proper species are left and

1 "Forest Fires," by Clyde Leavitt, Report National Conservation Commission, Vol. II, p. 462.

${ }^{2}$ Forest Planting, by A. S. Peck. Report National Conservation Commission, Vol. II, pp. 665-683. 


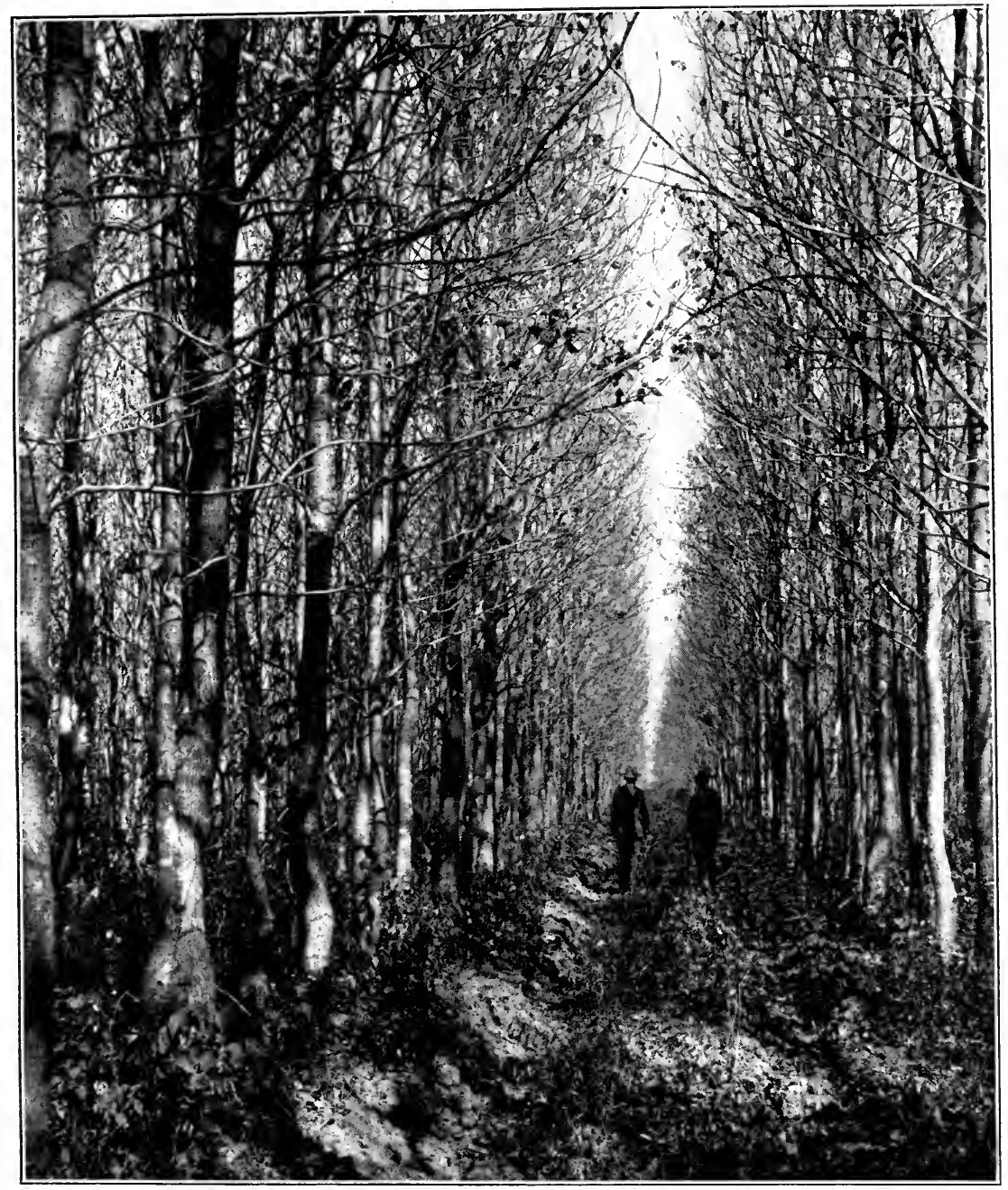

Plate IV. - Grove of hardy catalpa, Kansas. Photo by Forest Service. 




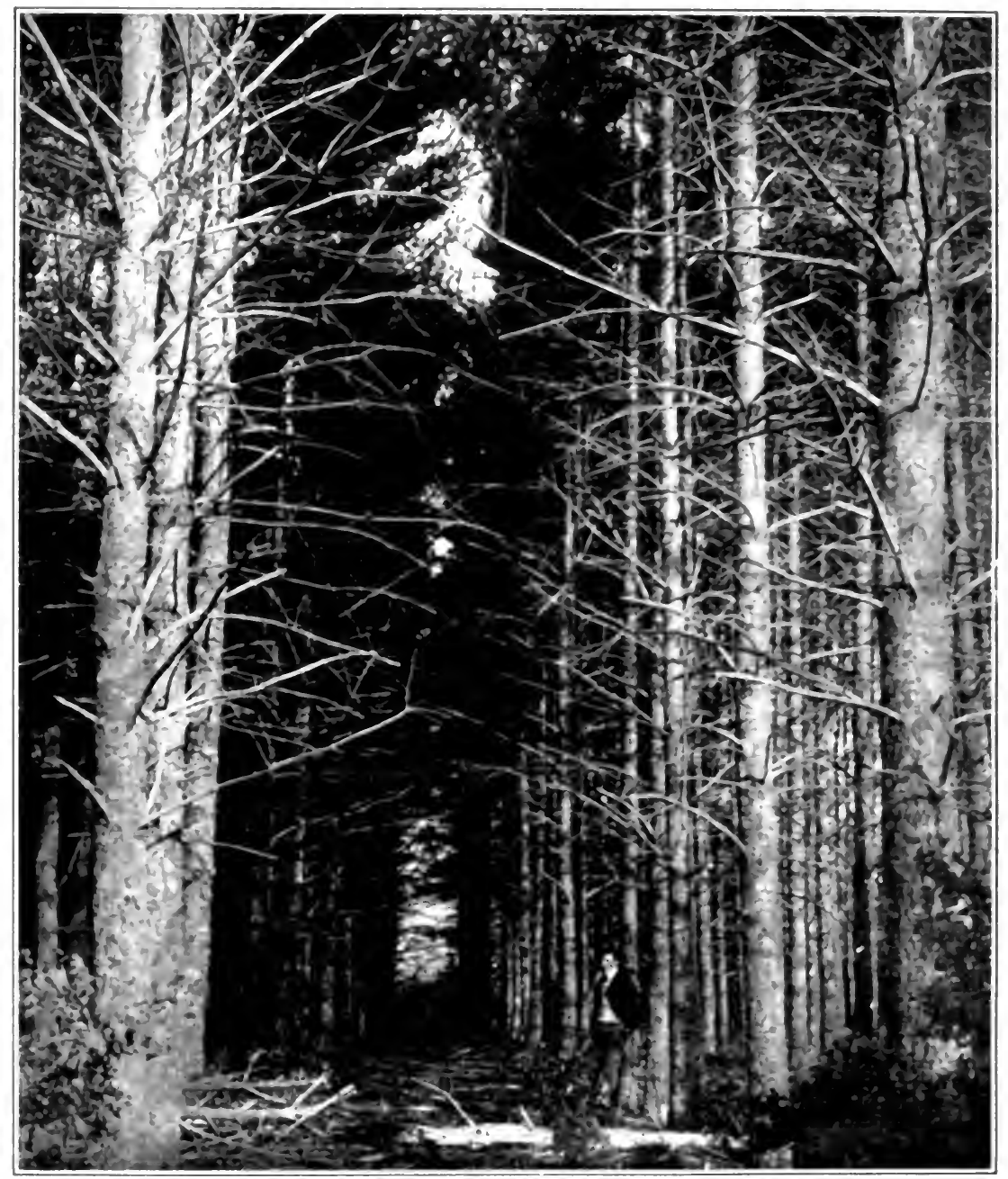

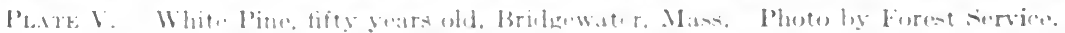


the slopes not too steep, the denuded areas will reforest themselves. But it has been explained that where fires have run several times, this is not the fact. Also there are extensive areas in which the stands of timber are of such poor quality that replanting is necessary. It is estimated by Peck that there are some 39,500,000 acres of cut-over and burned-over forest land, which it is necessary to reseed by artificial methods, in order that valuable timber shall again occupy the land. He also estimates that there are some $16,500,000$ acres of treeless land so poor, or in such positions, that it should be forested; making all together $56,000,000$ acres of land which should be forested by setting. Other estimates go as high as $80,000,000$ acres of such land. To plant this land will cost about $\$ 10$ per acre. Thus to do this work would involve a very large expense, and will require a considerable number of years.

\section{MAINTENANCE OF FORESTS ON ESSENTIAL AREAS ${ }^{1}$}

Forests should be permanently retained in certain essential areas, such as high altitudes, steep slopes, the source and banks of large streams, sand dunes, etc.

First, forests should be maintained on steep slopes and high altitudes because they tend to prevent floods. Beneath the trees of a forest a thick mantle of leaves and twigs covers the Absorption of water by forests. ground. These rest upon mold which is largely humus, and is very porous. All of this material is like a sponge in absorbing water. Leighton ${ }^{2}$ estimates that forest soil is capable of absorbing several inches of rainfall, with comparatively little run-off. Also, the surface of the ground in the forest as a result of the prying of roots, overturned trees, etc., is extremely irregular, and so gives numerous basins to hold water until it can be absorbed. The water absorbed passes underground and reaches the streams very slowly through seepage and springs. Therefore the forest cover, the mold,

1 "Methods of Increasing Forest Productivity," by E. E. Carter, Report National Conservation Commission, Vol. II, pp. 270-279.

2 "The Relation of the Southern Appalachian Mountains to Inland Water Navigation," by M. O. Leighton and A. H. Horton, Department of Agriculture, Forest Service Circular 143. 


\section{CONSERVATION OF NATURAL RESOURCES}

and the basins act as restraining influences and prevent the water from rapidly reaching the streams. In the winter, in the northern half of the United States and in mountainous areas, the precipitation is in the form of snow. As the snow melts the forest mold acts as an absorbent, although perhaps not so effectively as in the summer, and the shade of the trees results in slow melting. Therefore where forests are maintained the snow melts more slowly than on the open, and the water makes its way less rapidly to the streams.

Forests prevent erosion.

Interaction of erosion and floods.

Floods not wholly preventable.

Second, forests restrain erosion. The tangle of roots of the forest prevents wash, or reduces it to a minimum. It has taken ages to produce the soil and gravel on the steep slopes of the mountains. This material is held in place by the roots of the trees. When the forests are removed it may be carried down in enormous quantities to the valleys below. This results in choking the rivers with débris and making navigation difficult or impracticable. Not only so, but after the rivers are partly filled with silt, at times of flood they overflow their banks and often cover with coarse débris large areas of arable land. When this process of erosion has continued for a sufficient length of time after the removal of the forests, the steep mountains are left with nearly bare rock and little soil. When this stage of the process has been reached the violence of the floods is then further greatly increased. The rain falling upon the bare rocks is carried down to the streams below as from the roof of a house, and unites in torrential floods. It is after this condition of affairs has come about as a result of the removal of the forests that the enormous flood losses occur to railroads, cities, and other structures of man. This will be illustrated by the situation in foreign countries to be mentioned later.

While in the long run the evidence appears to be conclusive that forests on the headwaters of the streams do lessen the severity of the floods, it is not held that their presence will prevent floods in all cases. As already indicated, the best protection against floods is provided by a combination of forests and reservoirs. (See pp.125-129.) But even if forests are retained in essential areas and reservoirs are built to hold back 


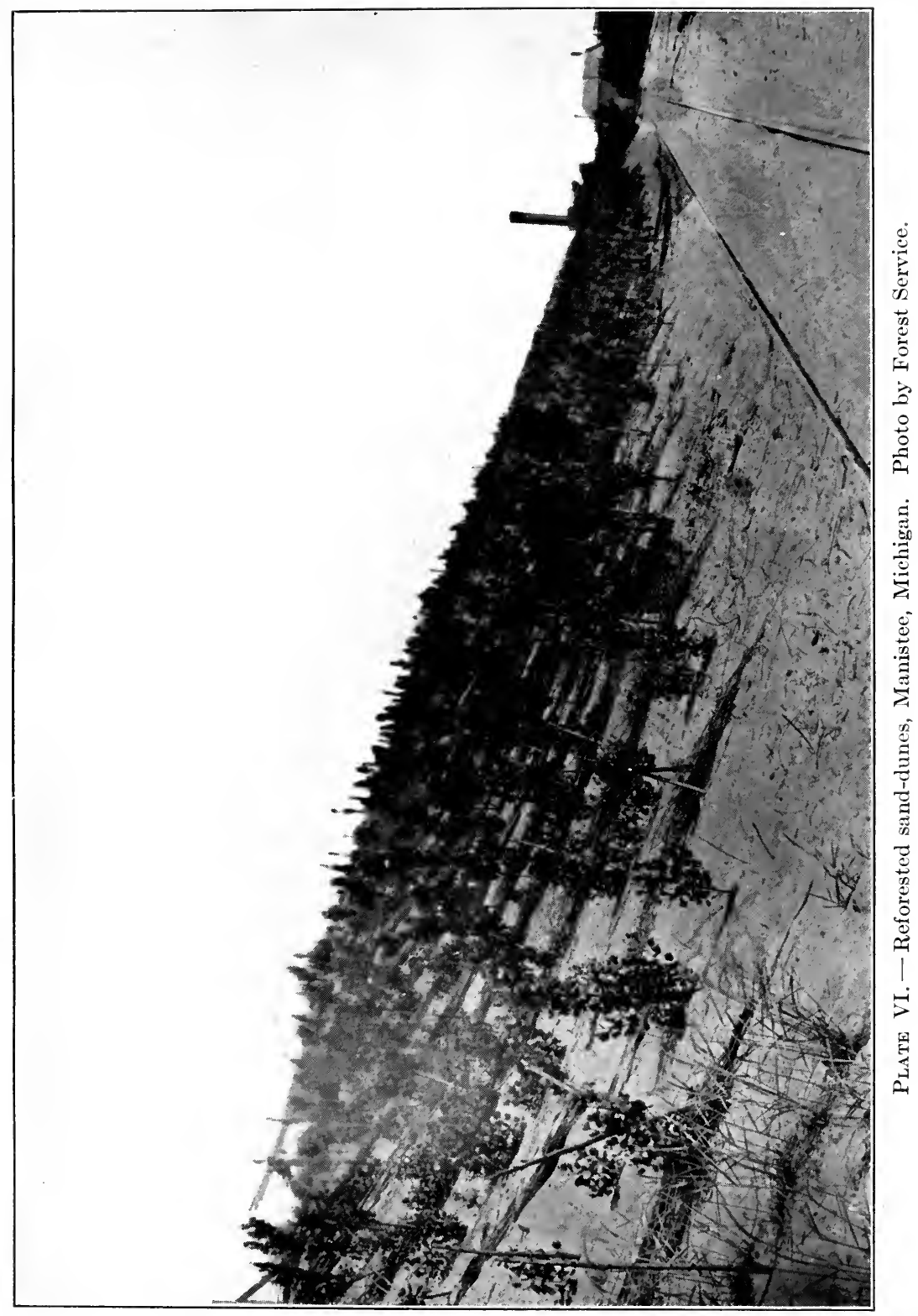




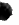




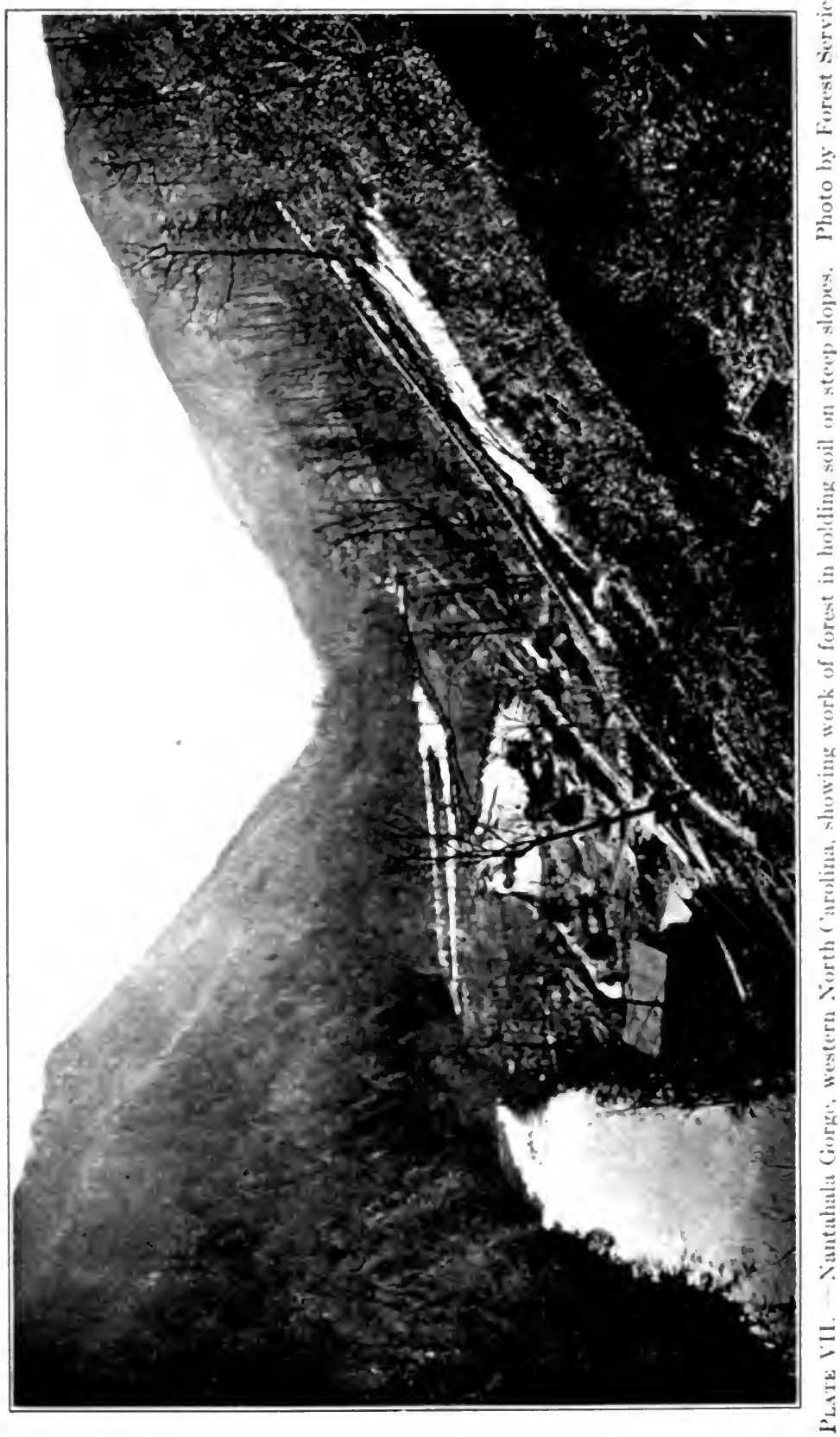


all the water possible, it will still be true that at times of extraordinary large rainfall, or exceptionally rapid melting of the snow under the influence of warm winds, or especially the two combined, there will be floods. Under such circumstances it is occasionally the case that even the absorbent power of the forests and the capacity of the reservoir are insufficient to care for more than a fraction of the storm waters; and the surplus, when large, as it will be occasionally under the best of conditions, may produce disastrous flood losses.

However, the above general principles are fully confirmed by the experience of other countries, which have allowed their mountains to be denuded of their forests; and this country already furnishes examples of increased erosion and irregularity of the streams because of the removal of the forests. The lessons furnished by other countries and by the existing illustrations in this country should be a sufficient warning to us. We should never permit the steep slopes of the mountainous regions to be further denuded of their forests.

In Italy, the Apennines have been denuded of their forests; and as a result there has been greatly increased destruction by the Po. This has led the government to begin reforestation of nearly a million acres. In Austria the mountains have been extensively deforested, with the result that great floods have occurred on the Tyrol and the Karnton. To remedy this the government has begun reforestation on the headwaters of one hundred streams.

But perhaps the most impressive illustration in Europe of the destructive effects of deforestation of the mountains is furnished by France. The Provençal Alps and other mountains have been denuded of their forests; and as early as 1861 reforestation was begun. "France has now a far-reaching plan for bringing under control about 3000 torrential streams in the Alps, Pyrenees, Cevennes, and the central plateaus." According to information furnished by Cox, of the United States Forest Service, by the end of the nineteenth century about 400,000 acres had been acquired, of which 218,000 had been planted. It is planned to continue to acquire land at the rate of 25,000 to 30,000 acres a year until 425,000 more

The forestless mountains of France. denuded Apennines.
The lesson from other countries.
The Ape 
acres are secured. The government expense up to 1910, aside from the coöperative expense of corporations and privato owners, was approximately $\$ 17,000,000$, of which more than $\$ 5,000,000$ was expended for purchases. It is estimated that to complete the plan will require between $\$ 20,000,000$ and $\$ 25,000,000$ additional; and that with an annual expenditure of $\$ 600,000$ this will be possible by $1945 .^{1}$

In France the great flood of 1910 has resulted in enormous loss of property and many lives. A considerable part of the beautiful city of Paris has been under water, and some of its most famous buildings have been greatly injured. It is not to be supposed, even if the work of reforestation had been completed, or that work combined with the development of a reservoir system, that they would have been sufficient to prevent a disastrous flood; but it is believed that the extent of the calamity would have been reduced, and probably the lessening of the damage due to the flood would have more than paid for the entire cost of reforestation of all the denuded mountains at the headwaters of the Seine.

The 1910 flood is not the first that Paris has suffered, although the damages of that year were larger than ever before. Great floods occurred in the sixth, thirteenth, and fourteenth centuries; and in 1615, 1740, and 1802. The 1615 flood was probably as great as that of 1910 . The fact that the four last great floods average about a century apart gives an excellent illustration of the principle that forest removal may be continued for a long time before the profound disaster follows. The early recorded floods show as indicated (pp. 246-247) that even before forests are removed floods may occur; the point is that by forest removal their destructive effects are greatly augmented.

Vast areas in China which were once heavily covered by forests are now completely denuded of timber; and as a result immense quantities of débris have gone down into the

${ }^{1}$ Relation of Forests to Stream Control, by Gifford Pinchot, Annals of the American Academy of Political and Social Science, Vol. XXXI, January, 1908, pp. 219-228. 


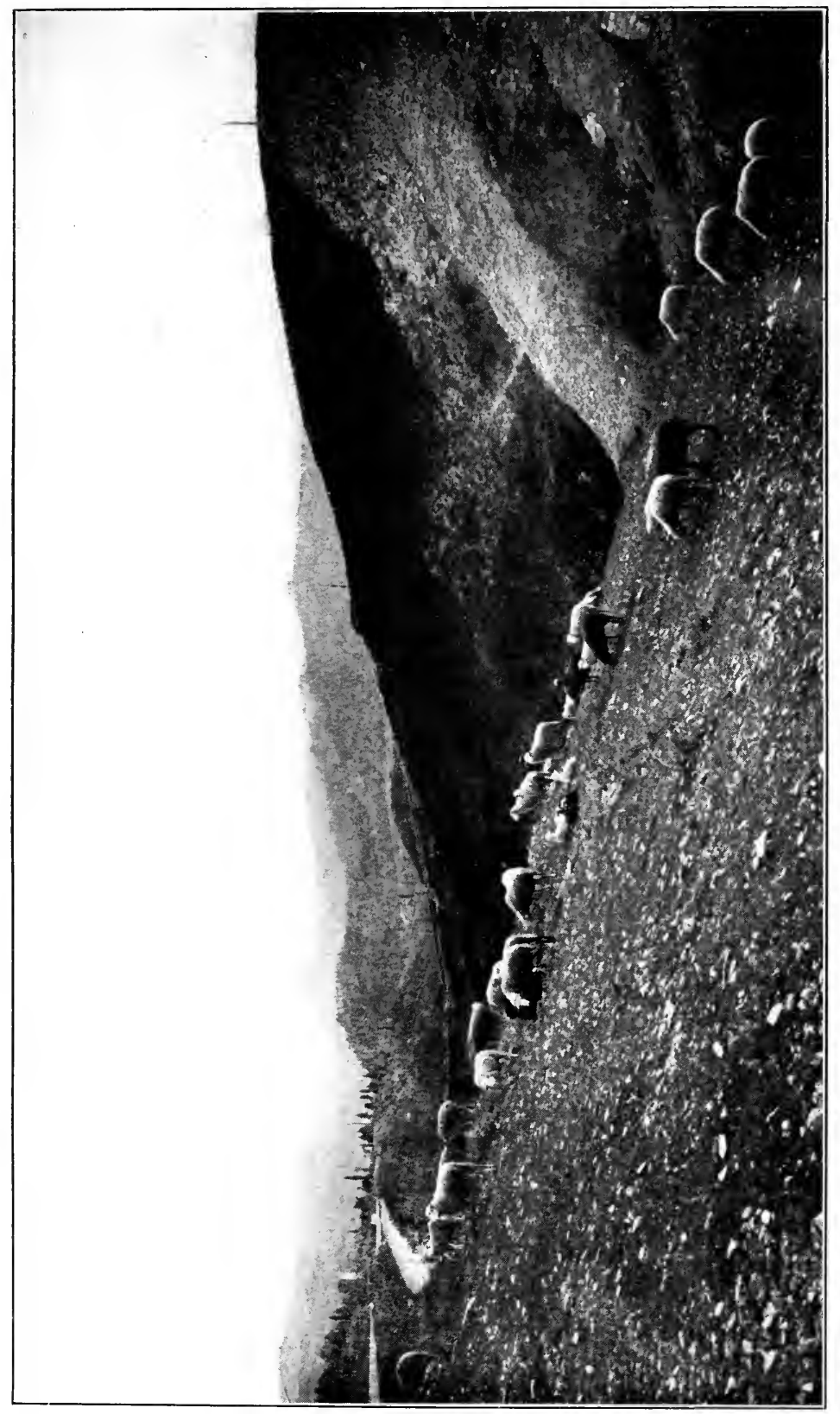

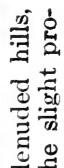

\&

$\pm$

봌요

5

$\frac{9}{10}$

ำ

浮。

동

त)

38

$+\mathbb{D}^{\circ}$

曲

马고

을

ㄷㅇ

둥

芝全

뮤웛

绕

풍

○

- की

记导

$\pm \approx 2$

웡

$\exists$

Ð

死

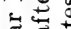

चु

व

น

. हृ

च

원.

$\pm=$

$\exists$ a

$\because \mathrm{C}$

递宁

$>$ 范。

-

ज寻

焉

国导 



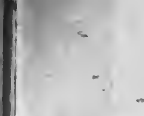

$-$

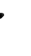

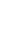

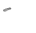




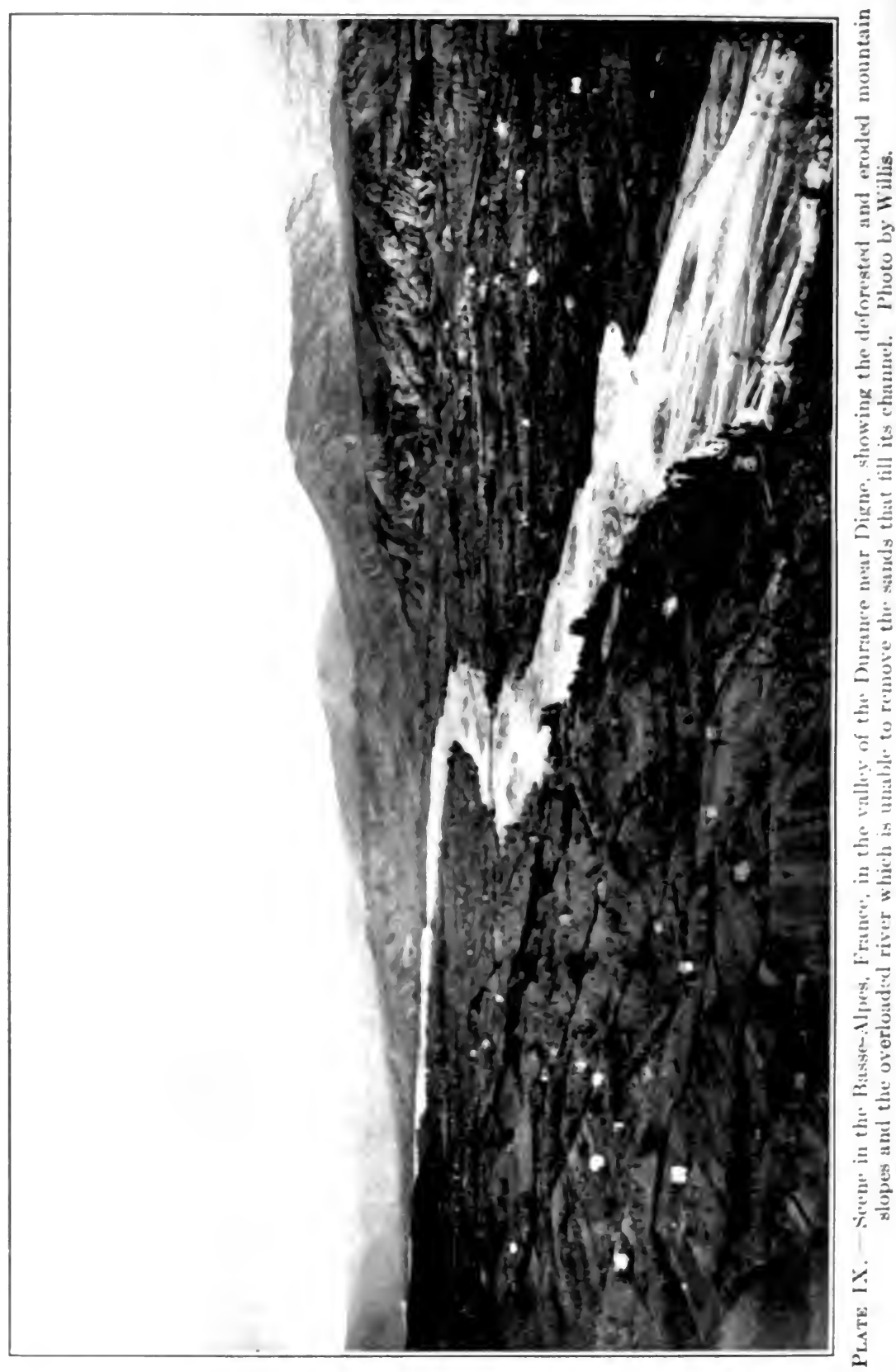


streams, checking them and at times of flood the waters spread over the valley lands.

These illustrations show that the removal of the forests from the headwaters of the streams has been an excessively expensive experience to many countries.

That similar procedure in this country yields like results is shown by the actual conditions in areas where some streams have been deforested and others not. The north fork of the Yuba River in the Sierras of California is forest-covered, and the south fork has been denuded. The first has a watershed of 139 square miles, and the second a watershed of 120 square miles. The first, well covered with timber and brush, gives a minimum run-off of 113 cubic feet per second. The second should have given a minimum run-off of about 100 cubic feet per second, but it is said to be practically nothing for four months in the year. ${ }^{1}$

Again, Queen's Creek in Arizona, having a drainage area of 143 miles, where the annual rainfall is only fifteen inches, which has an unforested watershed, is subject to violent floods. The maximum discharge in 1896 was 9000 cubic feet per second; whereas the mean discharge was only fifteen cubic feet per second, and during a large part of the year the stream was dry. In contrast with this is Cedar Creek in Washington, flowing over well-timbered watersheds, having a drainage area equal to that of Queen's Creek, and a precipitation of from 93 to perhaps 150 inches. This stream in 1907 had a maximum flood discharge of 3600 cubic feet per second, and a mean discharge of over 1000 feet. According to Pinchot, "This radical difference in the behavior of the two streams can be explained only by the difference in the soil cover of the two basins."

Contrasts similar to those prevailing between the north and south forks of the Yuba River are also found in streams flowing from the San Bernardino Mountains of southern California. There the streams which are deforested have a very heavy flow at times of rainfall or shortly after, and a very small flow during the remainder of the season; whereas

Contrast between forested and forestless mountains.

The San Bernardino Mountains. 
Hydraulic mining.

The Appslachisns.

the streams which are forested are much less violent in their fluctuations.

For these mountains, quantitative statements may be made as a result of studies by Toumey and Prentice. They found that by the end of March the forested areas of the mountains had lost 40 per cent of the winter's precipitation; whereas the cut-over and burned-over country had lost 95 per cent. In the season when irrigation was needed, the forested areas in April sent down from every square mile enough water to cover 155 acres a foot deep, whereas the cutover barrens supplied but 55 acres with the same depth of water; in May the relative numbers were 66 and 2; in June a square mile of forest still supplied enough water to cover 28 acres a foot deep, whereas no water came from the cut and burned-over areas. ${ }^{\prime}$

Fortunately as the result of the reservations of the national forests and national parks, the high mountains of the West in which the conditions are critical are to retain permanently their protective covering. This leaves as the one great critical unprotected area the southern Appalachians.

Before considering this region we may mention hydraulic operations in certain limited areas on the headwaters of the Sacramento. These have led to the choking of that stream so that there has been enormous damage to the lowlands below and vast injury to navigation. Indeed, the damage to the farmer was so great that unrestricted hydraulic operations are prohibited. The débris may be sent into the streams only to such amounts as they are able to handle.

If the forests be wholly removed from the southern Appalachians a disaster would occur one hundredfold worse than anything that befell California from the relatively small amount of débris from hydraulic operations. The southern Appalachians for the most part are protected by a dense forest, which springs from a thick soil produced by the disintegrated rock. The Appalachians have flat-topped ridges or domes with very steep slopes. If the vegetation were removed

1"The Water Savers," Walter V. Woehlke, Outlook, Mar. 26, 1910. p. 663. 


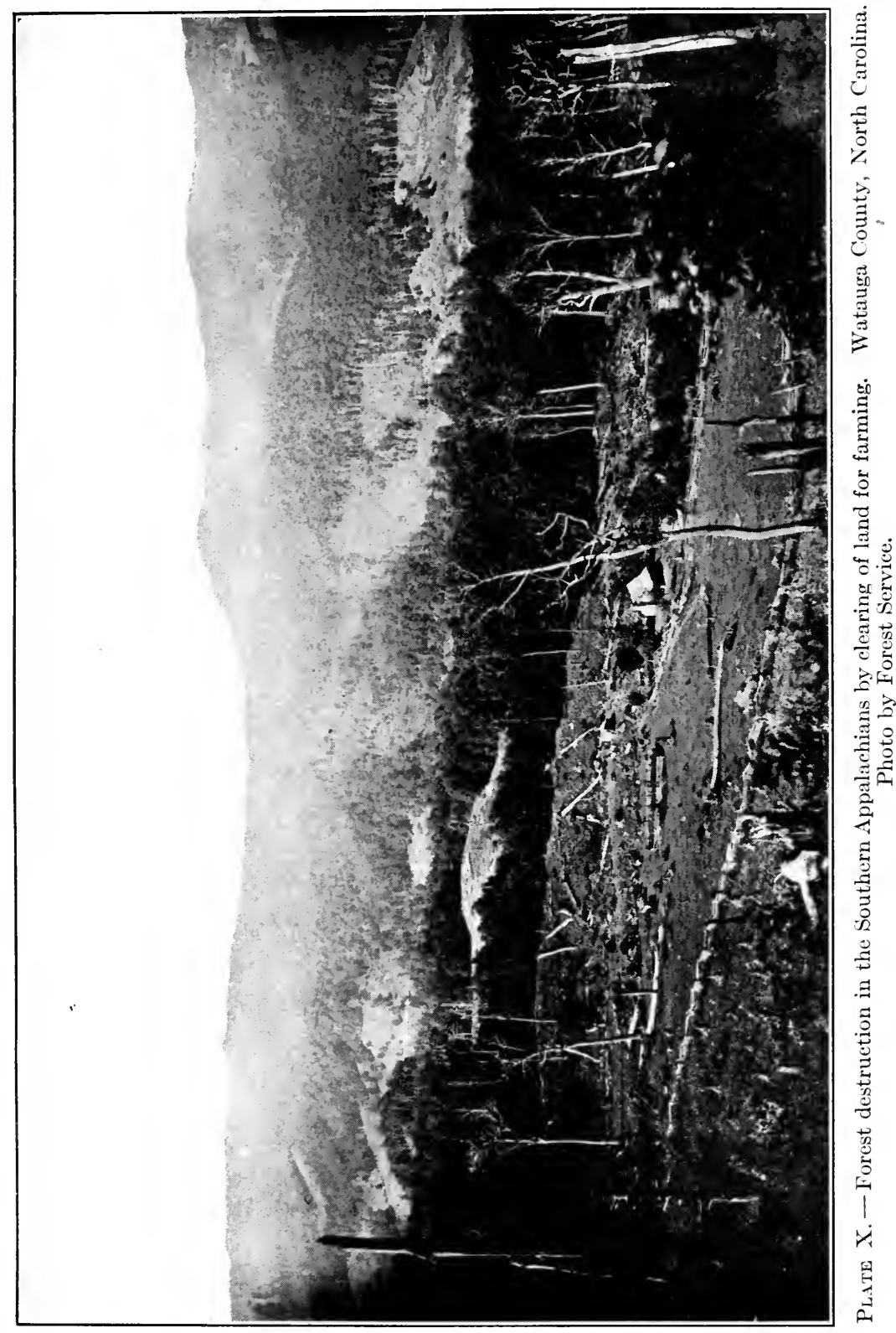



from the latter, the abundant rains of that area gathered into streams would carry enormous, indeed, incalculable masses of material to the valleys below. The headwaters of the Tennessee and Ohio would be silted up. The great Appalachian valley would be injured beyond computation, as would also other extensive tracts. We can make no estimate in money as to the damage which would result from the removal of the southern Appalachian forest. The experience of other countries should be sufficient to teach us not to go through that of France and China. If it does not, a democracy must, indeed, be incapable of wisdom.

Close studies by Leighton, Hall, and Maxwell of the Appalachian region lead them to the conclusion that the beginnings of the removal of the forests on the headwaters of Increase of flood frequency. the streams have increased the severity of the floods. For the larger streams which rise in that region investigations have been made for a variable period, and the frequency of the floods for the first half of the period compared with the second half. According to Hall and Maxwell ${ }^{1}$ eight of the ten rivers studied show greater floods in the last half of this period than the first. These are the Potomac, the Monongahela, the Ohio, the Cumberland, the Wateree, the Savannah, the Allegheny, and the Tennessee.

In the case of the Tennessee River, the most important of the streams, a very elaborate study has been made by Leighton, taking into account not only the number of floods during a period of twenty-four years, but the number of flood-producing rains. As a result of his investigations he concludes that the increase of floods in proportion to the number of floodproducing rains is about 19 per cent.

As yet the removal of the forests in the Appalachian region has just begun; but the studies which have been made, and especially those on the Tennessee, foreshadow the awful possibilities which are likely to befall if the forests are generally removed from the headwaters of its streams.

Already from time to time there have been severe floods on Floods of the Ohio which have resulted in great damage; but it is to be Ohio.

${ }^{1}$ U. S. Department of Agriculture, Article 176. 
remembered in this connection that the great floods are separated by long periods; they may not occur oftener than once in a century. This is illustrated by the modern great floods of the Seine, between which were intervals of about one hundred years on the average. To continue to remove the forests from the headwaters of the Ohio is but to invite to the cities along its waters and the waters of the Mississippi, from Pittsburg to New Orleans, disasters similar to those which befell Paris in 1910.

I am aware that Chittenden ${ }^{1}$ and Moore ${ }^{2}$ argue that the removal of forests does not tend to increase floods. They hold that the facts presented by Leighton, Hall, and Maxwell, in reference to the Appalachian region, are not sufficient to prove that there has been an increase in the frequency and intensity of floods because of the removal of the forests. In these general lectures I cannot possibly go into a detailed criticism of their papers, ${ }^{3}$ but it seems to me that for this region those who hold that the floods have increased in frequency and violence because of the removal of the forests have the better of the argument. In any case it remains to be explained why there is such remarkable discrepancy in flood frequency in the cases of those streams which rise in the same area, one of which has been denuded of its forests, while the other remains forest-covered (see pp. 249-250).

Deforestation and erosion.

However, even if the arguments of Chittenden and Moore were accepted with reference to floods in the Appalachian region to the present time, there would still be more than sufficient reason for the maintenance of the forests in these mountains, for the greatest losses due to the removal of the forests are not the flood damages to structures made by man, but the erosion of the soil in the highlands, with the enormous

1 "Forests and Reservoirs in their Relation to Stream Flow, with particular reference to Navigable Rivers," by H. M. Chittenden, Paper No. 1098, American Society of Civil Engineers.

${ }^{2}$ Report on The Influence of Forests on Climate and on Floods, by Willia L. Moore, Government Printing Office, Washington, D. C.

${ }^{3}$ Since the above was written there has appeared a complete and detailed refutation of the positions taken by Chittenden and W. L. Moore by Barrington Moore, Gilbert Roth, L. C. Glenn, and George F. Swain. The same may be found in American Forestry for April, 1910, pp. 199-240. 
damages attendant upon carrying down vast quantities of débris to the valleys below. This position is proven beyond peradventure by the case cited of hydraulic mining in California (see p. 250). If in the Appalachians the forests are removed and the soil and disintegrated rock material capable of absorbing water are carried away from the mountains, leaving the bare rocks protruding, there can be no question that when that time comes the intensity and violence of floods will be increased; for there will be little to restrain the storm waters from rushing from the uplands to the lowland in torrential masses. Therefore if the arguments of Chittenden and Moore be accepted that to the present time forest removal has not promoted flood intensity and frequency in the East, there is more than ample reason for the maintenance of the forests on the headwaters of the streams, and above all is this true of the Appalachian region.

Twice a bill establishing an Appalachian and White Moun- Appalachian tain Forest Reserve has passed the United States Senate, in June, 1901, and in January, 1907. Both of these bills failed forest reserve. in the House. In 1909 one bill making an appropriation for such a reserve passed the Senate and another the House. Each of these failed in the other branch of Congress; and thus there is still no legislation upon the subject. It is clear, however, that enlightened public sentiment has so developed that the bill for the acquiring of a national Appalachian reserve will become law in the near future. However, provision for a national forest in the Appalachian Mountains is not sufficient. The states and individuals must coöperate. If the states supplement the national appropriations by appropriations to make state forests, and with the nation and states the individual holders coöperate, each taking out only the mature timber and at all times preserving the forest areas, the future interests of the nation will be protected. 


\section{INCREASE FOREST GROWTH BY STOCEUTG :}

Average growth of forest.

Increase stocking.

Combination of trees.
The forest growth should be increased in the present forested area. The average growth of the different forests, as I have already said, varies from something like 30 to 110 cubic feet per annum per acre, with an average of about 28 cubic feet for the better forests and only about 12 cubic feet for the entire forest and woodland area. It is possible to increase greatly this amount. To do this will require several things: -

The land must be kept fully stocked by planting and seeding. At the present time there are nearly $135,000,000$ acres of forests which are relatively unproductive, because not fully stocked, or stocked with very poor material. Also, of the $225,000,000$ acres of productive forests some 80 per cent have not more than one half of the stock they could carry; this would be equivalent to $80,000,000$ acres with no stock whatever. Altogether this makes something like $215,000,000$ acres which really need to be restocked, in addition to the $56,000,000$ acres already considered upon which replanting is necessary.

In the restocking there should be introduced the rapidly growing and valuable species, - spruce, white pine, and other productive trees where the coniferous forests are prevalent; and tulip, poplars, catalpa, eucalyptus, and other rapidly growing trees in the hardwood areas.

Frequently the best stands are produced by combining two kinds of trees. One elass of trees is very eager for the sun; another class will grow fairly well in partly shaded areas. By combining trees of the two classes a heavier stand can be secured than by one alone. In many places this is accomplished under natural conditions; for instance, on the Pacific slope the Douglas fir is the dominant tree, and in its shade are the hemlock and red cedar. Similarly in the Rocky Mountain region under the lodge-pole pine may be found spruce and white fir. In the hardwood region, below the tulip tree there may be seen the beech and maple. In Silesia an experiment has shown

1 "Method of Increasing Forest Production," by E. E. Carter, N. C. C., Vol. II, pp. 270-279. 
that land stocked with a mixture of spruce and pine gave a larger yield by 18 per cent than spruce alone, and by 28 per cent than pine alone.

\section{I0. BATTLE WITH INSECT PESTS ${ }^{1}$}

In order to gain the largest annual increase, it is necessary Kinds of to battle with the insect pests. These under natural conditions in the primeval forests are pretty well under control; insect but as soon as a forest is cut in part, or if a forest is reseeded, the insect pests become more numerous and more difficult to control. The subject is a very complicated one, which cannot be more than mentioned here. The insect pests include beetles, worms, and moths. They attack fine forests and destroy them over extensive areas. Also over very large areas where they do not actually kill the trees they weaken them and make them less valuable. At the present time in the eastern part of the United States, New Haven, Boston, and other cities, and even New England villages, are having a severe struggle to keep alive their elms, the pride of the people. Indeed in Cambridge and a number of other towns, it looks as if they all would go, notwithstanding the best efforts to save them.

It is almost impossible to completely destroy the insect pests. The most successful methods have been those which have worked with nature through the encouragement of beneficial birds, beneficial insects, and beneficial diseases. Parasites are introduced that will attack objectionable insects exactly as the objectionable species attack the trees. This problem of the control of insect pests is one which will require long continuing investigations by entomologists, especially now that we are starting on a great era of planting; for in the work of reforestation new insect problems will begin to confront us.

1 "Waste and Reduction of Timber Supplies Caused by Insects, and Methods of Prevention and Control," by A. D. Hopkins. Report of National Conservation Commission, Vol. II, pp. 469-497. 


\section{CONSERVATION OF NATURAL RESOURCES}

\section{SUBSTITUTION OF OTHER PRODUCTS FOR WOOD}

Use steel and stone instead of wood.
Wood and fire losses.
So far as practicable other products should be substituted for wood. In America the houses in the country and in villages are mainly of wood, as are also a large proportion of them in the cities. We are still using wood for the making of many bridges. In other civilized countries houses and bridges are very rarely made of wood. These and other structures which require a large amount of material should be made of stone, cement, brick, and steel,- - permanent materials making durable structures. This reform would reduce by one third the demands upon our wood supply. Similarly steel should be substituted for wood for railway cars. In the past this has been a heavy draft upon wood. The steel car is stronger than the wooden car can possibly be, and is more durable. This substitution has already begun. No new cars should be made of wood. Metal should to a considerable extent be a substitute for wood for furniture and implements. This has already begun. Shelves in libraries are made of steel. For wagons and agriculture implements, metal is to a larger and larger extent displacing wood. To some extent also iron is being substituted for railway ties, but as yet this has not taken place upon a large scale.

Another great advantage which will come from the substitution of metal for wood, will be to reduce fire losses." In 1907 the fire losses of the United States amounted to $\$ 215,000,000$, of which about $\$ 109,000,000$ was in buildings, and about $\$ 106,000,000$ in the contents. The frame buildings and their contents amounted to about $\$ 146,500,000$, brick and other buildings and their contents to about $\$ 68,500,000$.

The above does not represent the total losses from fire, because in consequence of the inflammable character of many of our cities it is necessary to maintain very expensive fire departments and pay very high insurance. Indeed Wilson estimates that the losses due to excessive insurance and the increased expense of the city administration, including fire de-

1 "Waste of Structural Material from Fire and other Causes," by $\mathbf{H}$. M. Wilson, Report National Conservation Commission, Vol. III, pp. 604-619. 
partments and water supply, amount to $\$ 234,000,000$ per annum, or more than the actual fire losses. A large part of this amount in addition to the fire losses could be saved. It is therefore plain that the substitution of permanent materials for wood in all structural work would be more than justified from the point of view of fire losses without counting in the advantages in reducing the consumption of wood.

\section{REFORMATION OF THE TAX LAWS 1}

Another of the great essential steps that is necessary to preserve our forest is to reform our tax laws. At the present time timber is generally taxed in this country under the genTax laws compel cutting. eral property law, i.e. a stand of timber is assessed and taxed each year the same as other property. This, you can readily see, almost compels the owner to cut valuable timber to protect himself against loss. The influence of the general property tax is not to conserve wood, but to put it upon the market as soon as possible. This being the situation, all who have studied the forestry problem agree that the laws for taxing timber should be reformed. Several plans have been proposed, two of which seem to be worthy of serious consideration. Instead of taxing the timber each year, it could be taxed only when cut. A law of that kind would tend to restrain cutting instead of encouraging it. Or, if the states are not ready to go as far as this, a tax might be levied each year upon the value of the land estimating this as if there were no forest covering, and then a tax upon the timber when it is cut, - a combination tax. This intermediate measure is the one which is being urged at the present time in many states as being perhaps not the final solution, but the first step toward the final solution of the scientific taxing of forests.

It is evident that there are great difficulties in passing from the present method of taxation to one of those proposed. These difficulties are of various kinds. If a tax law were so

Difficulties in $\operatorname{tax}$ reform.

1 "Taxation of Timber Lands," by Fred Rogers' Fairchild, Report National Conservation Commission, Vol. II, pp. 581-632. 


\section{CONSERVATION OF NATURAL RESOURCES}

framed as greatly to reduce the taxes upon the forest, and this is probably desirable, it might leave a deficiency of income in certain parts of a state. In various states there are also constitutional provisions which prevent the imposing of a tax upon a crop. In other states there is a law which wholly prevents any exemption from taxation. Also there are a number of states in which it is not practicable either to classify the property and impose upon the classes different rates, or to give exemptions. It appears from the above that any thoroughgoing reform of the tax laws will probably require constitutional amendments in many of the states.

In each of the states there are likely to be local difficulties which cannot be here discussed. It is very clear that in the reform of the taxation of forests careful investigations of the conditions must be made in each state, and thus ascertain what is necessary to do in the way of constitutional amendments and modifications of existing laws, before definite laws for timber taxations under the principles suggested can be formulated.

This being the situation, it is inadvisable to make anything more than most general suggestions as to how the proposed change may be made, it being understood that they may be impracticable under some conditions and will need to be modified under others. If it be assumed that the situation will permit a change of the system of taxation to the form suggested, it should be made gradually.

Gradual change to new method of taxation.

It would not do the first year to tax the timber cut to the full amount it should be taxed after the method is fully in force, because that timber has been taxed year after year in the past under the general property tax. But a plan could be worked out by which the general property tax would be reduced by a fifth or a tenth each year, upon the standing timber, until this tax disappears; and at the same time a tax put upon the product cut which should increase during those five or ten years; and at the end of that period the new system would be in full force.

A reform in the method of taxing timber is certainly an absolute necessity. Many of the best lumbermen, - those who 
are anxious to conserve our forests, who desire to keep their holdings as the permanent property of their families, say that they are obliged to cut the timber. They say: "With the taxes as they are now we must cut the forest we hold during the next ten years, or at most twenty years, or its value is taken away from us."

The change in the system of taxation will be difficult to accomplish, but already laws for this purpose are being formulated; and we may hope that a realization of the seriousness of the situation will lead the states to pass laws for the conservation of the forests.

\section{TOTAL RESULTS OF MEASURES ADVOCATED}

Carter has made an estimate of the possible increased growth Possible of the forests which will finally result from putting in force all the remedial measures which have been discussed. He says increase in timber that the average growth of the forest can be made eighty cubic feet per annum per acre, instead of twelve cubic feet; and he says if this were applied to the $135,000,000$ acres of nonproductive forest, the $90,000,000$ acres of land which is practically waste by being imperfectly planted, and the $80,000,000$ acres on which there is no forest, but on which there should be a forest, that the total increase in yield each year would be $24,400,000,000$ cubic feet. To this he adds a possible ten cubic feet of increased growth per annum per acre upon the $145,000,000$ acres of the better forest of $1,450,000,000$ cubic feet. This gives a total annual increase of 25,850,000,000 cubic feet.

This is a very large estimate, but it looks far into the future. We cannot expect that this ideal situation will be reached for many years; probably it will be reached only when necessity drives us; and after exerting our best efforts, fifty or one hundred years will be required for full fruition. But if Carter's estimate is correct, the remedial measures when fully effected will furnish us more additional growth per annum than is now being taken, 23,000,000,000 cubic feet per annum. In addition to this we would have the normal growth of present conditions, 6,500,000,000 cubic feet. We must, however, 
remember that the total of the timber area is being reduced; also the population of this country is increasing very rapidly; and at the beginning of the next century, if the rate of increase of the past is continued, we shall need wood not for $100,000,000$, but possibly for $250,000,000$ people.

\section{CONCLUDING STATEMENTS}

In closing this part I may summarize the procedure in a

Produce as much wood as we use. forest under the supposed future ideal condition. Suppose a state owns a tract of 100,000 acres; and suppose it takes a hundred years to grow timber to the stage when it is advantageous to cut it. Under these circumstances you may imagine that the state each year cuts over 1000 acres and takes out all of the mature timber. Thus the entire area would be cut over each hundred years. The annual product of the 1000 acres cut will represent the entire annual increase of the 100,000 acres. Probably 100 years is a rather longer time than will actually be required; for when the mature trees are cut, there will be left a stand of intermediate size which will mature before another hundred years; but the illustration gives a definite conception of the ideal conditions toward which we must work. We shall be obliged so to handle our forests that we produce as much wood each year as we use; for it is to be hoped that this nation will not repeat the disastrous mistakes of other nations by ever allowing its forests to become too small to furnish the amount of wood necessary for the purposes of the people, and especially that it shall never allow the forests to be removed from the mountainous areas.

To accomplish the far-reaching reforms proposed to continue an adequate timber supply will require a great campaign of education. The feeling of responsibility of the nation, of the state, and the individual to posterity in the matter of wood must be developed. The work of conservation cannot be done by the nation alone; it cannot be done by the state alone; it cannot be done by the individual alone. Each must do what it can. The nation and the states should practice forestry on all public lands, and thus set an example to 
private holders. Already, as we have seen, the national government practices forestry upon all of its forest reserves. Some of the states have begun forestry upon their holdings; but many are still delinquent in this respect. As yet few individuals have begun the practice of forestry. It is estimated that about 70 per cent of the publicly held forests have scientific forestry practiced upon them; and that of the private holdings this is true for less than 3 per cent. The first duty of the nation and the states is to practice forestry upon their entire holdings, and then to pass laws requiring the same practice upon private holdings. Such laws should be gradual in their introduction and give reasonable time for the extension of the practice to the entire holdings. There is no question that in this matter the paramount right of the nation may control; and that as soon as public sentiment demands it, laws may be passed which shall compel the private holder to practice forestry. This is shown to be perfectly clear by the decision of the highest courts, including the United States Supreme Court (see p. 363).

The supreme court of the state of Maine gave an affirmative answer to the following question from the legislature: "In order to promote the common welfare of the people of Maine by preventing or diminishing injurious drought and freshets, and by protecting, preserving, and maintaining the natural water supply of the springs, streams, ponds, and lakes, and of the land, and by preventing or diminishing injurious erosion of the land and the filling up of the rivers, ponds, and lakes, and as an efficient means necessary to this end, has the legislature power under the constitution by public general law to regulate or restrict the cutting or destruction of trees growing on wild or uncultivated land, by the owner thereof, without compensation therefor to such owner?"

The great campaign of education which has been inaugurated by the National Forest Service, by the State Forest Services, by the various state and national forestry associations, by the university forestry schools, and by many other agencies, must be continued until enlightened public senti-

1 " Conservation of our Natural Resources and of our National Strength and Virility," A. A. Bruce, Pennsylvania Law Review, Vol. 58, p. 160. 
Conservation and forest cutting. ment secures the necessary reforms to preserve a sufficient amount of forest so that our land will be protected; so that our people may have wood. Frequently in the past in this campaign, sentiment rather than judgment has prevailed. Conservation does not demand that no tree be cut, but that whenever a tree is cut, measures shall be in force which will produce another tree. Forests are to be used exactly as our other natural resources, but used in such a manner that the interests of our posterity will be protected. Also, it must be appreciated that certain of the savings and reforms advocated cannot at once be put in force. We should save all byproducts, but if knowledge is inadequate, and the economic conditions are such that it is not possible to manufacture the by-products at a cost so that the returns from them will compensate for the expenditure involved, this cannot be done; and for a long time it will be the case in this country that large quantities of by-products will be wasted. They will need to be burned in the woods in order to save the forests; but this should be regarded merely as an intermediate stage of development, and the aim should be to further improve, and thus utilize in ever increasing proportion, the by-products.

I conclude with a quotation from the United States Forest Service showing where we might stand: "By reasonable thrift we can produce a constant timber supply beyond our present need, and with it conserve the usefulness of our streams for irrigation, water supply, navigation, and power.

"Under right management our forests will yield over four times as much as now. We can reduce waste in the woods and in the mill at least one third, with present as well as future profit. We can perpetuate the naval-stores industry. Preservative treatment will reduce by one fifth the quantity of timber used in the water or in the ground. We can practically stop forest fires at a total yearly cost of one fifth the value of the standing timber burned each year.

"We shall suffer for timber to meet our needs until our forests have had time to grow again. But if we act vigorously and at once, we shall escape permanent timber scarcity." 1

1 "The Forests of the United States: Their Use," by Overton W. Price, R. S. Kellogg. and W. T. Cox, U. S. Dept. of Agriculture Forest Service, Circular 171, p. 24. 


\section{PART IV}

\section{THE LAND}

$7 \mathrm{HE}$ land is the great fundamental resource of the nation, is indeed more important than all other resources. From the land comes our food and clothing; food and clothing clothing. we must have; all of our other needs are subordinate to these. The productivity of the land is therefore the basal factor which will control in the future the density of our population. Where the land is poor or barren, the regions are sparsely inhabited. This is well illustrated by southern Europe and various parts of Asia. In Europe, Greece and Spain; and in Asia, Palestine, India, and China, are commonly cited as countries in which there are extensive areas of deteriorated land. Even the delta of the Tigris and Euphrates, which in ancient times was one of the earth's gardens, is reported as being a greatly. depleted land.

It is true that the waters are a source of food. Of such waters the sea is that of immeasurably the greatest importance, although lakes and rivers are of consequence. For many centuries the sea has been an important source of food for man, especially for island and tidewater countries; i.e. for the people living on the fringe of land near the sea. At the present time it cannot be asserted that the amount of sea food is increasing; but by propagation of fish, oysters, etc., it may be that the average supply may be somewhat increased, possibly doubled or even trebled. But even if this be true, the sea will be a very subordinate source of food. This is illustrated by Japan. Of all the densely populated countries in the world, probably Japan is most favorably located with reference to feeding its people from the sea, - a group of linear islands with extremely irregular coast, inland bays and seas, having many thousands of miles of coast line. Not only so, 


\section{CONSERVATION OF NATURAL RESOURCES}

but the country has important fishing rights along Siberia and about Sakhalin. Also the people of the Japan islands, besides using animal food of many kinds from the sea, use certain seaweeds. Notwithstanding this extraordinarily favorable location and the pressure for food to feed the dense population, I am informed that probably not to exceed one twentieth of the food of the people of Japan comes from the sea, and certainly not so much as one tenth.

It is clear that for men the great multitude must be fed from the product of the land.

If we in this country maintain the fertility of our land, we shall have a numerous, well-fed, and well-clothed people; if our land is allowed to deteriorate, there will be a sparse and hungry population.

Extent of

The lands under the control of the United States are vast in area: the United States proper has an area of $3,026,789$ square miles; Alaska, 590,884; the Philippines, 115,026; and the remaining recently acquired possessions, including Porto Rico, Hawaii, the Panama Canal Strip, Guam and Tutuila group, Samoa, 10,645; making a total area of $3,743,344$ square miles. If the area were given in acres, the number would be $2,395,740,160$, of which $1,937,144,960$ are in the United States, 378,165,760 in Alaska, and 80,429,440 in the colonial possessions.

\section{THE SOIL}

Depth of soil.
The fertility of the land depends upon the thickness and character of the soil. What is meant by the soil, and how is it manufactured by the processes of nature? The soil comprises the upper part of the land, which serves as a source of food for plants. In general it varies from two or three inches in thickness in very poor soils to two or three feet for the better soils. For much the larger part of the country where the soil is good the thickness is from seven to eight inches. Below the soil is frequently a subsoil of greater thickness. Exceptionally in areas of deposition of water borne and wind borne material the soil may be several or many feet in thickness, or even hundreds of feet in depth; such areas are illustrated by the delta 
deposits of the Mississippi and the sediments of the great basin.

The soil consists of finely pulverized rock mixed with humus; the first is inorganic, disintegrated, and decomposed mineral Composition of soil. material; the second is partly decomposed organic material. In the soil are water and air; without these the soil is barren. A soil perfect in chemical and physical condition containing neither water nor air could not by any possibility sustain life. The water of the soil has been compared to the blood of an organism, and McGee has gone so far as to measure the productivity of the soil in terms of its water. He promulgates the tentative formula that the "agricultural duty of water may be defined as the production of $\frac{1}{1000}$ part of its weight in useful plant crop." ${ }^{1}$ There is a certain justification in this statement, since water is an essential factor of plant growth which is likely to be highly variable in amount. However, air is equally essential with water, but differs from the latter in that it is always present in sufficient amount where the water is not too greatly in excess. Also the composition and physical character of the soil itself, including both its organic and inorganic constituents, are of great importance in the growth of plants. Finally, in order that the soil may produce plant growth, there must be available sources of energy to do the work; these are heat and light derived from the sun.

The soil has been manufactured by the processes of nature; but its rate of making is so slow that its production has The making of the soil. required thousands of years, in most cases many thousands of years. It is probable that the average rate of manufacture of the soil is less than one inch in five hundred years. Its manufacture is due to the complex operation of various forces working through a number of agents. The chief forces are heat, light, and gravity; the chief agents are air, water, ice, and organisms, both plant and animal, minute and large. These forces and agents coöperating together in their work upon the rocks produce the soil. The heat and light from the sun are dominant sources from which the agents derive the energy for their work. The air tends to oxidize the mineral

Water, air, heat, and light. 
particles; the water hydrates them; the bacteria, the earthworm, and many other animals, and the plants, all assist in the disintegration and decomposition of the rocks.

By the conjoint work of these forces and agents the soil, including both its mineral part and the humus, is manufactured.

The nature of the soil depends much upon the character of the rock from which it is made, and also upon whether it is formed in place or transported. Thus, from limestone good soil is likely to be produced, from granite a poor soil. Soils of transportation, such as the bottom lands of streams, are likely to be fertile.

Supreme value of the soil.
Relations of soil and rocks.

The surface layer of soil, manufactured by the processes of nature through millions of years, is the most precious natural resource of the nation. Of all of our duties to our descendants that of maintaining the soil unimpaired in thickness and in richness is the most serious.

\section{CLASSIFICATION OF THE LAND}

The lands of the United States may be classified in various ways; they may be classified as areas of crystalline and sedimentary rocks; they may be classified as plains, plateaus, and mountains; they may be classified in reference to the covering which was originally upon them.

The crystalline areas have a wide variety of rocks, both igneous and metamorphic. For the most part the soils derived from them are relatively unfertile. They are likely to be rough, and are mainly upland, plateau, or mountain. The more common sedimentary rocks are limestones, shales, and sandstones. Where there are limestones, there are likely to be very fertile soils; where there are shales, the soils are reasonably fertile, but are likely to be somewhat heavy; sandstones are likely to give poor soils. The larger areas occupied by the sedimentary rocks are relatively smooth and commonly lowlands, although there are extensive plateaus and mountains composed of such rocks.

The plains comprise relatively smooth areas and are for the most part lowlands below 1000 feet. The plateaus are much 


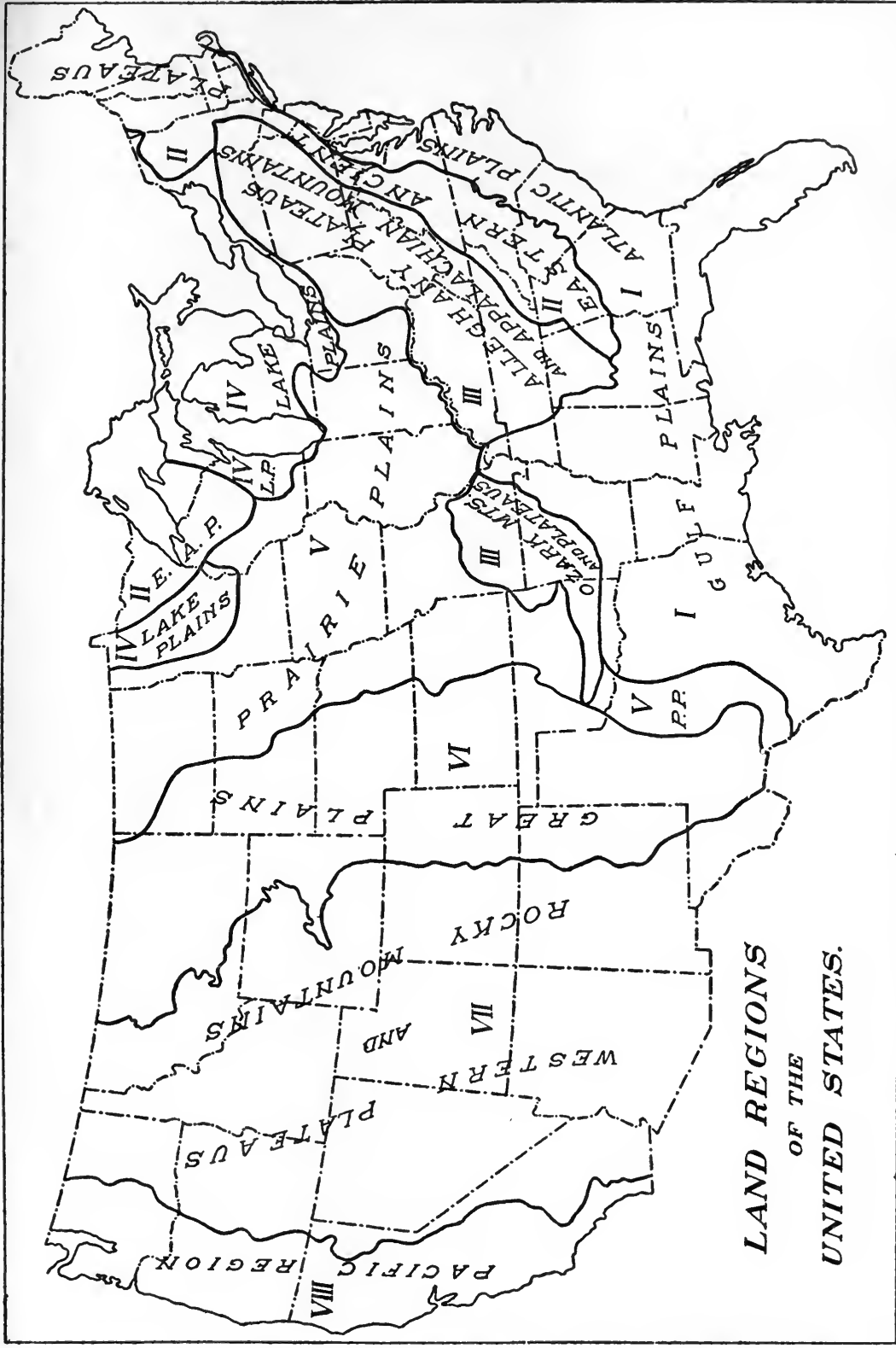


The soil

and elevation.

The soil and its covering.

rougher than the plains and have an elevation of 1000 feet or more. As indicated by the name, there are considerable areas which are relatively level, but these are likely to be cut by gorges and valleys. The mountains are both elevated and rough.

The lands according to their covering may be classified as forests, prairies, and deserts. The forests comprise those regions in which the precipitation is greater than forty inches per annum, the prairies those in which the precipitation varies from twenty to forty inches, and the deserts those in which the precipitation is less than twenty inches. You will understand that these statements are only broadly true. For instance, whether or not a forest is present in an area which has a precipitation between twenty and forty inches depends upon whether in the past the fires have been allowed to run. When the Indians occupied the land, the areas having an annual precipitation between twenty and forty inches were very largely prairie; now that the white man has taken possession of the country and the fires are not allowed to run so extensively, even under natural conditions the forests are encroaching upon the prairies; and under settlement by the whites prairie areas have been planted with trees about the homes and along the fences, as have also occasionally fields.

It is by a combination of these factors, character of rock, elevation and covering, that I shall classify the lands of the United States into eight provinces.

\section{the atlantic aNd gUlf plains}

Atlantic and Gulf plains.

The first of the great provinces is the Atlantic and Gulf plains. This includes the area of land running from Cape Cod along the border of the Atlantic and the Gulf of Mexico. It comprises a small part of Massachusetts, Rhode Island, and Connecticut, and large parts of all the states to the south bordering on the Gulf, and all of Florida. This land is for the most part that which is not more than 100 feet above the sea. It is the land which was easily occupied by the European immigrants, earlier along the Atlantic than along the Gulf, but comparatively early in both regions. 
This lowland area is one of sedimentary rocks; it was originally covered by forests; in large part it had a soil rich and deep, and was the prize toward which looked those coming from Europe during the early settlement of this country. In this province is included the enormously rich and immensely deep soil of the Mississippi River delta. The region has extensive tracts of land lying near the level of the sea; it is the tidewater country. As a result of this fact there are here included the largest areas of swamp land in the United States, - the Dismal Swamp of North Carolina, the Everglades of Florida, the bayous of Louisiana, Mississippi, and Arkansas, and the coastal swamps of Texas. While these lands are at present little utilized, in the future they will be one of the most valuable assets of the nation (see pp. 347-348). In the Gulf Plains are extensive belts of sandy soil which are relatively poor and barren.

Along the Atlantic the western border of the lowland plain is somewhat sharply separated from the upland by an elevation known as the "fall line." The fall line limits everywhere navigation for ocean-going vessels, and for the great majority of the streams limits navigation for any class of vessels. Therefore the fall line marks the place where transportation by water changes to transportation by land. This fact made of it a row of villages in the time of the Indians, and makes of it a line of cities in our modern civilization. Upon it are located the cities of New York, Trenton, Philadelphia, Baltimore, Washington, Richmond, Petersburg, Raleigh, Columbia, Augusta, Macon, and Montgomery.

\section{THE EASTERN ANCIENT PLATEAUS}

The second of the great provinces is the Eastern Ancient New Plateaus. It includes the New England, Piedmont, and Lake plateaus. The larger part of New England, with the excepEngland and Lake plateaus. tion of southeastern Massachusetts and Connecticut, falls in this region, as does also a great belt between the coastal plains and the Appalachian Mountains, and the northern parts of Michigan, Wisconsin, and Minnesota. This region is

The deltas and swamps.

\section{1}
The fall
line. line.


The Piedmont Plateau. mainly one of crystalline rocks; it is more than 100 feet in height and has altitudes varying from this amount to 1000 feet or more; here and there it rises into mountain groups, the more important of which are the White Mountains, the Green Mountains, the Berkshire Hills, and the Adirondacks. For the most part the northern half of the upland area is rather rugged and barren; it is covered by poor soil, strewn with stones and bowlders; it contains numerous lakes, ponds, and swamps. This is the great area of the Northern White Pine. The southern part, comprising the Piedmont Plateau, is south of the ice incursions, and there the uplands have a disintegrated rock soil, better than the upland of New England and the lakes, but still poor. However, in the New England and Piedmont plateaus are many valleys of varying magnitude which have rich and fertile fields. The largest and most important of these is that of the Connecticut River, and this valley has below it later sedimentary rocks.

\section{THE APPALACHIAN RANGES, ALLEghaNy PLATEAOS, AND OZARKS}

The third of the great land provinces of the country is a region of mountains and plateaus. This province has a principal eastern region and a subordinate western one.

The first lies west of the New England and Piedmont plateaus and east of the prairie and gulf plains. Its larger elements are the Appalachian ranges and the Alleghany plateaus. This region is composed in part of sedimentary and in part of crystalline rocks; it was originally covered with forests, and of its higher parts this is true in large measure to the present time. These uplands have a poor but frequently thick soil which, where denuded of the forests, is rapidly washed away. They should permanently remain as a part of our great forest reserve. The Appalachian ranges and Alleghany plateaus are cut by numerous valleys, of which the Appalachian limestone valley is by far the most important. This had originally high fertility. The Appalachian Valley is especially famous in the history of the country as being the first considerable belt of rich land available to the settlers after 
they broke across the easternmost ranges. It was, as you know, one of the main highways up and down which the armies of the North and South marched in the great struggle of the Civil War.

The western region of the third province is that of the Ozarks. This area lies in the states of Missouri, Kansas, Indian Territory, and Arkansas. It is an upland area of mountains, plateaus, and valleys, which constitute a relatively unfertile island in the midst of the prairie and Gulf plains.

\section{THE LAKE PLAINS}

The fourth of the provinces is that of the lake plains. As indicated by the name, this region is adjacent to the great lakes; it includes western New York, the northern part of Ohio, the major part of Michigan, and a belt in Wisconsin and Minnesota. It is an area of sedimentary rock, much of which is limestone. The entire region was forest covered (see p. 208). The northern part of the lake plains is somewhat inhospitable in climate; the extensive limestone areas have a fertile soil; but the sandstone areas of Michigan and Wisconsin are poor.

Over the region of the lake plains came the latest ice incur- Lakes and sion. In consequence of this there are extensive areas of stony moraines; there are innumerable lakes, ponds, swamps, and marshes. While no one area of wet land can compare in extent with the great swamps of the coastal plains, the total acreage is large, making the lake plains the second in the country in its total area of wet lands. As yet these lands are little utilized, but in the future they will constitute a highly productive part of the lake plains.

\section{THE PRAIRIE PLAINS}

The fifth province is that of the prairie plains. This comprises a great area south of the province just described, and west of the main area of the third province. It occupies a The garden of the country. large portion of the Upper Mississippi Valley and extends to 
the southwest, west of the Mississippi to the Rio Grande. It includes considerable parts of Ohio, Wisconsin, Minnesota, the Dakotas, Nebraska, Kansas, Oklahoma, and Texas, and practically all of Indiana, Illinois, and Iowa. The region of the prairie plains is the garden of the United States; it is the very heart of the country. This province is one of sedimentary rocks, largely limestone; it is of moderate altitude, being below 1000 feet in elevation. It is an area of neither too abundant nor too scanty rain; for the most part the annual precipitation being between twenty and forty inches. Originally it was largely covered with grasses, the trees being confined mainly to the borders of the streams. In passing from the center of this area to the provinces to the east and south, the area occupied by trees increases in amount, until adjacent to these provinces it approximated 50 per cent.

Comparison with other countries.
The world mainly composed of rock.
The entire province has a soil varying from eight inches to a foot in thickness, and locally the soil runs up to ten, fifteen, twenty feet or more in depth. Probably there is no other equally large area in the world which surpassed it in original fertility; and it is certain that no equally large area can be compared to it in present fertility. The nearest approaches are the densely populated regions of China and the black lands of Russia. Iowa, Illinois, Ohio, and Indiana have by far the largest percentage of improved lands of any states in the Union, varying in Iowa from nearly 90 per cent to more than 75 per cent in Indiana; whereas the next state in order is Delaware, a small state in the tidewater country, with 60 per cent.

Many of those who live in the region of the prairie plains think that highly fertile land is the normal thing in the world. I once traveled by chance from this region to central Canada with a young woman who had been born and brought up on the prairie plains. She was greatly surprised at the number of stones that appeared as the prairie plains were left behind. First, a few small bowlders were seen, and then more and ever larger, until bowlders of all sizes, up to eight to ten feet, were abundant. With these, ledges of rock here and 
IOWA

ILLINOIS

OHIO

INDIANA

DELAWARE

MARYLAND

KENTUCKY

MISSOURI

NEW YORK

KANSAS

PENNSYLVANIA

NEW JERSEY

VIRGINIA

TENNESSEE

NEBRASKA

VERMONT

WEST VIRGINIA

MINNESOTA

CONNECTICUT

MICHIGAN

WISCONSIN

SOUTH CAROLINA

GEORGIA

RHODE ISLAND

NORTH CAROLINA

ALABAMA

MISSISSIPPI

MASSACHUSETTS

SOUTH DAKOTA

NORTH DAKOTA

ARKANSAS

OKLAHOMA

NEW HAMPSHIRE

LOUISIANA

DIST. OF COLUMBIA

CALIFCRNIA

TEXAS

WASHINGTON

OREGON

FLORIDA

COLORADO

IDAHO

UTAH

MONTANA

WYOMINO

NEVADA

NEW MEXICO

ARIZONA

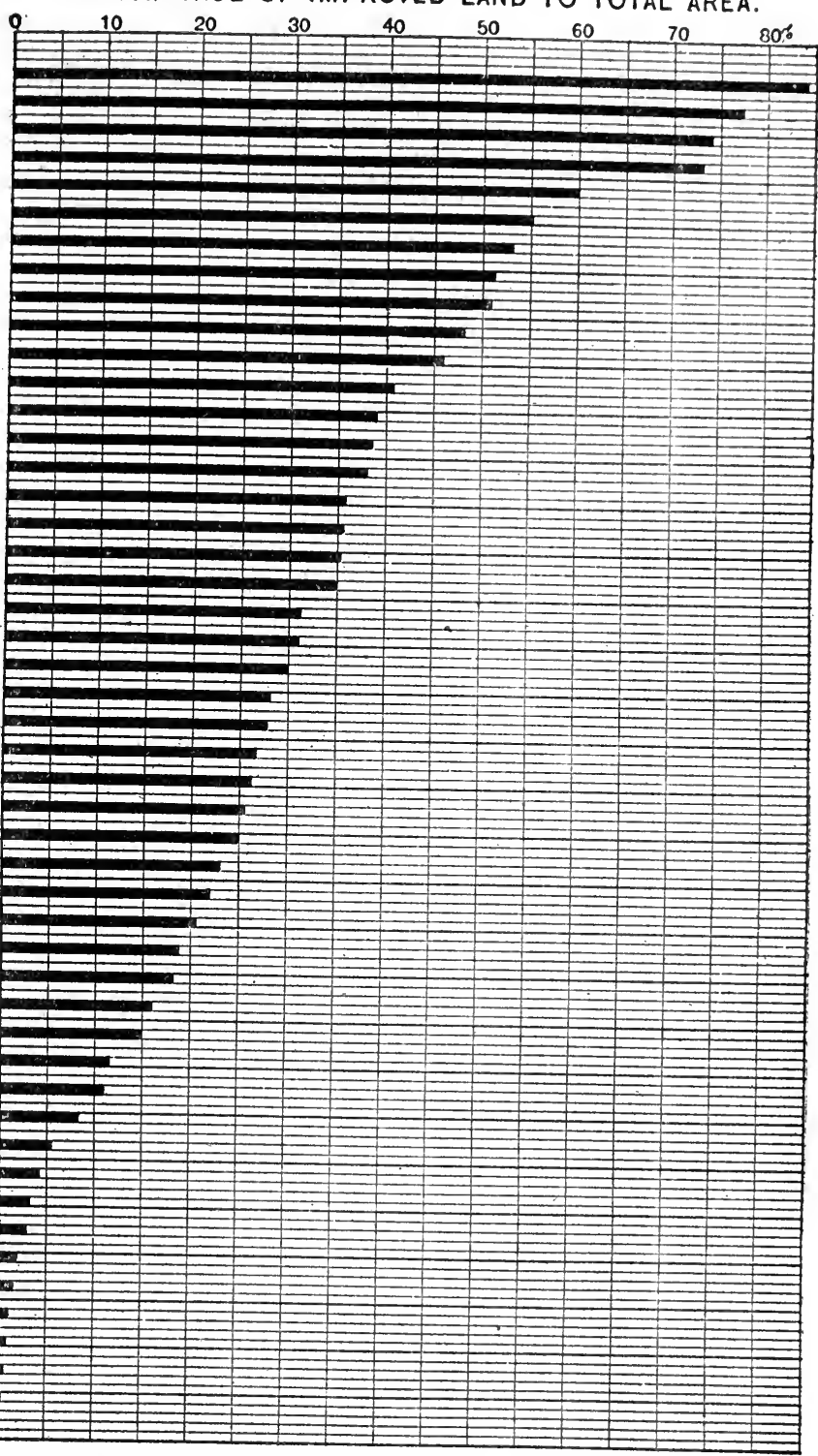

Fig. 19. - Percentage of improved land to total area. After Woodruff. 
there protruded from the soil, until the earth became one dominantly of rock instead of soil. To that time this young woman had supposed that the world was made of soil to its very center, rather than made of rock with a thin and exceptional film of soil. My boyhood days were spent in an area of the prairie plains, in which there were no solid ledges of rock exposed, and I can well remember my surprise and thrill of emotion when I first went through a railway cut showing solid rock.

The strangely favored inhabitants of the prairie plains scarcely realize that only exceptionally are there large and continuous areas of highly fertile soil. While there are a few such provinces on the globe, there are vastly larger and more numerous areas of thin and sparse soil, - the plateaus, the mountains, and deserts, which are either not productive, or only sparingly so under natural conditions.

\section{THE GREAT PLANS}

Dry farming and craxing.
The sixth province is the great plains. They occupy a broad belt between the prairie plains on the east and the Rocky Mountains on the west, and extend from North Dakota and Montana on the north to Mexico on the south. For the most part they have an elevation of more than 1000 feet and less than 6000 feet. The higher elements are to the west and the lower to the east; thus the plains have an eastern slant. Like the prairie plains, this region is one of sedimentary rocks covered in large part with a deep and fertile soil, and if it had sufficient rainfall would be highly productive land; but it is an area in which the rainfall is less than twenty inches. It is therefore one in which a crop cannot be raised each year with certainty without irrigation, although dry farming may be practiced upon it over extensive areas. In early days the great plains were known as the Great American Desert. It is the region which, as I have already explained to you, was settled up in a time of excessive rainfall; during the time following, when the rain was below the normal, the region was largely abandoned; and it is now 
again being settled rapidly on account of the excess of rain which has been falling for the past few years. It is like Palestine and Egypt, and like the Black Lands of Russia, an area in which there will alternate from time to time groups of lean and fat years; the lean years when there is deficient rainfall, the fat years when there, is an abundance of rain. So far as the great plains can be irrigated they are highly productive; but for the most part they must remain the region of dry farming and grazing.

\section{THE ROCKY MOUNTAINS AND WESTERN PLATEAUS}

The seventh region is that of the Rocky Mountains and Irrigation. Western Plateaus. In this region, which occupies a very extensive part of the United States, from the west side of the great plains to the Cascades and Sierra Nevadas, there are many mountain ranges, there are great and extensive plateaus, there is the Great Basin, there are numerous valleys. The region has large areas of both sedimentary and crystalline rocks. The higher lands are or were forest-covered and should ever remain so. Upon the whole, the region is one of deficient rainfall. It is a great region of irrigation, which has been discussed in another part of these lectures, and which therefore will not be taken up here. Already there are in this region some 4,500,000 acres of irrigated land, and this amount will be greatly increased in the future.

\section{THE PACIFIC REGION}

The eighth and last province of the United States is that The Great of the Pacific region, including on the east the Cascades and the Sierra Nevada, and extending on the west to the Pacific valleys. Pacific Ocean. The mountains are largely crystalline rocks; the valleys are mainly sedimentary. The mountains in this area were and still are for the most part heavily timbered; the valleys between have comparatively little timber except in the north. Between the Cascades and Sierra Nevada and the coastal ranges are, in Washington and Oregon, the great 
valley of Puget Sound and the Willamette River; and in California, the great valleys of the Sacramento and San Joaquin rivers. The great northern valley is abundantly watered and has a highly fertile soil; indeed, the fame of the Willamette Valley early became known in the East and it was settled about the same time as the states of the Middle West. The great valley of California has a soil of wonderful thickness and fertility. It is sufficiently watered in the north, in the central part has less water, and in the southern part cannot be used for agricultural purposes without irrigation.

The intermontane valleys.

The orange groves.

In the coast ranges are numerous intermontane valleys. These are comparable in breadth with the Appalachian Valley of the east. Some of the more famous of these are the Santa Clara and Napa valleys of central California, the Salinas in southern California, and the valleys in which are the cities of Los Angeles, Redlands, San Bernardino, and Riverside, the orange-grove region of southern California. These valleys have highly fertile soil; in the north, they frequently have sufficient water so that ordinary crops and even fruit may be raised without irrigation; but in the southern parts, where citrous fruits, olives, and nuts are raised, irrigation is almost universal.

It is frequently supposed that southern California is an almost continuous orange, lemon, and grapefruit grove; but as a matter of fact the area set out to fruits does not reach 2 per cent; indeed, the total irrigated land of southern California is not more than $10 \frac{1}{2}$ per cent of the total. Why is this the case? Simply because the streams coming from the mountains will not supply a sufficient amount of water to irrigate a greater area.

\section{GENERAL STATEMENTS}

One third of the land agricultural.
The foregoing paragraphs give a brief and inadequate description of the great land heritage which fell to our people. Considering the lands of the United States as a whole, not one half of the area is adapted to agriculture under natural conditions; indeed, probably one third is nearer the truth. 
We must subtract all the mountainous areas, from the Appalachians to the coast ranges; we must subtract large parts of the great plains and the high plateaus; we must subtract in large measure the rugged upland areas of New England and the Great Lakes; we must subtract the swamp land; thus leaving a mere remnant of the whole originally capable of high productivity. In the future, by reclamation of swamps, by the irrigation of arid lands, by the terracing of the steeper slopes, we shall add a large total acreage to the agricultural lands; but this addition will be but a small fraction as compared with the lands naturally agricultural.

\section{THE OWNERSHIP OF THE LAND}

The land of the United States was owned originally, or at least was roamed over and locally occupied, by the aborigThe number of Indians. ines. Very little of this land was possessed in the sense that it was the permanent home of an individual or a group of individuals. There is frequently misconception as to the number of Indians that lived in this country before the white man appeared. McGee estimates that there were probably more than 1,250,000 and less than 2,500,000. Other estimates are as low as 200,000 east of the Mississippi River. Before the time of the white man there was certainly upon the average less than one inhabitant to the square mile.

First, the land bordering the Atlantic was taken possession of by the colonists. This nation was later born, and the land, with the exception of minor reservations, passed gradually from the Indians to the citizens of the United States. I shall not undertake to discuss how this was accomplished, - the legitimacy of the methods, the fairness with which the Indians were treated, or any of those questions which belong to the domain of history. Sufficient to say that the inevitable happened. It has been true in the United States as in every part of the world that when a highly civilized people have appeared capable of occupying the land in large numbers, and capable of developing its resources, they have dispossessed a weaker, aboriginal people, either justly or un-

The dispossession of the Indians. 


\section{CONSERVATION OF NATURAL RESOURCES}

justly. We may wish that it could have occurred with a greater degree of fairness, but that it must have occurred was inevitable. The great principle of the greater good to the greater number must after all control.

In colonial times the lands were granted in large parcels by the king of England through royal charter; for instance, to Penn and Fairfax. Sales were made by these original charter owners to the settlers.

Cessions of state lands.

Government purchase of land.

Original extent of : public domain.
After the Revolution the lands west of the Alleghanies and east of the Mississippi belonging to the original thirteen states largely became the property of the United States government. The cessions of the western lands came from the states of Massachusetts, Connecticut, New York, Virginia, North Carolina, South Carolina, and Georgia. The lands later making the states of Vermont and Maine were not ceded to the United States. Also there were other reservations by these states, notable among which was the Western Reserve by Connecticut. New Hampshire, Rhode Island, New Jersey, Pennsylvania, Delaware, and Maryland owned no western lands and therefore made no cessions. According to Donaldson, ${ }^{1}$ land ceded by the original states to the United States aggregated 404,956 square miles, or $259,171,787$ acres. This area constituted the public domain before 1803 .

The great accessions to the public domain came from purchases from France, Spain, Mexico, and Russia. Also a small amount of land was purchased from Texas, although that state when it came into the Union retained the major portion of its public lands and has disposed of them under its own laws. Donaldson gives the average cost of the land purchased by the United States at 5.1 cents per acre.

The lands acquired by the government were indeed a magnificent domain. Excluding Alaska they constituted a great band of the temperate zone across a continent more than two and one quarter million square miles in area, $-1,441,436,160$ acres, according to the Public Land Commission of 1903 . This vast area has been occupied in one and a quarter centuries.

1 "The Public Domain," by Thomas Donaldson, Government Printing Office, Washington, 1884. 
When the United States began to dispose of the public lands, the country was sparsely occupied east of the Alleghanies, and west of those mountains were only scattered inhabitants. It was not unnatural under these conditions, with comparatively few people living in this apparently boundless domain, stretching from the Alleghanies to the Pacific Ocean, that liberal land laws should be adopted. It was not unnatural for the people to believe that there would be enough land to supply all the demands through the indefinite future; indeed, that belief held until a comparatively few years ago. It is not so many years since we heard the song: "Uncle Sam is rich enough to give us all a farm."

The better part of the public domain has now passed to private parties, and during the closing years of the nineteenth Land century the land hunger of hundreds of thousands of the citizens of the United States was for the first time unsatisfied. With these new conditions confronting us, we naturally are led to inquire as to the nature of the laws under which the public domain has been disposed of, and their manner of operation. This is important in order that we may reach wise conclusions as to what shall be done with the remnant of the lands which still belong to the United States. The disposal of the public domain is a very complicated subject and in these lectures I can only briefly discuss some of the more important phases of it. ${ }^{1}$

\section{THE LAND LAWS}

The public lands were first regarded as an asset to the government to be disposed of to pay its debts and to increase its revenues. Therefore the first land laws provided for their sale.

1 The data upon which the statements concerning the disposal of the public lands are made are mainly taken from the following sources: -

"The Public Domain," by Thomas Donaldson, 47 th Congress, 2 d session, House of Representatives, Miscellaneous Document 45, No. 4, Washington, 1844;

Reports of the Commissioner of the General Land Office, for the years ending June 30, 1907 and 1909.

Information furnished me by personal letter through the courtesy of Fred Dennett, Commissioner of the General Land Office. 
Interpretation of word "minimum."

The early 'sales of land under the laws of 1784,1787 , and 1792 were at prices which for the most part netted the government $66 \frac{2}{3}$ cents to 75 cents per acre; and the highest price received was $\$ 1$ per acre; but the acreage disposed of at these prices was not large. The first general land act was passed in 1796. Under this act and that of 1800 , the land after being surveyed was sold at public sale to the highest bidder at not less than $\$ 2$ per acre. Private sale was also permitted for lands offered at public sale, but not disposed of, at a minimum price of $\$ 2$ an acre. In 1820 the minimum price of land sold at public or private sale was fixed at $\$ 1.25$ per acre, which price has remained in force to the present time, with the exception of certain special classes of land, as for instance, mineral lands, fractional parts of 160 acres, certain lands near railroads, etc., on which there was a "double minimum" price of $\$ 2.50$ per acre.

The law permitting private sale was repealed in 1889 , and in 1891 the law authorizing public sale was finally repealed except for special tracts; for instance, isolated areas and certain Indian lands. From time to time large tracts of land have been offered for public sale, and the lands not sold at public sale have been disposed of at private sale uniformly. at the minimum price. Thus it came about that the word "minimum" in the law fixing the price at which land could be sold at private entry was early interpreted by the land department as the normal price. There was no attempt to appraise the land, or charge at private sale any other than the minimum price. Undoubtedly in this administration of the law the government land office followed the prevailing sentiment, the desire of the people being that the land should be freely and rapidly disposed of in order to develop the country.

Amount of cash sales.

The cash sales to June 30,1880 , amounted to $169,832,565$ acres. This amount, however, includes all the land disposed of to this date under the preëmption law and under the commutation clause of the homestead act, to be subsequently mentioned. From June 30, 1880, to June 30, 1909, there were disposed of at private sale $11,160,301$ acres and at public 
auction 1,522,423 acres. This makes the total here included $182,515,289$ acres.

The first general preëmption law was enacted in 1841. Early payUnder this law 160 acres could be preëmpted. The preëmptor was required to file a claim of settlement within three land. months of the time of preëmption; and it was necessary to make the required improvements and final payment of $\$ 1.25$ per acre within thirty-three months additional, or three years from the time of the preëmption. But there was a clause in this law which permitted payment to be made at the end of six months. This inevitably led to land speculation. While much of the land was taken up by individuals with the hope of becoming the owner of 160 acres, many entries were made with the expectation of disposing of the land at an advance before the time that it was necessary to make payment.

After the law permitting private sale of land was repealed in 1889 , the preëmption law was used to acquire large tracts Dummy entries. by the method of dummy entry, in which men acting for other parties made the entries and payment as soon as practicable, and, immediately upon receipt of patent, transferred the land to the person who employed them. A result of the preemption law has been that many large holdings have been secured by individuals and corporations in clear violation of the intent of the law, which was that one individual should secure only 160 acres. In 1891 the preëmption was finally repealed.

Under the preëmption law from June 30, 1880, to June 30, 1909 , there were sold $27,361,836$ acres. Sales under this law before 1880 have been included in the statement on the previous page.

In 1854 a so-called graduation act was passed to "cheapen the price of lands long in the market for the benefit of actual settlers and for adjoining farms." This law was repealed in 1862. Under it $25,696,420$ acres of land were sold at prices less than $\$ 1.25$ per acre.

To this point in the discussion it will be noted that land had been obtainable from the government only by the pay- 


\section{CONSERVATION OF NATURAL RESOURCES}

ment of a certain amount. In 1862 was passed the homestead act, the most important of all the land laws, which really resulted in the occupying of the land by bona-fide settlers. The homestead act was extended to include Alaska in 1898. Under the homestead law in the United States only 160 acres of land may be entered; in Alaska until 1903 the homestead entry was limited to 80 acres, but at that time was extended to 320 acres.

Conditions of homestead act.

The commutation clause.

Large holdings acquired.
Under the homestead law, land taken up, after five years of residence, improvements, and cultivation, is patented without cost, except for the fees. Two years additional beyond the five years may be taken before "proving up" and securing patent. So far as this act was used by the genuine homesteaders, this additional time has been frequently taken.

The homestead law has a so-called commutation clause in it, under which, after six months' residence, by the payment of $\$ 1.25$ per acre the land could be secured. In 1891 this was changed to fourteen months' residence, and it was the clear intent of the law that this should be the minimum residence required to secure land. But the land office construed that as a man had six months to settle after he had filed his claim, these six months might be accepted as a part of the fourteen months; and therefore only eight months of actual residence were required. This practice was continued until a year or two ago, when the land office gave orders that the full fourteen months' residence was necessary.

Because of the commutation clause, so far as speculation was concerned, the homestead act was not a great improvement upon the preëmption law. Final payment could be made in either case after six months' residence, or later, in the case of the homestead act, after eight months' actual residence. While the homestead law resulted in hundreds of thousands of homes, it gave the same opportunity for fraud as the preemption law, in that the commutation clause allowed the taking up of numerous areas of land through dummy entrymen for individuals or corporations desiring large holdings. The great estates which exist in the prairie plains and in the 
great plains are in large measure the results of the preëmption law and the commutation clause of the homestead act, although it is true that some of these have been produced by the purchase of adjacent holdings.

Mr. H. H. Schwartz, ${ }^{1}$ special agent of the land office, Land says, in reference to the commutation clause of the homefrauds.

stead act: "It has been my experience in ten years of field service that the commutated homestead is almost universally an entry initiated with a full intent never to make the land a home. Before the timber and stone law was extended to all public-land states the commutation clause in the homestead law was the vehicle through which timber was fraudulently acquired from the government. It has been my personal experience to examine solid townships in northern Wisconsin, in which practically all the even-numbered sections had been acquired under the homestead law, .quite generally commutation. The timber had been cut off after patent, and yet not a single voter or inhabitant could be found in the township."

Mr. Schwartz says further: "The government got $\$ 400$ a quarter section for lands frequently worth from $\$ 10,000$ to $\$ 20,000$. More recently actual farmers have purchased these stump lands from the mill companies."

He goes on to say: "Actual inspection of hundreds of commutated homesteads shows that not one in a hundred is ever occupied as a home after commutation. They become part of some large timber holding, or parcel of a cattle or sheep ranch."

Continuing: "Since the passage of the first commutation clause in the homestead law in 1862 there have been to 1909 practically $35,000,000$ acres of land acquired thereunder. The government received probably $\$ 70,000,000$ for lands worth over $\$ 350,000,000$ at the time title left the United States. The average yearly acreage commuted has been

1 "The Timber and Stone Act and the Commutation Clause of the Homestead Act," by H. H. Schwartz, Report National Conservation Commission, Vol. III, pp. 390-392. 


\section{CONSERVATION OF NATURAL RESOURCES}

Amount patented under homestead act.

Working of timber claim act.

approximately 600,000 . It is noted, however, that in the past few years the acreage of land annually commuted has largely increased. In 1905 there was a slight excess above 1,400,000 acres sold;" the year ending June 30, 1909, the acreage had increased to $2,907,783$.

According to the commissioner of the land office, to June 30,1909 , there have been patented under the homestead laws $115,124,295$ acres. Of this area there were commuted from June 30,1880 , to June 30, 1909, 30,638,106 acres. The year ending June 30,1909 , there were patented under the homestead law 6,534,090 acres, of which, as already noted, nearly $3,000,000$ acres were commuted. It appears from the figures given that, of the land acquired under the homestead law, about one third has been commuted, with the results described by Schwartz. It is perfectly clear that the commutation clause of the homestead act should be repealed at once.

Under the mineral land act, from its passage in 1866 to June $30,1909,1,541,607$ acres have been disposed of. Under the coal land act, from its passage in 1873 to June 30, 1909, 505,920 acres have been sold. Since these acts are discussed in another place (see pp. 35-44, 98-101), they will not be further considered here.

The next of the laws which have led to the acquiring of a large amount of land without satisfactory results is the timber culture act of 1873 . Under this act, in addition to acquiring 160 acres under the homestead law, a man could acquire 160 acres more, provided 10 acres of timber were planted and maintained for a period of ten years. Frequently, even when the required area of timber was set, it was not kept up, and oftentimes the claim was relinquished or taken up under the homestead act or commuted or assigned to another for a consideration. Under this act, to June $30,1909,10,865,480$ acres of land have been patented, and 1,010,305 acres were commuted, making the total acreage disposed of under this act $11,875,785$. The timber which has resulted from this law is insignificant in amount, but under it a large amount of land has passed from the public domain with 
"some fraud and much speculation." 1 In consequence of these results this law was repealed in 1901.

The next law requiring consideration is the timber and stone act of 1878. This act gave the right to purchase " 160 acres of unappropriated, uninhabited, unreserved, nonmineral public land of the United States, unfit for cultivation, and available chiefly for timber and stone, at the minimum price of $\$ 2.50$ per acre." The law reads: "may be sold at the minimum price of $\$ 2.50$ an acre." From 1878 to 1908, thirty years, this word "minimum" as in the case of the various land laws, was interpreted by the department to mean "maximum," and all the land sold under this act was at this minimum price of $\$ 2.50$ per acre. In December, 1908, without any act of Congress, or change of law, the land department reinterpreted this term, and the land disposed of under this act from that time has been appraised. The main effect of the timber and stone act has been to transfer large tracts of timber to individuals and corporations. While it was the intent of the law that the land should be taken up by the individual holder for his own benefit, as a matter of fact the greater portion of the land acquired under the law soon passed to large holdings. It is this law which has led to the concentration of the great areas of timber in the West.

Schwartz, ${ }^{2}$ special agent of the government land office, says in reference to the timber and stone act: "This law has resulted in the sale of over 12,000,000 acres (to June 30, 1909, $12,566,015$ ) of valuable timber lands, of which fully $10,000,000$ acres were transferred to corporate or individual timberland investors by the entrymen. These lands brought to the people or general government a gross sum of $\$ 30,000,000$. At the date of sale they were reasonably worth $\$ 240,000,000$. The profit of over $\$ 200,000,000$ went not to the needy settler engaged in subduing the wilderness, but to the wealthy investors. Not over a fractional part of one per cent of the timber pur-

1 "Summary of Most Important Land Laws," by Knute Nelson. Annals of the American Academy of Political and Social Science, Vol. XXXIII, No. 3 , pp. 615-617.

2 "The Timber and Stone Act," H. H. Schwartz, Report N. C. C., Vol. III, p. 387 .

Losses of government. 


\section{CONSERVATION OF NATURAL RESOURCES}

False swearing.

Perfunctory compliance with law.

chased from the United States under this act is held, consumed, or even cut by the men and women who made the entries." And this, notwithstanding the fact that all entrymen swear that they do not intend to purchase for speculation, but for their own use and benefit; that they have not directly or indirectly made any agreement or contract in any way or manner, with any person or persons whatever, by which any one shall acquire the title to the land; that the entry is not made with the intent to sell if the market improves, etc.

This situation very well illustrates the demoralizing effect of a defective land law. The timber and stone act should be repealed; and if any timber is disposed of, this should be done only after appraisal, and by public sale at a price not lower than the appraised value.

The next laws which led to the taking up of large areas of the public domain are the desert land acts of 1887 and 1891 . Under these acts there were permitted to be entered in the western states and territories any lands which were not sufficiently watered to raise a crop without irrigation (640 acres under the act of 1887 , reduced to 320 acres under the act of 1891), provided improvements were made upon the land, and the tract, or a part of it, irrigated. The land office ${ }^{1}$ held that one eighth of this area should be reclaimed and actually irrigated in order to make the claim valid. In many cases this has been more or less perfunctory, the irrigation being kept up only in a tentative way and continued a short time until patent was acquired, and then the land used for grazing or other purposes. This act has a clause by which the claims made under the law may be assigned. In 1904 the public land commission which investigated the operation of this law recommended that this clause be repealed, that the size of the claim be reduced to 160 acres, that two years of actual residence be required, and that a valuable crop be produced on one fourth of the area by irrigation with sufficient water. Under the desert land act, to June $30,1909,5,149,546$ acres had been patented.

${ }^{1}$ Report of the Public Land Commissioner, 58th Congress, 3d Session; Senate Documents, 189: Washington Govérnment Printing Office, 1905. 
The latest act for the entering of land by settlers is that of the enlarged homestead act, passed in 1909. Under this act, in the states of Colorado, Montana, Nevada, Oregon, Utah, Washington, and Wyoming, and the territory of Arizona, 320 acres of agricultural land, not susceptible of irrigation, may be entered under provisions similar to those of the homestead law, with the additional ones that one eighth of the land must be cultivated the second year, and thereafter, one fourth continuously; also that in case there is not sufficient water for domestic purposes continuous residence is not required, provided the portions of land cultivated the second and third years are as above stated, and one half during the fourth and fifth years. Residence cannot be commuted by payment under this act; its purpose is to provide for dry farming on the nonirrigable arid lands of the West.

Large tracts of the public domain have been disposed of as military bounties, under laws of 1812,1847, 1850, 1852, and 1885. To June 30,1909 , the acreage patented was 63,958 ,631 acres, leaving still to be settled warrants outstanding to the amount of 2,115,399 acres.

Also considerable tracts of land have been located by miscellaneous varieties of scrip, such as surveyors general, Indian, Value of scrip. forest reserve, lien land, etc. Excluding the outstanding military bounty scrip and the agricultural scrip to be mentioned later, Dennett estimates that 1,617,800 acres have been thus located. While scrip granted to the Indian or the soldier was intended to be used for his benefit, many of the rights have been assignable to other parties at ridiculously low figures, 50 cents up for 160 acres. Since scrip entitled the owner to locate upon any public land open for entry, and since the amount which could be acquired by any one man was not limited, it became very available. It furnished another method which has been taken advantage of to secure large consolidations of land or lands in close contiguity.

Vast areas of the public domains were granted as subsidies to railway, wagon-road, canal, and river improvement companies.

The amount of the railroad grants is enormous. ToJune 30 , 


\section{CONSERVATION OF NATURAL RESOURCES}

1909 , according to the commissioner of the land office, the railroad grants patented directly and through states amounted to $113,912,454$ acres, leaving outstanding claims to be adjusted for many millions of acres in addition.

Wagon-road Also, to the same date 2,962,964 acres were granted through and university grants compared. several states to companies for the construction of wagon roads. For instance, more than eight townships of land were granted for constructing a so-called military road through the forests of the upper peninsula of Michigan. This grant became a part of the great Ayer estate. This road itself was, I believe, never traversed by a military expedition, and by but few people; it served no public nor private purpose. Yet the tract of land which was given for its construction included an area of land, much of it containing valuable pine, four times as large as the land grants to the states for university purposes.

To canal companies, mainly through states, there were granted 4,597,668 acres. Some of the individual grants here included were very large, as, for instance, the three fourths of a million acres for the construction of the canal around the falls of St. Mary's River, and the 400,000 acres for the ship canal across Keweenaw Point. For river improvements there were granted $2,245,252$ acres.

Total To June 30,1909, the total amount of land patented by the corporation government directly or through the states to railroad, wagon-
grants. road, canal, and river improvement companies amounted to $123,718,338$ acres.

Cause of corporation grants.

Undoubtedly many grants to railroads and for other public improvements, and especially the earlier ones, were made by Congress in good faith, in the belief that only by such grants could the development of the country be secured. But undoubtedly also many of such grants were not made in consequence of public demand for the improvement; but as a result of the pushing of individuals and corporations that, desiring a franchise, wished to get as big a bonus as possible for the work to be constructed.

We have already seen that the land frauds under some of the acts have been numerous. Congress appropriated for 
the fiscal year June $30,1907, \$ 250,000$ to investigate the land frauds, and a like sum was continued for the following year. The amount for this purpose was increased to $\$ 500,000$ for Extirpation of land frauds. the year ending June 30,1909 , and to $\$ 1,000,000$ for the year ending June 30, 1910. According to Schwartz, to December 1, 1908 , that is, seventeen months after the law had been passed, there has been recovered about 630,000 acres of land which had been fraudulently entered; there had been released from fences over 1,000,000 acres which had been unlawfully inclosed; there had been 28,000 cases investigated; there were 32,000 cases requiring investigation; there were pending before the local courts 1021 cases; and the work of the investigation had fairly begun.

The report of the commissioner of the land office for the year ending June 30, 1909, tells of the land fraud work for that year. For trespasses of various kinds $\$ 403,444$ had been collected; 1,279,310 acres had been restored to the public domain. With the increased appropriation available for the current year, the work of the special field service to protect the public from fraudulent entry and trespass will go on with redoubled vigor.

The far-reaching degeneration of public morals in consequence of defective land laws has extended not only throughout the West, but through the nation, and from the humblest citizen to those in high places.

In contrast with this somewhat gloomy picture of the manner of disposal of the larger part of the public lands, we may mention the grants which have gone for educational purposes. Those states which were admitted prior to 1848 were granted section 16 in each township for common school purposes; beginning with 1848 , in each township there were granted sections 16 and 36 ; and Utah was granted sections $2,16,32$, and 36. Up to June 30, 1909, the land which had been granted for these purposes amounted to $69,048,269$ acres.

For seminaries or universities two townships of land, or their equivalent, 46,080 acres, were set aside for each state or University grants. territory having public land, for the maintenance of higher education. Some states, as, for instance, Ohio, Florida, Wis-

Degeneration of public morals.

\section{School} lands. 


\section{CONSERVATION OF NATURAL RESOURCES}

consin, and Minnesota, had larger grants than the above. Twenty-seven states and territories have had the advantage of these grants. To the normal schools were given, to June 30, $1909,960,000$ acres, and to the universities $2,280,000$ acres.

Agricultural In 1852 was made the agricultural mechanical college grant college lands.

- to each state, 30,000 acres for each representative and senator in Congress from that state. In those states in which there was still public domain the land must be there located; to states in which there were no public lands scrip was issued, and land open for entry could be located anywhere on the public domain. All together, to June 30, 1909, there were granted under this act land in place, 2,890,000 acres, and land scrip, $7,830,000$ acres, or a total of $10,720,000$.

The grand total for educational purposes to June 30, 1909, was $83,008,269$ acres.

The lands for educational purposes, after passing from the government to the states, were disposed of under the state administrations. The states acted very differently with reference to these trusts. Some of them have wisely handled the educational lands, kept them until they were valuable and disposed of them carefully, or even kept them to the present time. Other states have disposed of their educational lands rapidly and at very low prices.

Disposal of educational lands.

The good fortune of Cornell.
It is estimated by the state auditor of Minnesota that the probable future value of the University lands still owned by the institution will not be less than $\$ 40,000,000$. In contrast with this situation, in Wisconsin the university and agricultural college lands were disposed of in large measure at the minimum price of $\$ 1.25$ an acre; for some of them $\$ 1.50$ to $\$ 2.50$ an acre was received, and for a small amount an even higher price. The result is that the total capital from the sales of the university land amounts to about $\$ 300,000$ and for agricultural college lands to about $\$ 288,000$.

It so happens that a large part of the agricultural land scrip issued to the state of New York was purchased by Ezra Cornell and turned over to Cornell University. According to President Schurman, 511,070 acres of this scrip, the mats 
portion, was located on land in the state of Wisconsin. To March, 1910, this land had given a capital to Cornell University of $\$ 4,941,761$, leaving unsold 1699 acres. This amount then represents the capital account of Cornell University agricultural lands granted by the United States to the state of New York, located in Wisconsin. President Schurman says that the large profits which Cornell University has realized from the Morrill grant scrip sprang directly from the wisdom and foresight of Ezra Cornell.

But, even if, following the example of the United States government, a large part of the land granted to the states for educational purposes was sold at very low rates, these grants are the basis of the great system of free public education in this country. Doubtless with the strong democratic sentiment of America, the common schools would have developed without grants for this purpose; but there is no question that the extension of the common schools has been very greatly promoted by the money derived from the land grants.

With reference to public higher education, the lands granted were their very foundation. Early in the history of the counThe state universities. try, following the English precedents, higher education was supported only by private funds. It was not regarded as appropriate to use money derived from taxes for this purpose. The grants to the universities in each of the states admitted since 1848 have resulted in founding state universities, and the growth of these universities has reacted upon the growth of the state universities established in the older states. At the present time half of the Association of American Universities, including the 22 larger institutions in the country, are state universities.

Of equal importance with the university grants was the Morrill grant of 1862, which gave land to the older states as well as to the newer for the establishment of agricultural The agricultural colleges. and mechanical colleges. This great group of colleges, one of which is in every state in the Union, is the direct result of this grant. The profound importance and far-reaching effect of agricultural education are dwelt upon in another place (see pp. 353-358). 


\section{CONSERVATION OF NATURAL RESOURCES}

Reaction on secondary education.

Other grants to states.

The establishment of the state universities and agricultural colleges has had a far-reaching reaction upon secondary education, so that the high schools of the country are at a much higher stage of development than they would have been had the higher institutions not been established. Also the universities and agricultural colleges, in addition to imparting knowledge to students who come to them, have undertaken the great task of extension of knowledge.

To trace the widespread influence of the educational public land grants would in itself require a book. The conservation of the natural resources of the country, if accomplished, will only be possible through education. The beneficent effects of the public land grants for education, even from the point of view of conservation, extend beyond possible computation.

Under the acts of 1849 and 1850 the sroamp lands of the public domain were granted to the states in which they are located. To June 30,1909 , the states had received under these laws 66,554,804 acres. Since the swamp lands are elsewhere discussed (see p. 269), they will not be further considered here.

In addition to the swamp lands, to June 30,1880 , there were special donations to Florida, Oregon, Washington, and New Mexico, amounting to $3,084,797$ acres; and saline lands to various states amounting to 559,965 acres.

Also there have been various special grants to states. Among these are the grants, under the Cary Act of 1905, to certain western states. Under this act, to June 30, 1909, 2,657,488 acres of land had been segregated, of which 297,665 had been: patented. Since I have already spoken of this subject in connection with irrigation (see pp. 193-194), I shall not further allude to it here.

\section{THE PRESENT SITUATION}

It was the apparent attempt of the land laws, from the time of the preemption act of 1841 , to provide for holdings of small size, with the idea that the lands would be taken by 
individuals for their own benefit; but the laws were so drawn and administered as to have permitted the results described.

Of our magnificent original domain in the United States amounting to some 1,400,000,000 acres, more than one half has passed from the control of the government. What has become of this land, is shown in summary by the three tables following, which represent a recapitulation of data already given. ${ }^{1}$

TABLE SHOWING LANDS DISPOSED OF TO JUNE 30, 1909, TO INDIVIDUALS AND CORPORATIONS, THE LATTER LARGELY THROUGH STATES

1. Lands disposed of by eash sale, including preemption and commutation homestead sales to 1880 , but not since that date .

2. Preëmption act, July 1,1880 to June $3 \dot{0}, 1909$

3. Graduation act

4. Homestead act

5. Mineral and coal lands

6. Timber culture act

7. Timber and stone act

8. Desert land act

9. Military bounty

10. Scrip other than military bounty and agricultural college

$182,515,289$

$27,361,836$

$25,696,420$

$115,124,295$

$2,047,527$

$11,875,785$

$12,566,015$

$5,149,546$

$63,958,631$

$1,617,800$

11. Corporation grants . . . . . . . . 123,718,338

Totals to individuals and corporations . . $\overline{571,631,482}$

TABLE SHOWING LAND DISPOSED OF TO STATES

1. Educational

2. Swamp lands $:$

3. Special donations to Florida, Oregon, Washington, and New Mexico . . . . . .

4. Saline lands

$83,008,269$

$66,554,804$

5. Cary Act . . . . . . . .

6. Other special grants not determined :

$3,084,797$

559,965

297,665

Total state grants . . . . . $\overline{153,505,500+}$

TABLE SHOWING RESERVED LANDS IN THE UNITED STATES

1. National parks, June 30, 1909 • . . . . . . $3,624,472$

2. National forests, June 30, 1909 . $:$. $:$. 194,505,325

3. Forest administrative sites, outside national forests, November 1, 1909 . . . . . . .

1 The figures in these tables are only approximate; doubtless in some cases they are too small; in others they probably overlap; but they present the general situation as it is. 
4. National monuments, June 30, 1909 . . . •

5. Indian reservations, June 30, 1909 ...$\quad$ :

6. Military reservations, June $30,1909 \cdot 9^{\circ} \cdot{ }^{\circ}$

7. Reservations for reclamation, June 30,1909 , estimated by Dennett . $\cdot$. .

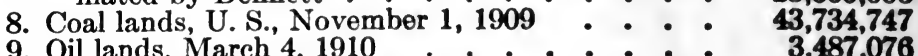

10. Phosphate lands, March 4, 1910 : $:$ : $:$ : $\quad 2,504,103$

11. Power sites, March 4, 1910 . . : : . : 1,300,000

12. Winter game refuge, November $1,1909:$ : :

846,603

48,477,796

839,724

$25,000,000$

43,734,747

138,240

Making a total, not including reservations for birds for which area has not been obtained, of $324,478,060$

To June 30,1909 , the area unappropriated and unreserved in the United States amounted to $363,338,043$ acres.

Putting these results together we have accounted for the following:-

Lands disposed of to individuals and corporations .

Granted to states for various purposes :..:

Reservations : . . . . : :

Unreserved and unappropriated $: .:$ : $^{\circ}$

$571,631,482$

$153,505,500$

$324,478,060$

Total accounted for

Subtracting this amount from the estimated amount of the original public domain in the United States, 1,441,436,160, leaves $28,483,075$ unaccounted for. A large part of this discrepancy is probably explained by lands upon which claims have been filed and are not yet adjusted. Thus at the present time the railroads have claims for many million acres which have not been patented. Also, as has already been indicated, there have been special grants to states and reservations of certain kinds, which have not been included in the foregoing because their amounts are undetermined. Finally the above tables are not based upon figures having the same date, and this fact introduces undetermined discrepancies.

All of the above is in reference to the lands in the United States. In Alaska there are $378,165,760$ acres, of which $368,016,038$ acres are unappropriated and unreserved.

It will be seen from the figures given in the above table that the grants to corporations exceed by $8,594,043$ acres the amount which was taken up under the homestead act; 
and it is to be remembered that under the homestead act, $35,000,000$ acres were commuted, of which at least $30,000,000$ acres went to large companies. The same is true, according Comparison of large and small holdto Schwartz, of at least $10,000,000$ acres under the timber and stone act. If we suppose that the small holders received, under the homestead law, 85,124,295 acres, under the timber claims act, 10,865,480 acres, and under the timber and stone act, 2,566,015 acres; and credit to the large holders the corporation grants, $123,718,338$ acres, $30,000,000$ acres under the commutation clause of the homestead act, and $10,000,000$ acres under the timber and stone act; it would follow that the large holders received $163,718,338$ acres and the small holders $105,555,790$ acres, or the former more than one and one half times as much as the latter.

In the above nothing is said about the preëmption act, nor of the lands which went to the states, since it is impossible to determine the portion of these lands which went to small and which to large holdings. Also it is realized that a large portion of the grants made to the corporations were sold by such corporations to small holders; however, with a large profit to the corporations.

Notwithstanding all the mistakes of our land laws, they The land resulted in giving farms to those who desired homes until the good lands were gone. This situation was reached about laws made homes. a score of years ago. The result is that the average of the holdings of the land in this country is still rather small. The average farm of the United States in 1906 was 146 acres; in the older states along the North Atlantic and South Atlantic and the North Central and South Central States, the average was 103.4 acres; and in the newer states, those west of the Mississippi River, the average was 297.7 acres. The difference in the average holdings in the East and West shows where the defects of the laws were taken advantage of. The large holdings of the choice lands are mainly in the West.

In 1878, Major J. W. Powell, in his report upon the lands of the arid region, strongly advocated the classification of the Public Lands into agricultural, pasture, timber, and

The classification of the public lands. 
mineral, and their separate treatment. When the geological survey was created in 1879 , this was one of the duties assigned to it by law; but the appropriation given to the organization was such that it was entirely impossible to accomplish this work. Therefore many years later, in 1907, when commissioner of the land office, Ballinger repeated Powell's recommendations. To the present time, the classification of the public land into agricultural, pasture, timber, coal, and other mineral land is incomplete. It is during the thirty years that have elapsed since Powell's recommendations were made that the great frauds have been committed and very valuable consolidated holdings acquired. The first report of the National Conservation Commission again strongly recommended to the people and to Congress that the remaining lands in the public domain be classified 80 that they may be disposed of intelligently.

ClassificaLaws for treating in a separate class the mineral lands tion of coal lands. and coal lands so far as they were recognized as such were early passed (see pp. 35-36, 98-100). But the first act which recognized that the same land might be disposed of for different purposes became a law in March, 1909. This act specifies that land taken up for agricultural purposes, which afterwards is found to contain coal, must be classified as coal land and the coal disposed of under the coal laws. The original entryman may gain patent for surface rights or relinquish the ground. Before that act was passed it is estimated that at least $100,000,000$ acres of the public domain containing coal had passed to individuals and corporations as agricultural.

Influence of conservation movement.

The administration of President Taft has recommended the completion of the classification of the public lands, and the geological survey is carrying on the work as rapidly as practicable. As has been seen, pending such classification, the administrations of President Roosevelt and President Taft have withdrawn from private entry vast areas of the public domain. There is now, May, 1910, pending before the Senate a bill, passed by the House, and recommended. by the Senate committee on public lands, of which Senator 
Knute Nelson, of Minnesota, is chairman, stating that "The President may at any time in his discretion temporarily withdraw from settlement, location, sale, or entry any of the public lands of the United States and reserve the same for water-power sites, irrigation, classification of lands, or other public purposes, to be specified in the orders of withdrawals, and such withdrawals and reservations shall remain in force until revoked by him or by an Act of Congress. Provided, That all lands withdrawn under the provisions of this Act shall at all times be open to exploration, discovery, occupation, and purchase, under the mining laws of the United States, so far as same apply to minerals other than coal, oil, gas, and phosphates. The Secretary of the Interior shall report all such withdrawals to Congress at the beginning of its next regular session after the date of the withdrawals." The committee on lands, in a report submitted to the Senate, holds that the President already has "the inherent power to reserve for public purposes lands of the United States from location, sale or entry." This power, the committee says, "rests upon various statutes, upon numerous decisions of the courts, and upon a longestablished, long-recognized usage." This being the case, the passage of the bill in the above form is not advisable, since it limits the power of the President by making all withdrawals temporary, by omitting forests, and by giving minerals a prior position over all resources. It might well be that a tract of land containing mineral is far more valuable for water power than for mineral. A bill originally reported favorably by the Senate committee did not have these limitations. Either no bill should be passed or else one which gives the President at least as large powers as he now has with reference to withdrawals of land.

\section{THE FARM LANDS}

The farm lands of the country, according to the census value of of 1900 , comprised $838,591,774$ acres, $-5,737,372$ farms. Of this land, $414,419,487$ acres, or about 50 per cent, were under cultivation at the time. This was 21.6 per cent, or about the farms. 
one fifth of the area of the country. The value of the farms was estimated by the census of 1900 at $\$ 16,614,647,491$, and by the Department of Agriculture at $\$ 18,279,503,887$. A reëstimate by the Department of Agriculture of these values, five years later, in 1905 , gave an increase of 33.5 per cent, or upon the basis of the census figure, $\$ 22,745,420,567$, and upon the basis of the agriculture figure, $\$ 24,410,276,963 .{ }^{1}$ The increase in farm values has continued since 1905, and it is safe to say that the value of the farm land of the country at the present time is between $\$ 25,000,000,000$ and $\$ 30,000,000,000$.

People engaged in farming.

The amount of the crop.

In $1900,10,381,765$ people, or 35.7 per cent of the wageearners of the country, were engaged in agriculture. This of course is the largest number engaged in any one vocation. It is a decrease as compared with 1880 , when the percentage was 48.3. With the rise of the cities and the increase of manufacturing industries, the percentage of people living on the farms is decreasing.

In the United States four fifths of the corn crop, three fifths of the cotton crop, and one fifth of the wheat crop of the world are grown. In 1909 were planted about 108,771,000 acres of corn, with an average yield of 25.5 bushels to the acre, and a product of 2,772,376,000 bushels; 46,723,000 acres of wheat, with an average yield of 15.8 bushels, and a product of $730,046,000$ bushels; and $30,820,000$ acres of cotton, with a yield of 156.6 pounds per acre, and a product of $4,826,344,000$ pounds.

\section{THE YIELD OF THE FARMS}

The yield for various crops is shown by a table from the bureau of statistics of the Department of Agriculture.

This table shows a slight ehange in yield during the past forty years in some crops. For instance, the corn yield of 1867-1876, as compared with 1897-1906, shows a decrease from 26.2 to 25.4 bushels per acre; on the other hand, wheat increased from 12 bushels to 13.8 bushels per acre; and for

1 "Changes in Farm Values, 1900-1905," by George K. Holmes, Bulletin No. 43, Bureau of Statistics, U.S. Department of Agriculture. 
the other crops there are similar slight decreases and increases. Upon the whole, however, taking the past forty years there has been neither marked increase or decrease in the average productivity of the land.

Table showing Yield of Principal Crops per Acre - DURing the Forty Years 1867-1906, and duRing TenYear Periods ${ }^{1}$

\begin{tabular}{|c|c|c|c|c|c|}
\hline Crop & $1867-1906$ & $1867-1876$ & $1877-1886$ & $1887-1896$ & $1897-1906$ \\
\hline $\begin{array}{l}\text { Corn, bushels } \\
\text { Wheat, bushels } \\
\text { Oats, bushels } \\
\text { Barley, bushels } \\
\text { Rye, bushels } \\
\text { Hay, tons } \\
\text { Buckwheat, bushels } \\
\text { Potatoes, bushels } \\
\text { Cotton, pounds }\end{array}$ & $\begin{array}{l}25.2 \\
12.7 \\
27.7 \\
23.4 \\
13.8 \\
1.28 \\
16.4 \\
83.3 \\
179\end{array}$ & $\begin{array}{l}26.2 \\
12 \\
27.5 \\
22.8 \\
13.6 \\
1.22 \\
17.6 \\
90 \\
181\end{array}$ & $\begin{array}{c}25.1 \\
12.5 \\
27.8 \\
22.4 \\
13.8 \\
1.24 \\
14.5 \\
82 \\
170\end{array}$ & $\begin{array}{c}24 \\
12.7 \\
25.5 \\
22.7 \\
12.9 \\
1.20 \\
15.3 \\
75 \\
172\end{array}$ & $\begin{array}{c}25.4 \\
13.8 \\
30.1 \\
25.5 \\
15.7 \\
1.43 \\
18.1 \\
86 \\
191\end{array}$ \\
\hline
\end{tabular}

The fact that there has been no decrease in the average yield has been held by some to mean that the fertility of the soil has not been depleted; but a closer investigation of the situation by Spillman, taking the country by regions and by districts, and considering what has actually happened, has led him to the conclusion that the fertility of the soil for 50 per cent of our country has been lessened. ${ }^{2}$

Along the same line are statements by Hill. He says: ${ }^{3}$ "There are ten states in the Union in which the wheat crop was less in 1908 than it was in 1888. Twenty years have cut this staple food product in many cases more than one half. They are not all the oldest and poorest soils originally. Both the total crop of this country and its yield per acre have been maintained by resort to new soils not yet robbed of their fertility."

1 "Crop Yield per Acre," by V. H. Olmsted, Report National Conservation Commission, Vol. III, pp. 3-8.

2 "Agricultural Production," by W. J. Spillman, Report National Conservation Commission, Vol. III, pp. 257-262.

3 Address delivered by James J. Hill at the National Corn Exposition, Omaha, Neb., Dec. 9, 1909. 
Improvement in farm crops.

Advance in practice.

Virgin soil.
These general conclusions are confirmed by other considerations.

(1) During the forty years which the figures, given in the above table, cover there has been very great improvements in the farm crops; old varieties of seed grains have been improved; new varieties have been introduced. If there were space so that the history of the improvement of each grain could be given in detail, it would be found that there is scarcely one in which there has not been great advancement; in most cases where the best seeds are used, yields are from one third to double the average.

(2) There have been simply enormous advances in agricultural practice during the past forty years, improvements in cultivation, in rotation of crops, etc.

(3) It is during the past forty years that the great areas of highly fertile virgin lands of the West have been opened up, of which as yet there has not been time for great deterioration. Also included in the averages are the irrigated lands with very exceptional yields. This is very well illustrated by the state of Montana, a new state, and one in which irrigation is practiced, the average yield of wheat for a period of ten years in this state, according to James $\mathbf{J}$. Hill, ${ }^{1}$ being 26.3 bushels.

Considering these facts we should have expected that the average yield by decades during the past forty years would have been a greatly increasing one, whereas it has been practically stationary. What is the explanation of this fact? The only adequate one is that there has been depletion of the soil for large areas. ${ }^{2}$

1 Address delivered by James J. Hill at the National Corn Exposition; Omaha, Neb., Dec. 9, 1909, p. 9.

${ }^{2}$ I am aware that these conclusions are at variance with those expresed by Mr. Milton Whitney of the Bureau of Soils, but they are in accordance with the judgment of most of the soil experts of the country. Mr. Whitney, in Bulletins 55 and 57 of the Department of Agriculture, argues that there has not been and is not likely to be, any marked deterioration of the soil. But in advocating this he wholly ignores the influence of the factors above mentioned, and the actual results which have been obtained when any field has been handled experimentally for a number of years under the conditions which have been extensively practiced in America; that is, single cropping. selling the crop off the soil, and careless cultivation. Where ouch practices obtain there has been but one result, reduction in yield. 
IOWA

ILLINOIS

KANSAS

MISSOURI

TEXAS

OHIO

MINNESOTA

NEBRASKA

INDIANA

NEW YORK

KENTUCKY

PENNSYLVANIA

CALIFORNIA

MICHIGAN

SOUTH DAKOTA

WISCONSIN

GEORGIA

TENNESSEE

VIRGINIA

NORTH DAKOTA

ALABAMA

NORTH CAROLINA

MISSISSIPPI

ARKANSAS

SOUTH CAROLINA

OKLAHOMA

WEST VIRGINIA

LOUISIANA

MARYLAND

OREGON

WASHINGTON

MAINE

COLORADO

VERMONT

NEW JERSEY

MONTANA

FLORIDA

IDAHO

MASSACHUSETTS

NEW HAMPSHIRE

CONNECTICUT

UTAH

WYOMING

DELAWARE

NEVADA

NEW MEXICO

ARIZONA

RHODE ISLAND

\begin{tabular}{llllllllllllllll}
0 & 2 & 4 & 6 & 8 & 10 & 12 & 14 & 16 & 18 & 20 & 22 & 24 & 26 & 28 & 30 \\
\hline
\end{tabular}

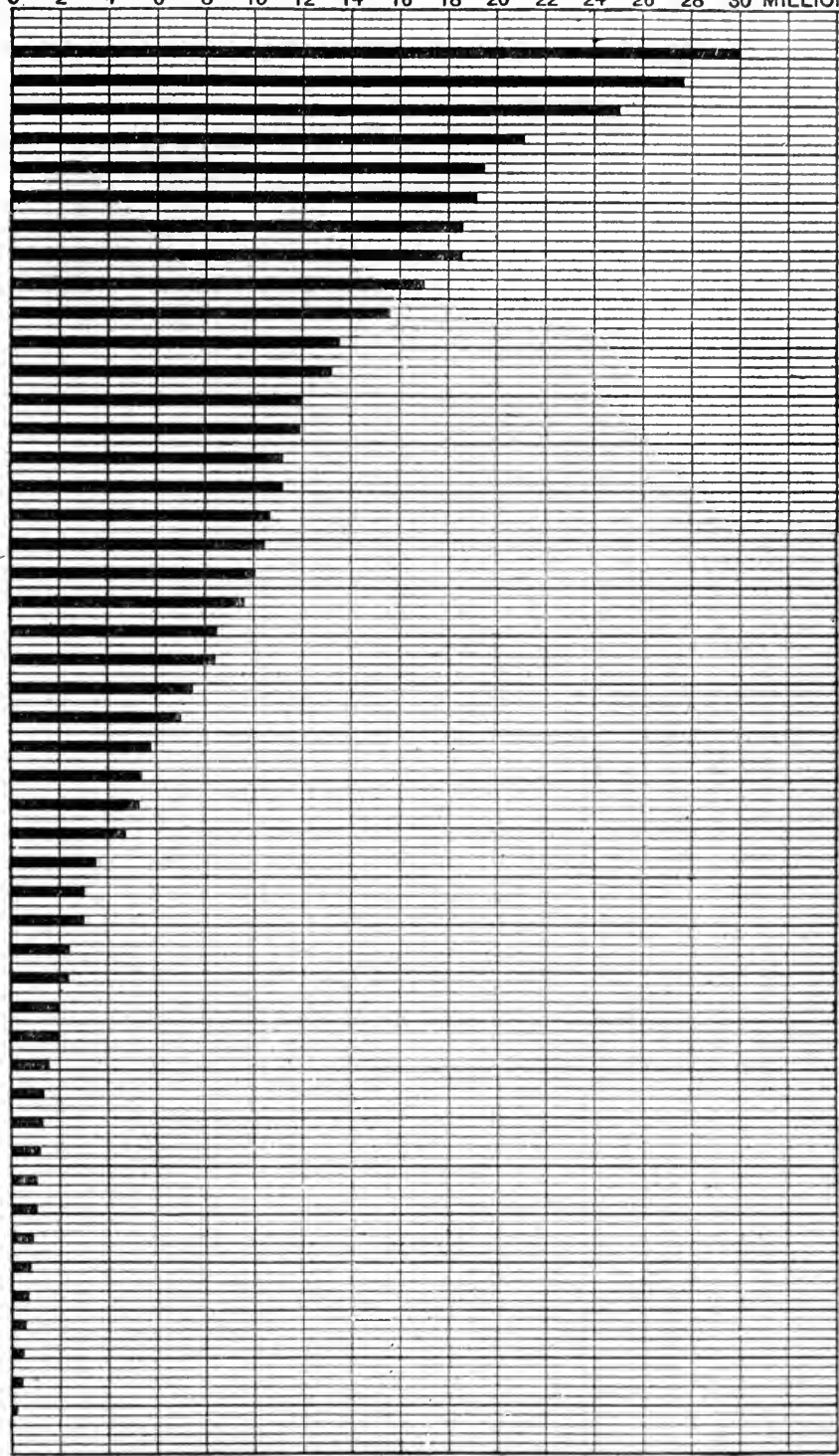

Fig. 20. - Acreage of Improved Land in 1900. After Woodruff. 


\section{CONSERVATION OF NATURAL RESOURCES}

In this connection Hill shows very strikingly that for any given crop there is a certain yield which just pays for its raising; if the yield falls below this amount, there is a loss; if it rises above this amount, there is a gain, which rises very rapidly with increase in yield. For wheat this is shown by the following table: ${ }^{1}-$

\section{Table Showing Profits and Losses in Relation to Yield of WheAT}

\begin{tabular}{|c|c|c|c|c|}
\hline $\begin{array}{l}\text { YIELD IN } \\
\text { BUSHELG }\end{array}$ & Price & $\begin{array}{c}\text { Market Valee } \\
\text { PER ACrf }\end{array}$ & $\begin{array}{l}\text { COBt OF Production, } \\
\text { INCLUDSO KENT }\end{array}$ & $\begin{array}{l}\text { Net Protrt on } \\
\text { Loss, pea Acke }\end{array}$ \\
\hline $\begin{array}{r}20 \\
16 \\
12\end{array}$ & $\begin{array}{r}50.638 \\
.638 \\
.638 \\
.638 \\
.638\end{array}$ & $\begin{array}{r}\$ 12.76 \\
10.21 \\
7.66 \\
\mathbf{6 . 3 8} \\
5.10\end{array}$ & $\begin{array}{r}\$ 7.89 \\
7.88 \\
7.89 \\
7.89 \\
7.89\end{array}$ & $\begin{array}{l}+84.87 \\
+\quad 2.32 \\
-\quad .23 \\
-\quad 1.51 \\
-\quad 2.79\end{array}$ \\
\hline
\end{tabular}

This table shows that when the market price is 63.8 cents, twelve bushels of wheat per acre must be raised in order to come out even; also that the profits with a twenty-bushel yield are twice as much as with a sixteen-bushel yield. Of course with a different market price for wheat, and with a different cost for raising, the number of bushels per acre which represents neither loss nor profit would vary, but the principle remains the same.

As showing the minimum possibilities as to the yield of the soil, we may compare the average yields of this country with those of Europe. ${ }^{2}$

\section{Table Comparing Crop Yield in United States and Other Countries}

\begin{tabular}{|c|c|c|c|c|c|c|c|c|}
\hline \multicolumn{5}{|c|}{ Country } & Wheat & OATS & BARLEY & Rrz \\
\hline $\begin{array}{l}\text { United Sta } \\
\text { Germany } \\
\text { Austria } \\
\text { Hungary } \\
\text { France } \\
\text { United Ki }\end{array}$ & $\begin{array}{c}\text { ates } \\
\cdot \quad \cdot \\
\cdot \quad \cdot \\
\cdot \quad \cdot \\
\text { ingdom }\end{array}$ & $\begin{array}{l}\dot{\circ} \\
\dot{0}\end{array}$ & $\begin{array}{l}\dot{\cdot} \\
\dot{\cdot} \\
\dot{\cdot}\end{array}$ & $\begin{array}{ll}\cdot & \bullet \\
\bullet & \bullet \\
\bullet & \bullet \\
\bullet & \bullet \\
\bullet & \bullet \\
\bullet & \bullet\end{array}$ & $\begin{array}{l}13.8 \\
28.0 \\
17.8 \\
17.6 \\
19.8 \\
32.2\end{array}$ & $\begin{array}{l}30.1 \\
47.4 \\
27.2 \\
30.4 \\
27.3 \\
44.6\end{array}$ & $\begin{array}{l}25.5 \\
33.5 \\
22.9 \\
22.7 \\
22.4 \\
34.3\end{array}$ & $\begin{array}{l}15.7 \\
24.2 \\
17.6 \\
17.3 \\
16.7 \\
26.2\end{array}$ \\
\hline
\end{tabular}

1 "The Natural Wealth of the Land and its Conservation," by Jame J. Hill. Conference of Governors, Washington, 1909, p. 71.

2 Lands, N. C. C., Vol. I, p. 77. 
This table shows that in the United Kingdom and Germany the average yield is much greater than in the United States; indeed, for the United Kingdom the yield of oats, barley, and rye is 50 per cent or more in excess of that of the United States. The lands of these European countries have been cropped not simply for twenty-five, fifty, or one hundred years, but for centuries.

\section{THE CONDITION OF THE LAND}

We now pass to the present condition of the land of the Original United States. As we have already seen, the land of this country was originally an area unsurpassed in fertility anywhere in the world. Although it has been only about three hundred years since settlement first began, and less than fifty years since more than half the farms were virgin fields, already there has been great deterioration of the soil in many localities.

The southeastern region, including the Atlantic and Gulf plains, is the one in which the deterioration has been greatest. In large measure this came about as a result of the abandonfertility of the land. ment of fields during the Civil War, with the resulting erosion; also it has come from a single or chief money crop; for instance, cotton or tobacco.

The northeastern region, like the southeastern, has been cropped for many years. Many of the uplands once cultivated have been abandoned. All have read of the abandoned farms of the uplands of Massachusetts, Connecticut, Vermont, and New Hampshire. Their abandonment has resulted in part from the deterioration of the soil, but an important factor has been the competition of the western, more fertile, lands, in connection with the improvement of transportation.

The east central area, including western New . York, Ohio, Indiana, and eastern Kentucky and Tennessee, was the area into which the immigration went after it burst over the mountains of the East. The lands for the most part have been occupied less than one hundred years. Notwithstanding this fact any one who has ridden over this region exten-

The old fields of the South.

The abandoned farms. 
sively must realize that the larger part of the lands has been depleted in their richness and that there are extonsive areas in which the productivity has been much diminished. The situation may be illustrated by Kentucky and western New York.

Says Shaler, "In the state of Kentucky, which has been occupied by our people for less than a hundred and fifty years, and has not been, to any considerable extent, tilled for more than a century, something like a tenth of its tillable area has passed through this process of soil destruction, and at least a thirtieth part of it cannot be brought back to its original fertility in any foreseeable time. It must return to the forested state and, in that condition, through the ages, slowly gather again its mantle of soil." !

Decreasing value of depleted lands.

Worn-out farms.
Hill says: "Good farms in the Mohawk Valley in New York State forty years ago were worth from $\$ 100$ to $\$ 150$ per acre; now many are sold at from $\$ 25$ to $\$ 30 . " 2$

While this difference may not altogether be explained by the deterioration of the soil, this is the chief cause; and one who is familiar with this area cannot but realize that, as contrasted with the rich fields of the Middle West, the land is very meager in its yield.

The eastern part of the prairie plains has not been occupied more than one hundred years, and for the most part the prairie plains have been settled during the last fifty years. As already indicated, the region is one of high fertility. But even in this region, so recently occupied, we find where there has been single cropping and where unsatisfactory farming methods have been practiced, there has been depletion of the soil. In Wisconsin, in Indiana, in Illinois, as one travels over the country and talks with any of the people, he learns about worn-out farms. This is of course less frequent in the western half of the prairie plains, in Iowa, Nebraska, and Kansas.

As yet all but a small percentage of the lands of the great plains and the Rocky Mountain regions have been but little

1 "Man and the Earth," Nathaniel Southgate Shaler, p. 129.

${ }^{2}$ Address delivered by James J. Hill at the Thirty-fifth Annual Convention of the American Bankers Association. 
-used for agriculture, and therefore the lands have not been depleted in their richness. But as has already been shown, some 13,000,000 acres in this region have been brought under irrigation; and where this has been practiced for some time there has been in many cases injury to the land. For the most part these injuries are due to the action of the water used. Many of these western lands contain a large amount of alkalies, sodium carbonate, sulphate, and chloride; and not infrequently these materials are especially abundant in the subsoil. When lands of this -kind are placed under irrigation, water bearing the salts mentioned in solution are brought upward by capillarity; and its evaporation results in the accumulation of alkalies at the surface. When these have reached a certain amount the crops will no longer thrive. Already in every state in the West where irrigation has been practiced, whether it be Colorado, Utah, or Washington, considerable tracts have been destroyed by the increase of the alkalies through this process. Also, through irrigation, many comparatively low-lying areas have become water-logged by seepage so that they have been transformed to a condition of swamps. The remedy for the accumulation of alkalies at the surface and that of the swamps is the same, - underdrainage to carry away the excess of water. Locally also where lands have been under irrigation for twenty-five years or more there has been serious depletion of phosphorus. This is illustrated by the Greely district of Colorado, which has need of phosphate fertilizers (see pp. 321-327).

In the Pacific region, in the irrigated districts of the San Joaquin Valley of California, accumulations of alkalies and the water-logging of the soil have taken place somewhat extensively; also in southern California there has been depletion in phosphorus. Locally, outside of the irrigated areas of this region, there has been serious loss of fertility, and especially in the Willamette Valley and the upper part of the great valley of California, where the yield of wheat for many farms is now smaller than in the earlier years.

An interesting commentary on the foregoing is a statement 


\section{CONSERVATION OF NATURAL RESOURCES}

by Jevons, who, discussing the course of events forty-five years ago, with reference to the settlement of the United States, said : "It is well known that in spreading over a new country, settlers are naturally apt to exhaust the virgin soil they get so eheap, regardless of manners and agricultural arts by which its fertility might be maintained." . . . Exhaustive agriculture and migration are the necessary results, in any country or social system, of a boundless supply of rich lands." 1 The principles enunciated in the above statements have been illustrated to a remarkable degree by the settlement of the United States.

How long will the lands be needed?

The amazing situation described has come about in a country in which settlement began only 300 years ago. By far the greater area has been settled within 100 years, and more than half of the land has been used less than 50 years. What is to be our measure of time with reference to the future? Are we to think of these lands as being available to man only 50 years, or 100 years? or should we consider 1000 years, or 10,000 years, or 100,000 years, or $1,000,000$ years, or $10,000,000$ years? From a geological point of view there is no reason whatever why people may not live in this country and occupy this land for the longer of these periods. Their mention makes you smile; 10,000 or $10,000,000$ years are practically synonymous with us. Either is farther ahead than we ean look. Whether we think of the future of man as 10,000 or $10,000,000$ years, it is clear that our duty to posterity demands that the process of depletion of the land be no longer continued: that from now on the lands be not permitted to become less fertile; not only so, but that those lands which have become depleted, if possible be restored in some measure, if not completely, to their original fertility. This problem is the most fundamental, far-reaching, most important of the problems of conservation which confront this nation.

The causes of deterioration of the soil may be classified under mechanical erosion and loss of essential elements. 


\section{MECHANICAL EROSION 1}

By mechanical erosion is meant the carrying away of the soil. This for the most part is done by running water, but locally may be done by the wind and in some localities by water and wind together. The material carried away is transpprted to the streams and thence toward or to the sea.

According to Dole and Stabler, ${ }^{2}$ at the present time the average rate of denudation in the United States, based upon estimates as to the amount of sediment the streams carry 1 to the sea, varies from one inch in 440 years to one inch in 3900 years, with an average of one inch in 760 years. This rate of erosion may seem extremely small; but the amount of material involved in it is enormous. Its total each year is $783,000,000$ tons, or $610,000,000$ cubic yards of surface soil; and this estimate is not more than half of the estimates of others. Before land is cleared, there is a close balance between the agencies of manufacture of the soil and its removal by erosion, since originally the soil of the country varied from a few inches to a few feet in thickness. Had the rate of manufacture upon the average been much faster than the processes of erosion, the soil would have been thicker.

We may safely conclude that where the soil is cultivated, the processes of its manufacture are slower than the rate of denudation, for at best the removal of the original protective covering of the soil and the practice of agriculture accelerate erosion. This follows from the fact that in agricultural operations the soil is usually left without any protective covering for a greater or less portion of the year; not only so, but many crops, especially the cultivated crops during the growing season, leave a large part of the soil bare and exposed to erosion. Often when a shower comes the rain falls upon the dry soil. This surface film, quickly wetted,

1 In compiling the section on erosion I have received great assistance from a paper upon "Soil Erosion," by W J McGee, a copy of which by his courtesy was sent me in advance of its publication.

2 "Denudation," by R. B. Dole and H. Stabler, Report National Conservation Commission, Vol. II, pp. 126-140. 


\section{CONSERVATION OF NATURAL RESOURCES}

Formation is produced. In a very short time, after the beginning of of gullies.

Wash of great storms.

begins to creep down the slope. The rain gathers into rills, the rills into rivulets. Where a stream forms, a gully an abundant shower, a field may have a network of small runways converging into a larger gully. If these gullies are not broken up before the next storm comes, they will be taken advantage of and the waste will be accelerated. Once a system of gullies form, that very fact tends to extend it rapidly. The main gully and its branches cut back and back, and rapidly widen its area.

At best is is very difficult on land under agriculture with any considerable slope to prevent excessive wash, and this is almost impossible when a great storm comes. The most severe storm of the year may result in greater wash than all other storms of the year; the greatest storm of a decade may produce greater wash than all other storms of that decade; and Gilbert goes so far as to suggest that the greatest storm of the century may be more destructive than all the storms of that century.

\section{FACTORS WHICH CONTROL EROSION}

Slope and erosion.

Destruction on steep slopes.

What are the factors which control erosion? First, the rate of erosion depends upon the steepness of the slopes. As the slope increases the energy of running water is enhanced in a geometrical ratio. Consequently, with increase of slope the power of the running water to carry away the soil goes up very rapidly. McGee says doubling the slope may octuple the erosion.

On very moderate slopes the amount of soil which may be carried away in a few years is very large.

The greatest losses by erosion have been on those slopes which are so steep that they should not have had their protective forest covering removed. In some cases, and this is especially true of extensive areas in the southern Appalachians, lands have been cleared of their forests and devoted to agricultural purposes, so steep that the erosive forces have carried away the soil in a half dozen years and the 


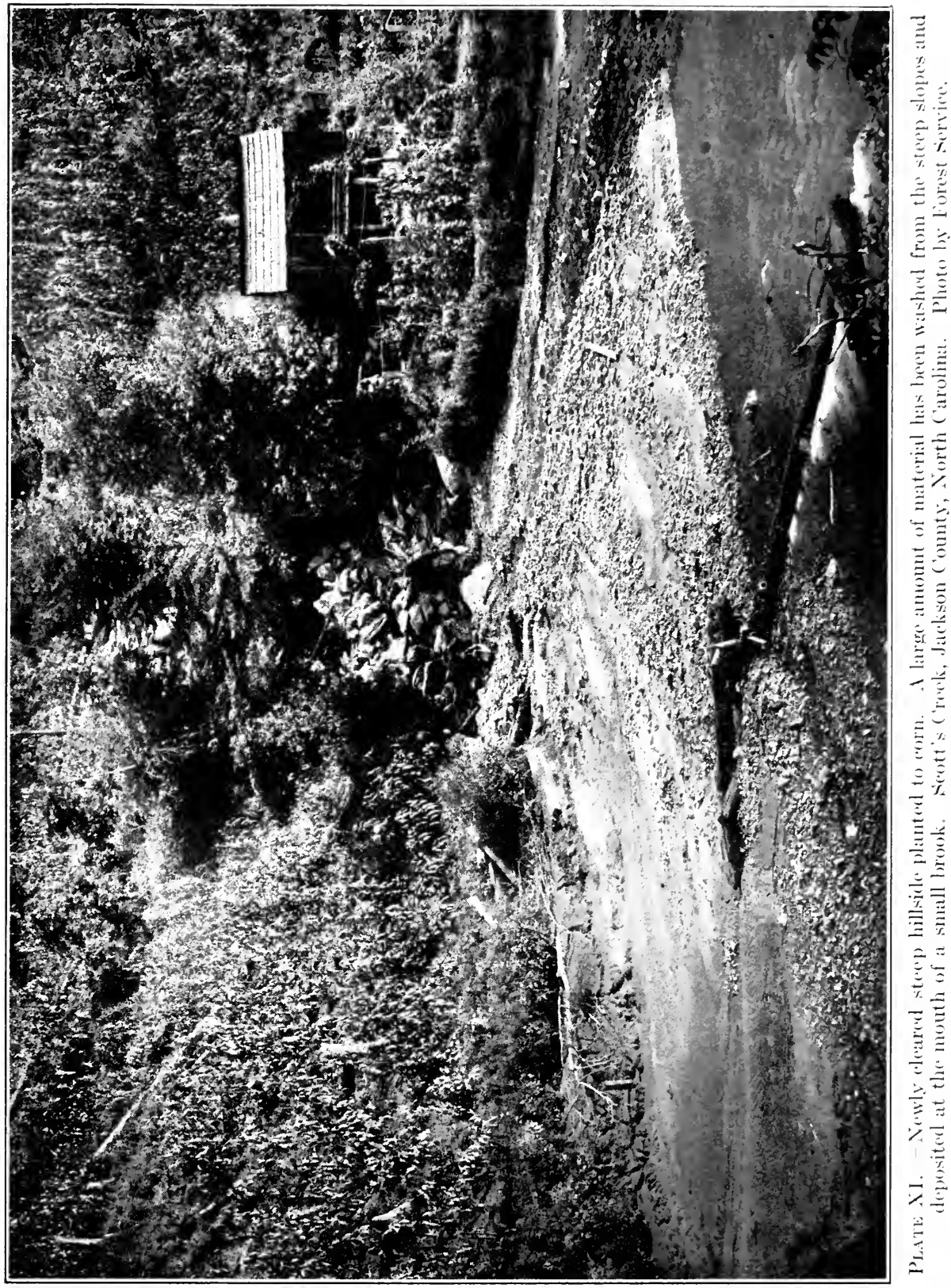





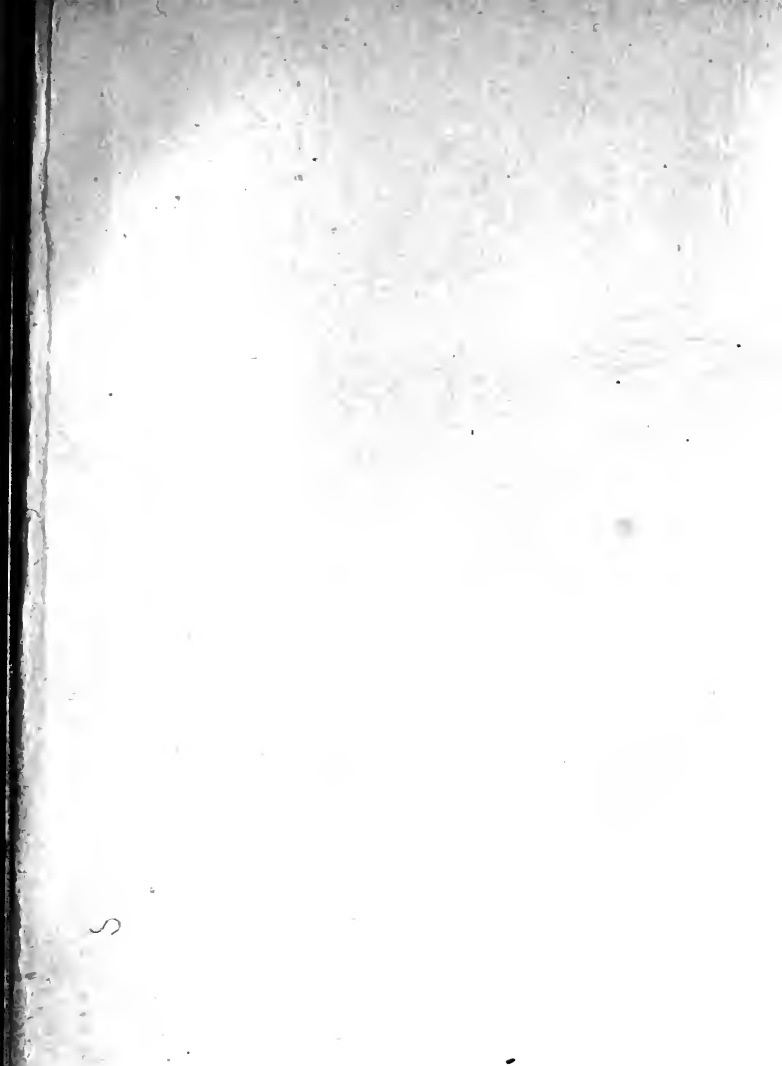




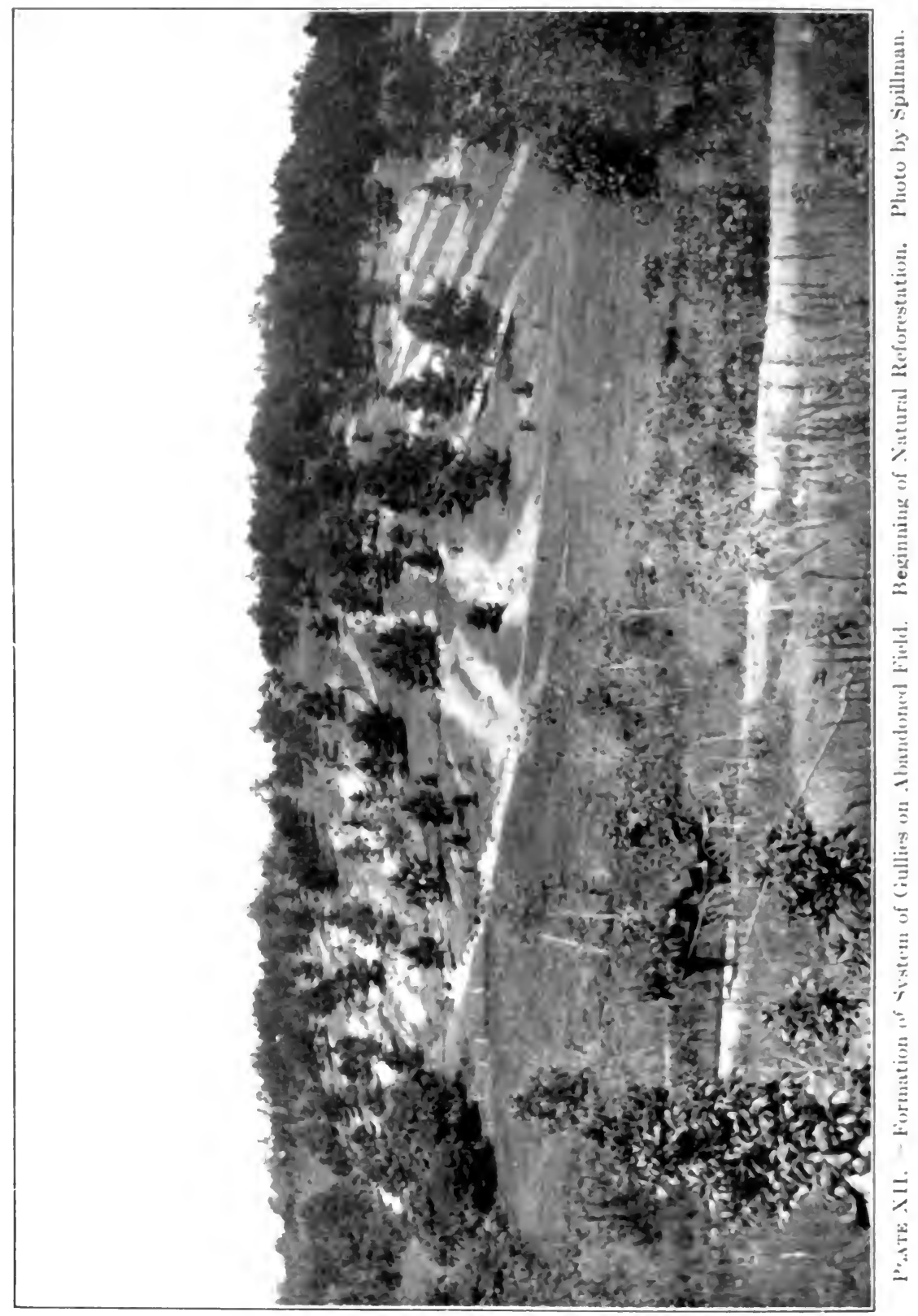


fields have been abandoned. In other cases the fields have had a life of ten or fifteen years. It is safe to conclude that where the slopes are so steep as to lead to the destruction of the soil in so brief a time, or even in a period of 25 or 50 years, such slopes should be retained permanently with a forest covering; or if the forest be removed the special protective measures later to be mentioned should be taken.

The second of the factors involved in erosion is the porosity of the soil and subsoil. If below the soil there is wholly impervious material such as rock, the amount of water which may be absorbed is small and there is likely to be destructive erosion. These are the conditions in the southern Appalachians. If, however, there is below the soil porous sand and gravel, the amount of water which may be absorbed is very much increased; and, therefore, the water is less likely to gather into destructive streams, and dangerously erode the fields.

Where there are slight slopes and porous subsoil the conditions are favorable to drainage with very moderate erosion. As illustrating these conditions may be mentioned the glaciated regions of the Upper Mississippi Valley, including the states of Ohio, Indiana, Illinois, Iowa, Wisconsin, and Min- . nesota.

The third factor which has relation to erosion is care. If the fields are once made bare, their covering of grass or forests being removed, they require constant care. If they are neglected or abandoned, erosion will be greatly promoted. This is illustrated in many of the farms on the Piedmont Plateau and on the Gulf plains. If neglect be combined with steep slopes and an impervious subsoil, the effect will be destructive.

Fourth, the system of rectangular plowing which is practiced throughout a large part of the country is favorable to erosion. Where rectangular plowing is practiced the furrows frequently run down slopes; this gives a series of ditches in which the water gathers and with its increased volume and speed greatly increases the amount of erosion. In the North, because favored by gentle slopes and by porous sub-

Erosion promoted by neglect."
Erosion promoted by rectangular plowing. 
soil, rectangular plowing is almost universally practiced. There is no question that this has accelerated erosion.

Erosion more rapid than necessary.

Extent of destruction of the land.

What are the results of erosion in this country thus far? Since denudation under agriculture is more rapid than the manufacture of the soil upon the average, an upper layer of soil has already been removed from the greater portion of the lands which have been cropped for some years. Not only so, but in consequence of bad farming erosion has been extremely unequally distributed. Much more rapid erosion has been allowed than is necessary.

Partly because of lack of knowledge of proper practice, and partly because of neglect, systems of gullies have formed already over extensive areas in the United States. This is illustrated by the Piedmont and Gulf states, especially on the farms which were abandoned as a result of the Civil War. To a less extent the same phenomena may be seen on the abandoned farms of Massachusetts and Connecticut.

Woodruff estimates that nearly 4,000,000 acres have been so deeply eroded as to be totally destroyed, a sufficient amount to make 100,000 forty-acre farms. This is something like .6 of 1 per cent of the entire land of the country under agriculture. A much larger area than this has been injured in different degrees, varying from little damage to nearly complete destruction; and this is an even more important factor with reference to the future than the actual destruction of 4,000,000 acres. If we continue destroying our lands by erosion at the rate we have in the past, it is easy to calculate that a few thousands of years hence the soil will be in a condition which will ill support a numerous people.

\section{REMEDIES FOR EROSION}

Erosion and water control.

As pointed out by Chamberlin ${ }^{1}$ the prevention of erosion rests in the regulation of the movement of water; by it the soil is carried away. If the water can be controlled, the soil will not be lost. The problem is to make each acre take care

1 "Soil Wastage," by T. C. Chamberlin. Proceedings of the Conference of Governors in the White House, p. 79, Washington, 1909. 


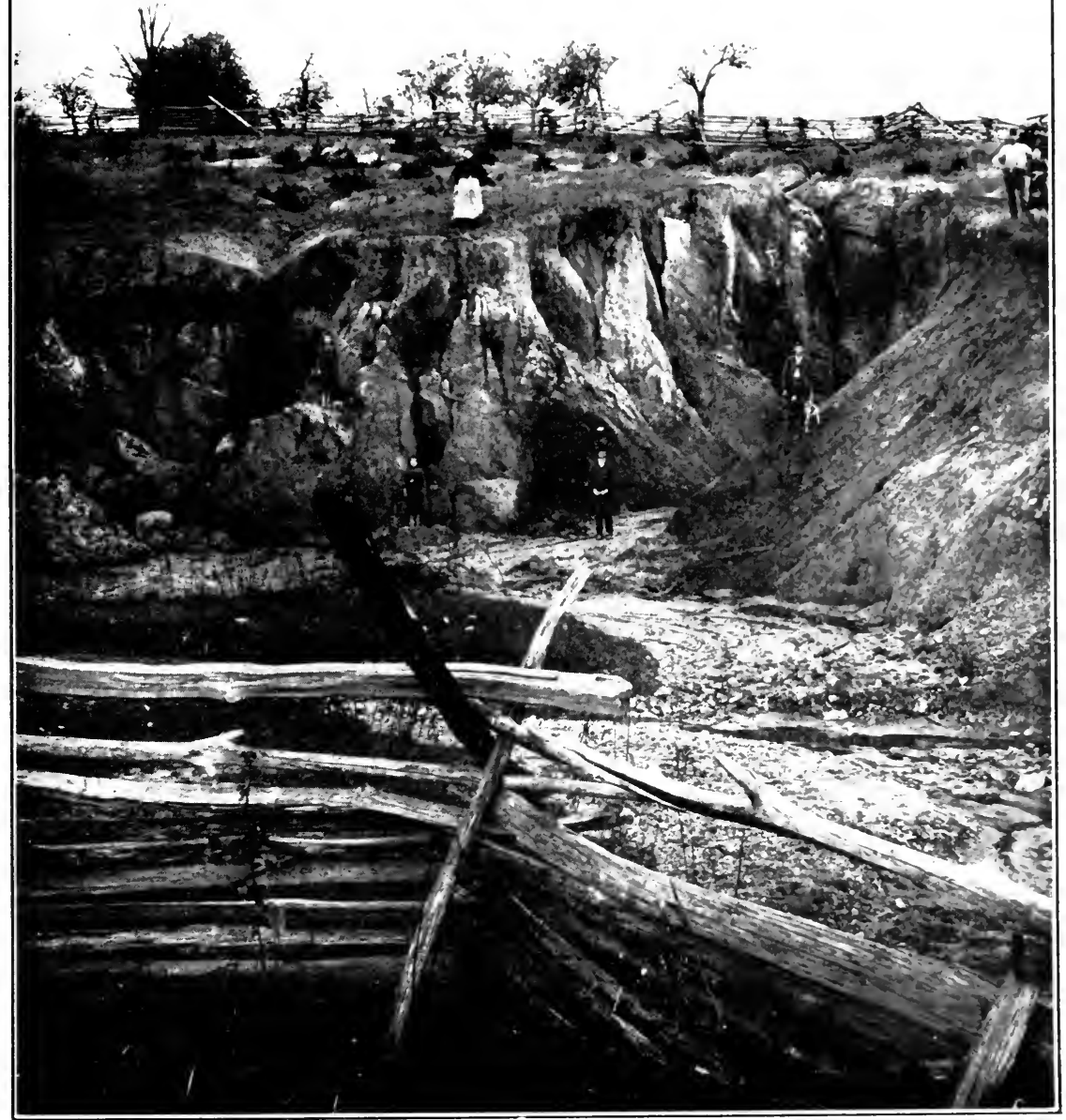

Plate XIII. - Gullied field showing destruction of level lands by erosion, The steep soil is underlain by decomposed rock which undermines very rapidly. Near (raig, North Carolina. Photo by Forest Service. 



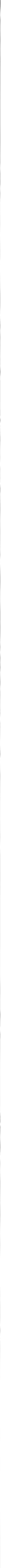




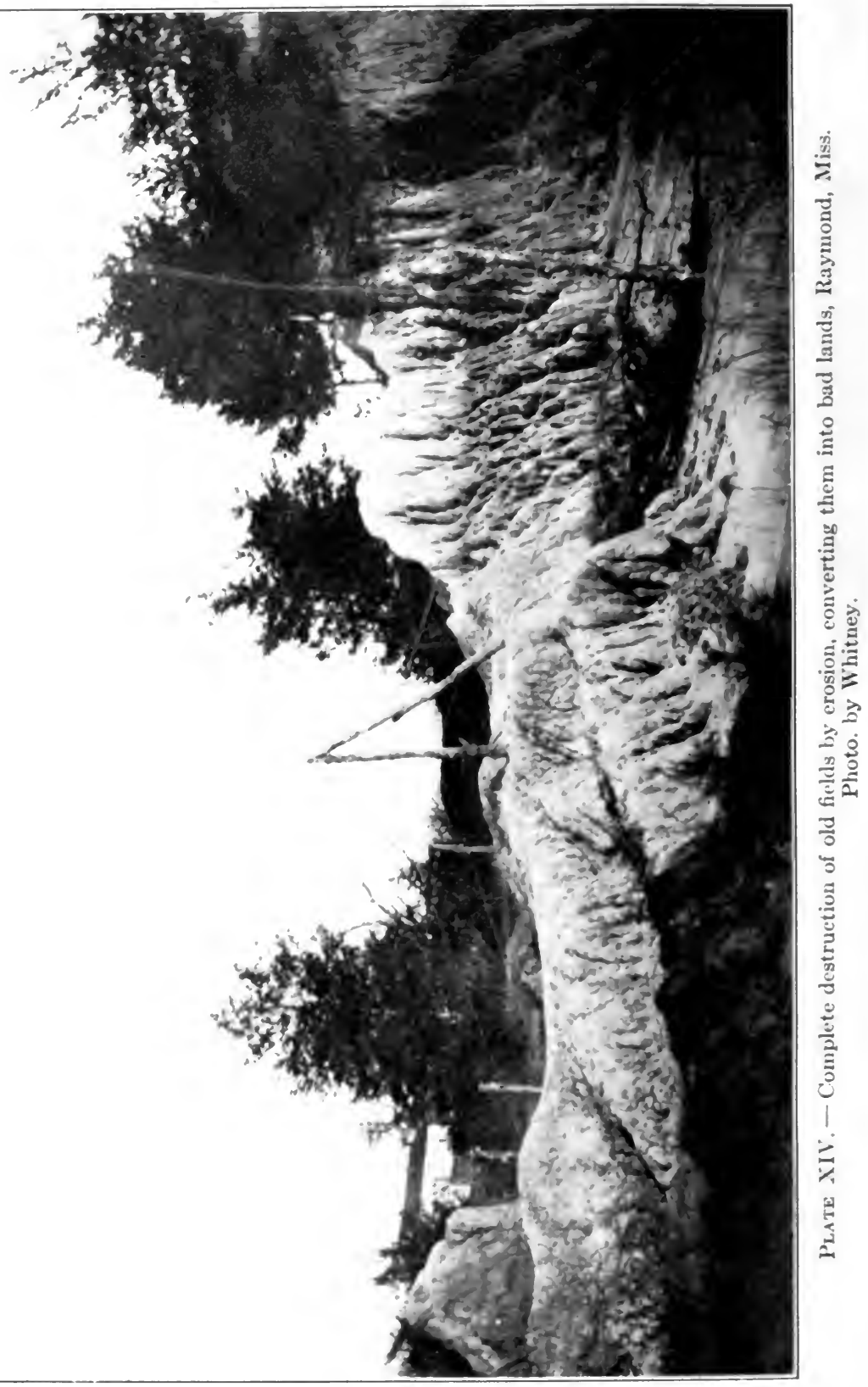


of its own rainfall. This can be done, according to McGee, by maintaining "a normal balance between slope, cover, soil, and water supply."

Before the protective covering is removed from the land this normal balance is maintained. Chamberlin says, for its accomplishment on lands under agriculture, "a due portion of the rainfall should go through the soil to its bottom to promote soil-formation there; a due portion of this should go on into the underdrainage, carrying away harmful matter; a due portion should go again up to the surface carrying solutions needed by the plants; a due portion should obviously go into the plants to nourish them; while still another portion should run off the surface, carrying away a little of the leached soil matter."

It has been pointed out already that the storms of exceptional severity are the main cause of erosion. The chief problem of reducing erosion is that of controlling the water which falls in the violent storms. The different parts of the country vary greatly in the frequency and intensity of flood-producing storms. McGee says that for the larger part of the country it is necessary to have the soil conditions such as to care for only an inch of water in a few hours, but that in areas of highly unequal rainfall this capacity must be increased to three or four inches.

(1) McGee states that open soils may absorb 10 to 40 per cent of their volume of water, with an average probably of Deep from 20 to 30 per cent. The first step therefore in getting the soils to care for the waters is deep and frequent tillage. By tillage, the upper surface of the soil is made rough and so gives basins to catch the water. Numerous openings are produced in which the water can sink. A field which has been deeply tilled since the last rainfall will be likely to absorb a large portion of the shower. It has already been pointed out (p. 114) that in regions of deficient rainfall such tillage is practiced not primarily with reference to the prevention of erosion, but in order to get the water into the soil and so save it to feed the crops.

Says Chamberlin: "Experimental studies have shown 
Make soil absorb water.

Contour plowing.

Contour plowing increases water supply.

that, on the average, within our domain, crops can use to advantage all the rainfall during the growing season, and that, in most cases, crops are the better for all the stored supplies that can be carried over from the non-growing seasons. This greatly simplifies the general problem, for it justifies the conclusion - to which there are many local exceptions, of course - that the highest crop-values will usually be secured when the soil is made to absorb as much of the rainfall and snowfall as practicable. In securing this maximum absorption and internal soil-work, the run-off, and hence the surface wash, will be reduced to a minimum." "

(2) By contour plowing is meant that the farmer should follow about a hill on the level. Where the slope exceeds ten degrees, and frequently where it exceeds five degrees, contour plowing should be practiced. No definite angle can be given, because with an easily washed soil, contour plowing is necessary with a lower slope than for soils not so likely to wash. By contour plowing there is produced a series of parallel depressions and elevations at right angles to the slope, and each depression is a trough which will catch and hold the water until it has time to get into the soil.

In general in the North, rectangular plowing is practiced; yet in many areas it is certain that the slopes are sufficient so that contour plowing should take its place. It is sometimes thought that the Southern states are more backward in agricultural practices than the Northern states; but in this respect the Southern states are in advance.

Contour plowing on slopes is not only necessary from the point of view of soil erosion, but it is profitable to the farmer. Elsewhere it is pointed out that there is scarcely a season in the eastern part of the United States in which some growing crop does not suffer because of deficiency of water. The additional amount of water which goes underground through contour plowing is a source of supply at time of drought. Even from the point of view of immediate returns the extra trouble of contour plowing and planting parallel with the contour is more than paid for by increased yield. This practice is one in p. 80 .

" "Soil Wastage," by T. C. Chamberlin, Conference of the Governors, 


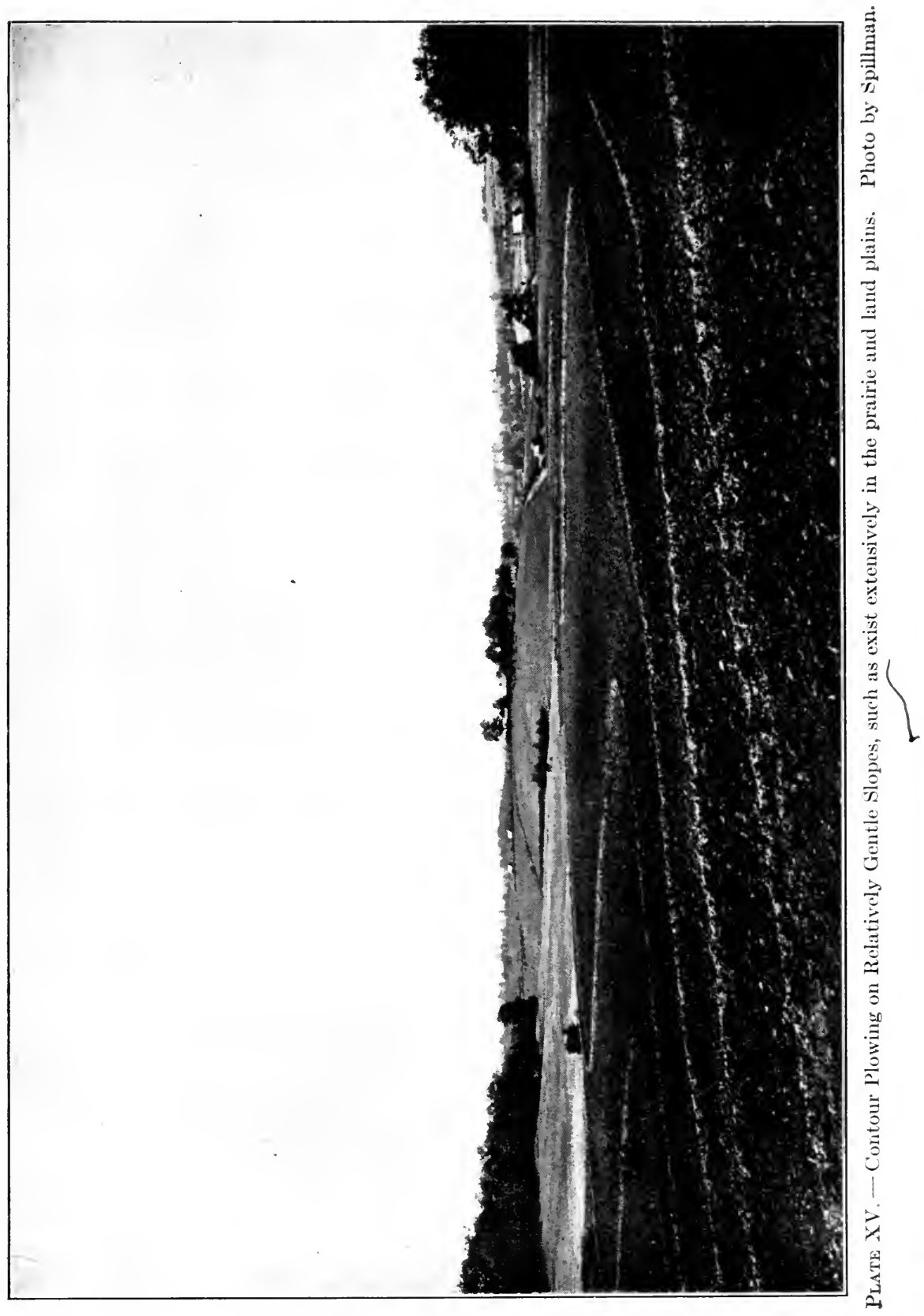





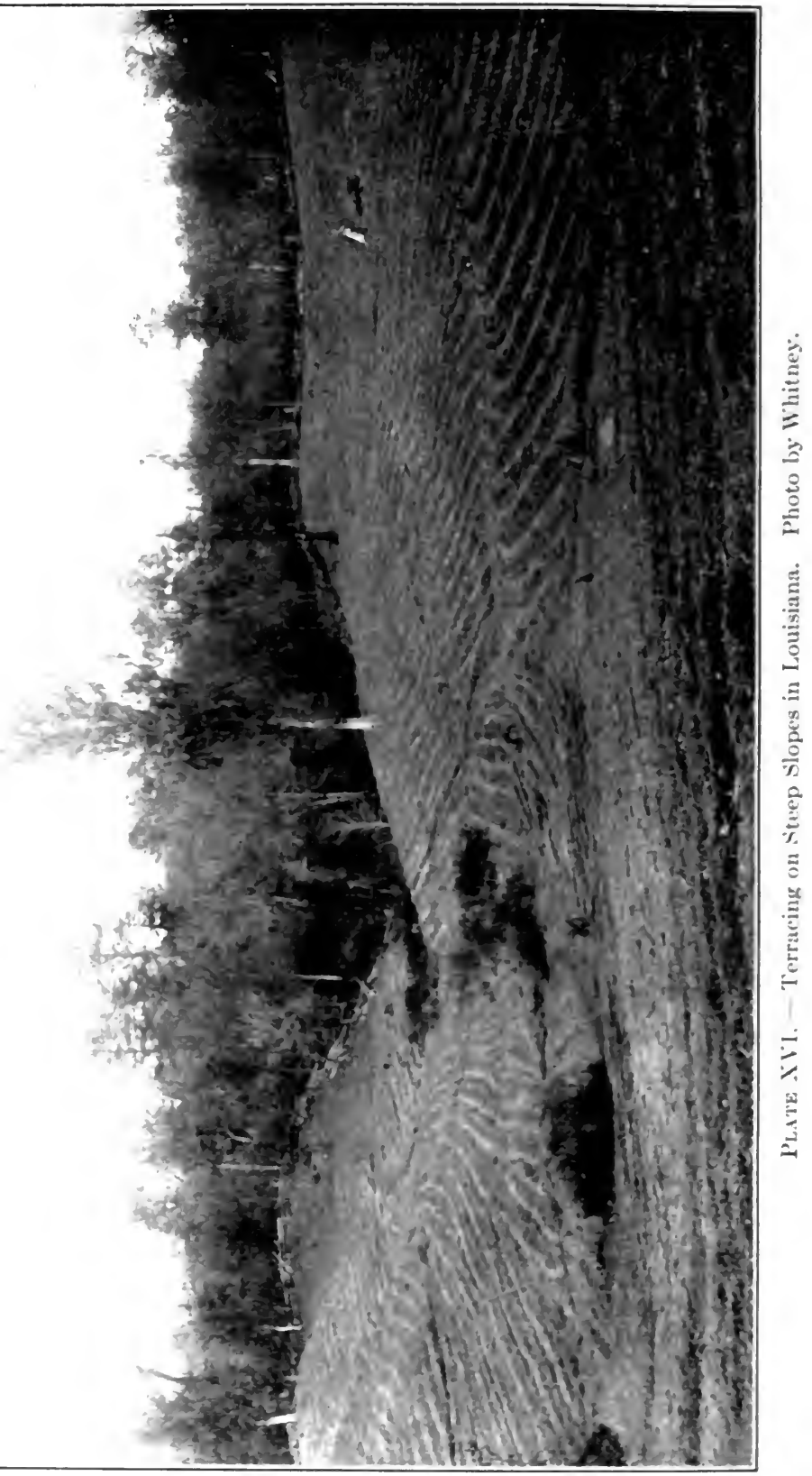


which duty to succeeding generations and gain to this generation are in accord.

(3) On slopes which are rather steep there may be developed Terraces. through modified contour plowing a system of terraces; this is very desirable where the slopes are from ten to twenty degrees. The land is divided into belts or terraces, each band of which sweeps around the hill on the contour. The advantages of such terraces are that they make the strip at each level more nearly horizontal, and reduce the wash. The terraces are separated by broad or narrow bands of soil with slopes as steep as will naturally lie. These should be covered with grass which can be used for forage, and should be kept free from weeds and brambles. Contour plowing and terracing are already extensively practiced upon the Piedmont Plateau, where in general the slopes are steep.

Where the slopes are so steep and the terraces are so numerous as not to be well adapted to ordinary farm crops they may be used for fruit. Berries, grapes, peaches, pears, apples, etc., grow on bushes and trees; therefore setting a fruit farm is in a measure the same as foresting an area. The orchard is permanent, and the roots tend to prevent wash. In some places it may be advantageous to set the trees on the terraces and the bush fruit on the steep slopes between the terraces.

(4) Where the slopes exceed twenty degrees, and in many areas where they are less than this, the land should not be deRetention of forests. nuded of its forest. Indeed, Shaler says that for extensive areas of the country where the declivity exceeds ten degrees, nearly all of the fields which have been stripped of their natural vegetation "are so far worn away by the rain that they cannot be restored to their pristine fertility." ${ }^{1}$ Where the land is steep, its protective covering should be retained; its product should be wood. While this statement is true in general, in areas of intensive cultivation, steep slopes may be made cultivable by numerous narrow terraces, held in place by retaining walls. This practice is illustrated in the vine culture of the Rhine and in the fields of China. Doubtless such practice will extend in this country as the land becomes valuable for special crops, such as fruit. 


\section{CONSERVATION OF NATURAL RESOURCES}

Annular foresting.

Control of gullies.

Erosion and law.

(5) In some cases where the steep slopes are cultivated this is done in connection with annular foresting, that is, on the slopes separating the cultivated areas are rows or bands of trees. These bands of trees tend to break up the streams which form on the slopes and halt the moving soil, thus saving it from transportation to the rivers below. This practice is illustrated in the mountainous areas of Italy, Austria, and other countries.

(6) Whenever lands are allowed to lie fallow they should always have a protective covering. This covering may be mulch or a catch or cover crop, such as clover or soybeans.

(7) Where a system of gullies has been allowed to form and is extending into the arable land, this should be checked by permanent planting, or if a gully be only of moderate size and the wash not great a grass covering may be sufficient; if the gully is a large one with very steep slopes shrubbery is usually necessary; and in the case of the larger ravines tree planting becomes advisable. Not infrequently it may be advantageous to combine two or three of these. In some cases planting alone is not sufficient; it may be necessary to construct at intervals brush or rubble dams which stay the moving soil and finally break up the ravine into a series of terraces. In favorable regions it may be practicable so to construct the dams as to constitute minor reservoirs to hold the water. The water of such minor reservoirs may be used for irrigation, either subsurface or surface, at the dry times between the storms.

(8) As rapidly as a sentiment can be developed for their enforcement, laws should be passed which will prevent neglect of the land. The precautions necessary to prevent excessive erosion may be enforced by law, since they vitally concern the common welfare not only of this but of all succeeding generations.

\section{LOSS OF ESSENTIAE ELEMENTS}

The second cause of the deterioration of the soil is the loss of valuable elements.

For what do we secure products from the soil? Mainly to 
feed and clothe man either directly or indirectly. Grain, vegetables, fruits, etc., directly feed man. Animals are fed the products of the soil in order that they may indirectly furnish man food, as meat, milk, butter, cheese, etc.; also to supply him with covering, wool and leather; and to serve as beasts of burden. We further produce from the soil materials with which to cover man (cotton), to house him (wood), and to serve other subordinate needs. The purpose then of the art of agriculture is to supply the needs of man.

But among all the needs of man that of food is the fundamental one. This raises the question as to the elements necessary to feed plants which directly or indirectly are the sources of sustenance for man.

The constituents of plants are few in number, - hydrogen, oxygen, carbon, silicon, calcium, nitrogen, potassium, phosphorus, with minute quantities of less important elements, such as iron, magnesium, sodium, sulphur, and chloride. Of the eight important elements the first five are practically illimitable in amount so far as plant and animal food are concerned. Hydrogen and oxygen are the chief constituents of water; the latter constitutes one fifth of the atmosphere and occurs combined with carbon. The supply of these elements in an available form is inexhaustible. The plants with the assistance of the sun take their carbon from the carbon dioxide in the atmosphere, or that produced by decaying vegetation in the soil. When plants and animals decompose they return in large measure their carbon to the air as carbon dioxide. Also the combustion of coal adds each year an enormous supply of carbon dioxide to the air. Therefore there will be no shortage of carbon for the plants. There is an abundant supply of calcium in most soils and an illimitable supply of calcium in limestone which may be drawn upon for those soils deficient in this element. ${ }^{1}$ Silicon is the most abundant of the elements. It therefore turns out, that of the materials we need to feed the plants to feed our bodies, the vital elements are nitrogen, potassium, and phosphorus. It is these three elements

1 The advantage of the addition of limestone or lime to many soils is most effectively discussed by Jos. E. Wing in "Alfalfa in America," pp. 107-149. 
Depletion in nitrogen.

Source of nitrogen.

only to which we need to direct our attention from the point of view of conservation.

\section{NITROGEN}

Nitrogen is an essential element of all the proteids and is therefore required in large quantity by man. By him it is derived from plants or from animals that have derived the proteids from plants. By most plants the proteids are built up from the small quantities of nitrates in the soil.

Nitrogen also exists in the soil in the humus. The oxidization of the humus by the oxygen of the air with the assistance of bacteria produces nitrates, and this resupplies the soil with this plant food. The soil is depleted in nitrogen by single cropping, wherever this is practiced. This is true whether the single crop be grain, or cotton, or tobacco. Wherever such practices have been followed the soils have become depleted in nitrogen. This is alike true of the wheat fields of California and Minnesota, ${ }^{1}$ the cotton fields of Georgia, and the tobacco lands of Connecticut and Kentucky.

Also nitrogen is very frequently seriously depleted in the soil by the running of fires. Already this has been spoken of in connection with the burning of the forests. Not only is the timber burned, but frequently the very humus of the soil itself; so that after a fire has run several times over a particular area, if we wish to reclothe it with vegetation, we are obliged to restore nitrogen to it. The ultimate source of nitrogen for plapt food is the atmosphere. In the atmosphere is a boundless supply; for, as you know, in a free state it comprises about four fifths of that great mobile sea which surrounds the earth and permeates the soil. But all the agricultural plants, with the exception of a single family, are unable to feed upon the free nitrogen of the soil. To be used by such plants as the grains,

${ }^{1}$ On lands on which grain has been grown continuously in Minnesota there has been heavy loss of nitrogen and humus. It has been the greatest in the case of wheat, but has been nearly as much in the case of oats and barley, and for corn has been one-half as much as for wheat. Where wheat was a continuous crop for eight years the loss of nitrogen was 1700 pounds per acre, and the loss of humus 2000 pounds per acre. (University of Minnesota, Agricultural Experiment Station, Bulletin No. 70.) 
the nitrogen must be combined with other elements as a nitrate, and hence the necessity of maintaining these compounds and the humus out of which nitrates are made in the soil. Not only are a great majority of the agricultural plants unable to use the free nitrogen of the soil, but their growth depletes the combined nitrogen which there exists.

But there is another class of plants with which the case is The the reverse. The leguminosæ, which include clover, alfalfa, peas, beans, etc., have numerous nodules upon their roots, legumes and which become the hosts of bacteria. ${ }^{1}$ The latter abstract nitrogen from the air and combine it with other elements, and the leguminous plants store the nitrogen compounds in their fruits, stalks, and roots. Experiments show that where leguminous plants are grown and turned under the soil, the gain in nitrogen is rapid and the accumulation of combined nitrogen great; this gain is due to the capacity of the bacteria and leguminous plants together to use the free nitrogen of the atmosphere.

The foregoing facts show the necessity of rotating crops of a kind which use up nitrogen with those which have the power of Rotation of fixing the nitrogen. As a result of empirical knowledge rotation of this kind has been long practiced to some extent. The cause of this advantage is a comparatively recent discovery. The discovery has led to far wider practice in the rotation of nitrogen combining plants with other crops. The better informed farmers systematically rotate clover or alfalfa or reas with the grains. Also as a result of this discovery, where the soil is deficient in nitrogen abstracting bacteria necessary to work with the leguminous plants, it is inoculated with them, and thus the leguminous plants are enabled to do their work effectively. Such inoculation is especially likely to be necessary in sand soils over which fires have run repeatedly.

Another method of adding nitrogen to the soil is to introduce it in the form of a fertilizer. This is done through ordinary Nitrogen in manure. manure and by using by-products, such as packing-house refuse, fish waste, ammonium sulphate, - a by-product of gas

1 Albert Fischer, "The Structure and Functions of Bacteria," trans. by A. C. Jones, Clarendon Press, Oxford, 1900, pp. 88-97. 


\section{CONSERVATION OF NATURAL RESOURCES}

Nitrates

from

Chile.

Nitrogen from the air.

Nitrogen not crucial element. manufacture. The use of manure puts back in the soil a part of the nitrogen taken away from it.

Another source of nitrogen for the depleted fields is the nitrates imported from dry countries, and especially Chile. At the present time large quantities of this material are used for fertilizer. It is imported into Europe much more extensively than to this country. Various estimates have been made as to the time the Chile material would last at the present rate of exportation, ranging from 25 or 30 years to 300 or $400 .^{1}$

While the total supply of this material is large, compared with future demands, even if the large estimates as to the amount are correct, it is small.

A final source of nitrogen fertilizer is from the air by the use of power developed by water.

By electrical methods it has been found that nitrogen can be combined with other substances, and thus nitrates made. This is already done on an extensive scale in Europe, and is likely to be extended to this country. It is not many years ago that the power of the leguminous plants and bacteria to combine the nitrogen of the air and the electric method of doing so were unknown. It was then supposed that the Chile deposits were the only source supplementary to manure. At that time Sir William Crooks gave a somewhat gloomy forecast as to the future, when the time should come that because of lack of nitrogen fertilizer the yield of the fields should decline. ${ }^{2}$

But the advance of science has solved the nitrogen problem. The fields can by sufficient effort have built up in them an adequate amount of nitrogen compound. If we have depleted our fields in this element in the past it has been expensive, but the damage is not irremediable. At sufficient cost we may obtain or produce the combined nitrogen that we need, not only now, but in the future. Therefore the nitrogen problem is not a crucial one with reference to food for the human race.

2 "The Nitrate Deposits of Chile," by R. W. T. Penrose, Jr., Journal of Geology, Vol. XVIII, p. 28.

2 "The Fixation of Atmospheric Nitrogen and the Food Supply," by L. F. Guttmann, Queen's Quarterly, Vol. XVII, No. 4, p. 297. 


\section{POTASSIUM}

The second of the elements requiring special consideration is potassium. The crust of the earth contains on an average Potassium $2 \frac{1}{2}$ per cent of this material. According to Hopkins, 100 in soil. bushels of corn contain 19 pounds of potassium; and the average amount in the soil is sufficient to supply 100 bushels of corn per acre for 2500 years, assuming that the corn stalks are returned to the land. Also there are various rocks which contain more than $2 \frac{1}{2}$ per cent of potassium. Some of them contain as much as 6 or 8 per cent of this element, or three times the normal amount, and the quantity of such rock is vast.

By nature's processes, potassium has been extensively abstracted from the original rocks, and has been concentrated so Potassium that in various parts of the world there are large quantities of this element in a readily soluble form in which it is available for fertilizing the soils deficient in it. Illustrating such segregation are the extensive potassium deposits of Germany, which are estimated to be sufficient to meet the demand at the present rate for thousands of years. Even if in the future these segregated and soluble deposits of potassium are exhausted, we may still use the original rocks, which are more than ordinarily rich in this element, as a source from which more concentrated material may be manufactured, or the very finely pulverized rocks may be used directly as a fertilizer.

Therefore it is clear that if we by carelessness deplete some of our fields in potassium, we may restore that element. Some lands when first occupied are found to be deficient in it, as for Potassium not crucial element. instance, the peat marshes; but there is an adequate supply of potassium available to meet the needs of such land. Thus through the indefinite future, with sufficient expenditure of money and labor, we may supply potassium to the fields depleted in it, and to those originally lacking it. Hence potassium is not a crucial element likely to limit the capacity of the lands to feed the human race. 


\section{PHOSPHORUS}

Phosphorus a crucial element.
The last of the elements which we need to consider is phosphorus. Just as we find in the arid region that water is a crucial factor, limiting production, so for the humid regions of the United States phosphorus is the crucial, the limiting factor, in the productivity of the soil. Phosphorus is an essential constituent of blood and flesh and bone and brain. How essential it is, has been very clearly shown by experiments which have been carried on in the Wisconsin experiment station, ${ }^{1}$ following somewhat analogous experiments elsewhere. Animals have been fed with a ration deficient in phosphate, with the result that these animals thrived for a time, but after three months they collapsed. In an intermediate stage some of them were killed and it was found that the flesh was taking the phosphate from the bone in order to supply its need. This went on until the bones were no longer able to supply phosphorus to the flesh, and then the irretrievable collapse came; they could not recover when fed a normal ration.

In this connection the relation of the phosphorus in wheat grain and wheat bran is interesting. Henry states the bran comprises about one fourth of the kernel. According to Tottingham, the average of phosphorus in the entire kernel is .39 per cent and in the bran 1.26 per cent. From this it follows that 100 pounds of wheat grain contains .39 pound of phosphorus, and that the 25 pounds of bran in the same contains .32 pound of phosphorus; this leaves only .07 pound of phosphorus in the grain exclusive of the bran. Hence about $\mathbf{8 0}$ per cent of the phosphorus is removed with the bran. Potatoes, in this country the most common food other than the white bread, contains only one sixth as much phosphorus as wheat. It is clear that the human beings whose main The food of food is bread made from white flour or such bread and babies.

1 "The Role of Inorganic Phosphorus in the Nutrition of Animals," by E. B. Hart, E. V. McCollum, and J. G. Folk, University of Wisconsin Agricultural Experiment Station, Research Bulletin No. 1, 1909. 
not surprising that mothers whose main articles of diet are white bread and potatoes are not able properly to nourish their babies.

On the average in the original rocks there is .11 of 1 per cent of phosphorus, the equivalent of about .25 of 1 per cent of phosphoric oxide. According to Whitson, ${ }^{1}$ the average for the virgin soils of Wisconsin is even lower than this, .17 of 1 per cent of phosphoric oxide. For the first eight inches of soil this would amount to 2940 pounds per acre. If this amount is as large as the average of the country for virgin soils, it would follow that in the manufacture of the soil itself about one third of the phosphorus in the original rocks is lost.

While the above doubtless represents a fair average, there are some soils, and especially limestone soils, which have a greater amount of phosphorus. To illustrate: "The silurian limestones in central Kentucky, which are so enduring to ill treatment that for a hundred years of misuse they have brought good crops of Indian corn and wheat, owe their continued fertility to the existence in the strata of layers containing often as much as twenty per cent of lime phosphate, which is continually coming into soluble condition and so replaces the waste." ${ }^{2}$

\section{Losses of Phosphorus}

An examination of the situation for the country shows that already the soils are seriously depleted in phosphorus. Indeed, for extensive areas in the South and East the phosSoils depleted in phospho. phorus is so deficient that there is scarcely any attempt to raise a crop without the use of phosphate compounds as fertilizers. Hopkins ${ }^{3}$ states that old soils from Virginia

1 "Factors Influencing the Phosphate Content of Soils," by A. B. Whitson and C. W. Stoddard, University of Wisconsin Agricultural Experiment Station, Research Bulletin No. 2.

2 "Man and Nature," Nathaniel Southgate Shaler, p. 135.

3 "The Soil and Prosperity of the State," by C. G. Hopkins, delivered before the 1909 Farmers' Course at University of Wisconsin. Quoted in Wis. Agr. Exp. Sta. Bull. 174, April, 1909. 
level land, "reported too poor for cultivation, were found by ultimate and absolute chemical analysis to contain only 340 pounds of total phosphorus in $2,000,000$ pounds of the surface soil"; whereas the best black soils of Illinois contain more than six times this amount. Western New York and Ohio, which not more than fifty or sixty years ago were regarded as the very center of the fertility of the country, are very seriously depleted in this element; and into them there is continuous importation of phosphate fertilizer. And even in the upper Mississippi Valley the situation is not altogether satisfactory. Hopkins of Illinois reports that the soil of at least one third of that state is deficient in this element. Tests made by Whitson ${ }^{1}$ show that on the average the fields in Wisconsin which have been cropped for fifty years have lost more than one third of that element.

Hopkins says that the worn-out fields of "Asia are very deficient in phosphorus. An invoice of the depleted lands of India shows phosphorus varying from a trace to 500 pounds per acre in the plowed soil of an acre. The report of an analysis of depleted land in Turkey, Asia, states that no phosphorus could be found in the surface soil." ?

Phosphorus and yield of soil.
In the case of soils depleted in phosphorus, that the main trouble is the lack of this element is proven conclusively by the increased crops when upon such soils phosphatic fertilizer is introduced. This is shown by experiments upon many varieties of crops in various localities, and especially in the states of Ohio, Illinois, and Wisconsin. ${ }^{3}$ Hopkins says in reference to Illinois that thirty-two tests in six different counties show an increase in 1908 of nine bushels per acre of corn as the result of using raw phosphate during the previous four or five years.

The waste of phosphorus resulting in the condition described has been going on up to the present time unchecked,

1 "Factors Influencing the Phosphate Content of Soils," by A. R. Whitson and C. W. Stoddart, University of Wisconsin, Research Bulletin No. 2. 43-45.

${ }^{2}$ Loc. cit.

3 "The Conservation of Phosphates on Wisconsin Farms," by A. $\mathbf{R}$. Whitson and C. W. Stoddart, Univ. of Wis. Ag. Exp. Station, Bull. 174, April, 1909, pp. 9-14. 
almost unnoticed, because studies in reference to the matter have been undertaken only within the past few years. The losses of the land in phosphorus are due to three causes:-

1. We have noted that there is phosphorus in grain. When a crop of grain is sold off the land, there is loss of phosphorus; if this goes on year after year this loss continues until the deficiency of phosphorus becomes a limiting factor in the productivity of the soil. At the present time the wheat fields- of northern California and those in the Willamette Valley cropped for many years are falling off in their yield. This is probably more largely due to depletion of phosphorus than to any other single cause.

A crop of wheat may be regarded as 20 bushels, of barley 40 bushels, of oats 50 bushels, of corn 65 bushels. According to Snyder, these amounts of grain carry away the following amounts of phosphoric oxide; wheat, 12.5 pounds, barley, 15 pounds, oats, 12 pounds, corn, 18 pounds. If there were 2940 pounds of phosphoric oxide in the soil it would therefore follow that there is a sufficient amount to furnish about from 160 to 250 crops. These figures would represent the maximum time the phosphorus of the soil would last if grain crops were produced to the amounts mentioned and the grain were sold off the farm. Other factors are of course involved. This statement on one side does not take into account any allowance for removal of the phosphorus by leaching nor on the other side does it consider the decrease in the amount of phosphorus extracted each year as the crop becomes smaller because of the depletion of the soil in that element.

Where the grain and other products, such as meat, milk, and cheese, are sold off the farm, there may be imported feeds which to a certain extent replace the phosphorus sold.

Whitson and Stoddart have made out a balance sheet for phosphorus on two farms of one hundred acres each, one of which is a dairy farm and the other a grain farm. On the first, on account of the importation of phosphorus in feed the net annual loss is only 30 pounds of phosphoric oxide; whereas in the case of the grain farm the loss is 615 pounds.

Phosphorus and number of crops.
Grain sold takes phosphorus.
Dairy and grain farming compared. 
This shows the great advantage of dairy farming over grain farming. Whitson and Stoddart have also prepared a phosphorus balance sheet for the state of Wisconsin, ${ }^{1}$ the only estimate of this kind of which I have knowledge. The loss of phosphorus from products leaving the state, and the amounts which come in through importation of bran, are given, with a net loss of $15,000,000$ pounds per annum of phosphoric oxide, as shown by the following table:-

\section{Amount of Phosphoric Acid Annually Lost from Wisconsin Farms}

I. Sold from farm annually:

Prompronso
Oxide Pound:

1. 150,000 hogs

2. 250,000 neat cattle

3. Milk and cheese from $1,200,000$ cows $2,000,000$

4. $15,000,000$ bu. oats

Loss in handling manure

Total loss through sales

$5,000,000$

$5,000,000$

$3,000,000$

$10,000,000$

$25,000,000$

II. Returned to farm:

150,000 tons of bran and other feed stuffs . . . . 10,000,000

Net loss to the farms . . . . . . . . $\overline{15,000,000}$

Value at five cents per pound . . . . . . $\$ \mathbf{\$ 7 5 0 , 0 0 0}$

If similar studies were made for other states, doubtless similar results would be reached. All would certainly show a loss, although the amount of the loss would be smaller for some states and larger for others; but it is believed that when such studies are made most states will be found to have suffered a greater loss than Wisconsin; for the latter is a dairy state which imports large quantities of phosphate carrying bran from the mills of Minneapolis.

Phosphorus lost in sewage.

The question now arises as to what becomes of the phosphorus sent from the farms. The farm products from the country go to the cities of the United States or are exported.

Some part of the phosphorus sent to the city is returned to the country through the manure derived from these

1 "The Conservation of Phosphates on Wisconsin Farms," by $\mathbf{A}$. $\mathbf{R}$. Whitson and C. W. Stoddart, Univ, of Wis. Ag. Exp. Station, Bull. No. 174, April, 1909, pp. 1-8. 
centers and through the fertilizers made by the packing and other industries; but much the larger portion goes into the sewage. The sewage systems of the cities are a modern invention. In this country the sewage of the great majority of the cities is run into the rivers or into lakes, and is carried by the waters to the sea. Whitson estimates that the loss in the cities due to human excreta alone is the equivalent to two or three pounds of phosphoric oxide per acre for the entire cropped region of the United States. Supposing this loss to be two pounds, one one thousandth of a ton, this amounts for $400,000,000$ acres of cropped land to 400,000 tons of phosphoric oxide - equivalent to $1,200,000$ tons of phosphate rock.

A considerable portion of the phosphorus sent from the farms goes out of the country with the exports, and especially exports of grain. In 1908 there were exported 100,371,057 bushels of wheat, $52,445,800$ bushels of corn, 4,349,078 bushels of barley, and smaller quantities of other grains. ${ }^{1}$

According to Snyder each bushel of wheat contains .625 of a pound of phosphoric oxide, corn .277 , and barley .375. This means that the wheat exported carried away with it 31,366 tons of phosphoric oxide, the corn 7264 tons, and the barley 815 tons, making a total of 39,455 tons. It is safe to conclude that exports of other grains, of meat, of dairy products, etc., increase the amount of phosphoric oxide exported in food products to not less than 50,000 tons. This, the equivalent to 150,000 tons of high grade phosphate rock, is a conservative estimate of the annual loss to the country of phosphorus through exportation of food products.

While in the past we have been a great food exporting nation, compared with our total products, exports are decreasing. The two chief grains exported are wheat and corn. The average amount of wheat, including that transformed 'to flour, exported per annum during the five years from 1889 to 1903 , inclusive, was $212,476,674$ bushels; the average for the five-year period 1904 to 1908, was 114,438,725 bushels, or only a little more than half as much. The average export

1 Year Book of the Department of Agriculture, Washington, 1908. 
Phosphorus lost by leaching. of corn for the fifteen years before 1896 was somewhat more than 50,000,000 bushels. For the three years from 1896 to 1898 the average amount of corn exported was $163,991,112$ bushels; for the five years 1899 to 1903, 135,290,376 bushels; and for the five years from 1904 to 1908, 81,968,293 bushels; and for the last year of this period only $55,063,860$, or about the same as before the great corn exporting epoch began. It is certain that in the not distant future our own people will need all the food we produce. Hill says that in a few years, he thinks ten, ${ }^{1}$ we shall need all the wheat we raise. When the time comes that we keep in this country the products of the lands, loss of phosphorus through the exportation of farm products will cease.

2. There is a loss of phosphorus to the soil in agricultural operations beyond the amount abstracted by the crops sold from the farm. Whitson determined this amount in the fields of Wisconsin cropped for fifty years at 301 pounds of phosphoric oxide in that time, or 10 per cent of the total amount in the soil; and 30 per cent as much as was taken away by the crops. Put another way, somewhat less than 80 per cent of the total loss was in the crop and somewhat more than 20 per cent unaccounted for. This unaccountedfor phosphorus doubtless represents the loss due to leaching and erosion.

The calculations given, p. 323 , that the soil contains a sufficient amount of phosphorus for from 160 to 250 crops does not take into account the loss of phosphorus in excess of that removed by the crop. The loss due to both these causes in fifty years Whitson finds to be 1255 pounds of phosphoric oxide, or somewhat more than 40 per cent of the total amount. Using these figures as the basis of calculation, there would be a sufficient amount of phosphorus in the soil to supply losses both by cropping and by leaching for 120 years. $^{2}$

Certain crops are especially extravagant in phosphorus.

1 Address delivered by James J. Hill at the 35th Annual Convention of the American Bankers Association, Chicago, Sept. 14, 1909.

2 "Factors influencing Phosphate Content of Soils," by A. R. Whitson and S. W. Stoddart, Univ. Ag. Exp. Station, Research Bull. No. 2, June, 1909. 
Such crops are illustrated by tobacco, which, when raised continuously on soil which is heavily manured, results in enormous losses in this element. Whitson finds that the loss in tobacco farming, in addition to the amount extracted by the crop itself, is twelve times as great as that with grain. In sixteen fields, which have been cropped upon the average with tobacco, thirty years and with other crops sixteen years, the amount of phosphorus lost was equal to that originally present in the soil. It is clear that in considering the profit of a crop like tobacco which results in extreme loss of phosphorus by leaching and washing, this factor should be considered. From the point of view of the future of the race, whatever the current profit, it is a most extravagant crop. Cotton is another extravagant crop so far as phosphorus is concerned.

3. There is a great loss of phosphorus from the wash of manure at stables and barnyards. Up to the present time the farmers of this country have not thought of manure as an especially valuable asset. They handle it as a material a part of which it is advantageous to get back upon the soil at some convenient time; but it has never been regarded as a necessity to save all of the manure produced by the animals, both liquid and solid. It is estimated that about one third of the value of the manure under present methods is lost. This causes probably the largest single loss of phosphorus. There is no way to estimate it accurately, but it is safe to say that it amounts to an' equivalent each year of a million, perhaps millions, of tons of high grade phosphate rock.

\section{Sources of Phosphorus}

James J. Hill, in his White House address, said: "Put fertilizers on the soil; they act as tonics." This is easy to say, but the statement raises the question in the case of phosphorus as to the source of this material.

It is one of the great laws of nature that under favorable conditions the forces and agents of rock-alternation tend to 
Segregation segregate locally each of the elements. To such processes of phosphorus.

Phosphorus in the guano.

of segregation are due the available metallic ores, since the average amounts of the valuable materials in the rocks are far below those in the workable ore deposits.

The segregative processes of nature have fortunately concentrated phosphorus in various ways, and these deposits are the chief source of supply of our phosphates.

The earliest phosphatic fertilizer to be used was guano, mainly derived from the islands off the western coast of South America. If the segregation of phosphorus in guano were fully described, it would be appreciated how slow and intricate is the process of concentration of a rare element. The story would involve, first, the solution of the widely disseminated phosphorus from the original rocks, its segregation through complex processes in the small plants and animals that become the food of fishes, which in turn become the food of sea birds. The dry excrement of the sea bird constitutes the guano. Much of the guano contains 25 per cent to 40 per cent of phosphoric oxide. Thus, nature's processes of segregation have multiplied the amount of phosphorus in the original rock from a hundred to more than a hundred and fifty fold.

Long before man existed on the earth the ancient segregation of birds and other animals, formed on an extensive scale, were buried among the sediment and have been partially preserved in the rocks. These deposits constitute the chief source of our mineral phosphates.

Phosphate rock in the South.

In the United States are deposits of rock phosphate both in the eastern and western parts. In the East the chief deposits are in South Carolina, Florida, and Tennessee; there are also phosphate deposits of considerable extent in Arkansas. These, however, are of low grade and probably will not be available until material can be marketed which contains as little as 30 to 50 per cent of calcium phosphate.

Van Horn gives the following estimate of the amount of high grade mineral phosphate in the Southern states in 1907:- 


\section{Table showing Estimate of High Grade Phosphate Rock}

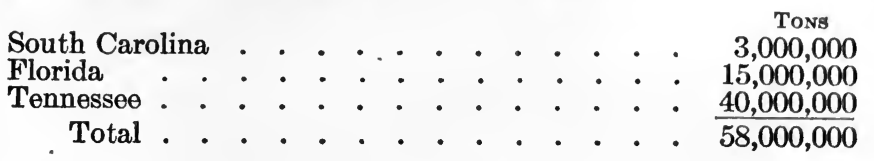

From the three Southern states all of the phosphate rock Life of which is now mined is derived. In 1908 the production of the mines was 2,661,459 tons of high grade phosphate rock. Southern phosphates. The increase in production has been rapid, and it is estimated by Van Horn that if this rate continues in the future as it has in the past that the amount mined would be some $17,000,000$ tons by 1932 . We, of course, are not sure that this rapid rate of increase will continue; and, therefore, it is somewhat uncertain as to how long in the future the high grade rock of the South will last, but an estimate from twenty-five to fifty years would be rather sanguine than otherwise; for with no increase the latter period would exhaust the estimated supply.

It is to be remembered, however, that there are undetermined quantities of lower grade rock, and the amount is Low grade phọsphate. known to be very large. It is certain that this material will be drawn on in the future. Of the amount of the low grade material we cannot give even an approximate estimate. At the present time only material is being mined which contains from 60 to 80 per cent of calcium phosphate. It is certain that in the future we shall be obliged to use material which contains not more than 50 per cent of calcium phosphate and probably ultimately material which contains 25 per cent or less. With reference to the future the large reserves of low grade rock are more important than the extremely limited supply of high grade material.

Notwithstanding this situation and the certainty that the high grade rock of the eastern part of the country will be available only for a short time, and that the low grade Exportation of phosphates. material will be wholly inadequate to meet the future needs of a nation, in 1908 we exported 1,188,411 tons of phosphate rock, or 45 per cent of the output of the mines. And since 


\section{CONSERVATION OF NATURAL RESOURCES}

the rock which is exported is of the highest grade, at least one half of the phosphorus mined in 1908 went abroad to restore to fertility the depleted fields of France, Spain, Germany, and England.

In 1908 it was announced that there had been formed the Franco-American Consolidated Phosphate Company, with a capital of several million dollars. At the time of the announcement this company had acquired over 16,375 acres of the best available land of Tennessee, and had secured options on 10,000 more. They have made plans to mine and ship phosphate rock on a large scale. It is therefore probable that, if no legislation occurs in reference to this matter, the percentage of the material which is shipped abroad will rise beyond 50 per cent.

Western phosphate deposits.

The western phosphate fields are the greatest of those in America. In reference to this region, Van Horn says: ${ }^{1}$ "The phosphate occurs over a considerable area in southeastern Idaho, southwestern Wyoming, and northeastern Utah. It is found in rocks of Upper Carboniferous age in a series of shales and limestones, 100 feet thick, within which are several beds of phosphate rock ranging in thickness from a few inches to 10 feet. At the base of the series is a limestone, and 6 to 8 inches of soft brown shale separates this from the principal phosphate bed, which is 5 to 6 feet thick. This phosphate bed is oolitic in character and high in phosphoric acid. There are in the series several other beds ranging from a few inches to 10 feet in thickness, and separated by thin beds of limestone or shale. Usually one and sometimes two of these beds at a given section are workable, and probably some of the others will eventually be mined. The lime phosphate content in the workable beds varies from 65 to 80 per cent, with an average of 72 per cent."

Blackwelder gives a more detailed description of that portion of the western deposits which are in Weber and Ogden valleys, Utah. He says, " the phosphate rock occurs in continuous, relatively uniform beds alternating with limestone

1 "Phosphate Rock," by F. B. Van Horn, Mineral Resources of the United States, Part II, Non-Metallic Products, 1908, U.S. Geol. Survey, p. 637. 
and shale. They are exposed in mountains of 2000 to 3000 feet relief and the beds are generally inclined 20 degrees to 50 degrees, being vertical locally. They are but little faulted, but are largely concealed by tertiary deposits. One outcrop has been traced with interruptions for fifteen miles, another for about six miles, and extensions can be inferred with some 'confidence for a length of twenty-five to thirty miles. There are generally two rich beds, each averaging eight feet thick. The rock is black and generally oolitic in structure. It consists of minute nodules of phosphatic material embedded in a cement which is largely calcite. There are all gradations from nearly pure phosphorite to pure limestone." Blackwelder estimates, on the basis of a workable depth of 3000 feet and an average thickness of ten feet, that there is in this district about 200,000,000 tons of high grade phosphate rock.

Hoyt F. Gale has made an estimate of the phosphate rock in a number of areas examined by his party. On the basis of a single five-foot bed and including only material averaging 70 per cent of tricalcium phosphate, this is as follows:-

Table showing Estimates of Phosphate Rock by Gale

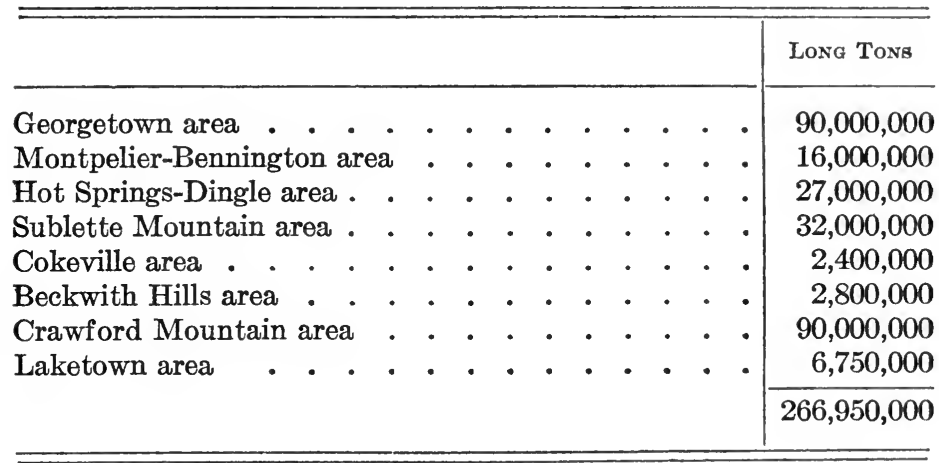

Putting Blackwelder's and Gale's results together we have $466,950,000$ tons. It thus appears that there is in the western phosphate fields nearly a half billion tons of high grade phosphate rock, which is practically in sight. There is little 


\section{CONSERVATION OF NATURAL RESOURCES}

Western phosphate deposits greatest known.

Phosphate - in iron ores.

Phosphate in bones.

Phosphate deposits of foreign countries.

doubt that more detailed work will largely increase this amount. In the above estimate Gale did not make any attempt to include the amount of high grade phosphate rock available in the thinner beds, nor was any estimate made by either Blackwelder or Gale of the low grade material. It thus appears that the amount of phosphate rock in the West is immeasurably greater than all other known supplies of phosphate rock in the world. They represent aside from coal and iron the most precious mineral heritage of the nation.

In addition to the deposits of phosphate rock considered there is a small percentage of phosphorus in certain iron ores. This is segregated in the blast furnace slags, or the iron ores are concentrated before smelting, and in the process the phosphates are separated. The phosphate slags are mainly from the Clinton ores and the concentrates from the Adirondack ores. The amount of available phosphate from this source is not large, and, therefore, cannot be depended upon as an important source of supply.

Another source of phosphate is that material in the bones of domestic animals. So far as such animals are killed in great abattoirs, the bones are used in connection with other by-products and go to the farmers as fertilizers, and thus a certain portion of the phosphate is returned to the soil.

The only other possible source for phosphates is importations from other countries. In the past there has been imported into this country considerable amounts of guano, for instance, 30,000 tons in 1907; but in 1908 the importation of guano fell to 5728 tons. The largest known deposits of foreign phosphate, according to Van Horn, are the three South Sea Islands, - Ocean, Pleasant, and Makatea, - which are estimated to contain $60,000,000$ tons of high grade rock. In Quebec in the old crystalline rocks there is phosphate in the form of apatite, but apparently the amount of high grade material is extremely limited. Whether there may be large quantities of low grade rock has not been determined. Deposits of phosphate rock are known also in other countries. However, none of the foreign phosphates can be looked to as a permanent source of supply for the United States. In 
the future, all such phosphates will be required by the countries in which they occur, or in the countries which control them. Indeed, the total production of phosphate in all other countries, in 1907, did not equal either in quantity or value the amount produced in the United States.

According to Shaler, the Indians on the west coast of South America, before the appearance of the Spaniards more than four hundred years ago, knew of the value of guano as a fertilizer. ${ }^{1}$

In reference to guano, Garcilaso de la Vega, ${ }^{2}$ in the sixteenth century, gave "a very interesting account of the manner in which the birds producing the guano were protected by the laws of the Incas of Peru, by which it was made a crime, punishable by death, to kill the sea fowl, to gather their eggs, or even to visit the islands during the breeding season."

A recent report by Robert Coker ${ }^{3}$ to the government of Peru on the future of the guano industry and the guanoproducing birds, tells of "the robbery of eggs on a large Killing the phosphateproducing scale in past years, the destruction of young and old birds, and the disturbance of the birds in their nesting grounds by the extraction of guano." He says an inevitable result "has been a great diminution in number." Mr. Coker's report pleads for regulations to increase the number of birds, and thus to perpetually maintain a large supply of guano. With reference to the most precious of the fertilizers, this twentieth century presents an ignominious and startling contrast with an ancient civilization. In considering the ill-treatment of the guano-producing birds, it is difficult for one to retain composure and speak with moderation of the odious combination of human greed and brutality exhibited by this case of exploitation of a natural resource, in complete ignorance and absolute disregard of its effect on the future of our race. The phrase "killing the goose that laid the golden egg" was never more applicable. We frequently contrast with pride our progressive age with the past!

1 "Man and the Earth," by N. S. Shaler, pp. 132-133.

2 "Johnson's Universal Encyclopedia," Vol. IV, p. 52.

3 Science, July 10, 1908, p. 60. 
It is clear that looking to the future we cannot expect that phosphate from other countries, either in the form of rock or guano, will furnish a supply of material for us.

Amount of phosphate needed. :

\section{Remedies for Phosphorus Depletion}

What are the remedies for the depletion of the soil in phosphorus, for remedies must be introduced if the soil is to meet the needs of our people for hundreds of thousands of years to come? But before we answer this question it will be well to consider the total extent of depletion at the present time in order that we may appreciate the seriousness of the problem.

Whitson's investigations show the loss of phosphoric oxide in the fields tested in Wisconsin to be annually about twenty pounds per acre. To be conservative, let us suppose that the average loss for the United States is but half of this amount. For $400,000,000$ acres, less than the total of the cropped lands, this would represent an annual loss of $2,000,000$ tons of phosphoric oxide; but since the phosphate mined is only about one third phosphoric oxide, to supply this amount would require $6,000,000$ tons of rock, or more than twice the entire amount mined and four times the amount retained in the country.

If we suppose the accumulated loss of phosphorus from the soils of the United States due to cropping is one half that found by Whitson in the fields tested in Wisconsin (and this estimate is far too conservative), the amount would be a quarter of a ton per acre, and for $400,000,000$ acres $100,000,000$ tons of phosphoric oxide, which is the equivalent of $300,000,000$ tons of phosphate rock. Thus, to make good the phosphorus already lost to the soil in the United States by reckless disregard of the future would require the present output of our mines for more than a century; even if at once it were possible to prevent further depletion of the soil, and no more of our phosphate rock were required to neutralize the current waste. 
In view of the situation, what shall be done?

(1) The waste in mining must cease. At the present time, in the mining of the deposits of Florida, Tennessee, and South Carolina, little attention is paid to anything that is Waste in mining phosphate. below 65 per cent of calcium phosphate. Great quantities of the lower grade material have been disregarded, and have been handled in such a way as to make it extremely difficult in the future to recover the product. For instance, in Tennessee, according to Van Horn, "in order to get the largest quantity of high-grade rock necessary for the exporting trade, 50 per cent rock in large quantities is thrown on the dump waste." 1

It is clear that with reference to the future we must regard the low-grade rock as an important asset of the nation; and, therefore, laws should be passed in those states in which phosphate rock occurs, which will regulate the mining of this material, which will require that the high grade material be handled in such a manner as to make low grade material available later.

(2) All the phosphate lands of the public domain should be retained by the government and exportation prohibited. The importance of this subject was brought to the attention of President Roosevelt and of Secretary Garfield in the summer and autumn of 1908. In December 9, of that year, the entire western field of phosphate rock so far as known (see p. 10), 4,702,520 acres, was withdrawn from private entry. As a result of later examinations of the Geological Survey, withdrawals of landis containing phosphate to the amount of 399,963 acres have been made under President Taft's administration; and large areas of land first withdrawn, not containing phosphate, have been released, leaving withdrawn, March 4, 1910, all unpatented lands within an area of 2,504,003 acres.

The Secretary of the Interior, with the approval of President Taft, has presented a bill to Congress under which phosphate lands of the public domain are to be retained by the government. It is proposed that these lands be leased

Future value of low-grade phosphate rock.

Phosphate lands of public domain withdrawn.

Proposed law controlling phosphate lands. 
in parcels of not more than 640 acres to any one individual for a period not to exceed thirty years, with a possibility of extension by periods of ten years. The lessee is to pay a royalty not to exceed 10 per cent of the value of the output at point of production, with small ground rental increasing to $\$ 1$ an acre after the fourth year, - this rental, however, to apply upon the royalties. The leases are to contain clauses as to the maximum price which may be charged for the phosphate rock, and the exportation of the rock from this country is prohibited. The leases when given should also rigidly prescribe methods of mining which will prevent waste and make available at a future time the lower grade products. If this bill becomes a law, the phosphate lands of the West with their enormous deposits will remain permanently the property of the nation; not only so, but since prices are controlled it would be assured that this material so essential to the agricultural interests may be secured by the farmers at reasonable prices.

Prohibition of phosphate exportation.

(3) Exportation of the phosphates from the privately owned lands of Tennessee, South Carolina, and Florida should be prohibited. The clause of the constitution which authorizes Congress to regulate interstate commerce gives ample power to prevent the exportation of phosphates, if this be required by the general welfare of the nation. But the question may be raised as to why it is important to prohibit exportation of the phosphate rock of the South, if the deposits of the West are of such great magnitude. The immediate importance of this lies in the factor of transportation. The present market price of the high grade southern phosphates at the mine is less than $\$ 5$ a ton. The deposits of Florida and South Carolina are close by the depleted fields of the southeastern region. The deposits of Tennessee are available for the upper Mississippi Valley. To transport the phosphates of Idaho, Wyoming, and Utah to the eastern humid regions would involve an average rail haul of not less than 1500 miles, and the cost of this even at an extremely low rate of one half a cent a ton a mile, which is less than any rate now given, would be $\$ 7.50$ a ton for the freight alone. It is clear 
that the people of the United States cannot afford to allow their eastern phosphate rock to be shipped abroad.

(4) The great loss of phosphate in farm manure must cease. A large proportion of the phosphate used by the animal as food passes into the manure. At the present time the agricultural population of this country is not educated upon this subject, and in consequence it is estimated that practically one third of the phosphate of manure is allowed to wash into the streams and thence into the sea. It is impossible to make any accurate estimate of the loss of phosphorus in this way, but probably it is the largest single loss of that element. Many other countries are far ahead of America in this respect. It is realized by the farmers that manure should not be allowed to wash away; all is carefully saved and returned to the land, so that the losses are comparatively small. This is especially true of the densely populated countries which have been cropped for centuries, perhaps in some cases for thousands of years, as with China and Japan.

(5) There must be reforms in the methods of sewage disposal. In the table given on p. 324 it has been seen how important are the contributions of phosphorus which go to the cities in the form of meat, milk, cheese, and grain. Under our present methods of sewage disposal, much the larger part of this phosphorus goes directly or indirectly to the sea. It is estimated by Whitson that the loss of phosphorus in city sewage is the equivalent of at least 1,200,000 tons of high grade phosphate rock; or, in other words, nearly one half of the output of the mines in 1908. And since about one half of the phosphate mined is shipped abroad, the loss by sewage alone approaches the amount added to the land through the mined product.

In this country there has been as yet practically no attempt to return the human excrement to the soil. This is true of both country and city. In the country the use of human excrement for a fertilizer is comparatively easy; but to get - the farmer to do this is difficult. In reference to the city it has been held that in this country it is impracticable to use

Reduction of phosphate loss through manure. Reduction of phosphate loss by sewage.

Loss of fertilizer produced by man. 


\section{CONSERVATION OF NATURAL RESOURCES}

sewage for fertilizer. The answer is, it is being done in other countries. The phosphorus of sewage can be saved either by direct use of the sewage or the separation of the phosphorus by some method to be developed. It is certain that one of these must be done, if in the future we are to conserve the fertility of the soil.

\section{General Statements}

China and Japan.

Agriculture and loss of phosphates.

Repeated use of phosphorus.
The wide dispersal of vast quantities of phosphorus, which it took the processes of nature an indefinite period to segregate, must cease so far as possible. The loss is irreparable. In this matter we may well turn to Japan and China for guidance. The evidence is clear that the people of these ancient nations, which have had a dense population for many centuries and have preserved the fertility of their soils, have carefully saved and utilized all the fertilizers produced. Not only so, but in Japan the depletion of the soil in phosphorus is prevented by using large quantities of fish and especially herring as fertilizers.

Even at the best it is difficult to see how agriculture can be carried on without loss of phosphorus. If no manure were lost, the sewage were saved, and no phosphate-bearing products sent from the farm, there would still be the loss which results from increased leaching and wash due to agriculture. This, as has been seen in the case of the lands of Wisconsin cropped for fifty years, amounts to 10 per cent of the total in the soil. By improved methods of farming this loss may be reduced, but it cannot be altogether prevented.

The situation with reference to phosphorus is dwelt upon because it is the crucial element in soil fertility. If we retain the phosphorus of the soil, it can be used again and again through the indefinite future like a circulating medium. An ounce of gold made into a coin may be used a thousand times, or may be kept in the vault and used as the basis of a gold certificate through thousands of years. Similarly this element phosphorus, incomparably of greater importance to us than all of our gold and silver and copper and lead and zinc, 
must be retained as a resource of this nation. We could far more wisely export our output of the precious metals with the certainty that it would not be returned to us than we can our phosphate rock. We could, if we must, get along without gold, or silver, or lead, or copper, or zinc. We cannot get along without food. The problem of the conservation of our phosphates therefore is the most crucial, the most important, the most far-reaching with reference to the future of this nation, of any of the problems of conservation.

\section{DAMAGE TO FARM PRODUCTS}

The next of the subjects to be considered is the damages which befall farm products. It is, however, a subject which can no more than be considered in briefest form; for to treat adequately any one phase of it would require a monograph.

\section{NOXIOUS INSECTS AND MAMMALS}

The first of the damages to be considered are those due to noxious insects and mammals. The noxious insects and Losses from insects. worms are very numerous. Corn is subject to the corn rootworm, bollworm, chinch bug, and many minor pests. Wheat suffers mainly from the chinch bug, the Hessian fly, the grain plant louse; and many other insects commit less important depredations. Cotton is chiefly subject to the ravages of the cotton boll weevil, the bollworm, and the leafworm. Each of these major pests on the great standard crops produce annual losses from $\$ 10,000,000$ to $\$ 40,000,000$.

Fruits are attacked by the codling moth, San José scale, peach tree borers, grape phylloxera. Marlatt estimates that Losses to in 1907 the losses due to these various worms and insects was more than $\$ 650,000,000 .{ }^{1}$ There is no question that a very large portion of this loss can be remedied. Those who have studied horticulture know that fruit trees should be sprayed with mixtures poisonous to the insect pests. The enemies of

1 "Losses due to Insects," by C. L. Marlatt, Nat. Con. Com., Vol. III, pp. 301-309. 
The chinch bug and wheat.

the insects and worms should be encouraged to multiply. By rotation of crops any one objectionable form is less likely to gain foothold than if the same crop be raised continuously. This is very well illustrated in the early days of wheat raising in the upper Mississippi Valley. When wheat was made the money crop year after year, the chinch bug became increasingly destructive until such ravages were made that wheat culture for extensive areas was no longer profitable. In this particular case what seemed to be a great disaster was really a benefit; because the pressure of the chinch bug was one of the chicf causes which led to diversified farming and rotation of crops in the Middle West.

\section{LOSSES DUE TO MAMMALS}

The losses due to the growing crops caused by mammals are also great. The destructive mammals include rabbits, prairie dogs, gophers, field mice, and others. Merriam estimates that in 1907 the losses due to rodents of various kinds and other burrowing animals was nearly $\$ 100,000,000$. Already a great campaign is being carried on in the West to eliminate the prairie dog and to reduce the numbers of the jack rabbit. The reduction of the numbers of the smaller of these animals, for instance the mice, is frequently very greatly promoted by the encouragement of carnivorous birds. It is difficult to make an estimate as to the amount that the losses due to mammals may be lessened, but it is certain that they may be made a small fraction of the present amount.

\section{PLANT DISEAses}

Grain rust. It is wholly impossible to make any estimate of the losses which the agricultural crops of the country suffer from plant diseases, but it is known that for the country as a whole the losses amount to hundreds of millions of dollars per annum. Such diseases as wheat rust and oat and barley smut give simply enormous losses every year. In the case of smut on oats in Wisconsin, a few years ago, R. A. Moore estimated 
the annual loss at $\$ 4,500,000 .^{1}$ The smut of oats and barley Smut on is especially mentioned since it has been discovered that by grain. the soaking of the seed grain in a formaldehyde solution, so that it is sterilized, the spores which produce the smut are killed. The problem is solved. It is only necessary to put into practice the knowledge available. The situation is very different with rust; as yet little progress has been made in its control. This disease is the cause of the greatest of the single losses to grain.

\section{NOXIOUS WEEDS}

Closely allied to plant diseases are noxious weeds. According to $\mathrm{McGee},{ }^{2}$ weeds are useless, in that they contribute nothing to human welfare, are injurious in that they consume water and plant food, are noxious in that they choke useful plants, and are malignant because by better constitution and greater persistency they dispossess the ordinary cultivated plants.

Some of the worst of the weeds for the northern part of the United States are, quack grass, Canada thistle, sow thistle, star thistle, English plantain, oxeye daisy, toad flax, dodder, velvet leaf, wild artichoke, amprosia, fox tail, and wild sunflower. In other parts of the country, some of these weeds are present and also others. One who has travelled widely over the United States cannot but be impressed with the extent to which weeds occupy the land. For instance, in the upland pastures of New England frequently half of the ground is occupied by weeds, among which Canada thistle is especially The land occupied by weeds. conspicuous. Throughout the fields of the northeastern part of the United States one may see abundantly wild mustard which very greatly decreases the yield of the grains. Not only are the fields widely overrun with the weeds, but for extensive parts of the country the public highways are even to a greater extent infested with them, and thus serve as lanes to distribute seeds to the adjacent fields.

1 "Oat Smut and its Prevention," University of Wisconsin Agr. Exp. Station, Bull. 111, 1904.

2 "Soil Erosion,". by_W J McGee. 


\section{CONSERVATION OF NATURAL RESOURCES}

Eradication of weeds.
By proper cultivation and other remedial measures noxious weeds may be eradicated, or at least greatly reduced in amount. Work by Moore and Stone ${ }^{1}$ shows that the wild mustard can be destroyed by spraying with iron sulphate, and that such spraying also acts as a powerful deterrent for cockleburr, ragweed, dandelion, daisy, wild lettuce, and various other common farm weeds. To destroy Canada thistle, proper rotation of crops seems the best method. As yet no quantitative estimates have been published as to the decrease in the efficiency of the fields because of weeds, but when such investigations are made it is certain that for extensive areas of the country it will be shown that the efficiency is very greatly decreased.

If the preventable money loss due to noxious weeds were known, without taking into account the ordinary farm weeds which appear in connection with cultivation and must each year be destroyed, the total would be enormous - certainly reaching many millions of dollars per annum.

\section{DISEASES OF LIVE STOCK}

The next of the losses to be considered are due to diseases of live stock. The diseases of live stock are, like those of human beings, of many kinds, and I shall mention only a halfdozen. Hog cholera, southern cattle tick, scabies of sheep and eattle, tuberculosis and anthrax, insect pests of various kinds, it is estimated, led to losses in 1907 amounting to $\$ 267,000,000$. These diseases are the subject of continued study by the United States Department of Agriculture and by the various state experiment stations. Much progress has been made in recent years in the reduction of the losses due to these diseases. For instance, at the present time vaccination is successfully practiced for hog cholera and Advance in anthrax. The former disease used to result in very great decontrol of animal diseases. struction, and no way was known to prevent its ravage, but it is now largely under control. In the same way anthrax,

1 "The Eradication of Farm Weeds," by R. A. Moore and A. L. Stonc, Univ. of Wisconsin Agr. Exp. Station, Bulletin 179, 1809. 
which used to be the cause of the destruction of entire herds, is now handled promptly; and whenever an outbreak of the disease occurs the animals are quarantined and the disease controlled, so that now for the greater part of the country its appearance is sporadic.

The most widespread of the diseases among animals, the one which occasions the greatest loss, is that of tuberculosis, and especially tuberculosis of cattle. However, in this matter Tuberculosis of cattle. great progress has been made. A method of testing animals by tuberculin has been discovered which will determine whether or not an animal has the disease. This was the first essential step in controlling it; for when once this determination could be made it became possible for a man to be certain that his own herd was free from the disease, and it was possible for him to put only animals into his herd which had been tested and thus keep it free from taint. Many states already have laws requiring imported animals to be proved to be free from tuberculosis by testing. In order to confine the infection to the herds in which it exists, we need only to have a law requiring that any animal which passes from one herd to another shall successfully pass the test for tuberculosis. The problem of eradication of tuberculosis will therefore be reduced to handling the tainted herds. There is little question that in a number of states, in the elimination of this disease among cattle, we are further advanced than we are in its elimination among men. It is probable that within the next score of years the ravages of bovine tuberculosis will in the more progressive states be practically limited to isolated localities.

Already many cities have adopted ordinances which require that only milk may be sold which comes from animals free from Milk regulations. tuberculosis. When all of the cities of the country have ordinances of this kind, it will be almost necessary for men who are prominently connected with the dairy industry to have their herds free from infection.

It is admittedly easier to handle diseases of animals than it is to handle diseases of man; and doubtless we shall free animals from contagious and infectious diseases to a much 
Animal diseases relatively easy to control.
Excess of water excludes air.

larger extent than we shall man within the next ten or fifteen years. It will not be more than fifty years, I venture to say, when all the diseases mentioned are practically extirpated from all the progressive states so far as animals are concerned. Unfortunately, this statement cannot be made with the same certainty with reference to man. You can readily see that the problem is much more difficult in the latter case, because we cannot handle human beings in the same ruthless way that we do infected animals.

\section{RECLAMATION OF WET LANDS !}

The area of the arable land may be extended in two ways: lands deficient in water may be irrigated; lands having an excess of water may be drained. The first of these, because so vitally connected with water, has been treated in connection with that subject (see pp. 185-207); and therefore I shall at once pass to the lands having an excess of water.'

The area of the swamp and marsh lands of the United States, according to the Department of Agriculture, is 79,005,023 acres, probably 4 per cent of the territory of the country. It has already been shown how important is the irrigation of the arid land; and it has been said that in the future we might possibly reclaim as much as $45,000,000$ acres. The problem with the wet lands is just the opposite of that with reference to the arid lands. In the arid lands the difficulty was the deficiency of water; in swamp and marsh land the trouble is an excess of water. Where water is in excess it may occupy all of the pore spaces between the particles of soil and thus exclude the air except that dissolved in the water. It has already been pointed out that for plant growth both water and air are necessary. The amount of air which is available under conditions of water saturation is too small for ordinary plants. Only the exceptional ones, adapted to the peculiar conditions of deficiency of air, will grow.

The above figures show that the area of swamp and marsh

1 " Swamp and Overflowed Lands," by Robert Follansbee and A. C. True, Report National Conservation Commission, Vol. III, pp. 361-374. 
land is nearly double the area of the reclaimable arid land. State Under laws passed in 1849 and 1850, the United States government granted the swamp lands to the states. Under this grant there was patented to the states to June 30, 1909, $66,554,804$ acres. This land is so located in many states but occurs especially in those which have tidewaters, deltas, or are in the glacial regions.

The southern Atlantic slope and the Gulf states all contain important areas of swamp either tidewater or delta, from Virginia to Texas. Of these Florida (18,560,000 acres), Mississippi (6,173,000 acres), Louisiana (9,600,000 acres), and Arkansas (5,760,000 acres) contain vast areas; and North Carolina, South Carolina, Alabama, Georgia, and Texas each contain more than from $1,000,000$ to $2,400,000$ acres each. We all know of the Great Dismal Swamp of North Carolina and Virginia and the Everglades of Florida. We all have heard of the delta swamps of Mississippi, Louisiana, and Arkansas.

The third great area of swamp lands is that covered by the glacial deposits, and especially the glacial deposits of the WisGlacial swamps. consin stage. The four states in which these are the most extensive are Michigan (4,400,000 acres), Illinois $(2,688,000$ acres), Minnesota (4,500,000 acres), and Wisconsin (2,500,000 acres). Other states containing $1,000,000$ or more acres of swamp land are California, Indiana, and Missouri.

The total area of the swamp lands of the United States is equal to that of the United Kingdom (England, Scotland, Ireland, and Wales); or, putting it another way, the total area of this land is equal to that of the three states of Ohio, Indiana, and Illinois.

While these great areas of swamp lands passed by the United States government to the states as a gift without cost to the state, they have been largely disposed of, so that at the present time probably 95 per cent of them are in private hands. There are a few states that still own considerable holdings of swamp lands. Among these are Florida with 2,640,000 acres and Minnesota with 2,500,000 acres.

Practically all of this swamp land can be reclaimed. The swamp lands.

Tidewater and delta swamps. 


\section{CONSERVATION OF NATURAL RESOURCES}

Swamps may be reclaimed.

Wet lands of Holland.

cost of such reclamation varies greatly, depending upon the processes which are required. In many cases it is only necessary to cut ditches and straighten out streams, and thus by surface work drain them. In such cases the cost per acre is usually not to exceed $\$ 4$ or $\$ 5$. In other cases the land must be tile-drained, and in such cases the cost runs from $\$ 6$ to $\$ 20$ an acre, and exceptionally, as with very heavy clay lands, even higher.

While much of the land may be reclaimed merely by ditches or tile drainage, or both, in other areas it will be necessary, in addition, to follow the Holland method of building dikes, and pumping over them the water brought by the ditches and tiles to central points. Two fifths of Holland lies not more than three feet above mean tide, or actually below sea level. These lands have a very high value. Experiments have shown the economic practicability of the Holland plan in this country. An area thus reclaimed at the University of Wisconsin at the present time is one of the best producing fields of the farm. In the near future there will be large extensions of the Holland method of draining.

\section{COÖPERATION IN DRAINAGE}

Coöperation in drainage.
It has been said that 95 per cent of the swamp lands are privately owned. This being the case and the drainage of a given tract requiring definite plans for the entire area, it is necessary that the different owners coöperate. This has been accomplished in many states by laws authorizing drainage districts. The laws vary in the different states. Illinois has passed a wise law which has been followed by several states. In that state, after organizing a drainage district an estimate is made as to necessary expenditure. Bonds are issued which are a mortgage upon the land, and these bonds are paid through a series of years (frequently 20 or 25) after the drainage is accomplished. In Wisconsin the cost of drainage may be paid for by the farmer at the time the improvement is made. 


\section{THE GAINS FROM DRAINAGE}

What gains may be expected by reclaiming wet lands?

In the first place there will be a great increase in the market value of the land. Wright ${ }^{1}$ estimates this increase as follows: He places the value of the land after having been drained at from $\$ 20$ an acre to $\$ 100$ an acre; and in some cases, when the lands are near cities, it may be even as high as $\$ 400$ or $\$ 500$. He thinks that $77,000,000$ acres may be drained, and when this is done that the land will have an average value of $\$ 60$ an acre, or $\$ 4,620,000,000$. The present average value of this land he places at $\$ 8$ an acre, and the average cost of the draining at $\$ 5$ an acre, making altogether $\$ 1,771,000,000$. Thus by drainage the increase in the value of the $77,000,000$ acres of land is $\$ 2,849,000,000$.

A closer estimate has been made in the case of Wisconsin by Whitson and Jones. ${ }^{2}$ In that state they estimate that there are 7,360,000 acres which should be drained. Of this one third is so wet as to be almost useless and two thirds gives no more than half an average crop. They estimate the cost of drainage at $\$ 66,750,000$, and the net gain above the cost of drainage at $\$ 114,000,000$.

Second, the lands before drainage are nearly worthless, being only available for marsh hay or grazing; after drainage they are available for valuable crops. The land drained and reclaimed will yield annually a crop varying in value from $\$ 10$ an acre to $\$ 100$ an acre or more, depending upon the location and the character of the crop. This becomes an additional source of wealth to the nation each year. If the yield were estimated at $\$ 10$ an acre only above its yield before drainage, on the $77,000,000$ acres reclaimable this would be an increase in the annual income to the people of the nation of $\$ 770,000,000$.

Third, by the drainage of wet lands the health of the community will be greatly improved. As you know, in the South

Increased yield from arainage. Drainage and health.

1 Swamp and Overflowed Land in the United States, by J. O. Wright, U. S. Dept. of Agr. Circular 76, 1907, p. 10.

2 Drainage Conditions in Wisconsin, by A. R. Whitson and E. R. Jones, University of Wisconsin Agr. Exp. Station, Bull. No. 146, 1907, p. 46. 
Drainage

and population.

and in certain parts of the East, malaria is severe and widespread. It is now known that malaria is transmitted from one human being to another through a certain genus of mosquito (anopheles). The reduction in the number of mosquitos, and especially the malarial mosquito, will be of inestimable importance to the nation in the matter of health. Howard estimates the loss due to malaria in the United States at not less than $\$ 100,000,000$ per annum.' When swamps and marshes are reclaimed this amount will be reduced to an insignificant sum. The prevention of this disease alone would more than justify the necessary expenditure.

Fourth, it is believed at a very moderate estimate that the drainage of the swamp and marsh lands of the country will furnish food for at least 10,000,000 people. Holland has a population of over $5,000,000$. The area of the land to be drained is ten times the entire area of Holland. Therefore in the future, if these lands are as densely populated as are those of Holland, they will maintain a population of 50,000,000. This, of course, will not be in the near future; but when the country is fully occupied, a century or two hence, it is certain that the number of people who occupy the lands that are now swamps and marshes will be of this order of magnitude.

\section{ADDITIONAL IMPROVEMENTS IN AGRICULTURE}

Looking toward the future, what additional improvements in agriculture may be reasonably expected beyond those already considered?

Yield of grain may be doubled.

First we may expect greatly increased yields of the crops by improving the seeds. In 1909 the yield per acre of corn in the United States was upon an average 25.5 bushels; the yield of wheat was 15.8; the yield of oats, 30.3 ; the yield of barley, 24.3; the yield of rye, 16.1; the yield of buckwheat, 20.9 ; and the yield of cotton, 156.6 pounds. There is no question whatever that by improving the seed used, and proper methods of farming, the yield of corn may be increased to

1 "Economic Loss of the People through Insects that Carry Disease," by L. O. Howard, Report National Conservation Commission, Vol. III, p. 756. 
more than 50 bushels per acre; the yield of wheat may be increased to at least 30 bushels per acre; and the yield of oats may be increased to 50 bushels an acre, as may also that of barley. The yield of cotton may be twice as great. In other words, it is certain that the yield of all these great standard crops may be doubled.

I shall give illustrations of this. In Alabama and Mississippi the amount of cotton raised on the demonstration farms is more than double that of the average planter, in the former state being in one case 428 pounds as compared with 169 pounds, and in the latter 445 as compared with 228. The average yield of rice in Arkansas in 1898 was forty bushels per acre, whereas the Experiment Station has made one acre yield 100 bushels.

In Kansas, Professor A. M. Ten Eyck of the department of agronomy has done a large amount of work in finding varieties of wheat adapted to that state and improving them in reference to Kansas conditions. The varieties used include wheats from Russia, Canada, and other countries. At the agricultural experiment station, of the better varieties of these wheats, there were produced in 1909 from 46 to 56 bushels per acre; and of ten varieties, each yielded more than 50 bushels per acre. ${ }^{2}$ This is about four times the average yield of the United States.

In Wisconsin the average yield of corn for the past five Yield in years, including the season of 1909, has been about 35 Wisconsin. bushels, whereas 600 men belonging to the Agricultural Experiment Association, scattered over the state, using improved seed furnished by the Experiment Station, have secured a yield of 59 bushels, or nearly twice as much. It is to be remembered that in this comparison, in the average yield of 35 bushels, are included not only the yields of those 600 men, but all others who are using improved seed. On a 30 -acre field of the Experiment Station the yield in one year reached 93 bushels. When the high-bred seed adapted

1 "The Need for Agricultural Education," David Y. Thomas, An. Am. Ac. Pol. Soc. Sci., Vol. XXV, pp. 152, 153.

2 Kansas State Agricultural College Experiment Station, Circular No. 3. 


\section{CONSERVATION OF NATURAL RESOURCES}

to that state is everywhere used, it is certain that the yield of corn will be doubled in Wisconsin. In the case of barley, the yield of the improved varieties which have been developed in Wisconsin has risen to fully 50 bushels per acre, or twice the average of the United States, and in some cases pedigreed barley in 1909 gave as high as 70 bushels per acre.

The

migration of alfalfa.

Second, the value of the farm products may be very greatly increased by the introduction of new varieties of crops which have been developed in other parts of the country or of the world. This principle is very well illustrated by alfalfa. While this crop in colonial times was brought directly from Europe to the eastern part of the United States, it did not thus gain a foothold in this country. Alfalfa was a Persian crop which in an ancient invasion of Greece was carried into that country; from Greece it went to Spain; from that country it was carried into Mexico and Peru by Cortez and Pizarro. From the former country alfalfa spread gradually to the arid lands of the West, and was supposed to be adapted only to such regions. Recently, after having been in America for hundreds of years, it has been tried in the Upper Mississippi Valley with remarkable results. For this region the standard hay crop was clover and timothy, or some mixture of them. However, it has been demonstrated conclusively by a large number of cases that alfalfa may be substituted for timothy and clover, with a yield for Wisconsin of about 4 tons of hay per acre as compared with $2 \frac{1}{2}$ tons for clover and timothy. Also, the crop is a more valuable one. Two tons of alfalfa contain as much nutriment as three tons of mixed clover and timothy. By the substitution for them of alfalfa, we gain not only a more valuable product but a much larger amount of that product. And in this connection too, it is to be said that alfalfa is one of those leguminous plants which very greatly increases the amount of nitrogen in the soil, - is even more effective in this respect than clover.

The Similarly in recent years the soybean has been introduced soybean. into this country from China and Japan. It is found to be very well adapted to it, and like alfalfa it is one of the plants 
which abstract nitrogen from the air. Moreover, it will grow upon the poor, sandy soils, and thus is adapted to regions which would not otherwise be productive. This bean contains 36 to 45 per cent of proteids, and thus furnishes the very highest grade of grain feed, being equivalent to oil meal.

Not so many years ago the sugar beet was brought into this country from Germany and France. Now Kansas, Colorado, Nebraska, and California are great producers of sugar from beets; and this crop is extending its area in Michigan, Wisconsin, and other states.

The South has especially suffered from adhering to a very small variety of crops; indeed, this has been called "the onecrop country," cotton being the main reliance of the planter for money, and corn the chief second crop. This region, according to Tracy, is adapted to a great variety of crops; among these he mentions wheat, oats, vetch, artichoke, rape, alfalfa, red clover, sorghum, cowpeas, sweet potatoes, soybeans, peanuts, and chufus. ${ }^{1}$

Many other illustrations could be given to show how important with reference to our agricultural products is the looking for new varieties of crops in all parts of the world adapted to the various districts of this country.

Third, not only can new varieties of crops be produced, but new varieties of fruits. One of the most striking examples is The navel orange. the navel orange, which was developed in southern California, as a mutation apparently, and now has become the standard orange which is grown in the state.

Only a few years ago the grapefruit was a curiosity not used at all as a fruit. Now it has become one of the important fruits of the country, being demanded in ever increasing amount; indeed, the demand so far exceeds the supply that the prices as yet for this fruit are very high.

These are but two illustrations. If a professor of horticulture were giving these lectures, he could tell of a hundred important improvements which have been made in the fruits of the country, both with reference to yields and with reference to adaptation to environment.

1 "New Farm Crops for the South," S. M. Tracy, An. Am. Ac. Pol. and Soc. Sci., Vol. XXXV, pp. 52-59. 
Fourth, Armsby points out that the great demand made upon food is as a source of energy. The food of $\operatorname{man}$ is the fuel which keeps him warm; a minor part only goes to growth, to muscular effort, to brain work. Of the products of the soil only a small proportion are adapted to man. He may eat grain, but he cannot digest forage. At the present time great quantities of grain are fed to animals, only a small proportion of the digestible material of which is recovered in meat, - Jordan says $2 \frac{2}{3}$ per cent in the case of beef and $15 \frac{1}{2}$ per cent for pork. When in the future the pressure of population is felt, it will be necessary to reserve for man the products of the soil which may feed him directly. Meat must be mainly produced from the by-products of the soil, - the stalks of corn, the straw of grain, clover, alfalfa, etc. It will be for the future to develop crops which will give the largest proportion of food directly for man and a large proportion of byproducts to feed animals in order to furnish meat and dairy products. $^{1}$

\section{TOTAL INCREASE IN VALUE OF FARM PRODUCTS}

According to the Secretary of Agriculture the value of the agricultural products in 1909 was $\$ 8,760,000,000$. Of this vast sum, corn contributed $\$ 1,720,000,000$; cotton, $\$ 850,000$,000 ; wheat, $\$ 725,000,000$; hay, $\$ 665,000,000$; oats, $\$ 400$,000,000 ; potatoes, $\$ 212,000,000$; and tobacco, $\$ 100,000,000$. Each of the remaining crops had a value less than $\$ 100,000,000$.

If the value of the products in 1899 was rated at 100 , the value of the 1909 product would be 186, an increase of 86 per cent in ten years. ${ }^{2}$

Relation of value and yield.

However, from this it must not be concluded that the average yield of the country has been increased 86 per cent, because this value has been due in large part to an extension of the area which has been under cultivation, and also in large part to the increased price of farm products; hence while the increased value in dollars seems enormous, it does not neces-

1 "Food Supply of the Future," H. P. Armsby, Science, Vol. XXX, No. 780 , pp. $817-825$.

2 Report of the Secretary of Agriculture, 1909, pp. 9-10. 
sarily follow that if we consider the yields per acre there is any considerable improvement (see pp. 298-300).

\section{NEEDED - A GREAT CAMPAIGN OF EDUCATION}

The things to be done which will prevent depletion of the soil have been pointed out, but how are we to get these things accomplished? This is a vital question. It will be indeed a dreary picture that the people of succeeding generations will paint of us, if they have insufficient food and clothing. They will charge us with destroying our soil through erosion; they will charge us with depleting the soil in the essential elements, and particularly the crucial element, phosphorus, by sending the crops off the land, by waste of manure, by dumping sewage into the sea, and by exploitive farming. It will be a heavy score that they will have against us. They will find small excuse for us except ignorance. This excuse will be available to about the end of the nineteenth century. But knowledge now exists upon which to base better methods; and if we continue the practices of the past they will not only charge us with ignorance, but with criminal profligacy.

What then is to be done to make the reforms advocated accomplished facts? The answer is always the same. It is necessary that there shall be carried on a great campaign of education, which shall directly or indirectly reach every farmer in the country. The agricultural products come not from a single concern or from a few manufacturers, but from about six millions of producers; and each one of these producers is independent of the others. Their education in improved methods is indeed an enormous task. According to Galloway, at least three fourths of these men are at the present time practicing exploitive farming, i.e. are taking from the land more than they put back.

Of all parts of the country the South has been the greatest sufferer from exploitive farming. This region is the one in which the campaign of education will be most difficult, largely due to the fact that the negro is the chief agricultural laborer, for it has been found as a matter of experience that it is esEducation

The arraignment of succeeding generations. the remedy. 


\section{CONSERVATION OF NATURAL RESOURCES}

pecially difficult to induce him to use new methods. But the work of the industrial schools, such as that at Tuskegee, shows that the negro is capable of making great progress; it shows that with sufficient pains the negro may be made a scientific agriculturalist. ${ }^{1}$

It is believed by Poe that as a result of improving and developing agricultural education in the South, the average value of the crop, which in the South Atlantic states is now about one half that in the North Atlantic states, and which in the South Central states is about one half that in the North Central states, can be doubled, and thus become equal to the present product of the North. ${ }^{2}$

Public

opinion and law.

At the present time the farmer is controlled in no way by public sentiment. Knowledge must be carried out to him before such control can become effective. With knowledge will come a sense of responsibility. Whenever knowledge and public opinion have sufficiently developed, laws may be enacted to restrain the reckless and lazy. Wise laws in reference to many of the reforms in agriculture could be framed at the present time; but it is useless to pass a law until public sentiment has been developed sufficiently to enforce that law.

Weed laws

not enforced.

This is well illustrated by the weed nuisance. At the present time the ficlds are suffering from the Canada thistle and quack grass. It was only twenty or thirty years ago that these were rarities in the upper Mississippi Valley; now large parts of this area are infested with these and other noxious plants, so that, according to Stone, on many 160 -acre farms from ten to forty acres are practically occupied by weeds.

Many of the states have laws making any one who allows noxious weeds to seed upon his land subject to fine, with provisions for their enforcement; but for the most part these laws are absolutely ignored. There is as yet no sufficient public sentiment in reference to the elimination of weeds to lead to their enforcement.

1 "The Negro's Part in Southern Development," Booker T. Washington, An. Am. Ac. Pol. and Soc. Sci., Vol. XXXV, pp. 124-133.

2 "Agricultural Revolution a Necessity," Clarence H. Poe, An. Am. Ac. Soc. and Pol. Sci., Vol. XXXV, pp. 42-51 ; "Agriculture a National Asset," by B. T. Galloway, Report National Conservation Commission, Vol. III, p. 144. 
This situation drives us back to the statement that it is necessary to have a great campaign of education in order to widely introduce the improvements in agricultural practice necessary to preserve the fertility of the soil. This campaign has been begun in many of the states of the Union. In an early section of this part, I spoke of the Morrill Act of 1862, which gave to each of the states an apportionment of land for the establishment of agricultural and mechanical colleges. This law led to the dawn of scientific agriculture in this country. At the present time in almost every state in the Union there is an agricultural college, either independent or connected with a state university. The agricultural college in some states is of college rank; in others is a secondary school; and in the greater number of states combines to some extent the functions of each. In a few states the agricultural college is supplemented by county secondary schools of agriculture, as in Wisconsin, where at the present time there are five. In other states, as for instance, Georgia and Alabama, there is to be an agricultural school in each Congressional district. In Minnesota there is an agricultural high school in connection with the university. However, this is but the beginning. There must be agricultural education not only in the college and the secondary schools but in the rural schools, so that every country boy may learn the fundamental principles of agriculture so necessary for the conservation of the soil.

Naturally in this campaign of agricultural education the colleges have taken the leadership. Their work has been along three lines.

First, the agricultural colleges with the accompanying experiment stations are the centers in which new knowledge is ascertained, in which the scientific investigations are made to solve the various problems confronting the agriculturalist, whether it be to improve the varieties of plants and animals or to remedy a defect in the soil or to eradicate plant and animal diseases.

Second, the colleges of agriculture must teach. The Agricultural students thus taught will become teachers of agriculture in instruction. the secondary schools and their pupils will become teachers

Agricultural colleges and schools.
Agricultural investigation. 
of agriculture in the rural schools. Not only so, but each college student who engages in the art of agriculture carries knowledge directly to the farmer by improved practice; each farm controlled by a man taught by the college is a demonstration farm to his neighbors. In Wisconsin the graduates in agriculture have organized themselves into an experimental association, and these men, some 1500 or more in number, are so many centers of dissemination of sound agricultural practice.

Agricultural extension.

The apprenticeship system.

Agriculture an applied science.
Third, the staff of the agricultural college must carry knowledge directly to the people through various lines of extension, the details of which cannot be entered into; but it includes farmers courses, farmers institutes, farmers short courses, correspondence, etc.

Some of my listeners may think it strange that I so strongly emphasize the subject of agricultural education.

But a few years ago it was thought that agriculture was an art in which education had no part. The father taught the son the art precisely as the master artisan taught to his apprentice his trade. The apprenticeship system has died out, and the trade is now beginning to be learned in the trade school. Similarly the apprenticeship system in agriculture fails, in that it stops with manual training. The principles of agriculture must be taught in the schools. The fatal defect of the apprenticeship system in agriculture is that the son does not advance beyond the father. The school has available the agricultural knowledge acquired in all parts of the world. The imparting of that knowledge can only be done by those whose profession is teaching, since it must be adapted to the local conditions. The boy must be made capable of applying the principles of agriculture to the special farm products in the particular area in which he may live.

Formerly the professions of doctor, lawyer, and preacher comprised the learned group. There are now, not three learned professions, but scores of them, and one of the greatest is agriculture. Agriculture is a complex applied science, built upon a knowledge of pure biology, pure physics, and pure chemistry. The agriculturalist must apply the principles of 
botany to his field crops and to his fruits; he must apply the principles of zoölogy in connection with his animals; he must apply the principles of physics and chemistry to the soil; he must be an engineer in the management of his machinery.

There is no other vocation which demands a wider knowledge of science than that of the agriculturalist. This new situation has changed the attitude of mind with reference to agriculture, not only of the young man upon the farm, but of the whole community. Agriculture used to be regarded as a somewhat inferior vocation. The son of small parts remained upon the farm and his larger-minded brother went to the city. It is now seen that he who stays upon the farm has an equal or superior opportunity with the one that goes to the town. What has caused this change of attitude? When agriculture was an art in which manual labor was the main requirement and in which there was little demand for the exercise of brain, it was meanly regarded; now that it has become a complex applied science in which there is a daily demand upon the highest intellectual faculties, and at the same time the heavy work is being done in large measure by machinery, it has come to be highly regarded. The broader the knowledge of the farmer, the more certain it is that each day he will have in his mind an unsolved problem with reference to some imperfect practice requiring improvement. The center of gravity of the vocation of the farmer has changed from that of manual effort to intellectual effort; and hence it has become intensely interesting. It is clear that the vocation of the farmer is to become recognized as of equal importance with any of the other learned professions. In proportion as the vocation Agriculture a learned profession. rises in dignity there will be multiplication of the products of the land; there will be conservation of the soils; and the future needs of the nation will be protected.

Of all the problems of conservation, the most difficult, the most pressing, is to get the necessary knowledge of the applied science of agriculture to the six million farmers Education and conservation. of the United States. James J. Hill recently said that 5000 teachers of agriculture are now needed in this country. This number should be at work in each of the great agriculture 


\section{CONSERVATION OF NATURAL RESOURCES}

states. Within the next twenty-five years there will be, I am confident, tens of thousands of teachers of agriculture in the colleges and secondary and rural schools, disseminating the principles of this science to the millions of boys who will practice this profession.

Says James J. Hill: “This country cannot feed the population which it must necessarily have within comparatively few years if it does not change its agricultural methods." If this change comes it must be because of the absorption by the millions of the modern scientific methods of agriculture. Some of you smile, I see, at the emphasis which I place upon agricultural education; but the people of a thousand years hence will not smile at the efforts now being made to expand such education, if in consequence there be retained in this country a fertile soil producing abundantly so that the people of that generation do not go hungry.

1 Address by James J. Hill at the National Corn Exposition, Omabs, Neb., Dec. 9, 1909. 


\section{PART V \\ CONSERVATION AND MANKIND}

$\mathrm{N}$ this closing lecture I shall give a summary of the prin-
ciples of conservation of the natural resources and con-
sider their relation to mankind.

\section{THE PRINCIPLES OF CONSERVATION}

The principles of conservation are different as applied to the different resources.

Coal, peat, oil, and gas are limited in amount. Their process of manufacture is so slow as to be negligible. When extracted from the earth, they must be used, if not at once, within a short time, and when so used are gone forever. Therefore the principles of conservation applicable to them are as follows: -

In reference to coal, reduce the waste in mining and in use. The waste in mining, now 50 per cent, should be reduced to 25 or 10 per cent; beehive ovens should be abolished; the smoking chimney should be condemned as a nuisance; the gas engine should be substituted for the steam engine. So far as practicable, substitutes should be used for coal; and of these that of developing power by water instead of coal is the most important. Even if all possible economies and substitutes are introduced, the most sanguine cannot hope that the supply of fuels will be sufficient to meet the needs of the people for more than a small fraction of the time we look forward to as the life of this nation. In reference to oil, so far as practicable it should be saved for the higher uses; these are for light and lubricant; only those oils not adapted to these purposes should be used for fuel. Exportation of oil should be prohibited. New wells should be opened up only 
Conservation of the metals.

Use water fully.

as fast as necessary to meet the needs under the above principles. In reference to natural gas, the great and pressing necessity is to stop its appalling waste by enacting and enforcing proper legislation. This ideal fuel should be used with the severest economy in order to prolong its life, which will be brief at best.

The metals, like coal, are absolutely limited in amount. Their quantity cannot be added to by any effort of man; but unlike coal, when extracted from the earth and reduced to metallic form, they may be used again and again. The principles applicable to the metals are as follows:-

First, reduce to a minimum the waste in mining and extracting. At the present time, for certain of the metals these wastes are extraordinarily high, especially for lead and zinc. In many cases by proper practice these losses may be reduced to one half or even one third their present amounts. Second, the metals should not be used for purposes such as destroy them by a single use, as is the case with lead and zinc when made into paint. Third, the metals should not be used in such a way as rapidly to deteriorate, as is the case when iron without a protective covering is exposed to the weather. At best the supply of metals is so limited that we cannot expect the amounts available will be sufficient to meet the needs of the vast numbers of people through thousands of years to come.

With water, the principles of conservation are different from those of coal and the metals. Each year, a vast quantity of water, through the power of the sun, is taken from the sea and added to the land supply. A roughly equivalent amount flows from the land to the sea. The water is ever in circulation, passing from the ocean to the land and from the land to the sea. The problem of the conservation of the moving water is therefore its complete utilization - and that for domestic purposes, for water power, for navigation, and for irrigation. Its use for one of these purposes does not exclude its use for others. Thus, water which is used for domestic purposes may be used for irrigation; indeed this use is most advisable for such water, because of its fertilizing 
contents. Water used for power may be used for domestic purposes, for navigation, or for irrigation. Water used for navigation may be later used for domestic purposes, for water power, or for irrigation. Water used for irrigation is in part evaporated, but in part goes back to the stream and may be again used for other purposes.

The forests are unlike fuels and minerals in that they may Renew be renewed, but slowly. To renew a forest takes from 50 to 100 years, and for some classes of forests an even longer time. forests as fast as The principle of conservation in reference to the forests is that we may use them, but not more freely than they can be renewed. This is the measure of their wisest consumption. To the present time we have been using the forests much more rapidly than they have been produced. In order to secure this balance we must reduce fire losses; we must reduce the great waste; so far as possible we must utilize byproducts; we must substitute cement and stone and brick for wood. Finally, we must increase the growth of the forests. This may be done by reforesting denuded areas better adapted to the growth of wood than to agriculture, and by improving existing forests. If the forests are maintained at their present area, in the United States, or even at a somewhat reduced area, there is every reason to believe that by the reduction of losses and waste, and by increasing the growth, we may secure the necessary balance between production and consumption.

The principles of soil conservation are somewhat like those of the forests. The soils may be renewed by the processes of nature, but very slowly; indeed probably at a rate not to exceed one inch in from 500 to 1000 years. The first principle Reduce erosion to rate of soil of conservation of the soils is not to allow erosion to occur more rapidly than it is manufactured. The second principle is not to deplete the soil in those elements limited in amount which are necessary for plant food, - nitrogen, potassium, and phosphorus, and especially phosphorus, for the latter is the element which is very scanty in the soil, and the supplies of which are extremely limited. Phosphorus is the crucial element in soil productivity. The conservation of the soil is the greatest of all the problems of conservation; because 
Relation of water to other resources.

upon its products we depend for food and clothing, the basal necessities of man.

Conservation is not a simple subject which can be treated with reference to a single resource, independently of the others; it is an interlocking one. The conservation of one resource is related to that of another. Thus the conservation of coal is to be accomplished in a large measure by the substitution of water as a source of power. The conservation of the metals is to be largely accomplished by the substitution of cement and stone and brick and other products.

The best utilization of water requires the maintenance of a uniform flow of the streams. This is true for domestic purposes, for water power, for navigation, and for irrigation. In order to get a uniform flow it is necessary that the forests be preserved in essential areas, especially the steep slopes of the mountains and hills, along the borders of the streams, and on the shifting areas, such as sand; it is necessary so to practice agriculture that a large part of the precipitation goes underground. If a uniform flow be maintained, the water will give a vastly increased available water power; it will immensely improve navigation; floods and flood losses will be reduced; the erosion of the land will be diminished; the waters will be confined to their banks, and they will render available lands which are now inundated. If erosion be lessened, the streams will be kept pure for domestic and other purposes. The increase in the use of water powers will enormously reduce the draft upon coal. The use of water for irrigation will make highly fertile extensive areas which are otherwise barren.

Thus, whatever subject we begin conservation with, before we have finished we pass into other of its branches. A complete treatment of any part of the subject in all of its ramifications of necessity repeats a portion of the treatment of another part of the subject.

The principles of conservation above enunciated require for their practice a sense of social responsibility upon the part of the individual and corporation. They demand a self-denial which cannot be expected from the owners of 
private property. They require that the needs of mankind shall be placed before immediate results. Therefore it is too much to expect that these principles will be generally practiced except as they are embodied into law and the law enforced by the community.

But what is the condition of the law? Is it such that these principles of conservation if placed in the statutes will be upheld by the courts. The decisions of the highest court make it clear that the needs of our descendants may be protected. The United States Supreme Court declares: "It is recognized that the state as a quasi-sovereign and representative of the interests of the public has a standing in court to protect the atmosphere, the water, and the forests within its territory, irrespective of the assent or dissent of the private owners of the land most immediately concerned." Again, in the same decision: "We are of the opinion further that the constitutional power of the state to insist that its natural advantages shall remain unimpaired by its citizens is not dependent upon any nice estimate of the extent of present use or speculation as to future needs." Further: "Rights of property," says Mr. Justice Shaw in the case of Commonwealth vs. Tewksbury, "like all other social and conventional rights, are subject to such reasonable limitation' in that enjoyment as shall prevent them from being injurious, and to such reasonable restraints and regulations established by law, as the legislature, under the governing and controlling power vested in it by the constitution, may think necessary and expedient." ${ }^{1}$

\section{THE PURPOSE OF CONSERVATION}

What is the purpose of conservation? It is for man. Its purpose is to keep the resources of the world in sufficient abundance so that man may have a happy, fruitful life, free from suffering - a relatively easy physical existence.

The chief efforts of animal life, and it may be said of plant life also, to the present time, have been directed toward secur-

1 " Conservation of Our Natural Resources and of Our National Strength and Virility," A. A. Bruce, Pennsylvania Law Review, Vol. 58, pp. 155, 156, 159. 
Subsistence ing subsistence. It makes no difference which animal in the main problem of men. a wild state we select, - it may be the swallow flying in the air by day, or the bat by night; it may be the lion in the jungle, - the paramount problem is subsistence. The same is true of man to the present moment. The great problem which confronts more than nine tenths of the human race to-day is that of securing food. This does not apply simply to densely populated countries, such as India and China; it applies to the larger number of people in the United States and Europe. It is the aim of conservation to reduce the intensity of struggle for existence, to make the situation more favorable, to reduce mere subsistence to a subordinate place, and thus give an opportunity for development to a higher intellectual and spiritual level.

\section{THE CONSERVATION OF MAN HIMSELF}

But if the conservation of the natural resources is for man, it is an obvious suggestion that man himself should be conserved. This opens up an enormously complex subject which cannot by any possibility be gone into in detail in this closing lecture. The conservation of man is one of the main purposes of government, of remedial legislation, of innumerable organizations, philanthropic and otherwise. The science of medicine, political economy, politics, and sociology are largely directed to this end.

The problem of the conservation of mankind involves the lengthening of human life and increasing its healthfulness. ${ }^{1}$ I can only speak very briefly upon one or two aspects of the subject.

Lengthening of human life.

At the present time in Sweden the average length of life is $52 \frac{1}{1}$ years; in India it is $23 \frac{1}{2}$ years, or less than one half as long. The averages in other countries fall between these extremes. In Massachusetts, the average length of life at the present time is 45.35 years. In Geneva, in the sixteenth century, the average length of life was 21.2 years. It is safe

1 The data for this part of the subject are largely taken from a Report of National Vitality, by Irving Fisher, Report National Commission, Vol. III, pp. 620-751. 
to say that from the sixteenth century to the end of the nineteenth century, the length of life of the people of enlightened nations has doubled. In New Hampshire, in 1789, the average length of life was 35 ; in 1855, 40; in the last decade of the nineteenth century, 45; the period has been lengthened by ten years in little more than a century. It is certain that the average human life can be still further lengthened.

The greatest of the influences which has led to the prolongation of life is the rise of modern scientific medicine, and especially the study of microscopic animal parasites. Pasteur and Koch, some fifty years ago, were isolating, cultivating, and studying with the compound microscopes the minute forms of life. If at that time any one had wished to pick out men of science about whom to be derisive, what better representatives could he have found than these men looking at objects so small that the naked eye could not see them? And yet, out of the work of these and other men similarly engaged have come the most beneficent gifts that mortal man has bestowed upon his fellow-men. Their discoveries are the foundation of a most important aspect of modern scientific medicine. For their work animal experimentation was of fundamental necessity. From it untold blessings in the saving of suffering from diseases have been bestowed not only upon man but upon the useful animals.

By Bardeen, ${ }^{1}$ I am informed that the diseases which afflict mankind may be roughly divided into two classes - constitutional and parasitic. He says constitutional diseases are due to defects in the human mechanism and may be inherited or may be acquired through adverse conditions to which the body is subjected, such as poor, insufficient, or improper food and drinks, bad air, dust, extreme dampness and cold, and exposure to various poisons as in many trades (painters' colic). Parasitic diseases are due to the growth in the body of microorganisms, which feed upon its fluids and tissues and at the same time give off poisonous substances. The normal body has considerable power of resistance to the invasion

1 From information furnished by Dean Charles R. Bardeen of the University of Wisconsin Medical School. 
Preserve healthy bodies and restrict parasites.

of most of the parasites which cause disease; but when the constitution is weakened, as by the excessive use of alcohol, the resistance to parasitic invasion becomes less marked; also the toxins produced by the microörganisms cause more or less permanent constitutional damage. In many instances it is at present impossible to determine whether a disease is primarily constitutional or parasitic.

For the conservation of man, therefore, the problem on the one hand is to take such steps as will best promote the development, preservation, and inheritance of sound and healthy bodies; and on the other to restrict, destroy, or weaken those parasites which now have the power of invading the body and giving rise to disease. In agriculture the aim is to improve the soil so that the crops will grow abundantly; in hygiene and medicine the aim is to improve the human body so that the organisms of disease cannot grow upon it. In agriculture the aim is to improve the breeding power of plants so that they will produce more abundantly; in hygiene and medicine the aim is to weaken the breeds of disease germs so that they can grow but feebly, if they find lodgment in the body.

Vaccination.

The control of several of the most serious of the parasitic diseases has been one of the greatest scientific and social triumphs of the past century. First, in 1796, came the discovery of vaccination by Jenner. Previous to this discovery, the majority of people had smallpox at some time during life; and each year in England, out of 100,000 people, 300 died of the disease. It was perhaps a more serious disease than tuberculosis is to-day. Jenner found that by inoculating human beings with cowpox they either did not contract smallpox or had it in a mild form. The soil for the smallpox germ was rendered infertile by the action of the cowpox germ; or, in other words, in reacting so as to destroy the inoculating cowpox germ, the body acquired the power to prevent the invasion of the smallpox germ. But this is not all. In communities where vaccination is practiced the smallpox germ itself, owing to lack of fertile soil for growth, becomes weakened. In Wisconsin, where there is unfortu- 
nately still too much of the disease, it is, as a rule, mild in type. If vaccination were discontinued, it probably would soon again assume its destructive forms.

Personal and public cleanliness have done much to eliminate some parasitic diseases. Cholera and plague, terrible diseases in Europe a few centuries ago, have little chance now of Cholera and plague. obtaining a foothold in Europe or the United States because of the increased cleanliness and of the better foods and lodgings enjoyed in civilized communities. Furthermore, the recent discovery that rats and other rodents carry the plague, and that this disease is transferred from rats to man by fleas, has given man new control over the disease. By isolating victims of the plague and destroying rodents, the disease can readily be controlled. Cholera has been discovered to be a water-borne disease, so that this too can be controlled through the water supply.

Diphtheria before 1890 was a word of terror to the parent. Diphtheria. Many a time have I seen the cheek of a mother whiten at its mention. The death rate used to be from 20 to 40 per cent. Through a series of brilliant experiments on animals, antitoxin was discovered by Behring and others. The substances produced in the blood of a horse to overcome the toxin of the diphtheria germ are here utilized for the same purpose in the human body. The death rate has been reduced to less than 5 per cent.

Typhoid fever, which used again and again to take people by the thousands at centers of infection, has been practically Typhoid fever. eliminated in all cities where the water is pure and proper sanitary regulations are enforced. The annual rate per hundred thousand for the country as a whole from 1890 to 1906 has decreased from 46.3 to 32.1 , a decline of 50 per cent. Typhoid fever may be reduced to the same situation as smallpox, if not completely eliminated.

That yellow fever is transmitted from one person to another by mosquitoes was pointed out in 1890 by Finley, and in 1900 Yellow fever. was definitely proved by Walter Reed and his colleagues, ${ }^{1}$ one

1 "Walter Reed and Yellow Fever," by Howard A. Kelly: McClure, Phillips \& Co., pp. 80-201. 
of whom, Dr. Jesse W. Lazear, contracted the disease and lost his life in the experiments which were necessary for the proof. In 1905, since this discovery, there has been one scourge of yellow fever in New Orleans and the South; but that is the last time it will ever gain a foothold in this country. Yellow fever can even be eliminated in tropical countries where it was supposed to be endemic, as was shown by the American occupation of Cuba in 1898. For the eight years before, the annual death rate from yellow fever at Havana was 550 per 100,000 . The first six years of the present century the death rate was 3.2 , or less than 1 per cent. The same thing is shown by the existing situation at the Panama Canal zone.

Malaria.

Tuberculosis.

Infant mortality.
The control of malaria, similar to yellow fever in its method of transmission, has already been spoken of in connection with swamps (see pp. 347-348).

If time permitted, we might go through the list of the more severe parasitic diseases, and show how rapid the progress has been toward their control, and still further show where progress may still be made. As illustrating the latter may be mentioned tuberculosis. This remains as the great scourge which at the present time in this country destroys more people than smallpox, typhoid fever, diphtheria, cancer, diabetes, appendicitis, and meningitis, combined. The death rate in 1907 was given as 183.6 per 100,000 . It is estimated that there are in the United States some 500,000 people suffering from this disease. However, it is now known that tuberculosis is a preventable and curable disease. Already many important steps have been taken with reference to its reduction and final control. It is to be hoped that by the middle of this century tuberculosis will be in the same situation in this country as is smallpox.

At the present time, next to tuberculosis, the most serious of controllable diseases are those disorders of digestion in infants which play so large a part in destroying human life, especially in large cities. Better public control of the milk supply, better education of mothers concerning the feeding of infants, and more sanitary houses are here the chief factors to be relied upon. 
The ridding of human society of infectious discases depends upon wise and efficient public health departments, upon scientific medical practice, and upon the intelligent coöpcration of the people.

Constitutional diseases may be in large part eliminated by the development of personal hygiene (exercise, fresh air, good food, and plenty of sleep) and by public control of the hygienic conditions in schools, factories, and other places in which unhealthy conditions are now so prevalent.

This morning, I cannot more than mention some of the predisposing causes of disease and premature death. Some of the more important are excessive use of alcohol, excessive use of tobacco, use of other drugs, and impurity with its attendant infections.

There should be mentioned also such causes as overwork, or working too long a period continuously. Among certain of the industries at the present time the working day is twelve hours. All enlightened people agree that this is too long. Some men in charge of large progressive establishments report that the change to nine or even eight hours a day has so increased the efficiency of the men that the decrease in the length of the working day lessens very little, if at all, their profits. Even from an economic point of view the twelvehour working day is believed to be a mistake, to say nothing of the conservation of humanity.

Certain diseases incident to occupations cut heavily into the life of the laboring classes. The laboring woman is in need of special protection. Child labor in factory or mine is admitted by all enlightened people to be a crime against the race.

The losses of life by accidents are appalling in this country. In 1907, in coal mining there were 2500 killed and 6000 seriDeath by accident. ously injured. Mr. John Mitchell says that for every 100,000 tons of coal mined there is on an average one man killed and several injured. According to the report of the Interstate Commerce Commission, the total number of casualties to persons on the railways for the year ending June 30,1908 , was 114,418, of which 10,188 represent the number of persons killed, and 104,230 the number injured; of

Women and child labor.

Predisposing causes.

The eighthour day. of constitutional disease. 
Aggregate of sickness and death.

Eugenics.

these the number of passengers who were killed was 381, and the number injured 11,556. In Wisconsin alone in the year ending October, 1907, the accidents were 13,572; more than 53 per cent of which were among employees in the industries. It is estimated that, of the 29,000,000 people who are working in the United States, each year 500,000 are killed or crippled, a larger number than were killed and injured on both sides during the Japanese-Russian War.

It is certain that by proper precautionary measures, including proper machinery and its proper operation, the accidents may be reduced to one tenth their present number.

The total deaths in the United States in one year are $1,500,000$. It is probable that for every death there are at least two additional who are sick, making 3,000,000. This means, for those who are ill, misery and loss of time. It seems somewhat heartless to transfer the unnecessary losses by death and sickness to dollars, but ingenious estimates have been made as to the economic losses which result from illness each year in the United States. They vary from $\$ 1,500,000,000$ to $\$ 3,000,000,000$ per annum, at least one third and possibly one half of which is preventable.

A further proposal in reference to the conservation of man is furnished by Eugenics. Breeding has been long practiced with reference to producing high grade stock. Until recently man has given very little attention to the matter as far as his own race is concerned. It is still true, even in civilized countries, that defectives of various classes are allowed to propagate the race. It is certain that as a first very moderate step toward the development of the stamina of the human race, defectives should be precluded from continuing the race by some proper method. In Indiana by somewhat exceptional methods this is already accomplished so far as certain classes of defectives are concerned. By other methods, the segregation of all defectives of each sex in asylums, hospitals, and institutes, the same result may be reached. In some states this is partially done, but nowhere completely. Whatever the method chosen, it should be thoroughgoing. Human de- 
fectives should no longer be allowed to propagate the race. We should reach at least as high a plane with reference to human beings as with the defective animals.

Remedial medicine and hygiene are public functions. The study and spread of the knowledge of hygiene is the duty of the United States government, of the states, of municipal authorities, and of all the educational institutions under these organizations, from the highest to the lowest, from the university to the rural school. The development of athletics and children's playgrounds will help the work. Medical men must continue their researches to find a remedy for the diseases which as yet they have been unable to find a way to control. One by one, as their causes become known, the more stubborn diseases will be conquered. Only, recently cerebrospinal meningitis has been overcome. Cancer, as yet wholly refractory, will finally yield.

The normal condition of a man should be that of health; continual health means continuous efficiency. Health and efficiency are fundamental to happiness; if a man is continuously healthy and efficient, probably he will be continuously happy.

How deeply rooted is the expectation of ill health is shown by our very salutation. As we greet one another we say, "How do you do?" and similar expressions we find in other languages. We who speak English as our mother tongue should substitute for "How do you do?" "Joy to you." This may seem a trivial matter, but there is at least one sect that holds it to be of fundamental importance. Personally, I do not go to the length of those of that sect; but there is no question that a normal happy attitude of mind in man is a most stimulating and conducive factor toward his bodily health.

It is safe to say that in the future we may expect that one half of the people will live to be seventy years of age; indeed Fisher says that the general practice of remedial medical "Joy to you."

Health and happiness.

Control of disease public function. happiness. knowledge now in existence will prolong the average length of human life for the people of the United States to sixty years. What will be the future normal length of human life? No

Future length of human life. 
one may tell; it has doubled in three centuries; it is not impossible that it may be doubled again and thus become ninety years.

We should live a life in which disease is practically eliminated, in which the normal condition is that of health and efficiency. When the time comes to go, a human being should die as a dead twig is snapped from a tree by the wind, and not with a lingering illness.

\section{POPULATION AND CONSERVATION}

The lengthening of human life is ultimately connected with that of the conservation of the natural resources. If with a given birth rate the length of life is doubled, this will double the number of people to be fed. It is doubtless true that as longevity increases the birth rate will decrease; and it may be that the decrease in birth rate will about compensate for the increased longevity, and thus the increase in numbers continue at about the same rate as in the past.

Rapid increase in population.

Future population.

With the exception of a comparatively small part of Asia and a minute fraction of Europe, the earth, to within a few hundred years, has been sparsely peopled. At the beginning of the fifteenth century, 500 years ago, the population of Europe was estimated at 50,000,000. At the beginning of the nineteenth century the population of Europe-was about $175,000,000$ and that of North America about 5,308,000. The population of these continents at the beginning of the twentieth century are for Europe $380,000,000$ and for America $100,000,000$.

On the basis of past increase in population, Gannett has made an estimate of the future population of the United States. He reached the conclusion that in the year 2000 in this country there will be $250,000,000$ people, and in the year 2100 , $500,000,000$. These numbers doubtless have a factor of error; they may be somewhat too small; they may be somewhat too large; but this is of little consequence. If the larger number is not reached by the year 2100 , it will be reached by the end of some subsequent century. Therefore, it is safe 
to say that in this nation, before many centuries have gone by, the problem of subsistence will be that of finding food and clothing for 500,000,000 people. And what are a few centuries compared with the future life of this nation?

It is true that various races of animals have had a long slow beginning, very rapid cumulation, and then a decline as a more powerful competitor appeared. This we have not expected with reference to man; we believe that he will retain his dominance. The gap between man and the lower animals has now become so wide, so completely is he master of them, that it is almost impossible to believe that he shall disappear before a more powerful rising antagonist. If this be so, we should think of man, not as the trilobite which came early in Cambrian times and disappeared at the end of the Paleozoic, but as a permanent type. Therefore we should think of the genus homo as continuing through future ages of the same order of magnitude as the geological ages of the past; for we know no reason why the earth may not spin on its axis, spin around the living sun, and with the sun traverse the stellar space for millions of years.

We might introduce speculations as to the influence of secular changes which may happen to the earth, such as modifications of the climate, including both temperature and precipitation, varying volcanic action, elevation and depression of the land.

It has already been indicated (see p. 33) that as a result of the combustion of coal by man it is wholly possible that the average temperature of the world will become higher and

Secular changes on the earth.

Change in temperature. a temperate climate extend as far north as Greenland - and this within a thousand years. In that event the area of habitable land in North America and Eurasia will be greatly extended. Vast regions in the far north might then support a population as dense as that of the temperate climate at the present time. However, if this were the case, it is probable that the equatorial and temperate regions would be warmer than now, and perhaps less favorable to high civilization.

In the future there may be an increase in the precipitation, so that extensive areas of land which are now semiarid or 


\section{CONSERVATION OF NATURAL RESOURCES}

Change in humidity.

Earthquakes and ice incursions.

Adaptabilities of man.

Responsibility in proportion to talents intrusted. arid, will be sufficiently humid to be cultivated without irrigation. From the geological evidence it is clear that the arid regions of the West were well watered a few thousand years ago. At the present time the trend of change is apparently toward aridity rather than toward humidity. How long it will be before the pendulum begins to swing the other way cannot be determined.

Doubtless in the future, volcanic catastrophes such as Krakatoa and Martinique, and times of earthquakes illustrated by San Francisco, Valparaiso, Kingston, Calabria, Messina, Cartago, will recur with great local damage and the loss of hundreds of thousands of lives. Man has existed on the earth since before the great Pleistocene ice incursions; doubtless by the ice he has been driven south several times, each time later to follow the ice north as it receded.

Notwithstanding these undoubted facts, geological studies show that for many millions of years the earth has been habitable for life; and of all living forms no other has shown itself so adapted to varying conditions of temperature, elevation, and humidity as has man. He is able to an amazing degree to adapt himself to changing conditions. Therefore while vicissitudes will influence man in the future as in the past, there is every reason to believe that he will permanently inhabit the earth and be its master so long as living forms exist upon it.

These considerations impose upon us as our most fundamental duty the transmission of the heritage of our natural resources to our descendants as nearly intact as possible. This is an individual responsibility as well as a state and national responsibility. There is a strongly developed opinion at the present time that the owners of great wealth and especially those who control great natural resources should act as trustees for the nation; this is easy to see. But every man who owns a farm is equally a trustee to the nation for his small property. If at the end of his life his farm goes to his son depleted in richness, he is as truly faithless to his trust as are the great interests, some of which think only of present gain and wastefully exploit the natural resources of the 
country. Each in proportion to his responsibility is a traitor to the nation. At the present time fortunately this sense of stewardship is gaining possession of those who control some of the great resources of the nation. As yet, there is scarcely a glimmering of responsibility in the case of the smaller holder of natural resources. But the future of the nation is only safe when small and large holders alike, from the man who owns forty acres of land to the groups of men who control the anthracite of the nation, shall administer their trust primarily for the benefit of the people now living and for succeeding generations rather than for themselves. Nature is a hard master, and each is responsible in proportion to the talents intrusted to him.

I do not hesitate to assert that from the point of view of our descendants this question of the conservation of our natural resources is more important than any political or social question, - indeed more important than all political and social questions upon the solution of which we are now engaged. Not only is it more important, but it is more pressing; for already some of our unnecessary losses are irremediable, and the situation is steadily growing worse.

When, a thousand years hence, the history of this time is written, I venture to predict that the amount of space which will be given to the current political and social questions which so puzzle and disturb us will be relatively small; and that the space given to the movement for the conservation of the natural resources will be large. If this movement succeeds, the names of the men who have led it to success will loom high.

\section{CONSERVATION AND PATRIOTISM}

The first decade of this twentieth century has been a time of unrest, such as has not been witnessed since the days of the Civil War. In legislation this unrest has expressed itself by a large number of remedial laws. The question naturally arises as to the underlying conditions which have led people to a deep feeling of dissatisfaction expressed by this outburst of remedial legislation. During the eighteenth and nineteenth

Conservation important and pressing.

Conservation from point of view of future.

Conquering the continent. 
centuries the continent was being conquered and occupied. The forest was an enemy. Our resources secmed illimitable. If a man failed at one place he moved to the West and began again. Opportunity was open to all. Under these circumstances it was natural that the resources of the nation should be given freely to any individual or corporation that would exploit them. Why not? The resources were exhaustless, and he who had the energy to take and develop should have the opportunity. That this opportunity was taken advantage of by men of large ability, many of whom in consequence have accumulated gigantic fortunes, was entirely natural. Many of us, had we had the ability and opportunity, would have done likewise.

But at the beginning of this twentieth century we have for the first time taken stock of our resources and find that they are not inexhaustible.

Free land gone.

The pressure of the new conditions.
Not only are our resources limited, but they have mainly passed from the ownership of the government to individuals and corporations. No longer can a man have for the asking a forest or a mine. He who has not, may no longer move West and begin the exploitation of any choice parcel of the public domain which he may select. If a man has not, he must seek employment from others or else starve. He is surprised and angry at the new conditions, which are contrary to all the traditions of the country, which were not the conditions of his fathers, or even of his youth.

Moreover, the change from an apparent plethora of natural resources, free to any one, to paucity, has come upon us so suddenly that the people find themselves in a position similar to that of the youth who, bequeathed a fortune, believes it far beyond his needs and draws heavily upon it as his fancy dictates, until one day the bank refuses to cash his check. He is dazed and indignant at the new conditions.

The unconscious pressure of these facts, because only recently have they been formulated, has been the controlling factor, although others have been important, in leading the people to change their views in reference to unrestrained freedom of individuals and corporations to control the resources 
of which they have possession; and thus the era of remedial legislation already mentioned is a direct growth of the limitation and the private possession of the natural resources of the country.

The eighteenth and nineteenth centuries, during which the natural resources of the country were being taken possession of, were naturally times of intense individualism. Each man took freely of the resources, did with them as he pleased, and regarded interference from any source as unwarranted. But the private possession of our resources has placed a new situation before us and demands of the people of the twentieth century different ideals from those that have obtained in the past.

As already said, so far as possible, each should hold the resources he possesses in trust for the generations to follow. Each should desire only what is right, and right must be deNew definition of right. fined as that which is best for the future of the race. In short, the period in which individualism was patriotism in this country has passed by; and the time has come when individualism must become subordinate to responsibility to the many.

In the days of '61 to '65, a million men laid aside their personal desires, and surrendered their individualism for the good of the nation. Now it is demanded that every citizen shall surrender his individualism not for four years, but for life, - that he shall think not only of himself and his family, but of his neighbors, and especially of the unnumbered generations that are to follow. It is by the criterion of what is best for posterity that we should judge of the interlocking questions of economics and conservation which confront us. Upon this principle should legislation be based. If we recognize this, we shall have made the great progressive fundamental step. When the criterion as to right, the good of posterity, is clearly accepted by the people, no individual or group of individuals can permanently retard progress.

But the demand for transformation of the ideals of the individual, who has felt himself free to do with what he has as he pleases, to social responsibility, will be as great a change of

Individualism. 


\section{8}

The new patriot.

Necessity for education.

Conservation a tidal wave.

Loss inevitable. heart as has ever been demanded by seer or by prophet. Already we have angry protestations from many who largely possess, when any restraint is proposed. Often those who make such proposals are denounced as dangerous to the welfare of the country. But still the demand will be pressed in upon each man that he shall surrender his individualism so far as is necessary for the good of the race. He who thinks not of himself primarily, but of his race, and of its future, is the new patriot. Only under conditions which permit of education to each, and education as far as his capacities will permit him to go, only under conditions which will give each man an opportunity to rise, will this new era of remedial legislation be safely guided.

Without the widest and wisest system of education, the poor will be led by impulse and not by reason. Without the widest and wisest system of education, those who possess largely will continue to be moved by individualism, as apparently are the group of men who control the anthracite coal of the country, - as if this privilege were granted from on high instead of by their fellow-men.

By some men largely possessing I have been asked the question, whether the new movement of restrictive legislation is merely a temporary flood which will subside. To such $I$ have said: The tide is just beginning to run; the part of wisdom is to coopperate, to be fair to this generation and considerate of generations to come, or you will be overwhelmed by a mighty tidal wave of mingled just indignation, passion, and prejudice. The new movement for conservation can no more be stilled than can the tides which depend upon the movements of the planets, because it rests upon as fundamental a cause, - severe limitation of the natural resources of the nation. The part of wisdom is to work with the movement,'and not against it; it may be guided; it cannot be stayed.

At the very best the outlook is not any too bright. Until within a century or two, the portion of the land which was used for agricultural purposes in Europe and America was but a small fraction of the total area. Now a large portion of this land is under cultivation. Even with the greatest care and the wisest applications of science, it is difficult to see how 
- the soil can be tilled and retain its full fertility. When a ton of coal is burned, it is gone forever. At best corrosion and other losses will disperse the metals, and the speed of nature's process of manufacture of new ore supplies is so slow as to be negligible.

We may hope that scientific advance will help in reference to some of these resources; but we cannot hope that we shall be able to reverse the great law that energy is run down in transformation, or that we can reuse indefinitely the resources of nature without loss.

It would be interesting, but idle, to prophesy as to the changes in our social structure which will result when people begin to be pinched by meager soil, by lack of sufficient coal. The people of that time will doubtless solve their problems as best they may, and any speculations which we might make at this time would certainly be far from future realization, but that the problem of pinching economy will confront our descendants is beyond all question; and, therefore, the paramount duty remains to us to transmit to our descendants the resources which nature has bequeathed to us as nearly undiminished in amount as possible, consistent with living a rational and frugal life. Now that we have imposed upon us the responsibility of knowledge, to do less than this would be a base communal crime.

In a few thousand years man has risen from the level of the savage to the height of the great creations of science, literature, and art. The human mind has dared to ask the meaning of the universe, even to the purpose of its own existence. These amazing accomplishments have taken place in the mere infancy of the human race. The most daring speculation that I might make as to human achievement would be poor and futile as compared with future realizations. It is in order that humanity itself may be given an opportunity to develop through millions of years to come under the most advantageous conditions that we should conserve our natural resources, and thus make possible to billions 'of future human beings a godlike destiny.

Conservation means "the greatest good to the greatest number - and that for the longest time."

The godlike destiny of man.

Future change in social structure. 



\section{APPENDIX I}

\section{DECLARATION OF GOVERNORS FOR CONSER- VATION OF NATURAL RESOURCES}

\section{INTRODUCTION}

THE Declaration of Governors contained in this bulletin was adopted by the conference of governors of the states and territories called by the President to consider the conservation of our natural resources, and which met at the White House May 13, 14, and 15, 1908. Besides the governors there were invited to the conference the members of the Cabinet, the justices of the Supreme Court, the members of both Houses of Congress, representatives of the great national organizations, the Inland Waterways Commission, and, as special guests, Hon. William Jennings Bryan, Mr. James J. Hill, Mr. Andrew Carnegie, and Mr. John Mitchell. The late exPresident Grover Cleveland was also invited as a special guest, but illness prevented him from attending. At the request of the President each governor brought with him to the conference three citizens from his state or territory to act as assistants or advisers.

The object of the conference was stated by the President in his letter of invitation to the governors, in which he said:-

It seems to me time for the country to take account of its natural resources, and to inquire how long they are likely to last. We are prosperous now; we should not forget that it will be just as important to our descendants to be prosperous in their time.

Papers which discussed the present state of our various natural resources were read by experts and specialists in each respective line, and these were followed by an open discussion among the governors of the points brought out.

The conference then appointed a committee to draft a declaration, consisting of the following: Governor Newton C. Blanchard, of Louisiana; Governor John FrankLin Fort, 
of New Jersey; Governor J. O. DAvidson, of Wisconsin; Governor John C. Cutler, of Utah; and Governor Martin F. Ansel, of South Carolina.

This committee prepared and submitted the declaration which follows, and it was unanimously adopted by the conference of governors as embodying their conclusions on the question of conservation.

\section{DECLARATION OF PRINCIPLES}

We, the governors of the States and Territories of the United States of America, in conference assembled, do hereby declare the conviction that the great prosperity of our country rests upon the abundant resources of the land chosen by our forefathers for their homes, and where they laid the foundation of this great nation.

We look upon these resources as a heritage to be made use of in establishing and promoting the comfort, prosperity, and happiness of the American people, but not to be wasted, deteriorated, or needlessly destroyed.

We agree that our country's future is involved in this; that the great natural resources supply the material basis upon which our civilization must continue to depend, and upon which the perpetuity of the nation itself rests.

We agree, in the light of the facts brought to our knowledge and from information received from sources which we cannot doubt, that this material basis is threatened with exhaustion. Even as each succeeding generation from the birth of the nation has performed its part in promoting the progress and development of the Republic, so do we in this generation recognize it as a high duty to perform our part; and this duty in large degree lies in the adoption of measures for the conservation of the natural wealth of the country.

We declare our firm conviction that this conservation of our natural resources is a subject of transcendent importance, which should engage unremittingly the attention of the Nation, the States, and the people in earnest coöperation. These natural resources include the land on which we live and which 
yields our food; the living waters which fertilize the soil, supply power, and form great avenues of commerce; the forests which yield the materials for our homes, prevent erosion of the soil, and conserve the navigation and other uses of the streams; and the minerals which form the basis of our industrial life, and supply us with heat, light, and power.

We agree that the land should be so used that erosion and soil wash shall cease; and that there should be reclamation of arid and semiarid regions by means of irrigation, and of swamp and overflowed regions by means of drainage; that the waters should be so conserved and used as to promote navigation, to enable the arid regions to be reclaimed by irrigation, and to develop power in the interests of the people; that the forests which regulate our rivers, support our industries, and promote the fertility and productiveness of the soil should be preserved and perpetuated; that the minerals found so abundantly beneath the surface should be so used as to prolong their utility; that the beauty, healthfulness, and habitability of our country should be preserved and increased; that sources of national wealth exist for the benefit of the people, and that monopoly thereof should not be tolerated.

We commend the wise forethought of the President in sounding the note of warning as to the waste and exhaustion of the natural resources of the country, and signify our high appreciation of his action in calling this conference to consider the same and to seek remedies therefor through coöperation of the Nation and the States.

We agree that this coöperation should find expression in suitable action by the Congress within the limits of and coextensive with the national jurisdiction of the subject, and, complementary thereto, by the legislatures of the several States within the limits of and coextensive with their jurisdiction.

We declare the conviction that in the use of the national resources our independent States are interdependent and bound together by ties of mutual benefits, responsibilities, and duties.

We agree in the wisdom of future conferences between the 
President, Members of Congress, and the governors of States on the conservation of our natural resources with a view of continued coöperation and action on the lines suggested; and to this end we advise that from time to time, as in his judgment may seem wise, the President call the governors of States and Members of Congress and others into conference.

We agree that further action is advisable to ascertain the present condition of our natural resources and to promote the conservation of the same; and to that end we recommend the appointment by each State of a commission on the conservation of natural resources, to coöperate with each other and with any similar commission of the Federal Government.

We urge the continuation and extension of forest policies adapted to secure the husbanding and renewal of our diminishing timber supply, the prevention of soil erosion, the protection of headwaters, and the maintenance of the purity and navigability of our streams. We recognize that the private ownership of forest lands entails responsibilities in the interests of all the people, and we favor the enactment of laws looking to the protection and replacement of privately owned forests.

We recognize in our waters a most valuable asset of the people of the United States, and we recommend the enactment of laws looking to the conservation of water resources for irrigation, water supply, power, and navigation, to the end that navigable and source streams may be brought under complete control and fully utilized for every purpose. We especially urge on the Federal Congress the immediate adoption, of a wise, active, and thorough waterway policy, providing for the prompt improvement of our streams and the conservation of their watersheds required for the uses of commerce and the protection of the interests of our people.

We recommend the enactment of laws looking to the prevention of waste in the mining and extraction of coal, oil, gas, and other minerals with a view to their wise conservation for the use of the people, and to the protection of human life in the mines.

Let us conserve the foundations of our prosperity.

Adopted May 15, 1908, at the White House, Washington, D.C. 


\section{APPENDIX II}

\section{NORTH AMERICAN CONSERVATION CONFER- ENCE}

\section{DECLARATION OF PRINCIPLES}

WE recognize the mutual interests of the Nations which occupy the Continent of North America and the dependence of the welfare of each upon its natural resources. We agree that the conservation of these resources is indispensable for the continued prosperity of each Nation.

We recognize that the protection of mutual interests related to natural resources by concerted action, without in any way interfering with the authority of each Nation within its own sphere, will result in mutual benefits, and tend to draw still closer the bonds of existing goodwill, confidence, and respect. Natural resources are not confined by the boundary lines that separate Nations. We agree that no Nation acting alone can adequately conserve them, and we recommend the adoption of concurrent measures for conserving the material foundations of the welfare of all the Nations concerned, and for ascertaining their location and extent.

We recognize as natural resources all materials available for the use of man as means of life and welfare, including those on the surface of the earth, like the soil and the waters; those below the surface, like the minerals; and those above the surface, like the forests. We agree that these resources should be developed, used, and conserved for the future, in the interests of mankind, whose rights and duties to guard and control the natural sources of life and welfare are inherent, perpetual, and indefeasible. We agree that those resources which are necessaries of life should be regarded as public utilities, that their ownership entails specific duties to 
the public, and that as far as possible effective measures should be adopted to guard against monopoly.

\section{PUBLIC heAlth}

Believing that the conservation movement tends strongly to develop national efficiency in the highest possible degree in our respective countries, we recognize that to accomplish such an object with success, the maintenance and improvement of public health is a first essential.

In all steps for the utilization of natural resources considerations of public health should always be kept in view.

Facts which cannot be questioned demonstrate that immediate action is necessary to prevent further pollution, mainly by sewage, of the lakes, rivers, and streams throughout North America. Such pollution, aside from the enormous loss in fertilizing elements entailed thereby, is an immediate and continuous danger to public health, to the health of animals, and, when caused by certain chemical agents, to agriculture. Therefore we recommend that preventive legislation be enacted.

\section{FORESTS}

We recognize the forests as indispensable to civilization and public welfare. They furnish material for construction and manufacture, and promote the habitability of the earth. We regard the wise use, effective protection, especially from fire, and promptrenewal of the forests on land best adapted to such use, as a public necessity and hence a public duty devolving upon all forest owners alike, whether public, corporate, or individual.

We consider the creation of many and large forest reservations and their permanent maintenance under government control absolutely essential to the public welfare.

We favor the early completion of inventories of forest resources, in order to ascertain the available supply and the rate of consumption and reproduction.

We recommend the extension of technical education and 
practical field instruction in forest conservation, afforestation, and reforestation, so as to provide efficient forest officers whose knowledge will be available for necessary public information on these subjects.

Believing that excessive taxation on standing timber privately owned is a potent cause of forest destruction by increasing the cost of maintaining growing forests, we agree in the wisdom and justice of separating the taxation of timber land from the taxation of the timber growing upon it, and adjusting both in such a manner as to encourage forest conservation and forest growing.

We agree that the ownership of forest lands, either at the headwaters of streams or upon areas better suited for forest growth than for other purposes, entails duties to the public, and that such lands should be protected with equal effectiveness, whether under public or private ownership.

Forests are necessary to protect the sources of streams, moderate floods, and equalize the flow of waters, temper the climate, and protect the soil; and we agree that all forests necessary for these purposes should be amply safeguarded. We affirm the absolute need of holding for forests, or reforesting, all lands supplying the headwaters of streams, and we therefore favor the control or acquisition of such lands for the public.

The private owners of lands unsuited to agriculture, once forested and now impoverished or denuded, should be encouraged by practical instruction, adjustment of taxation, and in other proper ways, to undertake the reforesting thereof.

Notwithstanding an increasing public interest in forestry, the calamitous and far-reaching destruction of forests by fire still continues, and demands immediate and decisive action. We believe that systems of fire guardianship and patrol afford the best means of dealing adequately with fires which occur, whether from natural causes, such as lightning, or in other ways; but we affirm that in addition thereto effective laws are urgently needed to reduce the vast damage from preventable causes.

Apart from fire, the principal cause of forest destruction is 
unwise and improvident cutting, which, in many cases, has resulted in widespread injury to the climate and the streams. It is therefore of the first importance that all lumbering operations should be carried on under a system of rigid regulation.

\section{W ATERS}

We recognize the waters as a primary resource, and we regard their use for domestic and municipal supply, irrigation, navigation, and power, as interrelated public uses, and properly subject to public control. We therefore favor the complete and concurrent development of the streams and their sources for every useful purpose to which they may be put.

The highest and most necessary use of water is for domestic and municipal purposes. We therefore favor the recognition of this principle in legislation, and, where necessary, the subordination of other uses of water thereto.

The superior economy of water transportation over land transportation, as well as its advantages in limiting the consumption of the nonrenewable resources, coal and iron, and its effectiveness in the promotion of commerce, are generally acknowledged. We therefore favor the development of inland navigation under general plans adapted to secure the uniform progress of the work and the fullest use of the streams for all purposes. We further express our belief that all waterways so developed should be retained under exclusive public ownership and control.

We regard the monopoly of waters, and especially the monopoly of water power, as peculiarly threatening. No rights to the use of water powers in streams should hereafter be granted in perpetuity. Each grant should be conditioned upon prompt development, continued beneficial use, and the payment of proper compensation to the public for the rights enjoyed; and should be for a definite period only. Such period should be no longer than is required for reasonable safety of investment. The public authority should retain the right to readjust at stated periods the compensation to the public and to regulate the rates charged, to the end that undue profit or extortion may be prevented. 
Where the construction of works to utilize water has been authorized by public authority, and such utilization is necessary for the public welfare, provision should be made for the expropriation of any privately owned land and water rights required for such construction.

The interest of the public in the increase of the productiveness of arid lands by irrigation and of wet lands by drainage is manifest. We therefore favor the participation of the public to secure the complete and economical development and use of all water available for irrigation and of all lands susceptible of profitable drainage, in order to insure the widest possible benefit. Special projects should be considered and developed in connection with a general plan for the same watershed. In the matter of irrigation, public authority should control the headwaters and provide for the construction of storage reservoirs and for the equitable distribution and use of the stored water.

\section{LANDS}

We recognize land as a fundamental resource, yielding the materials needed for sustaining population, and forming the basis of social organization. Increase in the productivity of the soil is a growing need, and the possession of the land by the men who live upon it not only promotes such productivity, but is also the best guarantee of good citizenship. "In the interest of the homemaker, we favor regulation of grazing on public land, the disposal of public lands to actual settlersoin areas each sufficient to support a family, and the subdivision of excessive holdings of agricultural or grazing land, thereby preventing monopoly.

The preservation of the productivity of the soil is dependent upon rotation of crops, fertilization by natural or artificial means, and improved methods in farm management. The quantity and quality of crops are also dependent upon the careful selection of seed. We therefore favor the distribution by government bureaus of scientific and practical information on these points, and we urge upon all farmers careful attention thereto. 
The national importance for grazing of nonirrigable public lands too dry for cultivation, and the public loss occasioned by overgrazing, are generally acknowledged. We therefore favor government control of such lands in order to restore their value, promote settlement, and increase the public resources.

The first requisite for forest or other covering which will conserve the rainfall and promote regularity of water flow is the retention of the soil upon watersheds. We therefore favor the construction of such artificial works as may effect this purpose and the encouragement thereof by remission of taxes, government coöperation, or other suitable means.

\section{MINERALS}

We recognize the mineral resources as forming the chief basis of industrial progress, and regard their use and conservation as essential to the public welfare. The mineral fuels play an indispensable part in our modern civilization. We favor action on the part of each government looking towards reduction of the enormous waste in the exploitation of such fuels, and we direct attention to the necessity for an inventory thereof. Such fuels should hereafter be disposed of by lease under such restrictions or regulations as will prevent waste and monopolistic or speculative holding, and supply the public at reasonable prices.

We believe that the surface rights and underground mineral rights in lands should be separately dealt with so as to permit the surface of the land to be utilized to the fullest extent, while preserving government control over the minerals.

Regulations should be adopted looking to the most economical production of coal and other mineral fuels and the prolongation of the supply to the utmost. We favor also the substitution of water power for steam or other power produced by the consumption of fuel.

Great economy in the use of fuel has resulted in the past from the application of scientific inventions and the use of improvements in machinery, and further progress can be made in the same direction. We therefore recommend that all 
possible encouragement and assistance be given in the development and perfecting of means whereby waste in the consumption of fuel can be reduced.

The loss of human life through preventable mining accidents in North America is excessive. Much needless suffering and bereavement results therefrom. Accompanying this loss there is great destruction of valuable mineral property and enhancement of the cost of production. The best method of eliminating these known and admitted evils lies in the enactment and strict enforcement of regulations which will provide the greatest possible security for mine workers and mines. We therefore favor the scientific investigation of the whole subject of mine accidents by the governments participating in this conference, the interchange of information and experience, and the enactment and enforcement of the best regulations that can be devised.

Mineral fertilizers should not be monopolized by private interests, but should be so controlled by public authority as to prevent waste and to promote their production in such quantity and at such price as to make them readily available for use.

\section{PROTECTION OF GAME}

We recognize that game preservation and the protection of bird life are intimately associated with the conservation of natural resources. We therefore favor game protection under regulation, the creation of extensive game preserves, and special protection for such birds as are useful to agriculture.

\section{CONSERVATION COMMISSIONS}

The action of the President of the United States in calling this first conference to consider the conservation of the natural resources of North America was in the highest degree opportune, and the proceedings which have followed, and the information, mutually communicated by the representatives assembled, have, we believe, been conducive to the best interests of the countries participating. To derive the greatest 
possible benefit from the work which has already been done, and to provide proper and effective machinery for future work, there should be established in each country a permanent Conservation Commission.

When such Conservation Commissions have been established, a system of intercommunication should be inaugurated, whereby, at stated intervals, all discoveries, inventions, processes, inventories of natural resources, information of a new and specially important character, and seeds, seedlings, new or improved varieties, and other productions which are of value in conserving or improving any natural resource shall be transmitted by each commission to all of the others, to the end that they may be adopted and utilized as widely as possible.

\section{WORLD CONSERVATION CONFERENCE}

The conference of delegates, representatives of the United States, Mexico, Canada, and Newfoundland, having exchanged views and considered the information supplied from the respective countries, is convinced of the importance of the movement for the conservation of natural resources on the continent of North America, and believes that it is of such a nature and of such general importance that it should become worldwide in its scope, and therefore suggests to the President of the United States of America that all nations should be invited to join together in conference on the subject of world resources and their inventory, conservation, and wise utilization.

Gifford Pinchot,
Robert Bacon,
James Rudolph Garfield,
Commissioners Repre-
senting the United
States.

SYDNEY Fisher, Clifford Sifton, HeNRI S. Béland, Commissioners Representing the Dominion of Canada.

Rómulo Escobar,

Miguel A. de Quevedo,

Carlos Sellerier,

Commissioners Representing the Republic of Mexico. 
E. H. OUterbridge,

Commissioner Representing the Colony of Newfoundland.

Attest:

Robert E. Young,

Thomas R. ShIPP, Secretaries of the Conference.

Washington, D. C., February 23, 1909. 


\section{APPENDIX III}

\section{THE NATIONAL CONSERVATION ASSOCIATION}

\section{STATEMENT OF PRINCIPLES}

Believing it to be of the utmost importance that the natural resources of the nation shall be comprehensively and vigorously developed and utilized for the promotion of the public welfare, without waste, destruction or needless impairment, and subject always to their intelligent conservation and the effective preservation of the rights and interests of the future generations of our people;

And in order to secure the recognition and support of these principles by the people and by their representatives, we hereby unite in the National Conservation Association... We form this association to advocate and support the adoption by the people themselves and by their representatives of definite and practical measures to carry the foregoing principles [the principles adopted by the conference of the governors, Appendix I] into effect, and to oppose in all appropriate ways all action which is in conflict with these principles, whether such action is attempted by individual citizens or by legislative or administrative officials. Among such measures are the following:-

\section{FORESTS}

The protection of the source waters of navigable streams, through the purchase or control by the nation of the necessary land within their drainage basins, especially in the Southern Appalachians and the White Mountains.

The enactment and enforcement, both by the nation and by the several states, of effective laws to prevent, by active patrol during dry weather, and by other appropriate means, 
the spreading of fire in all forests, whether publicly or privately owned.

The reasonable but effective public regulation of timber cutting on forest land, whether publicly or privately owned, the conservation of which is essential to the public welfare.

The separation, for purposes of taxation, of the timber from the land on which it grows, so that the forest crop shall be taxed only when it is harvested, while the land shall be taxed every year.

The support and extension of practical forestry.

\section{WATERS}

The preparation, by a commission appointed by the President of the United States, of a comprehensive plan for waterway improvement, extending to all the uses of the waters and the benefits to be derived from their control, including navigation, with the relation of railroads and terminals thereto, the development and disposition of water power, the irrigation of arid lands, the drainage of swamp and overflowed lands, the control of floods, the prevention of soil wash, and the purification of streams for water supply.

The immediate undertaking and continuous prosecution of works clearly necessary under such general plan.

The incorporation into all future grants of water power rights by state or nation of provisions to secure the following:

(a) Prompt development, on pain of forfeiture of the grant.

(b) Payment of reasonable compensation for the benefits granted by the people, with periodic readjustment of the rate of compensation, so as to insure justice both to the investor and to the public.

(c) The limitation of all such grants to periods not exceeding fifty years, and the reservation of the right to terminate and acquire or reconvey the grant for proper cause and upon equitable compensation; together with proper inspection and publicity of records and accounts.

(d) Recognition of the right of the appropriate public authorities to make reasonable regulations as to rates of service. 
The termination of all existing permits or grants for the dovelopment of water power and the substitution of new grants involving the foregoing principles as soon and to such extent as may be consistent with the terms of the existing grants.

The support and extension of the irrigation of arid lands and the drainage of swamp and overflowed lands.

\section{LANDS}

The directing of public attention to the need for preserving the fertility of our soils, and thus protecting the future food supply of our people.

The enactment of legislation whereby the title to the surface of public lands and to the minerals therein shall be granted separately, with every appropriate facility to miners to acquire such part of the surface as may be needed in the development of their claims.

The conservation and control of the unappropriated public range lands by the government in the interests of the stockman and homemaker, and subject at all times to homestead entry.

\section{MiNERALS}

The retention by the government of the title to all lands still in public ownership which contain phosphate rock, coal oil, or natural gas, and the development of the same by private enterprise, under conditions that will prevent extortion and waste.

The enactment of appropriate legislation to prolong our coal supply, to reduce waste in mining, and to establish sufficient safeguards against the loss of life in mines.

We desire to further all legislation which is wisely designed to diminish sickness, prevent accidents and premature death, and increase the comfort and joy of American life, believing that human efficiency, health, and happiness are natural resources quite as important as forests, waters, lands, and minerals.

The foregoing enumeration is intended to indicate the general character of some of the measures which this organization 
believes should be adopted to carry the principles of conservation into practical effect. It will, however, coöperate in every appropriate way with other organizations and with the state and national officials to cover the entire field of the conservation and development of our natural resources, and to bring to this coöperation the vigorous support of an intelligent and disinterested citizenship. 



\section{ADDENDUM}

The Land Withdrawal Bill, discussed on page 297, before passage by Congress, was amended to the form given below :An act (H. R. 24070) to authorize the President of the United

States to make withdrawals of public lands in certain cases.

Be it enacted etc., That the President may, at any time in his discretion, temporarily withdraw from settlement, location, sale, or entry any of the public lands of the United States, including the District of Alaska, and reserve the same for waterpower sites, irrigation, classification of lands, or other public purposes to be specified in the orders of withdrawals, and such withdrawals or reservations shall remain in force until revoked by him or by an act of Congress.

SEc. 2. That all lands withdrawn under the provisions of this act shall at all times be open to exploration, discovery, occupation, and purchase, under the mining laws of the United States, so far as the same apply to minerals other than coal, oil, gas, and phosphates : Provided, That the rights of any person who, at the date of any order of withdrawal heretofore or hereafter made, is a bona fide occupant or claimant of oil or gas bearing lands, and who, at such date, is in diligent prosecution of work leading to discovery of oil or gas, shall not be affected or impaired by such order, so long as such occupant or claimant shall continue in diligent prosecution of said work: And provided further, That this act shall not be construed as a recognition, abridgment, or enlargement of any asserted rights or claims initiated upon any oil or gas bearing lands after any withdrawal of such lands made prior to the passage of this act: And provided further, That there shall be excepted from the force and effect of any withdrawal made under the provisions of this act all lands which are, on the date of such withdrawal, embraced in any lawful homestead or desert-land entry theretofore made, or upon which any valid settlement has been made and is at said date being maintained and perfected pursuant 
to law; but the terms of this proviso shall not continue to apply to any particular tract of land unless the entryman or settler shall continue to comply with the law under which the entry or settlement was made: And provided further, That hereafter no forest reserve shall be created, nor shall any additions be made to one heretofore created within the limits of the States of Oregon, Washington, Idaho, Montana, Colorado, or Wyoming, except by act of Congress.

SEc. 3. That the Secretary of the Interior shall report all such withdrawals to Congress at the beginning of its next regular session after the date of the withdrawals.

All of the second section of this act, beginning with the word "Provided," in the fourth line, is an addition to the bill as first passed by the house.

On pages 214-215 we have seen how the authority of the President to withdraw land for the forest preserves has resulted in the great national forests. The last clause of section 2 of the act passed, the professed purpose of which was to advance Conservation, in effect repeals the law authorizing the President to create forest reserves so far as the States of Oregon, Washington, Idaho, Montana, Colorado, and Wyoming are concerned.

While the limitations imposed by the act are unfortunate, President Taft has questioned his authority to make land withdrawals; and therefore it is a gain to have an act passed which settles this question, even if it contains objectionable features.

The situation being as it is, the President should again withdraw under this act all the lands heretofore withdrawn by President Roosevelt and himself, in order that such withdrawals may have the protection of the new law. Already it is announced that on July $3 d$ the President has done this, so far as power sites, phosphates, petroleum lands and coal are concerned.

Apparently, the bill gives the President power to withdraw the coal lands in the United States from sale altogether if he so desires. If this were done, the interests of the public would be protected until Congress passes a law authorizing the leasing of the coal lands.

None of the other Conservation bills recommended by President Taft made any progress during the first session of the 
61st Congress. These include the coal lands bill (see pp. 42-43), providing for the management of the public coal lands upon the leasing system; the petroleum and natural gas bills (see pp. 54-55, 60), providing for the withdrawal of the petroleum and gas lands and the leasing of the same; the water power bill (see pp. 150-151), providing for the leasing of water powers on the public domain, and the phosphate land bill (see pp. 335-336), reserving the same as a part of the public domain and for operation under the lease system.

There is little chance that any of these bills will receive consideration at the short session of the 61st Congress. It therefore appears probable that, so far as Conservation is concerned, the only legislation of the 61st Congress will be the land withdrawal act above mentioned (see pp. 11-12), with the possible exception that the Weeks bill, providing for the purchase of forests on the headwaters of streams, may become law. 



\section{INDEX}

Abandoned farms, effect of, 303.

Abbott, Henry L., on the Panama Canal, 179.

Adams, T. S., on silver, 92.

Agricultural colleges, 290, 291, 355, $356,358$.

Agricultural education, 357, 358.

Agriculture, 276, 297, 300, 338, 348, $354,356,357$.

Air, relation of, to soil, 265,318 .

Alaska, amount of coal in, 39, 40.

Alfalfa, 350 .

Alkali, 305.

Alleghany plateaus, 270.

Aluminum, 94, 95.

American Association for the Advancement of Science, 3, 214.

Animals, diseases of, 342,343 .

Annular foresting, effect of, on erosion, 314 .

Anthracite coal, 19, 20.

Appalachian ranges, 250, 253, 270.

Arid region, rainfall of, 105, 189, 190.

Arizona, copper in, 78.

floods in, 249.

Armsby, H. P., on food supply, 352.

Arrhenius, on carbon dioxide in the air, 33.

Arsenic, loss of, 96.

Ashley, George H., on coal lands, 38, $39,43$.

Atlantic and Gulf Plains, 268, 269.

Ballinger, R."A., cited, 37, 42, 55, 61 , $150,296,335$.

Bardeen, C. R., on diseases, 365.

Barley, average crop of, 323. yield of, in Wisconsin, 350 .

Beehive coke ovens, waste of coal in, 28.

Bessemer steel, use of, 72.

Bible, imagery of, in reference to water, 105.

Bien, M., on water rights, 203.

Bitumen, use of, as preservative coating for iron, 73 .

Bituminous coal, 19, 20.

Blackwelder, E., on phosphate deposits of west, 330,331 .
Brass, use of zinc for, 86 .

Brazil, iron ores of, 65.

Bristol, H. S., on wood waste, 232.

Brooks, A. H., on coal, 19, 28, 40.

Bruce, A. A., on laws concerning conservation, 113, 203, 204, 261, 363.

Burgess, C. F., on corrosion of iron, 72.

Butler, T. J., on coal, 16.

By-products, 232, 235.

California, referred to, $88,113,136$, $153,249$.

Campbell, M. R., on coal, 20.

Canada, iron ores of, 65 .

Canals, 164, 288.

Carbon dioxide, increase of, in air, 33, 373.

Carter, E. E., cited, 245, 254, 259.

Cary act, irrigation under, 193.

Cattle, tuberculosis among, 343 .

Cement, 69, 73, 102.

Central heating plants, advantage of, 30.

Chamberlin, T. C., on soil wastage, $310,311$.

Charcoal, waste of wood in manufacture of, 233.

Chile, amount of nitrates in, 318 .

China, floods in, 248.

Chittenden, H. M., on forests and reservoirs, 252.

Chlorination, extraction of gold by, 89.

Cholera, control of, 367 .

Clapp, E. N., on conservative logging, 223.

Cleveland, Grover, withdrawals of land under, 215.

Climate, effect of increase of carbon dioxide on, 33,373 .

Coal, amount of, available, 22 .

anthracite, 19, 20.

bituminous, 19, 20.

classification and occurrence of, 19 .

deposits of, 19,22 .

efficiency of, $19,31,33,35$.

increase in amount used, 23. 
Coal, kinds of, 17. land laws, 35, 36.

lignite, 19.

loss of, in making light, 32.

making of, 17.

most important mineral resource, 18.

necessity for prolonging life of, 18 . 25.

per capita use, 23.

principles of conservation applicable to, $61,359$.

ratio between coal mined and that available, 26.

regulation of price of, 44 .

relation of use of, to use of iron, 74. saving of by-products of, 28.

substitution of water power for, 124 .

the public lands, 35, 39, 41, 42, 43.

the rights of owners of, 35 .

waste of, $26,27,28,29$.

Coal lands, classification of, 296.

laws, 35, 36.

price of, 38.

unlawfully taken, 38 .

withdrawal of, 37, 39.

Coast line, in United States, 162.

Coke, 28, 33.

Coker, Robert, on guano, 333.

Colorado, production of silver in, 88, 91, 153.

Commutation elause, of homestead act, 282.

Congress, attitude of, toward conservation movement, 10, 12.

power of, to impose franchise charge on water, 148.

Conservation, complexity of subject. 362.

definition of, 379.

demands upon man, 362, 363.

importauce of, 375 .

law in reference to, 363 .

of man, 359, 366, 370.

principles of, 1, 61, 106, 135, 262, $339,357,359,360,361,363$.

relation to large holdings, 97.

to patriotism, 375 .

to population, 371 .

Conservation movement, attitude of Congress toward, 10, 12.

history of, 2.

rise due to scientific men, 3 .

Contour plowing, advantages of, 312.

Copper, 74, 79.

Corn, 319, 323, 326, 349.
Cornell, educational grants of, 290.

Corporation land grants, 288.

Cotton, losses of phosphorus due to, 327.

Cox, W. T., on forests, 262.

Crooks, Sir William, on nitrogen fertilizer, 318.

Crope, 187, 201, 298, 317, 323, 351.

average value of, 354 .

improvement in, 300 .

losses of, 340.

of the South, 351.

rotation of, 317.

yield of, 299, 300 .

Cuba, iron ores of, 65.

Cut-off, 107, 109, 114.

Cyaniding, extraction of gold by, 89 .

Dairy farming, advantagee of, 323.

Dams, 146, 147, 158.

Darton, N. H., on undereround waters, 192.

Davis, C. A., on peat reserves, 46.

Day, D. T., cited, 47, 65, 58.

Deathrate, 366-370.

Deforestation, 249, 252.

Deneen, Charles S., recommendations of, in reference to construction of waterway in Illinois, 176.

Dennett, Fred, cited, 279, 287.

Denton, Frank, on water power control in Ontario, 143.

Deschutes River, 127.

Desert land act, amendment to, 285, 288.

Diphtheria, 367.

Diseases, control of, 366, 371.

of animals, 342, 343.

of man, 365-369.

Dole, R. B., on denudation, 307.

Domain, public, original extent of, 278.

Donaldson. Thomas, on public domain, 278, 279.

Douglas, James, on lose of sulphur, 97.

Drainage, 345-348.

Earthquakes, occurrence of, in future, 374.

Eastern Ancient plateaus, 269-270.

Education, necessity for, $353, \mathbf{3 5 5}$, 378.

Educational grants, 289-292. disposal of, 290.

Eminent domain in Wisconsin, franchises include right of, 159. 
Enamel, use of, as preservative coating for iron, 73.

Energy, demand upon food as source of, 352 .

Enlarged homestead act, 287.

Erlanger, Joseph, on water used by organisms, 104.

Erosion, 246, 252, 306-314.

Eugenics, relation to conservation of man, 370 .

Evaporation, conditions upon which dependent, 108.

Exports, of grain, 325, 326.

metals, 101.

petroleum, 52.

phosphates, 325, 329, 336.

wheat, 325.

Fairchild, F. R., on taxation of timber lands, 257.

Fall line, 269.

Farm lands, 297.

Farm products, 339, 340, 352.

Farms, abandoned, 303.

wearing out of, 303,304 .

Fertilizer, loss of, 337.

Fire losses, 220, 235, 237, 243, 244, 256.

Fires and forests, 220, 238, 242.

Fires, causes of, 236.

control of, 240, 244.

effect of, on composition of forests, 238.

on stream flow, 239.

laws in forests, $242,243$.

Fischer, Albert, on bacteria, 317.

Fisher, Irving, on conservation of man, 364 .

Flood damages, 181, 182.

Floods, 125, 246, 251.

increase of frequency of, 251.

in various countries, $247-249$.

Fly-off, amount of, 107-108.

Follansbee, Robert, on swamp lands, 344.

Food, demand upon, as a source of energy, 352.

the main problem of man, 364 .

Forestry Bureau, establishment of, 4.

Forest Service, establishment of, 215.

Forests, absorption of water by, 245 .

age of trees in, 220.

average growth of, 254.

campaign of education in reference to, 261.

consumption of, 218.

contents of, 208-209.

destruction of, by insects, 255. effect of, on reservoirs, 129.

effect of removal of, on Appalachians, 250.

erosion prevented by, 246, 313 .

extent of, 208-210, 217.

fire laws in, 242, 243.

fircs, 220, 235, 237, 239, 243.

how owned, 210.

increased stocking of, 254.

maintenance of, 245 .

materials from, 218.

methods of restocking, 254.

national, $215,216,243$.

patrol, 240, 244.

per capita use of wood in, 222 .

possible yield of, 262 .

principles of conservation applicable to, 262,361 .

private, 212.

relation of irrigation to, 191.

reserves, 212, 214, 215, 253.

responsibility of owner, 260 .

saw timber in, 217.

situation in, under ideal conditions, 260.

taxation of, 257-259.

waste of, 218.

Forests and fires, 220, 238, 242.

France, control of water power in, 142.

floods in, 248.

reforestation in, 249.

Frauds, land, extirpation of, 288.

Freight rates, 179, 180.

Freund, E., on fixing prices of products, 44 .

Fruits, losses from insects, 339 .

new varieties of, 351 .

Gale, Hoyt F., on phosphate deposits of the west, 331 .

Galloway, B. T., cited, 353, 354.

Gannett, Henry, cited, 16, 25, 372.

Garfield, James R., cited, 37, 335.

Gas, lands, withdrawal of, 61.

principles of conservation applicable to, 360 .

Gas engine, substitution of, for steam engine, 31 .

Gas lands, withdrawal of, 61.

General Electric Co., amount of water power owned and controlled by, 135 .

Germany, potassium deposits of, 319 .

Gilmore, E. A., cited, 44, 144, 145.

Glenn, L. C., on forests and floods, 252. 
Gold, 86-91.

in circulation, 90 .

losses of, 88.

production of, 86,90 .

relation to prices, 90 .

reserve of, 74,88 .

substitution of certificates for, 90 . used in the arts, 91.

uses of, 89, 91.

Goss, W. F. M., on use of anthracite coal in locomotive, 34 .

Graduation act, 281.

Grain, exports of, 325. 326.

improvement in yield of, 348 .

losses of, due to smut, 340 .

Grain farming, expensive, 323.

Grape fruit, devclopment of, 351.

Great American Desert, location of. 274.

Great Lakes, navigation on, 162, 166, 171.

shore line of, 162.

Great Plains, 272-274.

Griffith, E. M., on utilization of byproducts, 234.

Guano, 328, 333.

Gullies, control of, 314.

Hale, Eugene, referred to, 11.

Hall, W. L., on the Appalachian region, 251.

Harder, E. C., cited, 63, 66, 69.

Harrison, Benjamin, withdrawals of land under, 212, 215.

Hart, E. B., on phosphorus, 320.

Hawley, L. F., on wood waste, 232.

Hayes, C. W., cited, 54, 63, 64.

Health, effect of drainage on, 347 .

relation of, to happiness, 371 .

Heat, relation of, to soil, 265.

Herring. W. E., on applications of water power, 136.

Hill, B., on natural gas, 56.

Hill, James J., cited, 164, 167, 181 , $298,300,302,326,327,357$. 358.

Holmes, G. K., on farm values, 298.

Holmes, J. A., on conservation of metals, 101.

Homans, G. M., on forests, 212.

Homestead act, 282-284.

Hopkins, C. G., cited, 319, 321.

Horton, A. H., on absorption, 245.

Hough, F. B., on forest reserves, 212.

Howard, L. O., on losses due to malaria, 348.

Howe, F. C., cited, 124, 141.
Humid region, irrigation in, 200.

Humidity, effect of change in, 374.

Hydraulic mining, effect of, 250.

Hydro-electric power, extension of, 132.

Idaho, control of water power in, 154.

Illinois, water power in, 132, 161.

Indians, dispossession of, 277.

fires caused by, 236.

number of, 277.

Individualism, age of, 377.

Infant mortality, decrease of, 368.

Inland Waterways Commisaion, 5 , 104, 162, 167, 175.

Insects, destruction of trees by, 255.

losses due to, 339,340 .

Iron, 62-73.

cstimate of resources, 63.

lose by rust, 72.

most important of the metals, 62.

preservation of, 68, 72, 73.

relation of use of, to use of coal, 74.

substitution of cement and stone for, 69.

use of, in place of wood, 70.

use of zinc for galvanizing of, 86 .

uses of, 62.

waste of, 74.

Iron ore, distribution of, 64.

holdings of U.S. Steel Corporation; 65.

in other countries, 65.

Lake Superior region, 64.

life of, 68-71.

phosphate in, 332.

production of, in the United States, 66.

Irrigated lands, 187-192.

Irrigation, 185-207.

amount of water required in, 116, 189.

crops to which applied, 201.

definition of, 185.

effect of, on productivity and value of land. 188.

importance of, 187.

in humid regions, 200.

in the United States, 186.

laws of. 202.

methods of, 191, 192-194.

practiced by ancients, 185.

relation to forests, 191.

to reservoirs, 191.

water power developed in connection with, 149. 
Irrigation division, establishment of, 4.

Italy, control of water and rcforestation, $142,247$.

Japans, used as preservative coating for iron, 73.

Jevons, W. S., on fertility of land, 306.

Johnstown flood, damage caused by, 140.

Joint Committee on Conservation, establishment of, 12.

Jones, E. R., on drainage, 346.

Kellogg, R. S., cited, 208, 220, 262.

Kerr, Frank M., on cost of improvement of waterways, 175.

King, F. H., cited, 105, 185.

Lacquers, use of, as preservative coating for iron, 73.

Lake Plains, 271.

Lake Superior, iron ores of, 64 .

Lakes-to-the-Gulf Waterway Convention, 134.

Land, agricultural, 276.

amount of cash sales of, 280 .

amount irrigated, 192.

classification of, 266.

coal, 35, 36, 39, 296.

decreased fertility of, 298.

destruction of, by alkali, 305 .

extent of, 264.

fertility of, 264, 303 .

frauds, 288.

gas, withdrawal of, 61 .

government purchase of, 278 .

granted for educational purposes, $289,292$.

influence of conservation movement on classification of, 296.

laws, $36,99,279,280,289,295,296$, $297,335$.

laws pending in reference to classification, 296, 297.

mineral, 98.

ownership of, 277.

petroleum, withdrawal of, 54 .

phosphate, 335.

power sites, withdrawal of, 9, 150 .

public, price of, 279 .

relation of depth of soil to fertility of, 264.

relation of productivity of to population, 263.

state, cession of, 278 .

swamp, $344,345$. timber, taxation of, 257-259.

withdrawal of, 212, 215.

wet, reclamation of, 344 .

Laws, agriculture, 354 .

conservation, 363 .

drainage, 345 .

erosion, 314 .

fires, $242,243$.

irrigation, 202.

land, $36,99,279,280,289,295,296$, 297,335 .

phosphate, 335.

Leaching, phosphorus lost by, 326.

Lead, 79-82.

losses of, 80.

low grade ores, 80 .

production of, 79,80 .

reserve of, 74 .

use of, in manufacture of paint, $\mathbf{8 2}$.

uses of, 82.

Leavitt, Clyde, on forest fires, 235.

Legumes, manufacture of nitrogen by, 317.

Leighton, M. O., cited, 116, 118, 120, $124,128,142,146,147,182$, $245,251$.

Life, length of, 364, 365, 371 .

Light, production from water power, 124.

relation to soil, 265 .

Lightning, fires caused by, 236 .

Lignite, nature of, 19.

Lindgren, Waldemar, cited, 78, 88.

Livestock, control of diseases of, 342 .

Lumber, consumption and production of, 222 .

McCollum, E. V., on phosphorus, 320 .

McGee, W J, cited, 107, 111, 113, $120,164,183,188,190,265$, $277,307,311,341$.

McKinley, William, withdrawals of land under, 215.

Malaria, 348, 368.

Mammals, losses due to, 340 .

Man, adaptability of, 374 .

conservation of, 364,366 .

demands of conservation upon, 362 , 363.

destiny of, 379 .

diseases of, 365 .

dominance of, 373 .

length of life of, 364 .

relation of eugenics to conservation of, 370 .

responsibilities of, 374,377 .

Manure, 317, 327, 337. 
Margolin, Louis, on waste in milling, 227.

Marlatt, C. L., on losses due to insects, 339.

Martin, G. C., on amount of coal in Alaska, 39.

Maxwell, H., on the Appalachian region, 251.

Mechanical stokers, coal saving on, 29.

Medicine, influence of, in lengthening life, 365 .

Mendenhall, W. C., cited, 112, 115 , 214.

Merriam, C. H., on losses due to mammals, 340.

Metals, classification of, 62 .

exportation of, 101.

principles of conservation applicable to, 61,360 .

Michigan, production of copper in, 78.

Military bounties, land disposed of under, 287.

Milk, ordinance regulating sale of, 343.

Mineral fuels, classification of, 16.

Mineral land act, 284.

Mineral lands, disposal of, 99, 100 , 284.

segregation of, 98.

Mineral resources, 15, 16, 18.

Mining, hydraulic, effect of, 250.

Minnesota, reservoins of, 128.

Missouri, loss of lead in mining in, 80 .

Mondell bill, 36 .

Montana, metals of, 78, 91.

Moore, Barrington, on forests and floods, 252.

Moore, R. A., cited, 340, 342.

Moore, W. L., on forests and floods, 251.

Muscle Shoals, development of water power at, 133.

National Academy of Science, effect of work of, 4.

National Conservation Association, $12,13$.

National Conservation Commission, $7,8,11,36,104,296$.

National Conservation Congress at Seattle, 134.

National forests, $4,150,215,216,223$, 243.

National Irrigation Congress at Spokane, 134.
National Rivers and Harbors Congreas, 172.

Natural gas, 55, 61.

life of, 56.

use of, 56.

waste of, 56, 58, 60 .

Natural resources, amount of, 2, 8, 376.

definition of, 1.

Naval stores, 230.

Navigation, 162, 185.

Nelson, Knute, cited, 10, 285.

Nevada, production of gold in, 88 .

Newell, F. H., cited, 133, 185, 194.

New South Wales, control of water power in, 141.

New York, water power in, 155, 156.

New York State Supply Commission, 124, 131.

Niagara, water power at, 126, 129.

Nitrates, 318.

Nitrogen in soil, 316, 318, 350, 351.

Noble, J. W., referred to, 214.

Non-metallic resources, 102.

Normal School grants, amount of, 290.

North American Conservation Conference, 9, 133.

North Dakota, control of water in, 154.

Oats, average crop of, 323.

Ohio, floods of the, 251 .

system of reservoirs on, 128.

Oil, principles of conservation spplicable to, 359.

Olcott. W. J., on boats on Great Lakes, 166.

Olmsted, H. V., on crop yield, 299.

Ontario, control of forest fires in, 241.

control of water power in, 143.

Orange groves, extent of, 276.

Orange, navel, introduction of, 351.

Oregon, control of water power in, 155.

Ozarks, 271.

Pacific region, 275.

Paint, use of lead, zinc, and iron in manufacture of, $73,82,86$.

Panama Canal, 179.

Parker, E. W., on areas and quantities of coal, 20.

Patriotism and conservation, 375,377 , 378.

Patrol, forest, 240, 244. 
Peat, amount of, 46.

problem of conservation in reference to, 61 .

Peck, A. S., on forest planting, 244.

Penrose, R. A. F., on nitrate deposit, 318.

Peters, I. G., on forests, 212.

Petroleum, 47, 55.

, exportation of, 52.

lands, lease of, 55.

withdrawal of, 54 .

life of, $47,48,55$.

uses of, 48.

Phosphates, 330, 339.

amount of available, 328, 331, 332.

exportation of, $325,329,336$.

future value of, 332,335 .

in bones, 332 .

in iron ores, 332.

lands, withdrawals of, 335 .

laws, 335 .

life of, 329 .

loss of, in fertilizer produced by man, 337.

power of government to control export of, 336.

waste in mining, 335 .

Phosphorus, in grain, 320, 323.

amount of, in soil and original crop, 321.

comparison of dairy and grain farming with reference to, 323.

depletion of soils in, 321 .

importance of, $320,338$.

in guano, 328 .

losses of, 321-327, 337.

principle of conservation applicable to, 339 .

relation of agriculture to loss of, $322,323,338$.

remedies for depletion of, 334 .

repeated use of, 338 .

segregation of, 328 .

sources of, 327 .

Piedmont plateau, 270.

Pinchot, Gifford, referred to or cited, $4,215$.

Plague, control of, 367.

Plains, Atlantic and Gulf, 268.

Plants, constituents of, 315 .

use of water by, 108.

Poe, C. H., on the necessity of agricultural education, 354 .

Population, and conservation, 371372.

effect of drainage on, 348 .

Population, relation of, to productiv-

Potassium, 319.

Powell, J. W., referred to or cited, 4, 197, 296.

Power sites, withdrawal of, 9, 150.

Power, sources of, 118-122.

Prairie Plains, 271.

Precipitation, amount of, 107, 114, 189.

Preëmption act, 281.

Price, O. W., on forests, 262.

Prices, regulation of, 44-45, 137.

relation of, to gold, 90.

of transportation to, 167 .

Prior appropriation of water, 198, $203,205$.

Private sale, law permitting, 280.

Prussia, amount of land burned over in, 240.

Public Domain, 278, 293.

Public opinion, position of farmer toward, 354.

Railroad grants, amount of land disposed of under, 287, 288.

Railways, amount necessary to develop, 167.

congestion of, 180.

Railways and waterways, 170,171 .

Rainfall, 105, 106, 107, 189, 190.

Randall, on central heating plants, 30 .

Reclamation, advantages from, 346.

of wet lands, 34 .

storing storm waters incidental to, 183.

Reclamation service, work of, 194196.

Rectangular plowing; effect of, on erosion, 309.

Reforestation, 244, 247.

Reservoirs, benefits of, 127, 128, 129, $132,183,191$.

cost of, 174.

in Wisconsin, 128, 160.

necessity for, 126 .

on Ohio River, 128.

on Upper Mississippi, 173.

power of government to construct, 174.

public control and ownership of, 138-139.

relation of irrigation to, 191 .

withdrawal of sites for, 4 .

Right, new definition of, 377 .

Riparian rights, 159, 203, 204.

Rivers, improvement of, 165, 172, 173. 
Rivers, number used for transportation, 163.

Rocks, relation of, to soil, 266.

Rocky Mountains and Western Plateaus, 275.

Roosevelt, T., referred to or cited, 5 , $7,9,10,37,39,54,150,215$, 335.

Roots, extent of, 112.

Rotation of crops, effect of, on nitrogen, 317.

Roth, Gilbert, on forests and floods, 252.

Run-off, 107, 115, 116, 117.

Rust, lose of iron by, 72.

St. Lawrence, natural reservoir of, 126.

Salt, supply of, 102.

Sawdust, utilization of, 234.

Schwartz, H. H., cited, 282, 285, 289.

Script land, 287.

Secondary education, effect of educational grants on, 292.

Beepage, loss of water by, 198.

Sewage, phosphorus lost in, 324, 337.

Shaler, N. S., cited, 313, 321, 333.

Sherfesce, W. F., on wood preservatives, 231.

Silver, 91-94.

production of, 91.

reserve of, 74.

substitution of certificates for, 92. uses of, 91, 94.

Slashings, burning of, 241-243.

Smallpox, 366.

Smith, Herbert K., cited, 135, 162. $164,167$.

Smith, Hokc, work in reference to forest reserves, 215.

Smokc, loss of coal by, 29.

Smoking chimney, losses due to, 30 .

Social structure, future change in. 379.

Soil, causes of deterioration of, 307 . 314.

composition of, 265.

depth of, 264.

making of, 265, 307.

of Alleghany plateaus, 270.

Appalachian ranges, 270.

Atlantic and Gulf Plains, 269.

Eastern Ancient plateau, 270.

Great Plains, 272.

Lake Plains, 271.

Ozarks, 271.

Pacific region, 275.
Piedmont plateau, 270.

Prairie Plains, 271.

Rocky Mountains and Western plateaus, 275.

principle of conservation applicable to, 361 .

relation to air, $265,318$.

elevation, 268.

heat, 265.

light, 265.

man, 315.

phosphorus, 319, 321.

population, 263.

potassium, 319.

rocks, 266.

water, 265.

Soybean and nitrogen, 350 .

Sphagnum, see Peat, 46.

Spillman, W. J., on agricultural production, 299.

Stabler, H., on denudation, 307.

State Conservation Commissions, number of, 8.

State lands, cession of, 278.

State park, history of, in Wisconsin, 216.

State universities, founding of, 291.

Steam engine, substitution of gas engine for, 31 .

Steam power, 130, 131.

Steel, 72, 73, 256.

Stoddart, C. W., cited, 105, 110, 321, 324, 326.

Stone, A. L., on weeds, 342.

Stone, substitution for other materials, 102, 256.

Storm waters, advantages of storing of. 181-183.

Stream flow, estimate of, in United States, 119.

influence of forest on, 126.

reservoirs on, 126.

Streams, navigable, of Wisconsin, 158.

relation of bed of, and water rights, 158.

unequal flow of, 125, 173.

Subhumid region, where located, 199.

Sudworth, G. B., on turpentining, 229.

Sugar beet, introduction of, 351.

Sulphur, 96, 97, 103.

Sun, energy of, used for power, 121.

Swain, G. F., on forests and floods, 252.

Swamp land act, 292.

Swamp lands, area of, 344, 345.

grants, 292, 345. 
Swamps, glacial, location of, 345 . reclamation of, 345 .

Switzerland, water power of, 124, 141.

Taft, W. H., President, referred to or cited, $37,42,54,61,150$, $175,196,335$.

Tannic acid, waste of, 233.

Tavernier, René, on water powers, $142,146,147$.

Tawney, James A., referred to, 11.

Tax, on forests, 257-259.

on water powers, 137, 184.

Tax laws, reformation of, 257, 258, 259.

Teal, I. N., on development of water power on Deschutes River, 127.

Temperature, change in, 373.

Terraces and erosion, 312,313 .

Thayer, Walter, on transportation on the Great Lakes, 163.

Thomas, David Y., on agricultural education, 349 .

Tides, use of, for power, 120 .

Timber, growth may be increased, 223-227.

life of, extended by preservative treatment, 231.

loss of, by cutting, 224 .

by insects, 255 .

in turpentining, 229.

possible production of, 260-262.

reducing loss in milling, 228-229.

saw, 217.

waste of, 218, 223-227.

See Forests.

Timber and stone act, 285.

Timber culture act, 284 .

Tin, used as preservative coating for iron, 73.

Tobacco, losses of phosphorus due to, 327.

Towns, relation of natural resources to, 239.

Tracy, S. M., on farm crops of the South, 351.

Traffic, amount of, on coast line, 162. on Great Lakes, 171.

decline of, on canals, 164 .

development of, on Great Lakes, 171.

effect of Panama Canal on, 180.

Transportation, cost of, by rail and water, 165.

railway and water compared, 164, 169. relation of, to prices, 167.

water, influence of, on frcight rates, 179.

Trees, destruction of, by insects, 255.

True, A. C., on swamp lands, 344.

Tuberculosis, 368 .

extent of, among cattle, 343 .

Turpentine, saving of, 232 ,

Turpentining, loss of timber in, 229.

Typhoid fever, 367.

Underground water, 110-115. circulation of, 115.

United States Census Bureau, on amount of water power developed, 118.

United States Geological Survey, cited, $23,31,32,38$.

United States Steel Corporation, holdings of iron ore of, 65 .

University grants, amount of, 289.

Upper Mississippi Valley, reservoirs of, 128.

Utah, production of copper and silver in, 91 .

Vaccination, introduction of, 366 .

Valleys, intermontane, fertility of, 275.

Van Dyke, J. C., on roots, 112.

Van Horn, F. B., on phosphate deposits, $329,330,332$.

Victoria, Australia, control of water power in, 141.

Wagon road grants, amount of, 288.

Washington, control of water power in, 154.

Washington, Booker T., on the negro's part in southern development, 354 .

Water, 104-207.

absorption of, by forests, 245 .

amount falling upon United States, 106.

amount required by organisms, 104.

in irrigation, 189.

control of, 145, 205.

control, relation of, to erosion, 310 , 311.

extent to which public, 145.

imagery of Bible in reference to, 105.

importance of, 104, 105.

influence of, on extent of roots, 112. 
Water,

law of West in reference to, 202.

losses due to careless use of, 198. new laws in reference to, 207.

ownership of, 206.

principles of conservation applicable to, 106, 360 .

prior appropriation of, 198, 203 , 205.

relation of bed of stream and, 158.

relation to other resources, 362.

to productivity of soil, 265.

rights, abuses of, 206.

source of, 106.

sources of, for irrigation, 191.

supply, 106, 116.

amount of, in cities, 116, 117.

table, lowering of, 113.

transpiration of, by plants, 109.

use of, by desert plants, 110.

Water power, 118-161.

advantages of development of, 122.

public control, 135.

amount available, 118.

of run-off used for, 116.

charge for, on government domain, 149.

concessions in national forest, 150 .

conditions for satisfactory development of, 125.

consolidation of, 135.

control of, 133-151.

by states, 136, 152-155.

in foreign countries, 141.

in the United States, 144.

cost of, 129, 130.

declarations in reference to control of, 133-134.

district monopoly of, 136.

economic advantage of substitution of, for coal, 124.

economy in substituting for steam power, 131.

effect of irrigation on development of, 149.

public control on development of, 138, 139.

reservoirs on development of, 127, 128.

storing of storm waters on, 183.

estimate of, 119.

influence of exhaustion of coal on, 120.

on manufacturing industries, 122.

on position of nations. 124.

laws concerning, in public domain. 150. leases in reference to, 161.

original ownership of, 125.

power of Congrees to impose firapchise charge on, 148.

principle of conservation with reference to, 135.

public control of, 133-140, 162.

sale of, 147, 149.

sites, withdrawals of, 150 .

subdivision of enercy from, 122.

substitution of, for coal, 124.

$\operatorname{tax}$ on, 137, 184.

transmission of, 120-121.

undeveloped, control of, 126.

use of, for light, 124.

for railways, 123.

value of, 129.

Waterways, advantages of development of, 181-185.

amount necessary to develop, 167. coöperation of railways with, 171. improvement of, 167, 172, 174.

probable future development of, 178.

situation in Europe in reference to, 167.

Waterways and rail ways, 170, 171.

Weeds, eradication of, 342.

extent of, 341.

losecs due to, 341.

Weiss, H. F., on wood preservatives, 231.

Welliver, J. C., on European waterways, 167.

Westinghouse Company, amount of water power owned and controlled by, 135.

Wet lands, of Holland, 345.

reclamation of, 344.

Wheat, exports of, 325.

loses due to insects, 339.

profits and loseses in yield of, 302.

yield of, 302, 323, 340.

White House Conference, calling of, 5-7.

White, I. C., cited, 29, 58, 59.

Whitson, A. R., cited, 321, 324, 326, $334,346$.

Wickersham. on water power, 147.

Wilson, H. M., cited, 30, 256.

Winds, use of, for power, 121.

Wisconsin, referred to, $128,158,159$. $160,216,350$.

Wisconsin River, reservoirs on, 128.

Wisconsin State Conservation Commission, recommendations of, 159. 
Woelke, W. V., on water, 114, 250. Wright, Charles E., on water, 145, Wood, consumption of, 222.

effect of forest fires upon value of, Wright, J. O., on swamp lands, 346. 239.

loss of, in logging, 223.

per capita use of, 222.

production of, 222, 223, 259.

pulp, waste of, 234.

relation of use to fire loss, 256.

substitution of other products for, $70,256$.

waste of, in manufacture of charcoal, 233.

See Timber,

Wyoming, control of water power in, 154.

Yellow fever, 367, 368 .

Ziegler, E. A., on forests, 222.

Zinc, 82-85.

losses of, 84-85.

production of, 82 .

reserve of, 74 .

uses of, $73,83,86$. 


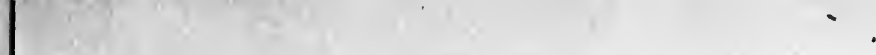
$\therefore$ 

M.c. d. d. $2 / 3 / 46$

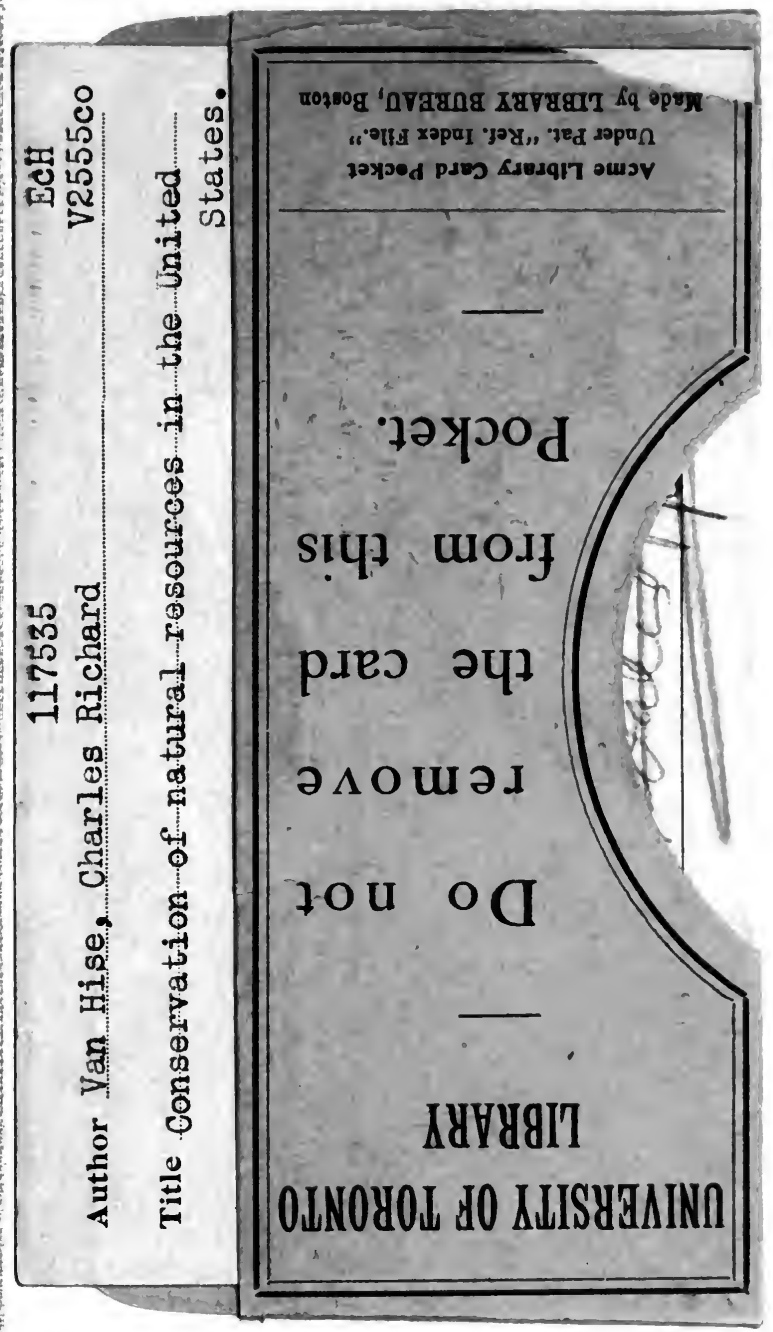


